NISTIR 7267

\title{
Low Temperature Calorimetry Studies of Hydrating Portland Cement Pastes
}

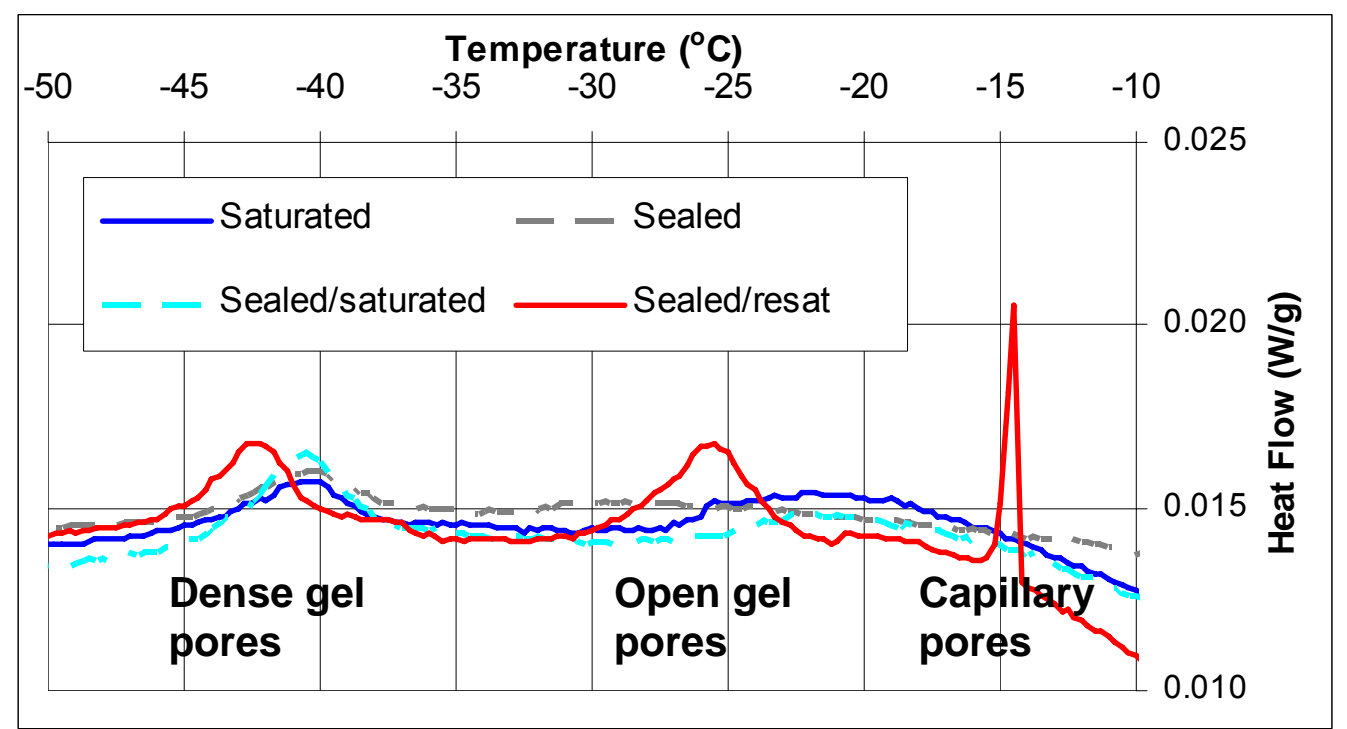

Dale P. Bentz

National Institute of Standards and Technology Technology Administration, U.S. Department of Commerce 


\section{Low Temperature Calorimetry Studies of Hydrating Portland Cement Pastes}

Dale P. Bentz Materials and Construction Research Division Building and Fire Research Laboratory National Institute of Standards and Technology Gaithersburg, MD 20899-8615

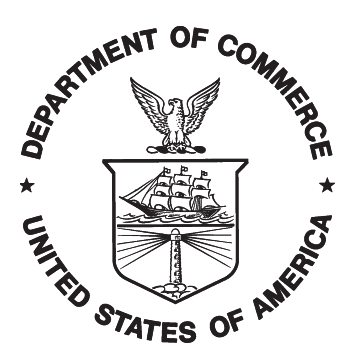

U.S. DEPARTMENT OF COMMERCE Carlos M. Gutierrez, Secretary TECHNOLOGY ADMINISTRATION

Michele O'Neill, Acting Under Secretary of Commerce for Technology NATIONAL INSTITUTE OF STANDARDS AND TECHNOLOGY William Jeffrey, Director 


\begin{abstract}
This report presents nearly 200 low temperature calorimetry (LTC) scans performed on hydrating portland cement pastes between 2002 and 2005. Because the LTC scans provide valuable information on the percolation of various size pore networks within the hydrating cement pastes as well as the quantity of freezable water as a function of temperature, it was decided to present a compilation of the plots of all of the LTC results obtained over the course of several research projects. Variables include water-cement mass ratio $(w / c)$, curing time, curing temperature, saturation, and limestone and alkali additions. Each plot is characterized by the portland cement used, the mixing solution used, the $w / c$, the curing temperature, the measured degree of hydration (when available), the curing conditions with respect to saturation, the specimen age when tested, the specimen mass, the filename of the raw LTC data, and the testing date of the LTC run. The experimental procedures used to prepare and evaluate the samples are briefly presented, along with a set of observations obtained from interpretation of the numerous individual data sets.
\end{abstract}

Keywords: Building technology; curing; freezing; hydration; low temperature calorimetry; percolation. 


\section{Table of Contents}

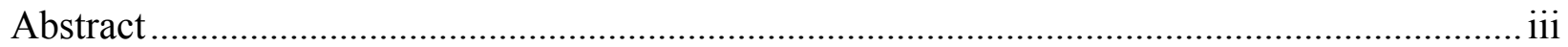

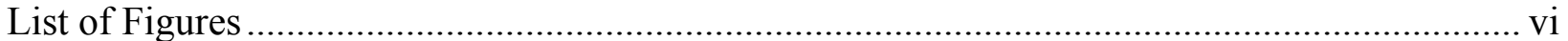

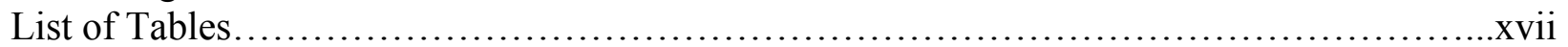

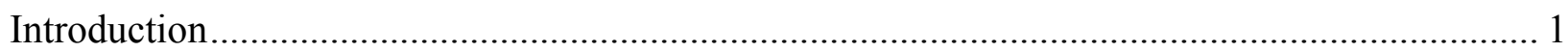

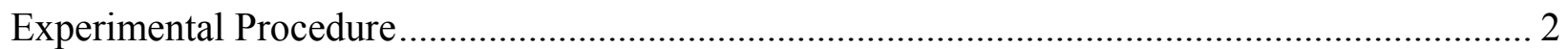

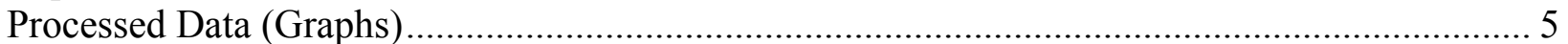

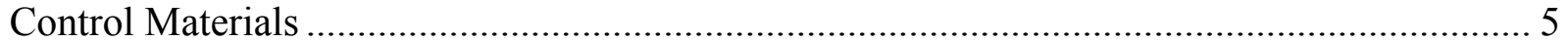

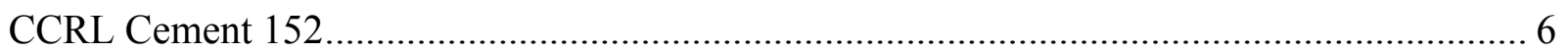

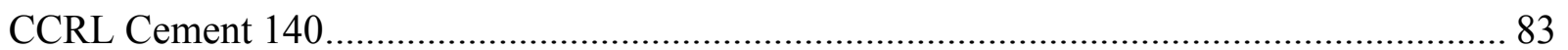

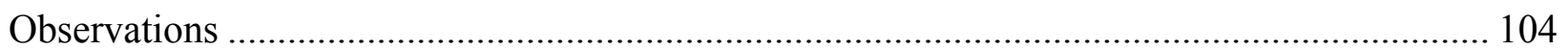

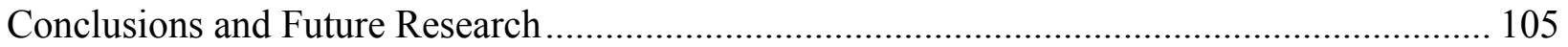

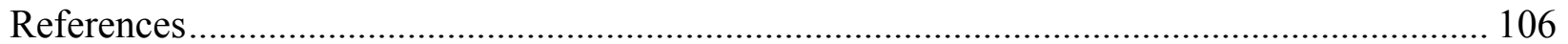




\section{List of Figures}

Figure 1 Typical LTC scans for a hydrating portland cement paste.................................................... 1

Figure 2 LTC scan for CCRL Cement 140 (dry) powder. ................................................................. 5

Figure 3 LTC scan for Gaithersburg tap water at two different scan rates. ................................................. 5

Figure 4 LTC scan for CCRL Cement 152, $w / c=0.25$, cured for $1 \mathrm{~d}$ under saturated conditions at $20^{\circ} \mathrm{C} \ldots 6$

Figure $5 \mathrm{LTC}$ scan for CCRL Cement 152, $w / c=0.25$, cured for $1 \mathrm{~d}$ under sealed conditions at $20{ }^{\circ} \mathrm{C}$.......6

Figure 6 LTC scan for CCRL Cement 152, $w / c=0.25$, cured for $2 \mathrm{~d}$ under saturated conditions at $20{ }^{\circ} \mathrm{C} \ldots 7$

Figure 7 LTC scan for CCRL Cement 152, $w / c=0.25$, cured for $2 \mathrm{~d}$ under sealed conditions at $20{ }^{\circ} \mathrm{C}$...... 7

Figure $8 \mathrm{LTC}$ scan for CCRL Cement $152, w / c=0.25$, cured at $20^{\circ} \mathrm{C}$ for $1 \mathrm{~d}$ under sealed conditions, then

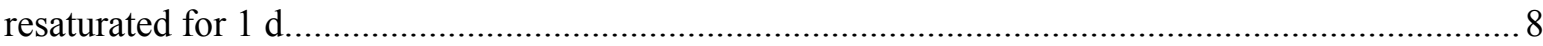

Figure $9 \mathrm{LTC}$ scan for CCRL Cement $152, w / c=0.25$, cured for $3 \mathrm{~d}$ under saturated conditions at $20{ }^{\circ} \mathrm{C} \ldots 8$

Figure $10 \mathrm{LTC}$ scan for CCRL Cement 152, $w / \mathrm{c}=0.25$, cured for $3 \mathrm{~d}$ under sealed conditions at $20{ }^{\circ} \mathrm{C}$..... 9

Figure $11 \mathrm{LTC}$ scan for CCRL Cement $152, w / C=0.25$, cured at $20^{\circ} \mathrm{C}$ for $2 \mathrm{~d}$ under sealed conditions,

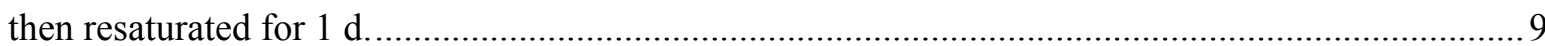

Figure 12 LTC scan for CCRL Cement $152, w / c=0.25$, cured at $20{ }^{\circ} \mathrm{C}$ for $3 \mathrm{~d}$ under sealed conditions,

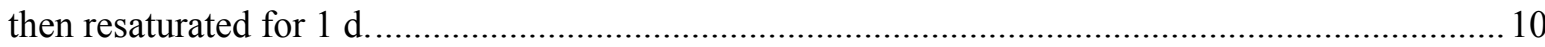

Figure 13 LTC scan for CCRL Cement 152, $w / c=0.25$, cured for $7 \mathrm{~d}$ under saturated conditions at $20{ }^{\circ} \mathrm{C}$.

Figure $14 \mathrm{LTC}$ scan for CCRL Cement 152, w/C $=0.25$, cured for $7 \mathrm{~d}$ under sealed conditions at $20{ }^{\circ} \mathrm{C}$.. 11

Figure $15 \mathrm{LTC}$ scan for CCRL Cement $152, w / c=0.25$, cured at $20{ }^{\circ} \mathrm{C}$ for $7 \mathrm{~d}$ under sealed conditions,

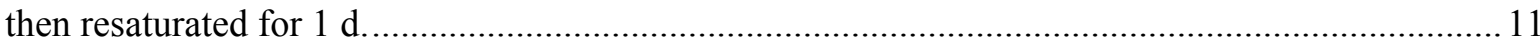

Figure $16 \mathrm{LTC}$ scan for CCRL Cement $152, w / C=0.25$, cured for $15 \mathrm{~d}$ under saturated conditions at $20{ }^{\circ} \mathrm{C}$.

Figure $17 \mathrm{LTC}$ scan for CCRL Cement 152, w/c $=0.25$, cured for $15 \mathrm{~d}$ under sealed conditions at $20{ }^{\circ} \mathrm{C} .12$ Figure $18 \mathrm{LTC}$ scan for CCRL Cement $152, w / c=0.25$, cured at $20{ }^{\circ} \mathrm{C}$ for $15 \mathrm{~d}$ under sealed conditions,

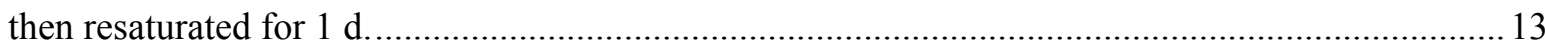

Figure $19 \mathrm{LTC}$ scan for CCRL Cement $152, w / c=0.25$, cured for $21 \mathrm{~d}$ under saturated conditions at $20^{\circ} \mathrm{C}$.

Figure $20 \mathrm{LTC}$ scan for CCRL Cement 152, w/c $=0.25$, cured for $21 \mathrm{~d}$ under sealed conditions at $20^{\circ} \mathrm{C} .14$ Figure $21 \mathrm{LTC}$ scan for CCRL Cement $152, w / c=0.25$, cured at $20{ }^{\circ} \mathrm{C}$ for $21 \mathrm{~d}$ under sealed conditions, then resaturated for $1 \mathrm{~d}$.

Figure 22 LTC scan for CCRL Cement $152, w / c=0.25$, cured for $36 \mathrm{~d}$ under saturated conditions at $20{ }^{\circ} \mathrm{C}$. 15

Figure 23 LTC scan for CCRL Cement 152, $w / c=0.25$, cured for $37 \mathrm{~d}$ under sealed conditions at $20{ }^{\circ} \mathrm{C} .15$ 
Figure 24 LTC scan for CCRL Cement $152, w / c=0.25$, cured at $20{ }^{\circ} \mathrm{C}$ for $37 \mathrm{~d}$ under sealed conditions,

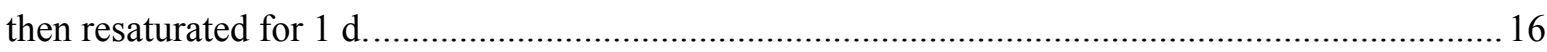

Figure $25 \mathrm{LTC}$ scan for CCRL Cement $152, w / c=0.25$, cured for $56 \mathrm{~d}$ under saturated conditions at $20{ }^{\circ} \mathrm{C}$. 16

Figure $26 \mathrm{LTC}$ scan for CCRL Cement $152, w / c=0.25$, cured for $56 \mathrm{~d}$ under sealed conditions at $20{ }^{\circ} \mathrm{C} .17$ Figure $27 \mathrm{LTC}$ scan for CCRL Cement $152, w / c=0.25$, cured at $20{ }^{\circ} \mathrm{C}$ for $56 \mathrm{~d}$ under sealed conditions,

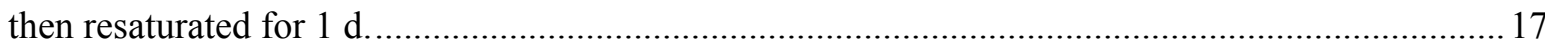

Figure $28 \mathrm{LTC}$ scan for CCRL Cement $152, w / c=0.25$, cured for $91 \mathrm{~d}$ under saturated conditions at $20^{\circ} \mathrm{C}$.

Figure $29 \mathrm{LTC}$ scan for CCRL Cement $152, w / c=0.25$, cured for $91 \mathrm{~d}$ under sealed conditions at $20{ }^{\circ} \mathrm{C} .18$ Figure $30 \mathrm{LTC}$ scan for CCRL Cement $152, w / c=0.25$, cured at $20{ }^{\circ} \mathrm{C}$ for $91 \mathrm{~d}$ under sealed conditions, then resaturated for $1 \mathrm{~d}$.

Figure $31 \mathrm{LTC}$ scan for CCRL Cement $152, w / C=0.35$, cured for $1 \mathrm{~d}$ under saturated conditions at $20^{\circ} \mathrm{C}$.

Figure $32 \mathrm{LTC}$ scan for CCRL Cement 152, w/c $=0.35$, cured for $1 \mathrm{~d}$ under sealed conditions at $20^{\circ} \mathrm{C}$... 20 Figure 33 LTC scan for CCRL Cement 152, $w / C=0.35$, cured for $2 \mathrm{~d}$ under saturated conditions at $20^{\circ} \mathrm{C}$.

Figure 34 LTC scan for CCRL Cement 152, w/c $=0.35$, cured for $2 \mathrm{~d}$ under sealed conditions at $20{ }^{\circ} \mathrm{C}$... 21 Figure $35 \mathrm{LTC}$ scan for CCRL Cement 152, $w / c=0.35$, cured for $2 \mathrm{~d}$ under saturated conditions at $20{ }^{\circ} \mathrm{C}$ (replicate mixture).

Figure 36 LTC scan for CCRL Cement 152, $w / c=0.35$, cured for $2 \mathrm{~d}$ under sealed conditions at $20{ }^{\circ} \mathrm{C}$ (replicate mixture).

Figure $37 \mathrm{LTC}$ scan for CCRL Cement $152, w / c=0.35$, cured for $3 \mathrm{~d}$ under saturated conditions at $20{ }^{\circ} \mathrm{C}$.

23

Figure $38 \mathrm{LTC}$ scan for CCRL Cement $152, w / c=0.35$, cured for $3 \mathrm{~d}$ under sealed conditions at $20^{\circ} \mathrm{C}$... 23 Figure $39 \mathrm{LTC}$ scan for CCRL Cement $152, w / C=0.35$, cured at $20^{\circ} \mathrm{C}$ for $2 \mathrm{~d}$ under sealed conditions,

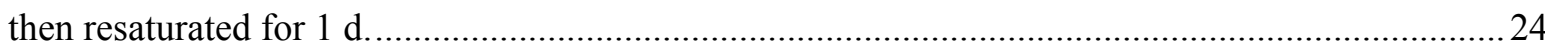

Figure $40 \mathrm{LTC}$ scan for CCRL Cement $152, w / c=0.35$, cured for $4 \mathrm{~d}$ under saturated conditions at $20{ }^{\circ} \mathrm{C}$.

Figure $41 \mathrm{LTC}$ scan for CCRL Cement $152, w / c=0.35$, cured for $4 \mathrm{~d}$ under sealed conditions at $20^{\circ} \mathrm{C}$.. 25 Figure $42 \mathrm{LTC}$ scan for CCRL Cement $152, w / C=0.35$, cured at $20{ }^{\circ} \mathrm{C}$ for $3 \mathrm{~d}$ under sealed conditions,

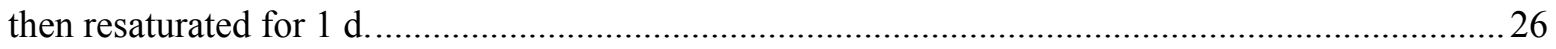

Figure $43 \mathrm{LTC}$ scan for CCRL Cement $152, w / c=0.35$, cured at $20{ }^{\circ} \mathrm{C}$ for $4 \mathrm{~d}$ under sealed conditions, then resaturated for $1 \mathrm{~d}$. 26 
Figure $44 \mathrm{LTC}$ scan for CCRL Cement $152, w / c=0.35$, cured for $5 \mathrm{~d}$ under saturated conditions at $20{ }^{\circ} \mathrm{C}$.

Figure $45 \mathrm{LTC}$ scan for CCRL Cement 152, w/c $=0.35$, cured for $5 \mathrm{~d}$ under sealed conditions at $20{ }^{\circ} \mathrm{C} \ldots 27$ Figure $46 \mathrm{LTC}$ scan for CCRL Cement $152, w / c=0.35$, cured for $7 \mathrm{~d}$ under saturated conditions at $20{ }^{\circ} \mathrm{C}$.

Figure $47 \mathrm{LTC}$ scan for CCRL Cement 152, w/c $=0.35$, cured for $7 \mathrm{~d}$ under sealed conditions at $20{ }^{\circ} \mathrm{C}$... 28

Figure $48 \mathrm{LTC}$ scan for CCRL Cement $152, w / c=0.35$, cured at $20^{\circ} \mathrm{C}$ for $5 \mathrm{~d}$ under sealed conditions, then resaturated for $2 \mathrm{~d}$.

Figure $49 \mathrm{LTC}$ scan for CCRL Cement $152, w / c=0.35$, cured at $20{ }^{\circ} \mathrm{C}$ for $7 \mathrm{~d}$ under sealed conditions, then resaturated for $2 \mathrm{~d}$.

Figure $50 \mathrm{LTC}$ scan for CCRL Cement $152, w / c=0.35$, cured at $20{ }^{\circ} \mathrm{C}$ for $7 \mathrm{~d}$ under sealed conditions, frozen during an LTC scan (Figure 17), then resaturated for $1 \mathrm{~d}$. 30

Figure $51 \mathrm{LTC}$ scan for CCRL Cement 152, w/c $=0.35$, cured for $9 \mathrm{~d}$ under saturated conditions at $20{ }^{\circ} \mathrm{C}$.

Figure $52 \mathrm{LTC}$ scan for CCRL Cement $152, w / c=0.35$, cured for $9 \mathrm{~d}$ under sealed conditions at $20{ }^{\circ} \mathrm{C}$... 31 Figure $53 \mathrm{LTC}$ scan for CCRL Cement $152, w / c=0.35$, cured for $14 \mathrm{~d}$ under saturated conditions at $20{ }^{\circ} \mathrm{C}$.

Figure $54 \mathrm{LTC}$ scan for CCRL Cement 152, $w / c=0.35$, cured for $14 \mathrm{~d}$ under sealed conditions at $20^{\circ} \mathrm{C} .32$ Figure $55 \mathrm{LTC}$ scan for CCRL Cement $152, w / c=0.35$, cured at $20{ }^{\circ} \mathrm{C}$ for $14 \mathrm{~d}$ under sealed conditions, then resaturated for $1 \mathrm{~d}$.

Figure $56 \mathrm{LTC}$ scan for CCRL Cement $152, w / \mathrm{c}=0.35$, cured at $20{ }^{\circ} \mathrm{C}$ for $14 \mathrm{~d}$ under sealed conditions, then resaturated for $4 \mathrm{~d}$.

Figure 57 LTC scan for CCRL Cement $152, w / c=0.35$, cured for $18 \mathrm{~d}$ under saturated conditions at $20{ }^{\circ} \mathrm{C}$.

Figure $58 \mathrm{LTC}$ scan for CCRL Cement 152, $w / \mathrm{c}=0.35$, cured for $18 \mathrm{~d}$ under sealed conditions at $20{ }^{\circ} \mathrm{C} .34$ Figure $59 \mathrm{LTC}$ scan for CCRL Cement $152, w / c=0.35$, cured at $20{ }^{\circ} \mathrm{C}$ for $17 \mathrm{~d}$ under sealed conditions, then resaturated for $1 \mathrm{~d}$.

Figure $60 \mathrm{LTC}$ scan for CCRL Cement $152, w / c=0.35$, cured at $20{ }^{\circ} \mathrm{C}$ for $14 \mathrm{~d}$ under sealed conditions, then resaturated for $7 \mathrm{~d}$.

Figure $61 \mathrm{LTC}$ scan for CCRL Cement $152, w / c=0.35$, cured at $20{ }^{\circ} \mathrm{C}$ for $14 \mathrm{~d}$ under sealed conditions, then resaturated for $15 \mathrm{~d}$ .36

Figure $62 \mathrm{LTC}$ scan for CCRL Cement 152, $w / \mathrm{c}=0.35$, cured for $30 \mathrm{~d}$ under saturated conditions at $20{ }^{\circ} \mathrm{C}$.

Figure $63 \mathrm{LTC}$ scan for CCRL Cement 152, w/c=0.35, cured for $30 \mathrm{~d}$ under sealed conditions at $20{ }^{\circ} \mathrm{C} .37$ 
Figure 64 LTC scan for CCRL Cement $152, w / c=0.35$, cured at $20{ }^{\circ} \mathrm{C}$ for $30 \mathrm{~d}$ under sealed conditions,

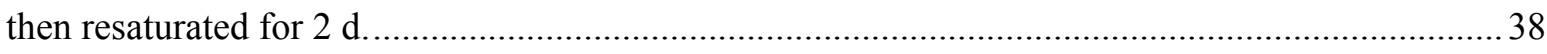

Figure $65 \mathrm{LTC}$ scan for CCRL Cement $152, w / c=0.35$, cured at $20{ }^{\circ} \mathrm{C}$ for $30 \mathrm{~d}$ under sealed conditions,

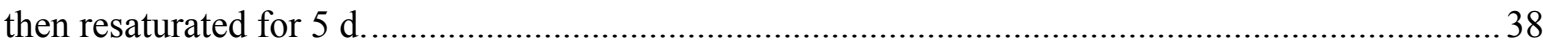

Figure 66 LTC scan for CCRL Cement $152, w / c=0.35$, cured at $20{ }^{\circ} \mathrm{C}$ for $30 \mathrm{~d}$ under sealed conditions, then resaturated for $12 \mathrm{~d}$

Figure $67 \mathrm{LTC}$ scan for CCRL Cement $152, w / c=0.35$, cured at $20{ }^{\circ} \mathrm{C}$ for $30 \mathrm{~d}$ under sealed conditions,

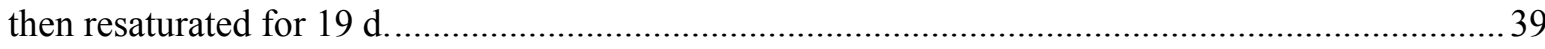

Figure $68 \mathrm{LTC}$ scan for CCRL Cement 152, w/c $=0.35$, cured for $50 \mathrm{~d}$ under saturated conditions at $20{ }^{\circ} \mathrm{C}$.

Figure $69 \mathrm{LTC}$ scan for CCRL Cement 152, w/c $=0.35$, cured for $50 \mathrm{~d}$ under sealed conditions at $20{ }^{\circ} \mathrm{C} .40$ Figure $70 \mathrm{LTC}$ scan for CCRL Cement $152, w / c=0.35$, cured at $20{ }^{\circ} \mathrm{C}$ for $50 \mathrm{~d}$ under sealed conditions, then resaturated for $1 \mathrm{~d}$.

Figure $71 \mathrm{LTC}$ scan for CCRL Cement $152, w / c=0.35$, cured at $20{ }^{\circ} \mathrm{C}$ for $50 \mathrm{~d}$ under sealed conditions, then resaturated for $2 \mathrm{~d}$.

Figure $72 \mathrm{LTC}$ scan for CCRL Cement $152, w / c=0.35$, cured at $20{ }^{\circ} \mathrm{C}$ for $50 \mathrm{~d}$ under sealed conditions, then resaturated for $13 \mathrm{~d}$.

Figure $73 \mathrm{LTC}$ scan for CCRL Cement $152, w / c=0.35$, cured at $20^{\circ} \mathrm{C}$ for $88 \mathrm{~d}$ under sealed conditions, then resaturated for $3 \mathrm{~d}$.

Figure 74 LTC scan for CCRL Cement 152, $w / c=0.35$, cured for $90 \mathrm{~d}$ under saturated conditions at $20{ }^{\circ} \mathrm{C}$.

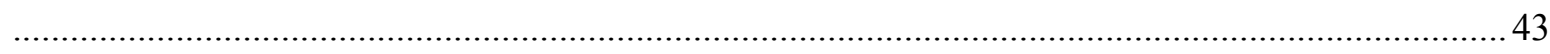

Figure $75 \mathrm{LTC}$ scan for CCRL Cement 152, w/C $=0.35$, cured for $90 \mathrm{~d}$ under sealed conditions at $20{ }^{\circ} \mathrm{C} .43$ Figure 76 LTC scan for CCRL Cement $152, w / c=0.35$, cured for $182 \mathrm{~d}$ at $20{ }^{\circ} \mathrm{C}$ under saturated conditions.

Figure $77 \mathrm{LTC}$ scan for CCRL Cement $152, w / c=0.35$, cured for $182 \mathrm{~d}$ at $20^{\circ} \mathrm{C}$ under sealed conditions.

Figure $78 \mathrm{LTC}$ scan for CCRL Cement $152, w / c=0.35$, cured at $20{ }^{\circ} \mathrm{C}$ for $7 \mathrm{~d}$ under sealed conditions, then resaturated for $175 \mathrm{~d}$.

Figure $79 \mathrm{LTC}$ scan for CCRL Cement $152, w / c=0.35$, cured at $20{ }^{\circ} \mathrm{C}$ for $182 \mathrm{~d}$ under sealed conditions, then resaturated for $1 \mathrm{~d}$. 45

Figure $80 \mathrm{LTC}$ scan for CCRL Cement $152, w / c=0.35$, cured for $204 \mathrm{~d}$ at $20{ }^{\circ} \mathrm{C}$ under sealed conditions.

Figure $81 \mathrm{LTC}$ scan for CCRL Cement $152, w / c=0.35$, cured at $20^{\circ} \mathrm{C}$ for $203 \mathrm{~d}$ under sealed conditions, then resaturated for $1 \mathrm{~d}$. .46 
Figure $82 \mathrm{LTC}$ scan for CCRL Cement $152, w / c=0.35$, cured at $20{ }^{\circ} \mathrm{C}$ for $203 \mathrm{~d}$ under sealed conditions, then resaturated for $4 \mathrm{~d}$.

Figure $83 \mathrm{LTC}$ scan for CCRL Cement $152, w / c=0.35$, cured at $20{ }^{\circ} \mathrm{C}$ for $203 \mathrm{~d}$ under sealed conditions, then resaturated for $21 \mathrm{~d}$. 47

Figure $84 \mathrm{LTC}$ scan for CCRL Cement $152, w / c=0.35$, cured at $20{ }^{\circ} \mathrm{C}$ for $203 \mathrm{~d}$ under sealed conditions, then resaturated for $35 \mathrm{~d}$. 48

Figure 85 LTC scan for CCRL Cement $152, w / c=0.35$, cured for $228 \mathrm{~d}$ at $20{ }^{\circ} \mathrm{C}$ under saturated conditions.

Figure 86 LTC scan for CCRL Cement 152, w/c $=0.35$, cured for $7 \mathrm{~d}$ at $20{ }^{\circ} \mathrm{C}$ under sealed conditions, then resaturated for $221 \mathrm{~d}$.

Figure $87 \mathrm{LTC}$ scan for CCRL Cement $152, w / c=0.435$, cured for $214 \mathrm{~d}$ at $20{ }^{\circ} \mathrm{C}$ under saturated conditions.

Figure $88 \mathrm{LTC}$ scan for CCRL Cement $152, w / c=0.435$, cured for $214 \mathrm{~d}$ at $20{ }^{\circ} \mathrm{C}$ under sealed conditions.

Figure $89 \mathrm{LTC}$ scan for CCRL Cement $152, w / c=0.435$, cured for $7 \mathrm{~d}$ at $20{ }^{\circ} \mathrm{C}$ under sealed conditions, then resaturated for $207 \mathrm{~d}$.

Figure $90 \mathrm{LTC}$ scan for CCRL Cement $152, w / c=0.435$, cured for $214 \mathrm{~d}$ at $20{ }^{\circ} \mathrm{C}$ under sealed conditions, then resaturated for $4 \mathrm{~d}$.

Figure $91 \mathrm{LTC}$ scan for CCRL Cement $152, w / c=0.435$, cured for $214 \mathrm{~d}$ at $20^{\circ} \mathrm{C}$ under sealed conditions, then resaturated for $41 \mathrm{~d}$. .52

Figure $92 \mathrm{LTC}$ scan for CCRL Cement 152, $w / C=0.435$, cured for $204 \mathrm{~d}$ at $20^{\circ} \mathrm{C}$ under sealed conditions, then resaturated for $34 \mathrm{~d}$. .52

Figure 93 LTC scan for CCRL Cement 152, $w / C=0.435$, cured for $256 \mathrm{~d}$ at $20{ }^{\circ} \mathrm{C}$ under sealed conditions.

Figure 94 LTC scan for CCRL Cement 152,w/c=0.435, cured for $276 \mathrm{~d}$ at $20{ }^{\circ} \mathrm{C}$ under saturated conditions.

Figure 95 LTC scan for CCRL Cement 152 with $20 \%$ limestone filler substitution, $w / s=0.35$, cured for

$91 \mathrm{~d}$ at $20{ }^{\circ} \mathrm{C}$ under saturated conditions.

Figure 96 LTC scan for CCRL Cement 152 with $20 \%$ limestone filler substitution, $w / s=0.35$, cured for

$91 \mathrm{~d}$ at $20^{\circ} \mathrm{C}$ under sealed conditions.

Figure 97 LTC scan for CCRL Cement 152 with $20 \%$ limestone filler substitution, $w / s=0.35$, cured under sealed conditions for $91 \mathrm{~d}$ at $20^{\circ} \mathrm{C}$, then resaturated for $1 \mathrm{~d}$. .55

Figure 98 LTC scan for CCRL Cement 152 with $20 \%$ limestone filler substitution, $w / s=0.35$, cured under sealed conditions for $91 \mathrm{~d}$ at $20{ }^{\circ} \mathrm{C}$, then resaturated for $92 \mathrm{~d}$. .55 
Figure 99 LTC scan for CCRL Cement 152 with $20 \%$ limestone filler substitution, $w / s=0.35$, cured for

183 d at $20^{\circ} \mathrm{C}$ under saturated conditions.

Figure 100 LTC scan for CCRL Cement 152 with $20 \%$ limestone filler substitution, $w / s=0.35$, cured for

$183 \mathrm{~d}$ at $20{ }^{\circ} \mathrm{C}$ under sealed conditions. .56

Figure 101 LTC scan for CCRL Cement 152 with $20 \%$ limestone filler substitution, $w / s=0.35$, cured

under sealed conditions for $183 \mathrm{~d}$ at $20^{\circ} \mathrm{C}$, then resaturated for $1 \mathrm{~d}$. .57

Figure 102 LTC scan for CCRL Cement 152 with $20 \%$ limestone filler substitution, $w / s=0.435$, cured for

$213 \mathrm{~d}$ at $20{ }^{\circ} \mathrm{C}$ under saturated conditions. .57

Figure 103 LTC scan for CCRL Cement 152 with $20 \%$ limestone filler substitution, $w / s=0.435$, cured for $219 \mathrm{~d}$ at $20{ }^{\circ} \mathrm{C}$ under sealed conditions. .58

Figure 104 LTC scan for CCRL Cement 152 with $20 \%$ limestone filler substitution, $w / s=0.435$, cured under sealed conditions for $218 \mathrm{~d}$ at $20^{\circ} \mathrm{C}$, then resaturated for $1 \mathrm{~d}$. .58

Figure 105 LTC scan for CCRL Cement $152, w / c=0.25$, cured for $8 \mathrm{~h}$ under saturated conditions at $40{ }^{\circ} \mathrm{C}$. .59

Figure $106 \mathrm{LTC}$ scan for CCRL Cement $152, w / c=0.25$, cured for $1 \mathrm{~d}$ under saturated conditions at $40{ }^{\circ} \mathrm{C}$.

Figure 107 LTC scan for CCRL Cement 152, $w / c=0.25$, cured for $1 \mathrm{~d}$ under sealed conditions at $40{ }^{\circ} \mathrm{C} .60$ Figure 108 LTC scan for CCRL Cement $152, w / c=0.25$, cured for $2 \mathrm{~d}$ under saturated conditions at $40{ }^{\circ} \mathrm{C}$.

Figure 109 LTC scan for CCRL Cement 152, $w / c=0.25$, cured for $2 \mathrm{~d}$ under sealed conditions at $40{ }^{\circ} \mathrm{C} .61$ Figure $110 \mathrm{LTC}$ scan for CCRL Cement $152, w / c=0.25$, cured for $1 \mathrm{~d}$ at $40{ }^{\circ} \mathrm{C}$ under sealed conditions, then resaturated for $1 \mathrm{~d}$.

Figure $111 \mathrm{LTC}$ scan for CCRL Cement $152, w / c=0.25$, cured for $3 \mathrm{~d}$ under saturated conditions at $40{ }^{\circ} \mathrm{C}$.

Figure 112 LTC scan for CCRL Cement 152, $w / c=0.25$, cured for $3 \mathrm{~d}$ under sealed conditions at $40{ }^{\circ} \mathrm{C} .62$

Figure $113 \mathrm{LTC}$ scan for CCRL Cement $152, w / c=0.25$, cured for $2 \mathrm{~d}$ at $40{ }^{\circ} \mathrm{C}$ under sealed conditions, then resaturated for $1 \mathrm{~d}$.

Figure 114 LTC scan for CCRL Cement $152, w / c=0.25$, cured for $3 \mathrm{~d}$ at $40{ }^{\circ} \mathrm{C}$ under sealed conditions, then resaturated for $1 \mathrm{~d}$.

Figure $115 \mathrm{LTC}$ scan for CCRL Cement $152, w / c=0.25$ cured for $14 \mathrm{~d}$ under saturated conditions at $40{ }^{\circ} \mathrm{C}$.

Figure 116 LTC scan for CCRL Cement $152, w / c=0.25$, cured for $14 \mathrm{~d}$ under sealed conditions at $40{ }^{\circ} \mathrm{C}$. 
Figure $117 \mathrm{LTC}$ scan for CCRL Cement $152, w / c=0.25$, cured for $14 \mathrm{~d}$ at $40{ }^{\circ} \mathrm{C}$ under sealed conditions,

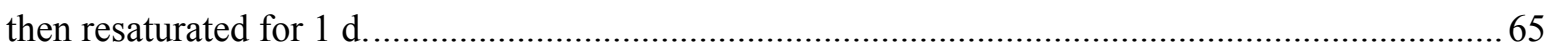

Figure $118 \mathrm{LTC}$ scan for CCRL Cement $152, w / c=0.25$ cured for $28 \mathrm{~d}$ under saturated conditions at $40{ }^{\circ} \mathrm{C}$.

Figure $119 \mathrm{LTC}$ scan for CCRL Cement $152, w / c=0.25$, cured for $28 \mathrm{~d}$ under sealed conditions at $40{ }^{\circ} \mathrm{C}$.

Figure $120 \mathrm{LTC}$ scan for CCRL Cement $152, w / c=0.25$, cured for $28 \mathrm{~d}$ at $40{ }^{\circ} \mathrm{C}$ under sealed conditions, then resaturated for $1 \mathrm{~d}$. .66

Figure $121 \mathrm{LTC}$ scan for CCRL Cement $152, w / c=0.35$, cured for $1 \mathrm{~d}$ under saturated conditions at $40{ }^{\circ} \mathrm{C}$.

Figure $122 \mathrm{LTC}$ scan for CCRL Cement $152, w / c=0.35$, cured for $1 \mathrm{~d}$ under sealed conditions at $40{ }^{\circ} \mathrm{C} .67$ Figure $123 \mathrm{LTC}$ scan for CCRL Cement $152, w / c=0.35$, cured for $1 \mathrm{~d}$ at $40{ }^{\circ} \mathrm{C}$ under sealed conditions, then resaturated for $1 \mathrm{~d}$.

Figure 124 LTC scan for CCRL Cement $152, w / c=0.35$, cured for $1 \mathrm{~d}$ at $40{ }^{\circ} \mathrm{C}$ under sealed conditions, then resaturated for $2 \mathrm{~d}$.

Figure $125 \mathrm{LTC}$ scan for CCRL Cement $152, w / c=0.35$, cured for $2 \mathrm{~d}$ under saturated conditions at $40{ }^{\circ} \mathrm{C}$.

Figure $126 \mathrm{LTC}$ scan for CCRL Cement 152, $w / c=0.35$, cured for $2 \mathrm{~d}$ under sealed conditions at $40{ }^{\circ} \mathrm{C} .69$ Figure 127 LTC scan for CCRL Cement $152, w / c=0.35$, cured for $7 \mathrm{~d}$ under saturated conditions at $40{ }^{\circ} \mathrm{C}$.

Figure $128 \mathrm{LTC}$ scan for CCRL Cement $152, w / c=0.35$, cured for $7 \mathrm{~d}$ under sealed conditions at $40{ }^{\circ} \mathrm{C} .70$ Figure $129 \mathrm{LTC}$ scan for CCRL Cement $152, w / c=0.35$, cured for $2 \mathrm{~d}$ under sealed conditions at $40{ }^{\circ} \mathrm{C}$, then resaturated for $5 \mathrm{~d}$.

Figure $130 \mathrm{LTC}$ scan for CCRL Cement $152, w / c=0.35$, cured for $7 \mathrm{~d}$ under sealed conditions at $40{ }^{\circ} \mathrm{C}$, then resaturated for $6 \mathrm{~d}$.

Figure $131 \mathrm{LTC}$ scan for CCRL Cement $152, w / c=0.35$ cured for $14 \mathrm{~d}$ under saturated conditions at $40{ }^{\circ} \mathrm{C}$.

Figure $132 \mathrm{LTC}$ scan for CCRL Cement $152, w / c=0.35$, cured for $14 \mathrm{~d}$ under sealed conditions at $40{ }^{\circ} \mathrm{C}$.

Figure $133 \mathrm{LTC}$ scan for CCRL Cement $152, w / c=0.35$ cured for $28 \mathrm{~d}$ under saturated conditions at $40{ }^{\circ} \mathrm{C}$.

Figure $134 \mathrm{LTC}$ scan for CCRL Cement $152, w / C=0.35$, cured for $28 \mathrm{~d}$ under sealed conditions at $40{ }^{\circ} \mathrm{C}$. 
Figure $135 \mathrm{LTC}$ scan for CCRL Cement $152, w / c=0.35$, cured for $14 \mathrm{~d}$ under sealed conditions at $40{ }^{\circ} \mathrm{C}$,

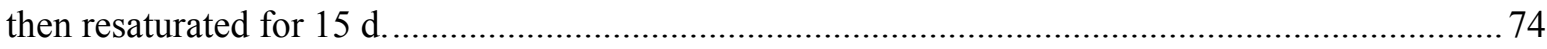

Figure $136 \mathrm{LTC}$ scan for CCRL Cement $152, w / c=0.35$, cured for $28 \mathrm{~d}$ under sealed conditions at $40{ }^{\circ} \mathrm{C}$,

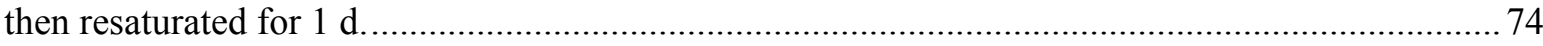

Figure 137 LTC scan for CCRL Cement $152, w / c=0.35$ cured for $58 \mathrm{~d}$ under saturated conditions at $40{ }^{\circ} \mathrm{C}$. .75

Figure $138 \mathrm{LTC}$ scan for CCRL Cement $152, w / c=0.35$, cured for $58 \mathrm{~d}$ under sealed conditions at $40{ }^{\circ} \mathrm{C}$.

Figure $139 \mathrm{LTC}$ scan for CCRL Cement $152, w / C=0.35$, cured for $57 \mathrm{~d}$ under sealed conditions at $40{ }^{\circ} \mathrm{C}$,

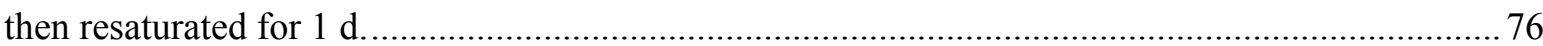

Figure $140 \mathrm{LTC}$ scan for CCRL Cement $152, w / c=0.35$, cured for $57 \mathrm{~d}$ under sealed conditions at $40{ }^{\circ} \mathrm{C}$,

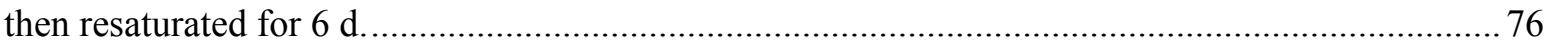

Figure $141 \mathrm{LTC}$ scan for CCRL Cement $152, w / c=0.45$, cured for $3 \mathrm{~d}$ under saturated conditions at $40{ }^{\circ} \mathrm{C}$. .77

Figure $142 \mathrm{LTC}$ scan for CCRL Cement 152, w/c $=0.45$, cured for $3 \mathrm{~d}$ under sealed conditions at $40^{\circ} \mathrm{C} .77$ Figure $143 \mathrm{LTC}$ scan for CCRL Cement $152, w / c=0.45$, cured for $8 \mathrm{~d}$ under saturated conditions at $40{ }^{\circ} \mathrm{C}$. .78

Figure 144 LTC scan for CCRL Cement 152, w/c $=0.45$, cured for $8 \mathrm{~d}$ under sealed conditions at $40{ }^{\circ} \mathrm{C} .78$ Figure 145 LTC scan for CCRL Cement $152, w / c=0.45$, cured for $3 \mathrm{~d}$ under sealed conditions at $40{ }^{\circ} \mathrm{C}$, then resaturated for $5 \mathrm{~d}$

Figure $146 \mathrm{LTC}$ scan for CCRL Cement $152, w / c=0.45$ cured for $14 \mathrm{~d}$ under saturated conditions at $40{ }^{\circ} \mathrm{C}$.

Figure 147 LTC scan for CCRL Cement 152, w/C $=0.45$, cured for $14 \mathrm{~d}$ under sealed conditions at $40{ }^{\circ} \mathrm{C}$.

Figure $148 \mathrm{LTC}$ scan for CCRL Cement $152, w / c=0.45$, cured for $3 \mathrm{~d}$ under sealed conditions at $40{ }^{\circ} \mathrm{C}$,

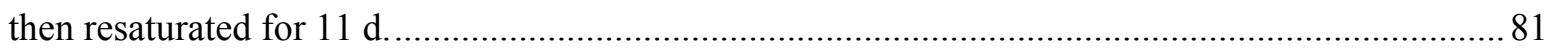

Figure 149 LTC scan for CCRL Cement $152, w / c=0.45$, cured for $8 \mathrm{~d}$ under sealed conditions at $40{ }^{\circ} \mathrm{C}$,

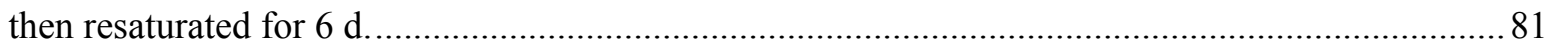

Figure $150 \mathrm{LTC}$ scan for CCRL Cement $152, w / c=0.45$, cured for $29 \mathrm{~d}$ at $40{ }^{\circ} \mathrm{C}$ under saturated conditions. 82

Figure $151 \mathrm{LTC}$ scan for CCRL Cement $152, w / c=0.45$, cured for $29 \mathrm{~d}$ at $40{ }^{\circ} \mathrm{C}$ under sealed conditions.

Figure $152 \mathrm{LTC}$ scan for CCRL Cement $152, w / c=0.45$, cured for $28 \mathrm{~d}$ under sealed conditions at $40{ }^{\circ} \mathrm{C}$, then resaturated for $1 \mathrm{~d}$. 83 
Figure 153 LTC scan for CCRL Cement 140, $w / c=0.40$, prepared with distilled water and cured for $2 \mathrm{~d}$ at $20{ }^{\circ} \mathrm{C}$ under saturated conditions. .83

Figure 154 LTC scan for CCRL Cement $140, w / c=0.40$, prepared with a solution of alkali sulfates and cured for $2 \mathrm{~d}$ at $20{ }^{\circ} \mathrm{C}$ under saturated conditions. 84

Figure 155 LTC scan for CCRL Cement $140, w / c=0.40$, prepared with a solution of alkali hydroxides and cured for $2 \mathrm{~d}$ at $20{ }^{\circ} \mathrm{C}$ under saturated conditions. 84

Figure 156 LTC scan for CCRL Cement $140, w / c=0.40$, prepared with a $\mathrm{LiOH}$ solution and cured for $2 \mathrm{~d}$ at $20{ }^{\circ} \mathrm{C}$ under saturated conditions. 85

Figure 157 LTC scan for CCRL Cement 140, w/c=0.40, prepared with a $\mathrm{LiNO}_{3}$ solution and cured for $2 \mathrm{~d}$ at $20{ }^{\circ} \mathrm{C}$ under saturated conditions. 85

Figure $158 \mathrm{LTC}$ scan for CCRL Cement $140, w / c=0.40$, prepared with a LiOH solution and cured for $4 \mathrm{~d}$ at $20{ }^{\circ} \mathrm{C}$ under saturated conditions. 86

Figure $159 \mathrm{LTC}$ scan for CCRL Cement 140, $w / c=0.40$, prepared with a $\mathrm{LiNO}_{3}$ solution and cured for $4 \mathrm{~d}$ at $20{ }^{\circ} \mathrm{C}$ under saturated conditions. 86

Figure 160 LTC scan for CCRL Cement $140, w / c=0.40$, prepared with a LiOH solution and cured for $7 \mathrm{~d}$ at $20{ }^{\circ} \mathrm{C}$ under saturated conditions.

Figure $161 \mathrm{LTC}$ scan for CCRL Cement 140, $w / c=0.40$, prepared with a $\mathrm{LiNO}_{3}$ solution and cured for $7 \mathrm{~d}$ at $20{ }^{\circ} \mathrm{C}$ under saturated conditions.

Figure 162 LTC scan for CCRL Cement 140, $w / c=0.40$, prepared with distilled water and cured for $8 \mathrm{~d}$ at $20{ }^{\circ} \mathrm{C}$ under saturated conditions. 88

Figure 163 LTC scan for CCRL Cement $140, w / c=0.40$, prepared with a solution of alkali sulfates and cured for $8 \mathrm{~d}$ at $20{ }^{\circ} \mathrm{C}$ under saturated conditions.

Figure 164 LTC scan for CCRL Cement $140, w / c=0.40$, prepared with a solution of alkali hydroxides and cured for $8 \mathrm{~d}$ at $20{ }^{\circ} \mathrm{C}$ under saturated conditions.

Figure 165 LTC scan for CCRL Cement 140, $w / c=0.40$, prepared with a solution of $\mathrm{LiOH}$ and cured for 8 d at $20{ }^{\circ} \mathrm{C}$ under saturated conditions.

Figure $166 \mathrm{LTC}$ scan for CCRL Cement 140,w/c=0.40, prepared with a solution of $\mathrm{LiNO}_{3}$ and cured for $8 \mathrm{~d}$ at $20{ }^{\circ} \mathrm{C}$ under saturated conditions.

Figure 167 LTC scan for CCRL Cement 140, w/c=0.40, prepared with distilled water and cured for $14 \mathrm{~d}$ at $20{ }^{\circ} \mathrm{C}$ under saturated conditions.

Figure 168 LTC scan for CCRL Cement $140, w / c=0.40$, prepared with a solution of alkali sulfates and cured for $14 \mathrm{~d}$ at $20{ }^{\circ} \mathrm{C}$ under saturated conditions. 91

Figure 169 LTC scan for CCRL Cement 140, $w / c=0.40$, prepared with a solution of alkali hydroxides and cured for $14 \mathrm{~d}$ at $20^{\circ} \mathrm{C}$ under saturated conditions. 
Figure 170 LTC scan for CCRL Cement 140, w/c $=0.40$, prepared with a solution of $\mathrm{LiOH}$ and cured for

$14 \mathrm{~d}$ at $20{ }^{\circ} \mathrm{C}$ under saturated conditions. 92

Figure $171 \mathrm{LTC}$ scan for CCRL Cement 140, w/c $=0.40$, prepared with a solution of $\mathrm{LiNO}_{3}$ and cured for

$14 \mathrm{~d}$ at $20{ }^{\circ} \mathrm{C}$ under saturated conditions. 92

Figure 172 LTC scan for CCRL Cement $140, w / c=0.40$, prepared with distilled water and cured for $30 \mathrm{~d}$ at $20{ }^{\circ} \mathrm{C}$ under saturated conditions..... 93

Figure 173 LTC scan for CCRL Cement $140, w / c=0.40$, prepared with a solution of alkali sulfates and cured for $30 \mathrm{~d}$ at $20^{\circ} \mathrm{C}$ under saturated conditions. .93

Figure 174 LTC scan for CCRL Cement $140, w / c=0.40$, prepared with a solution of alkali hydroxides and cured for $30 \mathrm{~d}$ at $20{ }^{\circ} \mathrm{C}$ under saturated conditions. .94

Figure 175 LTC scan for CCRL Cement 140, w/c=0.40, prepared with a solution of $\mathrm{LiOH}$ and cured for $30 \mathrm{~d}$ at $20^{\circ} \mathrm{C}$ under saturated conditions.

Figure $176 \mathrm{LTC}$ scan for CCRL Cement 140, w/c $=0.40$, prepared with a solution of $\mathrm{LiNO}_{3}$ and cured for $30 \mathrm{~d}$ at $20^{\circ} \mathrm{C}$ under saturated conditions. 95

Figure 177 LTC scan for CCRL Cement 140, $w / c=0.40$, prepared with distilled water and cured for $63 \mathrm{~d}$ at $20{ }^{\circ} \mathrm{C}$ under saturated conditions. 95

Figure 178 LTC scan for CCRL Cement $140, w / c=0.40$, prepared with a solution of alkali sulfates and cured for $63 \mathrm{~d}$ at $20{ }^{\circ} \mathrm{C}$ under saturated conditions.

Figure 179 LTC scan for CCRL Cement $140, w / c=0.40$, prepared with a solution of alkali hydroxides and cured for $63 \mathrm{~d}$ at $20{ }^{\circ} \mathrm{C}$ under saturated conditions. .96

Figure 180 LTC scan for CCRL Cement $140, w / C=0.40$, prepared with a solution of LiOH and cured for $63 \mathrm{~d}$ at $20{ }^{\circ} \mathrm{C}$ under saturated conditions.

Figure $181 \mathrm{LTC}$ scan for CCRL Cement 140, w/c $=0.40$, prepared with a solution of $\mathrm{LiNO}_{3}$ and cured for $63 \mathrm{~d}$ at $20{ }^{\circ} \mathrm{C}$ under saturated conditions.

Figure 182 LTC scan for CCRL Cement 140, $w / c=0.40$, prepared with distilled water and cured for $90 \mathrm{~d}$ at $20{ }^{\circ} \mathrm{C}$ under saturated conditions. .98

Figure 183 LTC scan for CCRL Cement 140, w/c=0.40, prepared with distilled water and cured for $91 \mathrm{~d}$ at $20{ }^{\circ} \mathrm{C}$ under saturated conditions. 98

Figure 184 LTC scan for CCRL Cement $140, w / c=0.40$, prepared with a solution of alkali sulfates and cured for $90 \mathrm{~d}$ at $20^{\circ} \mathrm{C}$ under saturated conditions.

Figure 185 LTC scan for CCRL Cement $140, w / c=0.40$, prepared with a solution of alkali sulfates and cured for $91 \mathrm{~d}$ at $20{ }^{\circ} \mathrm{C}$ under saturated conditions.

Figure 186 LTC scan for CCRL Cement $140, w / c=0.40$, prepared with a solution of alkali hydroxides and cured for $90 \mathrm{~d}$ at $20^{\circ} \mathrm{C}$ under saturated conditions. 100 
Figure 187 LTC scan for CCRL Cement 140, w/c=0.40, prepared with a solution of LiOH and cured for $90 \mathrm{~d}$ at $20{ }^{\circ} \mathrm{C}$ under saturated conditions. 100

Figure $188 \mathrm{LTC}$ scan for CCRL Cement 140, w/c $=0.40$, prepared with a solution of $\mathrm{LiNO}_{3}$ and cured for $90 \mathrm{~d}$ at $20^{\circ} \mathrm{C}$ under saturated conditions. 101

Figure $189 \mathrm{LTC}$ scan for CCRL Cement $140, w / c=0.40$, prepared with distilled water and cured for $101 \mathrm{~d}$ at $20{ }^{\circ} \mathrm{C}$ under saturated conditions.

Figure 190 LTC scan for CCRL Cement 140, $w / c=0.40$, prepared with distilled water and cured for $105 \mathrm{~d}$ at $20^{\circ} \mathrm{C}$ under saturated conditions.

Figure 191 LTC scan for CCRL Cement $140, w / c=0.40$, prepared with a solution of alkali sulfates and cured for $101 \mathrm{~d}$ at $20{ }^{\circ} \mathrm{C}$ under saturated conditions.

Figure 192 LTC scan for CCRL Cement $140, w / c=0.40$, prepared with a solution of alkali sulfates and cured for $110 \mathrm{~d}$ at $20{ }^{\circ} \mathrm{C}$ under saturated conditions.

Figure 193 Four particle model for hydrating cement paste microstructure, indicating hydration under saturated and sealed curing conditions. Dark grey is unhydrated cement grains, textured material and light grey are hydration products, white is water-filled porosity, and black is empty porosity, from reference [2]...... 


\section{List of Tables}

Table 1: Mixture proportions of the CCRL proficiency cement sample 140 paste mixtures

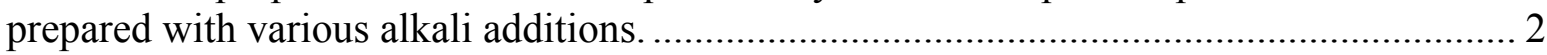

Table 2: Plots corresponding to different sets of cement paste mixtures. ....................................... 4 
xviii 


\section{Introduction}

Low temperature calorimetry (LTC) can be conveniently used to examine the percolation of various size pore networks in hydrating cement pastes [1]. During a freezing scan, as the temperature is lowered, water will freeze in progressively smaller pores. For hydrating cement pastes, as shown on the cover of this report and duplicated in Figure 1 below, up to three peaks may be observed in a typical freezing scan, corresponding to percolated networks of capillary pores, open gel pores, and dense gel pores, respectively, adopting the naming convention introduced in [1]. This experimental technique has been utilized extensively in several recent studies to provide valuable information on the influence of curing conditions and alkali additions on the depercolation (and sometimes the repercolation) of the capillary porosity in hydrating portland cement pastes [2-5]. During the course of these studies, nearly 200 individual LTC scans were conducted on a wide variety of hydrated cement paste specimens. Because most of these data could not be included in references [2-5], in this report, all of the plots generated for these scans are presented individually. It is envisioned that this graphical database will be of use for comparison purposes to other researchers utilizing this technique on cement-based materials and may suggest further avenues of research employing LTC.

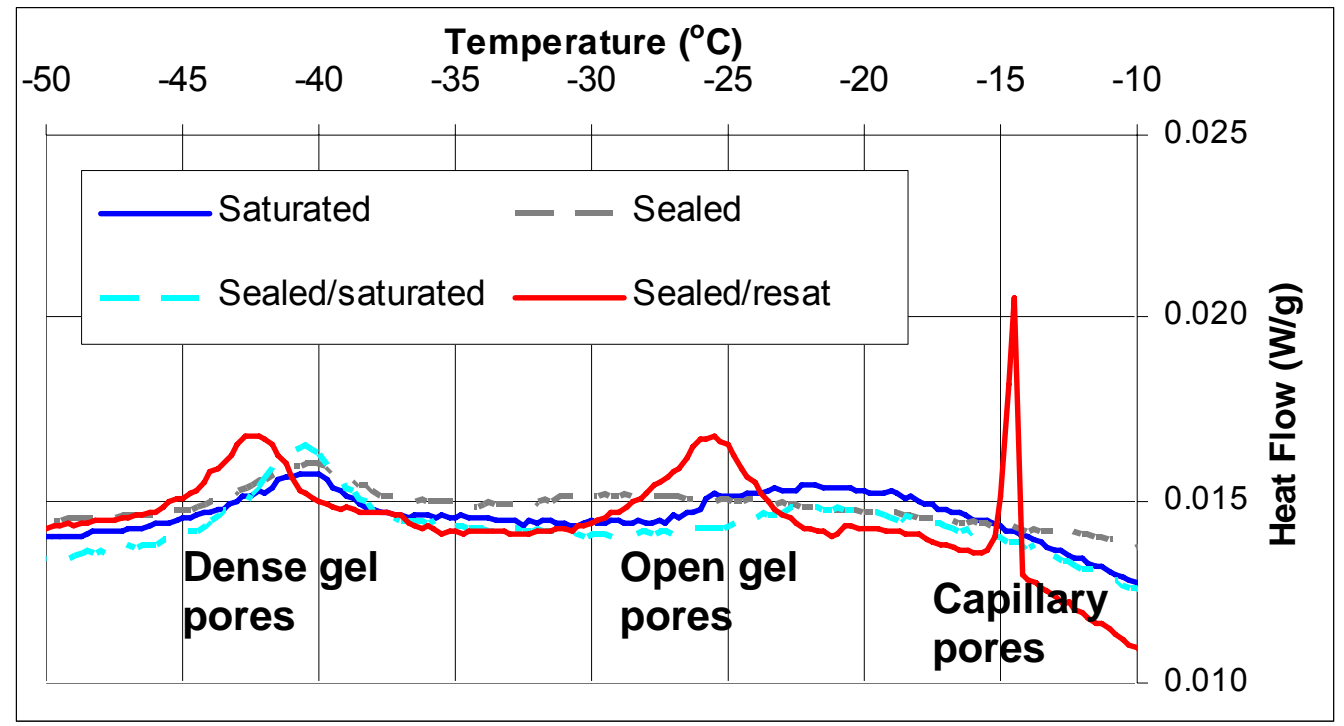

Figure 1 Typical LTC scans for a hydrating portland cement paste. 


\section{Experimental Procedure}

Cement pastes were prepared by mixing Cement and Concrete Reference Laboratory (CCRL) proficiency cement samples (either CCRL cement 140 or CCRL cement 152) with either distilled water or a solution of alkali compounds dissolved in distilled water, using a temperature-controlled high speed blender at either $20^{\circ} \mathrm{C}$ or $40{ }^{\circ} \mathrm{C}$. Details on the particle size distributions and phase compositions of the two cements can be found in an online database available at http://ciks.cbt.nist.gov/bentz/phpct/database/images. CCRL cement 152 was used for the studies where curing conditions (temperature and saturation) and water-cement mass ratio $(w / c=0.35$ or $w / c=0.45)$ were the major variables [2,5], while CCRL cement 140 was used in a study $(w / c=0.40)$ where the alkali type and content of the cement paste were varied $[3,4]$. The alkali solutions were prepared by adding the appropriate compounds (see Table 1) to distilled water and stirring with a glass rod until complete dissolution. Cement 140 is a low-alkali cement, containing only $0.093 \% \mathrm{Na}_{2} \mathrm{O}$ and $0.186 \% \mathrm{~K}_{2} \mathrm{O}$ per unit mass of cement. The additional alkalis prepared for each mixture are listed in Table 1; their masses were selected to provide the same number of moles of additional cations $\left(\mathrm{K}^{+}, \mathrm{Na}^{+}\right.$, and $\left.\mathrm{Li}^{+}\right)$in each mixture. After mixing, cast cylindrical wafers $(\approx 5 \mathrm{~g})$ of the pastes were placed in sealed plastic vials. A small quantity of water was added to the tops of some of the wafers to maintain saturated curing conditions. The capped vials were placed either in a walk-in environmental chamber maintained at $20^{\circ} \mathrm{C}$ or in a water bath maintained at $40{ }^{\circ} \mathrm{C}$.

Table 1: Mixture proportions of the CCRL proficiency cement sample 140 paste mixtures prepared with various alkali additions.

\begin{tabular}{|c|c|c|c|c|c|}
\hline Material & Mixture 1 & Mixture 2 & Mixture 3 & Mixture 4 & Mixture 5 \\
\hline Cement & $300 \mathrm{~g}$ & $300 \mathrm{~g}$ & $300 \mathrm{~g}$ & $300 \mathrm{~g}$ & $300 \mathrm{~g}$ \\
\hline $\mathrm{Water}$ & $120 \mathrm{~g}$ & $120 \mathrm{~g}$ & $120 \mathrm{~g}$ & $120 \mathrm{~g}$ & $120 \mathrm{~g}$ \\
\hline $\mathrm{K}_{2} \mathrm{SO}_{4}$ & & $2.79 \mathrm{~g}$ & & & \\
\hline $\mathrm{Na}_{2} \mathrm{SO}_{4}$ & & $2.28 \mathrm{~g}$ & & & \\
\hline $\mathrm{KOH}^{*}$ & & & $2.02 \mathrm{~g}$ & & \\
\hline $\mathrm{NaOH}$ & & & $1.30 \mathrm{~g}$ & & \\
\hline $\mathrm{LiOH}$ & & & & $2.7 \mathrm{~g}$ & \\
\hline $\mathrm{LiNO}_{3}$ & & & & & $4.42 \mathrm{~g}$ \\
\hline
\end{tabular}

* $89 \%$ purity as supplied by chemical company.

For the CCRL cement 152 specimens with $w / C=0.45$ cured at $20{ }^{\circ} \mathrm{C}$, the vials were opened after $4 \mathrm{~h}$ of curing and any accumulated bleed water was removed using a small pipette. This resulted in a nominal achieved $w / c=0.435$ for these pastes. Three curing conditions were employed for the CCRL cement 152 studies. In saturated curing, a small amount of distilled water was placed on top of the paste wafers (after removing the bleed water). (All of the CCRL cement 140 paste specimens were also cured under saturated conditions). In sealed curing, the wafers were simply sealed in their plastic vials after removal of the bleed water. In sealed/saturated curing, the wafers were cured under sealed conditions for $7 \mathrm{~d}$, then the plastic vials were opened and a small amount of distilled water was added on top of the wafers. At various ages, specimens of the pastes were removed from the vials for further analysis. For some of the LTC studies to be detailed below, many of the specimens cured under sealed conditions 
were crushed to smaller pieces and resaturated for a few days in an attempt to refill any pores that had been emptied during self-desiccation.

For many of the specimens, degree of hydration was estimated based on measurement of their non-evaporable water content. The non-evaporable water content $w_{\mathrm{n}}$ of a sample was determined as the mass loss between $105{ }^{\circ} \mathrm{C}$ and $1000{ }^{\circ} \mathrm{C}$ divided by the mass of the ignited sample, corrected for the loss-on-ignition (LOI) of the unhydrated cement powder, determined in a separate LOI measurement. Previously, the expanded uncertainty in the calculated $w_{\mathrm{n}}$ has been estimated to be $0.001 \mathrm{~g} / \mathrm{g}$ cement, assuming a coverage factor of 2 [6]. The values of $w_{\mathrm{n}}$ were converted to estimated degrees of hydration based on the phase compositions of the cements and published coefficients for the non-evaporable water contents of the various cement clinker phases [7]. Based on a propagation of error analysis, the estimated uncertainty in the calculated degree of hydration is 0.004 .

Small pieces of the hydrated cement pastes were used in the LTC experiments. Sample mass was typically between $30 \mathrm{mg}$ and $90 \mathrm{mg}$. For each LTC experiment, one small piece of the relevant cement paste was surface dried and placed in a small open stainless steel pan. The pan with the sample, along with an empty reference pan of similar mass to the empty sample pan, was placed in the calorimeter cell. Using a protocol developed previously [1], a freezing scan was conducted between $5{ }^{\circ} \mathrm{C}$ and $-55^{\circ} \mathrm{C}$ at a scan rate of $-0.5{ }^{\circ} \mathrm{C} / \mathrm{min}$. For temperatures between $-100{ }^{\circ} \mathrm{C}$ and $500{ }^{\circ} \mathrm{C}$, the equipment manufacturer has specified a constant calorimetric sensitivity of $\pm 2.5 \%$ and a root-mean-square baseline noise of $1.5 \mu \mathrm{W}$. The peaks observed in a plot of heat flow (normalized to the mass of the sample) versus temperature correspond to water freezing in pores with various size entryways (pore necks). The smaller the pore entryway, the more the freezing peak is depressed. Thus, the presence of, absence of, or change in peaks can be used to infer information concerning the characteristic sizes of the "percolated" (connected) water-filled pores in the microstructure of the hydrating cement pastes.

One advantage of LTC over mercury intrusion porosimetry, and other techniques for assessing pore size and connectivity, is that specimens are evaluated without any external drying that might damage their pore structure. Of course, the LTC technique can only assess the size and connectivity of water-filled pores. For non-saturated curing conditions, it is assumed that the "empty" pores formed due to self-desiccation will not contain any freezable water and thus will not show up on the LTC scans. A further complication for LTC studies with variable alkali contents is the change in freezing point depression due to the variable ionic concentration of the (freezing) pore solution. For the experiments presented here, the initial dosages of added alkalis in the cement paste mixtures would be expected to depress the freezing point of bulk water between about $1{ }^{\circ} \mathrm{C}$ and $2{ }^{\circ} \mathrm{C}[8]$.

Table 2 on the following page is provided to give some guidance as to the mixtures and curing conditions corresponding to the various sets of graphs. 
Table 2: Plots corresponding to different sets of cement paste mixtures.

\begin{tabular}{|c|c|c|c|c|}
\hline Cement & w/c or w/s & $\begin{array}{c}\text { Curing } \\
\text { Temperature }\left({ }^{\circ} \mathrm{C}\right)\end{array}$ & Starting Figure & Ending Figure \\
\hline 152 & 0.25 & 20 & 4 & 30 \\
\hline 152 & 0.35 & 20 & 31 & 86 \\
\hline 152 & 0.435 & 20 & 87 & 94 \\
\hline $152+20 \%$ limestone & 0.35 & 20 & 95 & 104 \\
\hline 152 & 0.25 & 40 & 105 & 120 \\
\hline 152 & 0.35 & 40 & 121 & 140 \\
\hline 152 & 0.45 & 40 & 141 & 152 \\
\hline 140 & 0.40 & 20 & 153 & 192 \\
\hline
\end{tabular}




\section{Processed Data (Graphs)}

\section{Control Materials}

Cement: CCRL Cement 140

Solution: None

$w / c:$ N/A

Temperature: N/A

Degree of hydration: N/A
Curing: N/A

Age when tested: N/A

Sample mass: $45.1 \mathrm{mg}$

Filename: c140powder

Date tested: April 18, 2005

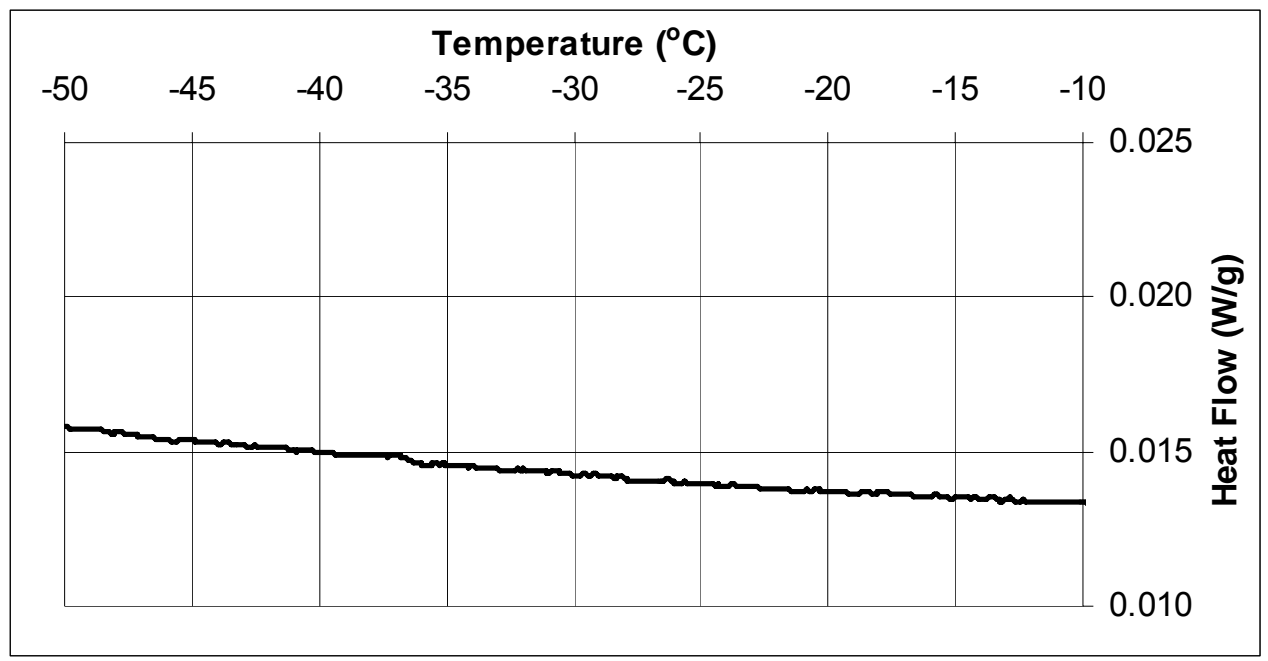

Figure 2 LTC scan for CCRL Cement 140 (dry) powder.

Cement: N/A

Solution: Tap water

$w / c:$ N/A

Temperature: N/A

Degree of hydration: N/A
Curing: N/A

Age when tested: N/A

Sample mass: $25.2 \mathrm{mg}$

Filename: tapwatersmall

Date tested: April 28, 2005

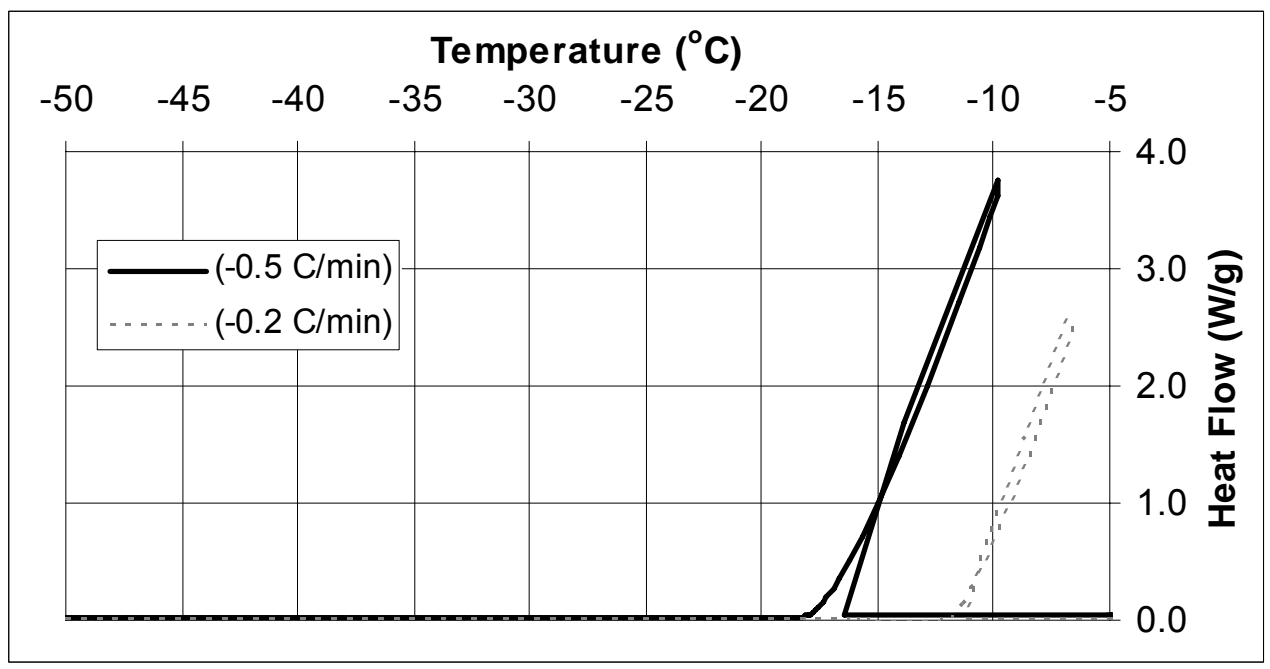

Figure 3 LTC scan for Gaithersburg tap water at two different scan rates. 


\section{CCRL Cement 152}

Cement: CCRL Cement 152

Solution: Distilled water

w/c: 0.25

Temperature: $20{ }^{\circ} \mathrm{C}$

Degree of hydration: 0.284
Curing: Saturated

Age when tested: $1 \mathrm{~d}$

Sample mass: $75.0 \mathrm{mg}$

Filename: c152w025T20Csat1d

Date tested: May 17, 2005

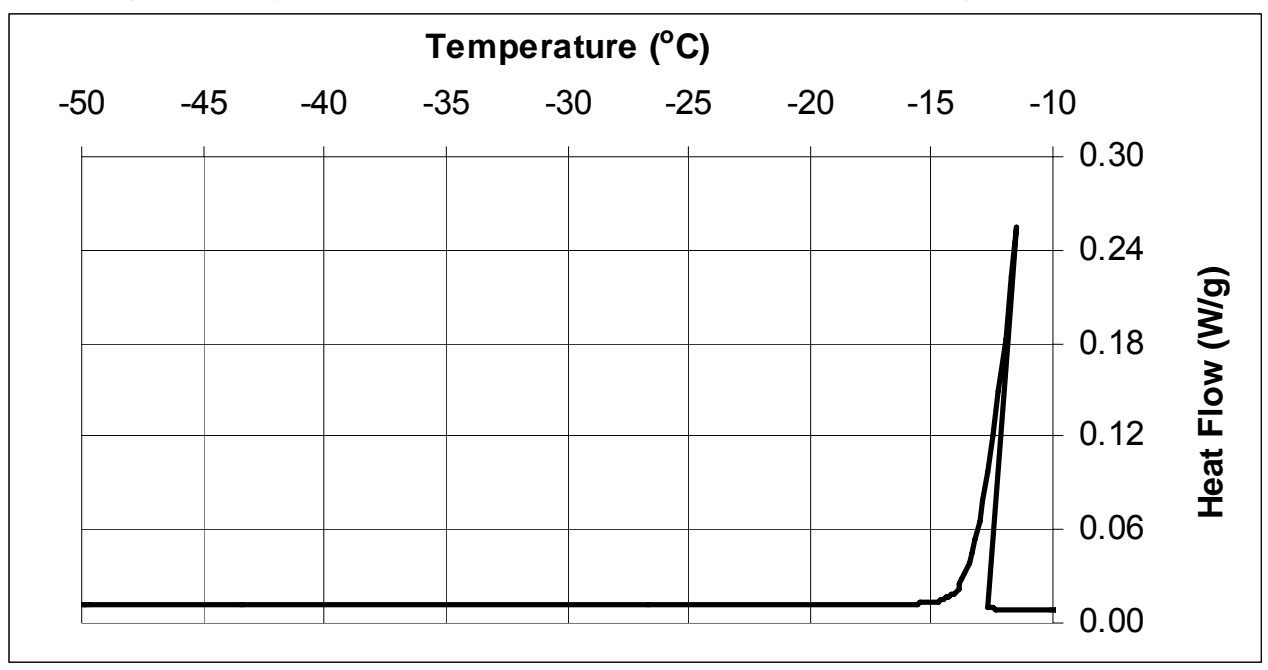

Figure $4 \mathrm{LTC}$ scan for CCRL Cement $152, w / c=0.25$, cured for $1 \mathrm{~d}$ under saturated conditions at $20^{\circ} \mathrm{C}$.

Cement: CCRL Cement 152

Solution: Distilled water

w/c: 0.25

Temperature: $20{ }^{\circ} \mathrm{C}$

Degree of hydration: 0.285
Curing: Sealed

Age when tested: $1 \mathrm{~d}$

Sample mass: $57.3 \mathrm{mg}$

Filename: c152w025T20Csealld

Date tested: May 17, 2005

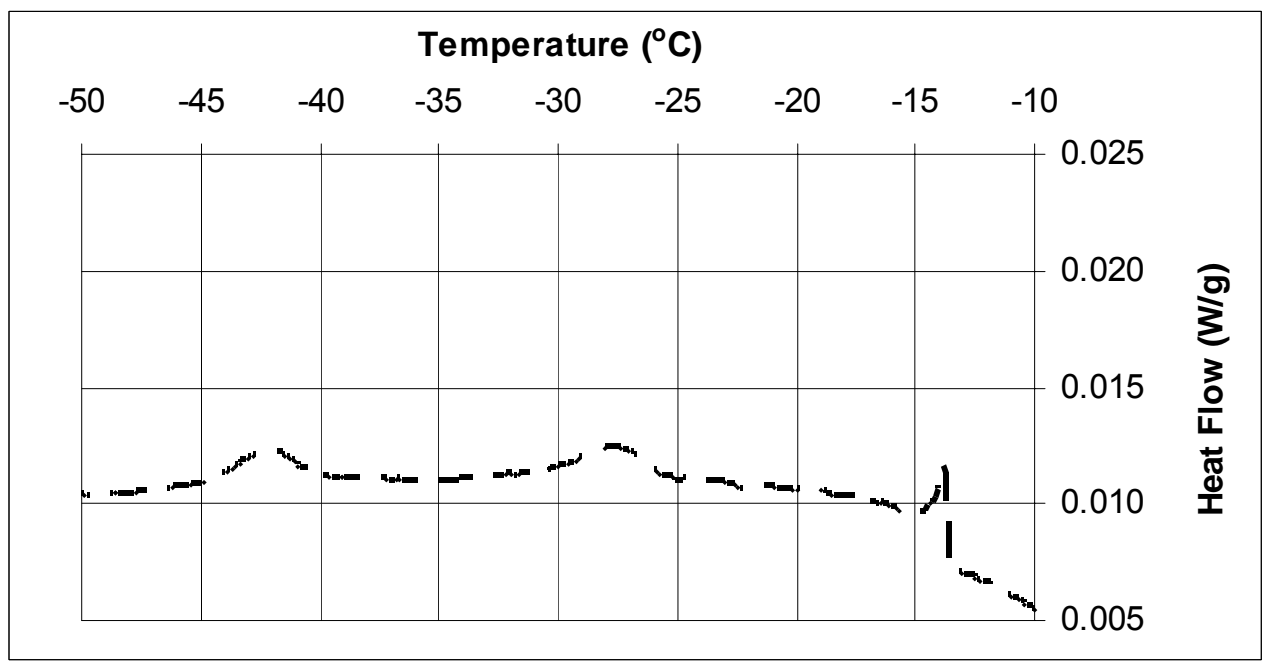

Figure 5 LTC scan for CCRL Cement 152, $w / c=0.25$, cured for $1 \mathrm{~d}$ under sealed conditions at $20^{\circ} \mathrm{C}$. 
Cement: CCRL Cement 152

Solution: Distilled water

$w / c: 0.25$

Temperature: $20{ }^{\circ} \mathrm{C}$

Degree of hydration: 0.403
Curing: Saturated

Age when tested: $2 \mathrm{~d}$

Sample mass: $65.4 \mathrm{mg}$

Filename: c152w025T20Csat2d

Date tested: May 18, 2005

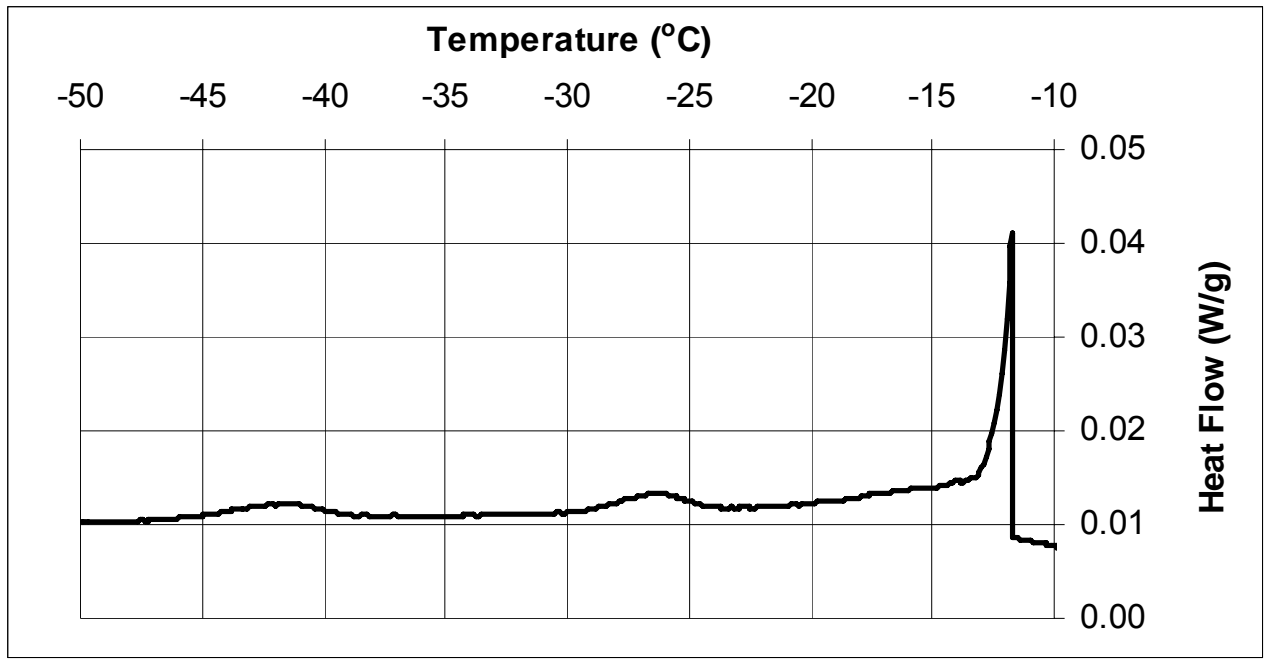

Figure $6 \mathrm{LTC}$ scan for CCRL Cement 152, $w / c=0.25$, cured for $2 \mathrm{~d}$ under saturated conditions at $20^{\circ} \mathrm{C}$.

Cement: CCRL Cement 152

Solution: Distilled water

$w / c: 0.25$

Temperature: $20{ }^{\circ} \mathrm{C}$

Degree of hydration: 0.381
Curing: Saturated

Age when tested: $2 \mathrm{~d}$

Sample mass: $43.7 \mathrm{mg}$

Filename: c152w025T20Cseal2d

Date tested: May 18, 2005

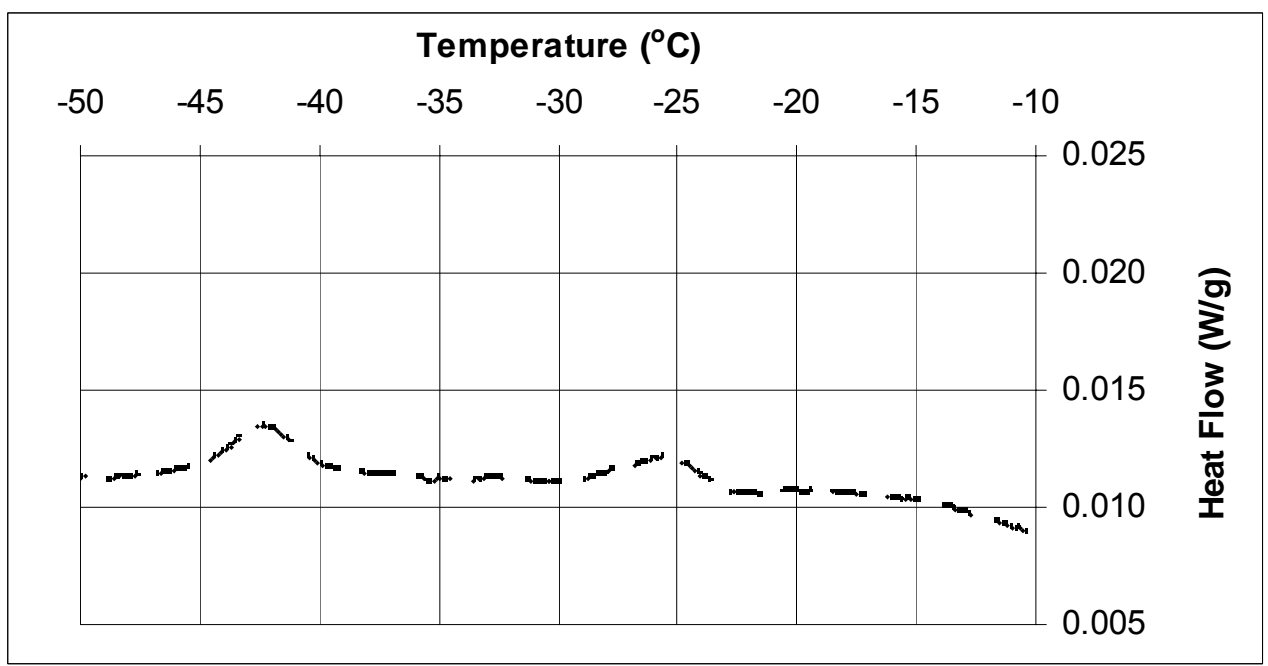

Figure 7 LTC scan for CCRL Cement 152, $w / c=0.25$, cured for $2 \mathrm{~d}$ under sealed conditions at $20{ }^{\circ} \mathrm{C}$. 
Cement: CCRL Cement 152

Solution: Distilled water

$w / c: 0.25$

Temperature: $20{ }^{\circ} \mathrm{C}$

Degree of hydration: N/A
Curing: Sealed $1 \mathrm{~d} /$ resaturated

Age when tested: $2 \mathrm{~d}$

Sample mass: $78.4 \mathrm{mg}$

Filename: c152w025T20Csealresat1t2d

Date tested: May 18, 2005

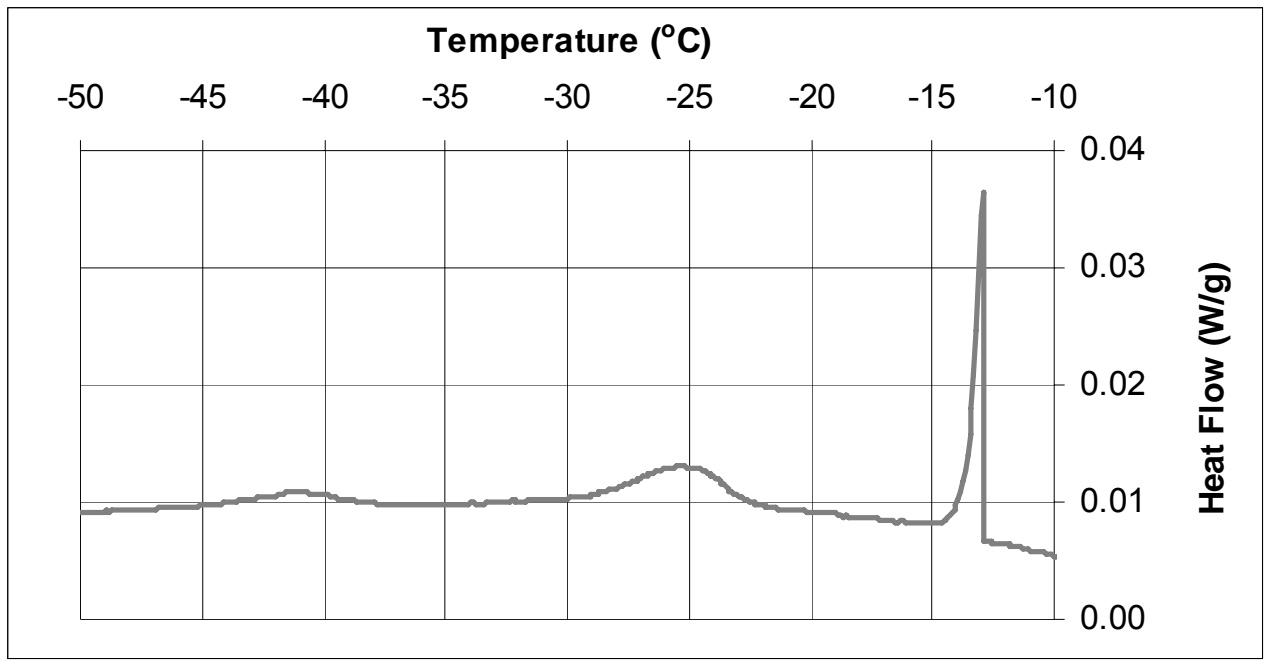

Figure $8 \mathrm{LTC}$ scan for CCRL Cement $152, w / c=0.25$, cured at $20{ }^{\circ} \mathrm{C}$ for $1 \mathrm{~d}$ under sealed conditions, then resaturated for $1 \mathrm{~d}$.

Cement: CCRL Cement 152

Solution: Distilled water

$w / c: 0.25$

Temperature: $20{ }^{\circ} \mathrm{C}$

Degree of hydration: 0.456
Curing: Saturated

Age when tested: $3 \mathrm{~d}$

Sample mass: $58.6 \mathrm{mg}$

Filename: c152w025T20Csat3d

Date tested: May 19, 2005

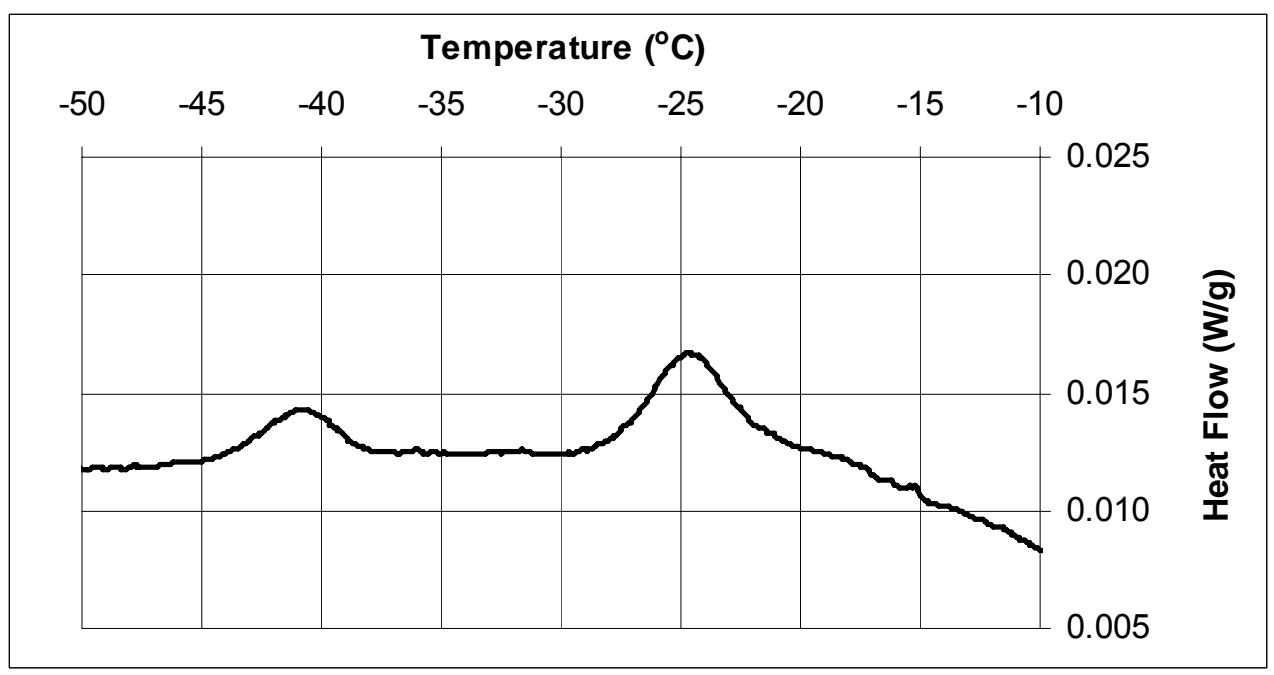

Figure 9 LTC scan for CCRL Cement 152, w/c $=0.25$, cured for $3 \mathrm{~d}$ under saturated conditions at $20{ }^{\circ} \mathrm{C}$. 
Cement: CCRL Cement 152

Solution: Distilled water

$w / c: 0.25$

Temperature: $20{ }^{\circ} \mathrm{C}$

Degree of hydration: 0.412
Curing: Sealed

Age when tested: $3 \mathrm{~d}$

Sample mass: $40.1 \mathrm{mg}$

Filename: c152w025T20Cseal3d

Date tested: May 19, 2005

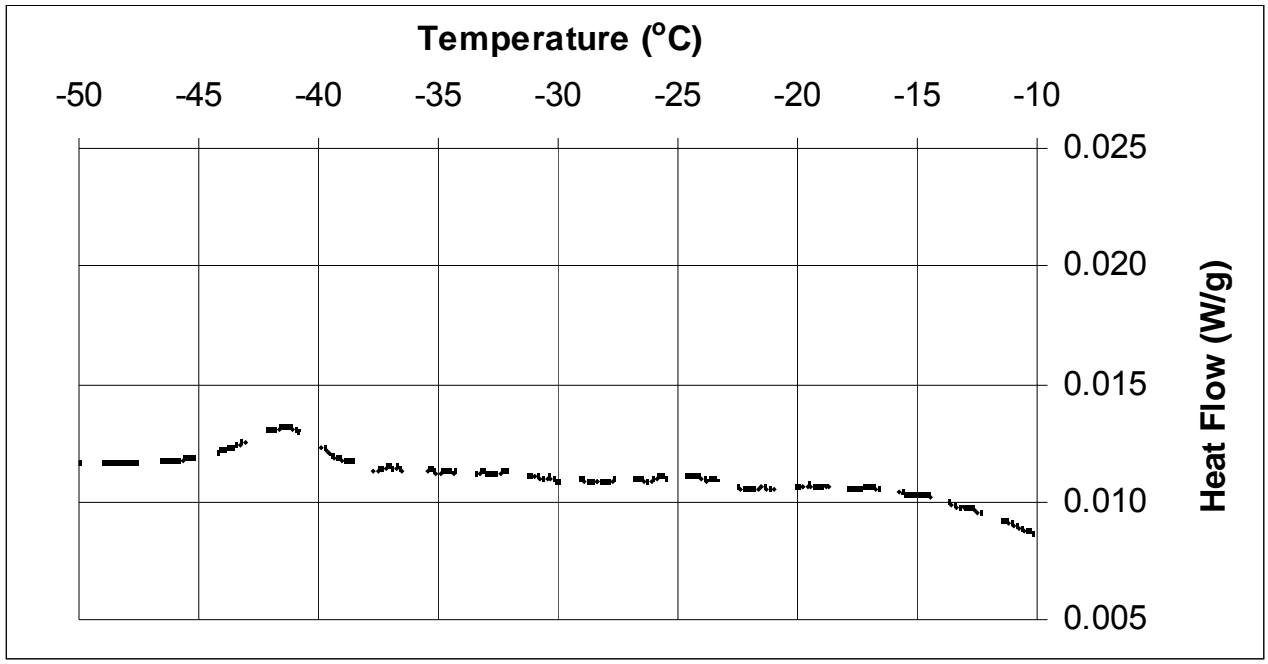

Figure $10 \mathrm{LTC}$ scan for CCRL Cement $152, w / c=0.25$, cured for $3 \mathrm{~d}$ under sealed conditions at $20{ }^{\circ} \mathrm{C}$.

Cement: CCRL Cement 152

Solution: Distilled water

$w / c: 0.25$

Temperature: $20{ }^{\circ} \mathrm{C}$

Degree of hydration: N/A
Curing: Sealed $2 \mathrm{~d} /$ resaturated

Age when tested: $3 \mathrm{~d}$

Sample mass: $68.1 \mathrm{mg}$

Filename: c152w025T20Csealresat2t3d

Date tested: May 19, 2005

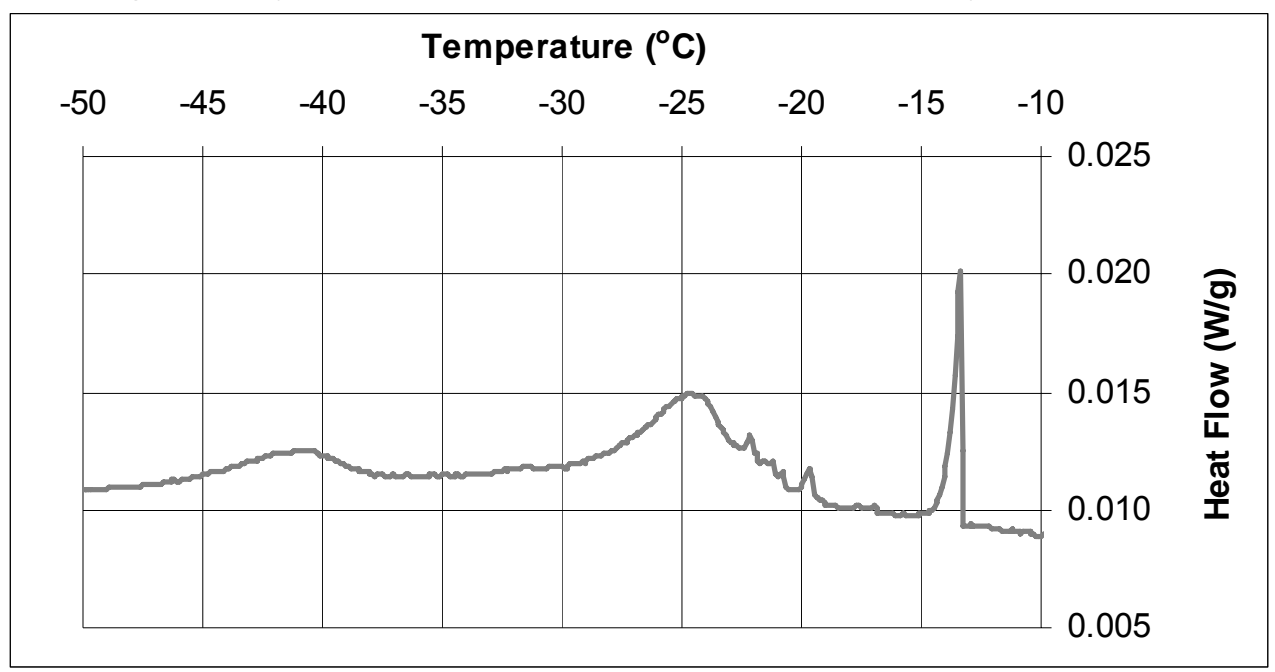

Figure $11 \mathrm{LTC}$ scan for CCRL Cement $152, w / c=0.25$, cured at $20{ }^{\circ} \mathrm{C}$ for $2 \mathrm{~d}$ under sealed conditions, then resaturated for $1 \mathrm{~d}$. 
Cement: CCRL Cement 152

Solution: Distilled water

$w / c: 0.25$

Temperature: $20{ }^{\circ} \mathrm{C}$

Degree of hydration: N/A
Curing: Sealed $3 \mathrm{~d} /$ resaturated

Age when tested: $4 \mathrm{~d}$

Sample mass: $59.1 \mathrm{mg}$

Filename: c152w025T20Csealresat3t4d

Date tested: May 20, 2005

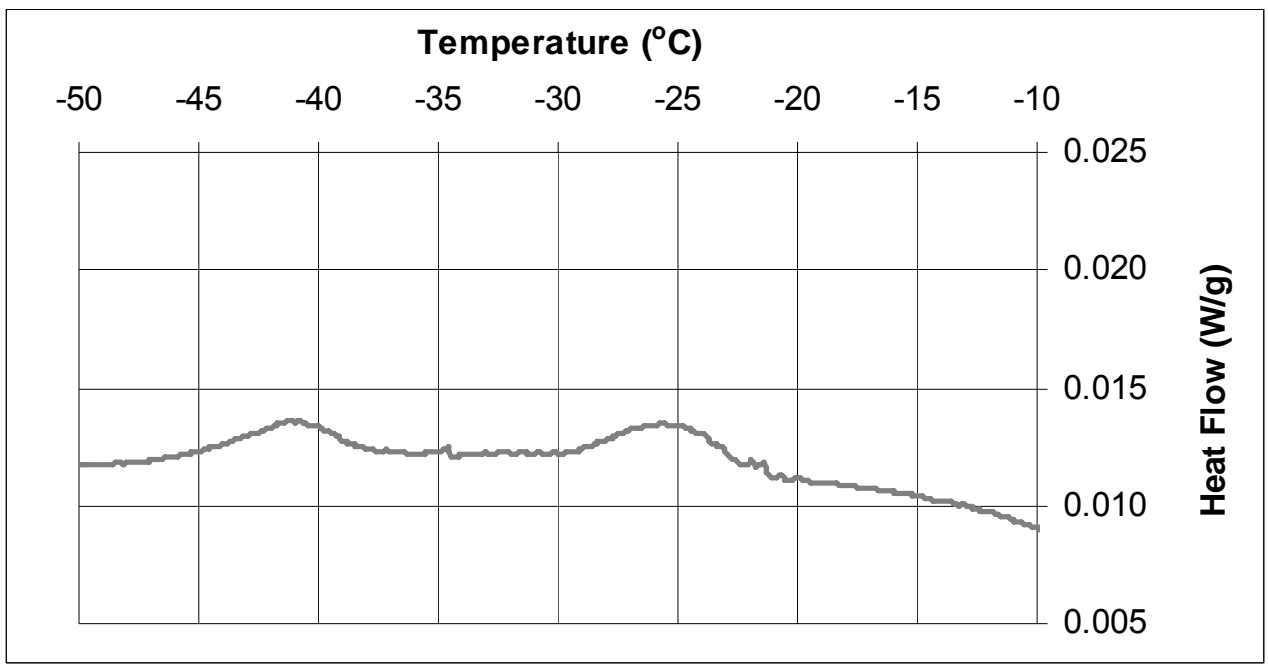

Figure $12 \mathrm{LTC}$ scan for CCRL Cement $152, w / c=0.25$, cured at $20^{\circ} \mathrm{C}$ for $3 \mathrm{~d}$ under sealed conditions, then resaturated for $1 \mathrm{~d}$.

Cement: CCRL Cement 152

Solution: Distilled water

w/c: 0.25

Temperature: $20{ }^{\circ} \mathrm{C}$

Degree of hydration: 0.615
Curing: Saturated

Age when tested: $7 \mathrm{~d}$

Sample mass: $25.7 \mathrm{mg}$

Filename: c152w025T20Csat7d

Date tested: May 23, 2005

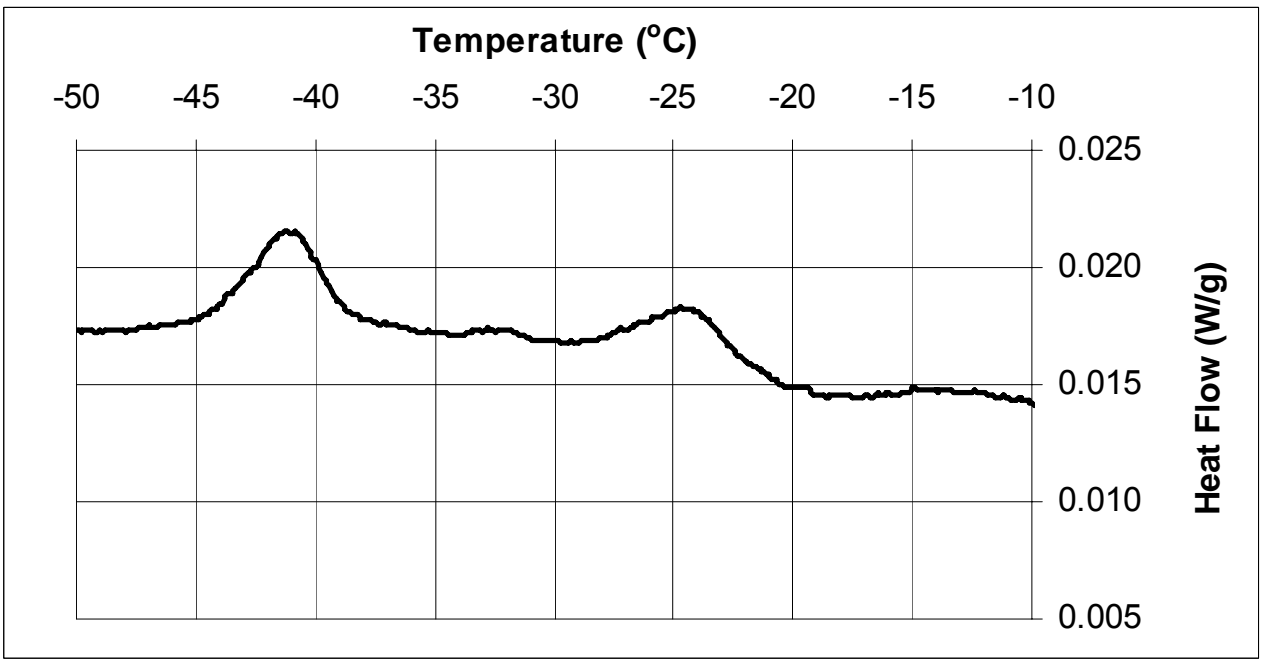

Figure $13 \mathrm{LTC}$ scan for CCRL Cement 152, w/c $=0.25$, cured for $7 \mathrm{~d}$ under saturated conditions at $20{ }^{\circ} \mathrm{C}$. 
Cement: CCRL Cement 152

Solution: Distilled water

$w / c: 0.25$

Temperature: $20{ }^{\circ} \mathrm{C}$

Degree of hydration: 0.458
Curing: Sealed

Age when tested: $7 \mathrm{~d}$

Sample mass: $45.3 \mathrm{mg}$

Filename: c152w025T20Cseal7d

Date tested: May 23, 2005

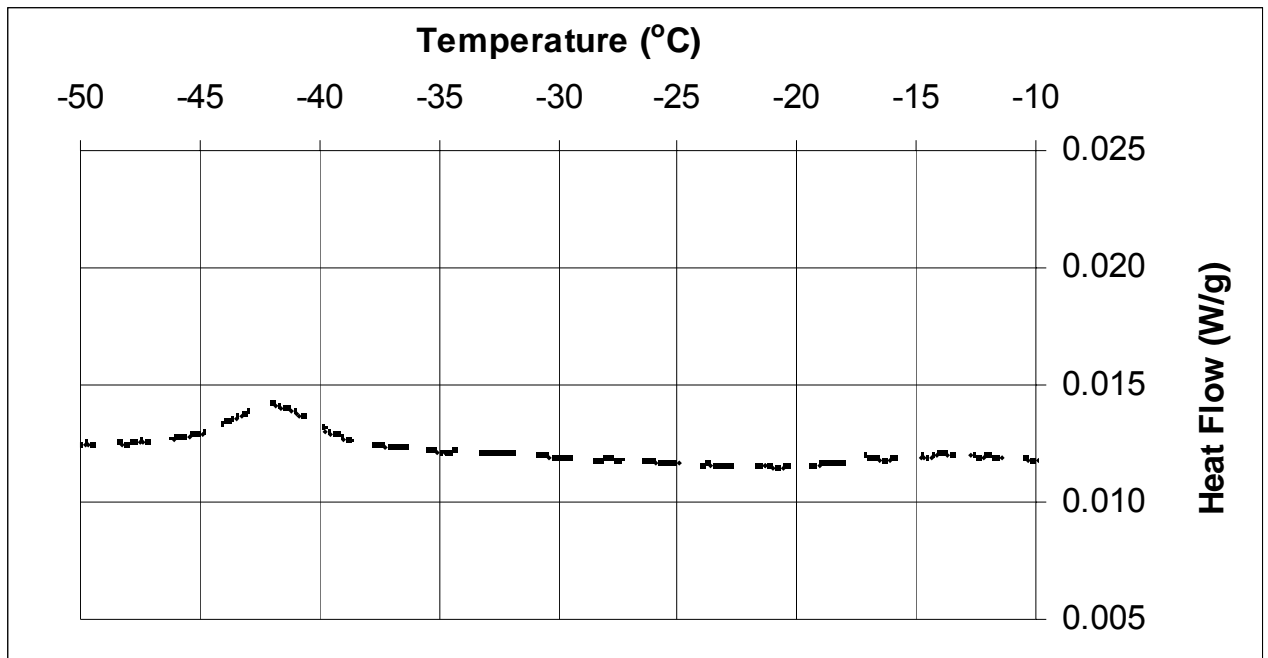

Figure $14 \mathrm{LTC}$ scan for CCRL Cement $152, w / C=0.25$, cured for $7 \mathrm{~d}$ under sealed conditions at $20^{\circ} \mathrm{C}$.

Cement: CCRL Cement 152

Solution: Distilled water

$w / c: 0.25$

Temperature: $20{ }^{\circ} \mathrm{C}$

Degree of hydration: N/A
Curing: Sealed $7 \mathrm{~d} /$ resaturated

Age when tested: $8 \mathrm{~d}$

Sample mass: $59.2 \mathrm{mg}$

Filename: c152w025T20Csealresat7t8d

Date tested: May 24, 2005

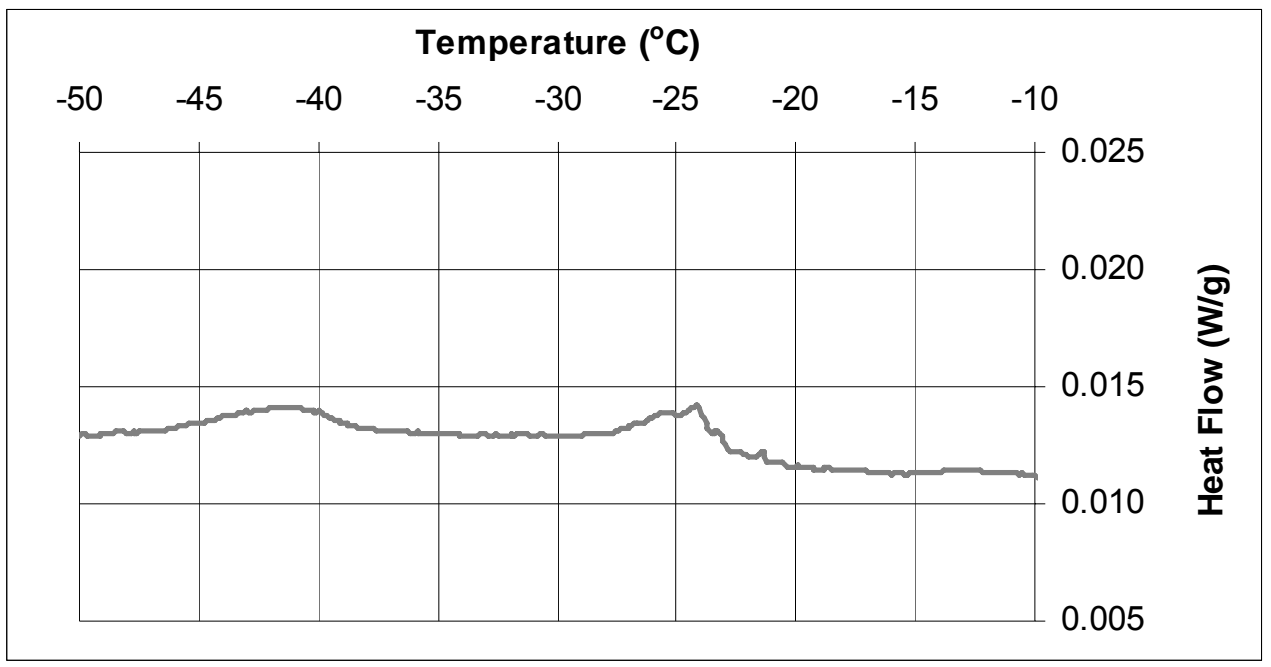

Figure $15 \mathrm{LTC}$ scan for CCRL Cement $152, w / C=0.25$, cured at $20^{\circ} \mathrm{C}$ for $7 \mathrm{~d}$ under sealed conditions, then resaturated for $1 \mathrm{~d}$. 
Cement: CCRL Cement 152

Solution: Distilled water

$w / c: 0.25$

Temperature: $20{ }^{\circ} \mathrm{C}$

Degree of hydration: 0.669
Curing: Saturated

Age when tested: $15 \mathrm{~d}$

Sample mass: $59.1 \mathrm{mg}$

Filename: c152w025T20Csat15d2

Date tested: May 31, 2005

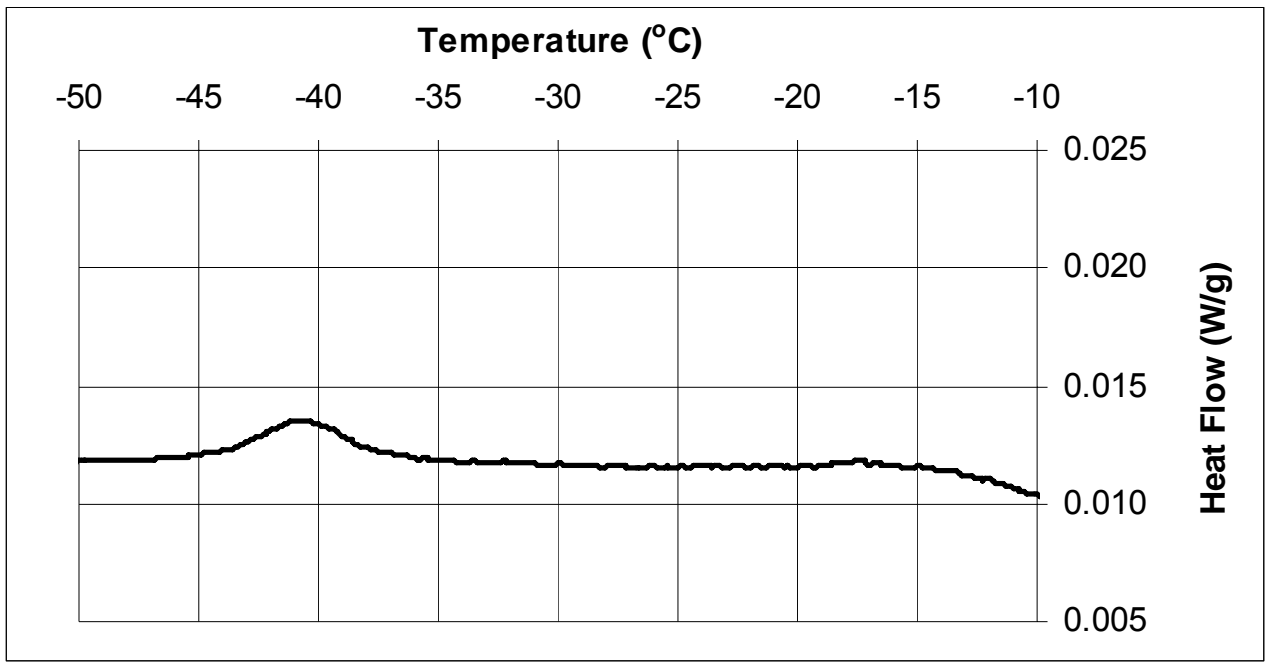

Figure $16 \mathrm{LTC}$ scan for CCRL Cement $152, w / c=0.25$, cured for $15 \mathrm{~d}$ under saturated conditions at $20{ }^{\circ} \mathrm{C}$.

Cement: CCRL Cement 152

Solution: Distilled water

w/c: 0.25

Temperature: $20{ }^{\circ} \mathrm{C}$

Degree of hydration: 0.488
Curing: Sealed

Age when tested: $15 \mathrm{~d}$

Sample mass: $45.2 \mathrm{mg}$

Filename: c152w025T20Cseal15d

Date tested: May 31, 2005

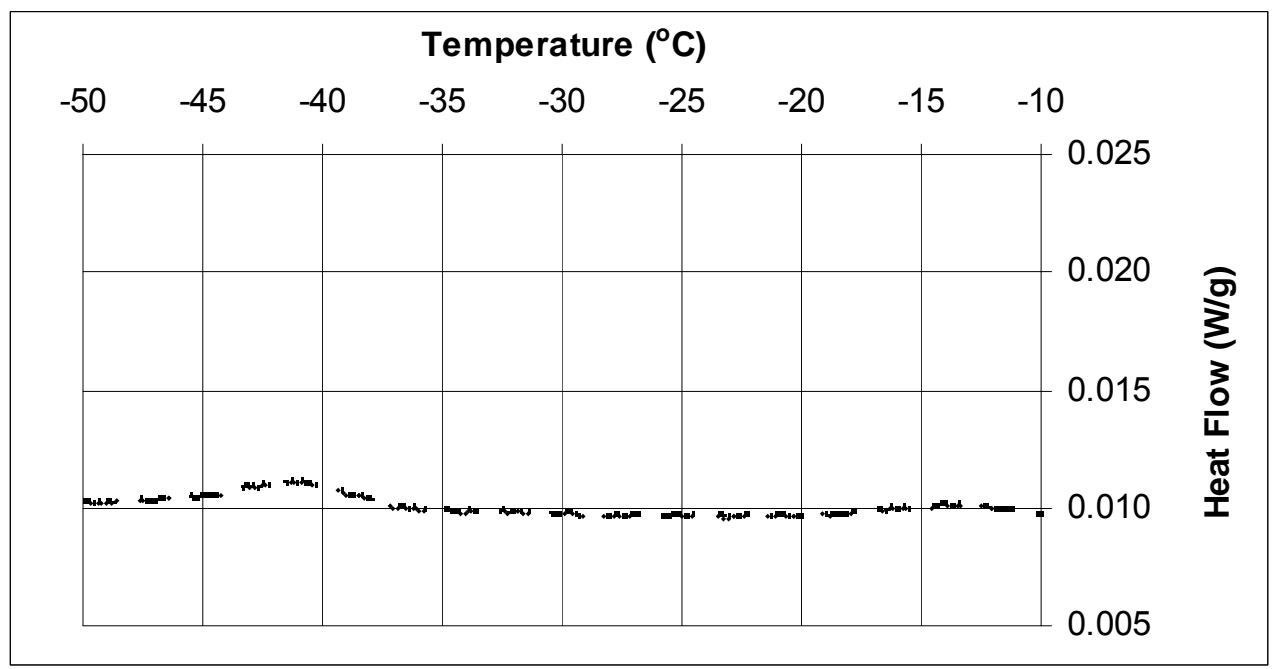

Figure 17 LTC scan for CCRL Cement $152, w / c=0.25$, cured for $15 \mathrm{~d}$ under sealed conditions at $20{ }^{\circ} \mathrm{C}$. 
Cement: CCRL Cement 152

Solution: Distilled water

$w / c: 0.25$

Temperature: $20{ }^{\circ} \mathrm{C}$

Degree of hydration: N/A
Curing: Sealed $15 \mathrm{~d} /$ resaturated

Age when tested: $16 \mathrm{~d}$

Sample mass: $59.2 \mathrm{mg}$

Filename: c152w025T20Csealresat15t16d

Date tested: June 1, 2005

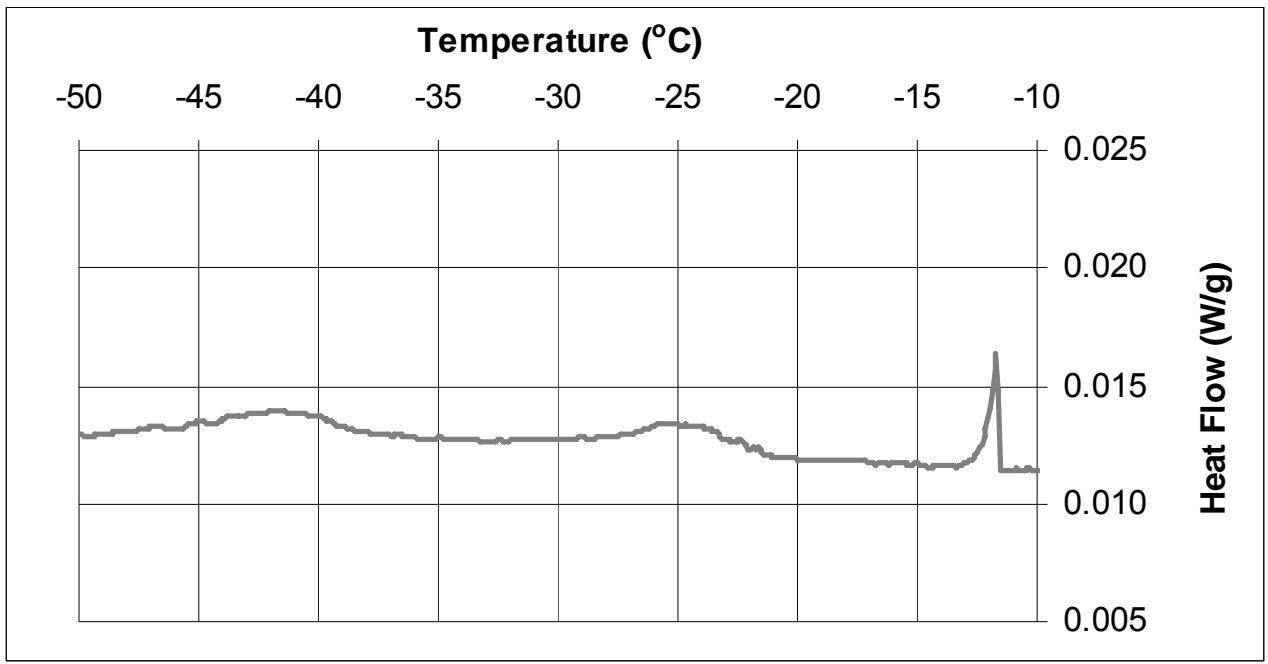

Figure $18 \mathrm{LTC}$ scan for CCRL Cement $152, w / c=0.25$, cured at $20{ }^{\circ} \mathrm{C}$ for $15 \mathrm{~d}$ under sealed conditions, then resaturated for $1 \mathrm{~d}$.

Cement: CCRL Cement 152

Solution: Distilled water

w/c: 0.25

Temperature: $20{ }^{\circ} \mathrm{C}$

Degree of hydration: 0.679
Curing: Saturated

Age when tested: $21 \mathrm{~d}$

Sample mass: $63.3 \mathrm{mg}$

Filename: c152w025T20Csat21d

Date tested: June 6, 2005

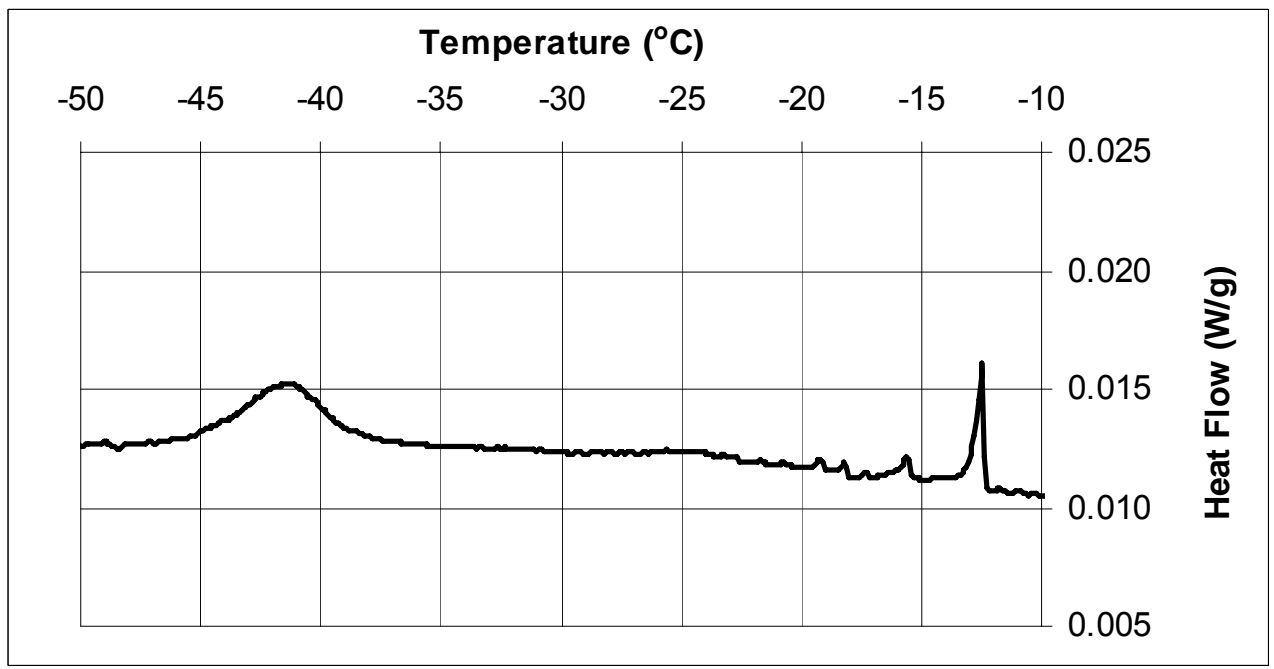

Figure $19 \mathrm{LTC}$ scan for CCRL Cement $152, w / c=0.25$, cured for $21 \mathrm{~d}$ under saturated conditions at $20{ }^{\circ} \mathrm{C}$. 
Cement: CCRL Cement 152

Solution: Distilled water

$w / c: 0.25$

Temperature: $20{ }^{\circ} \mathrm{C}$

Degree of hydration: 0.474
Curing: Sealed

Age when tested: $21 \mathrm{~d}$

Sample mass: $65.8 \mathrm{mg}$

Filename: c152w025T20Cseal21d

Date tested: June 6, 2005

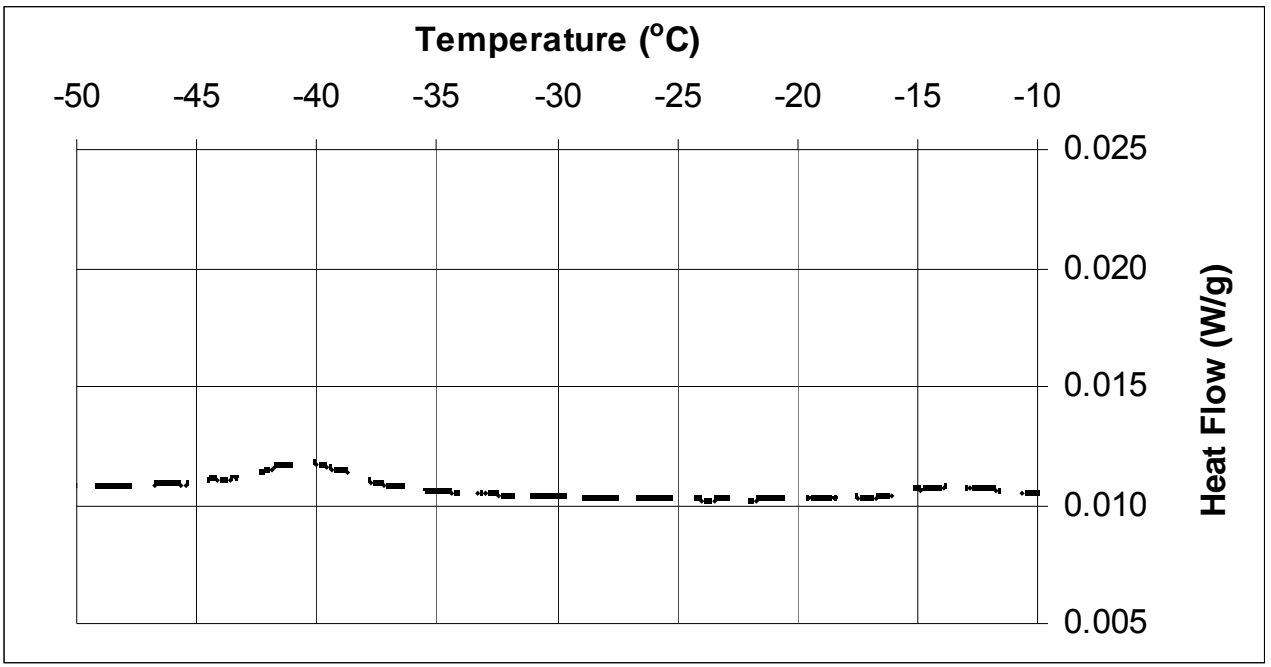

Figure 20 LTC scan for CCRL Cement 152, w/c $=0.25$, cured for $21 \mathrm{~d}$ under sealed conditions at $20{ }^{\circ} \mathrm{C}$.

Cement: CCRL Cement 152

Solution: Distilled water

$w / c: 0.25$

Temperature: $20{ }^{\circ} \mathrm{C}$

Degree of hydration: N/A
Curing: Sealed $21 \mathrm{~d} /$ resaturated

Age when tested: $22 \mathrm{~d}$

Sample mass: $71.6 \mathrm{mg}$

Filename: c152w025T20Csealresat21t22d

Date tested: June 7, 2005

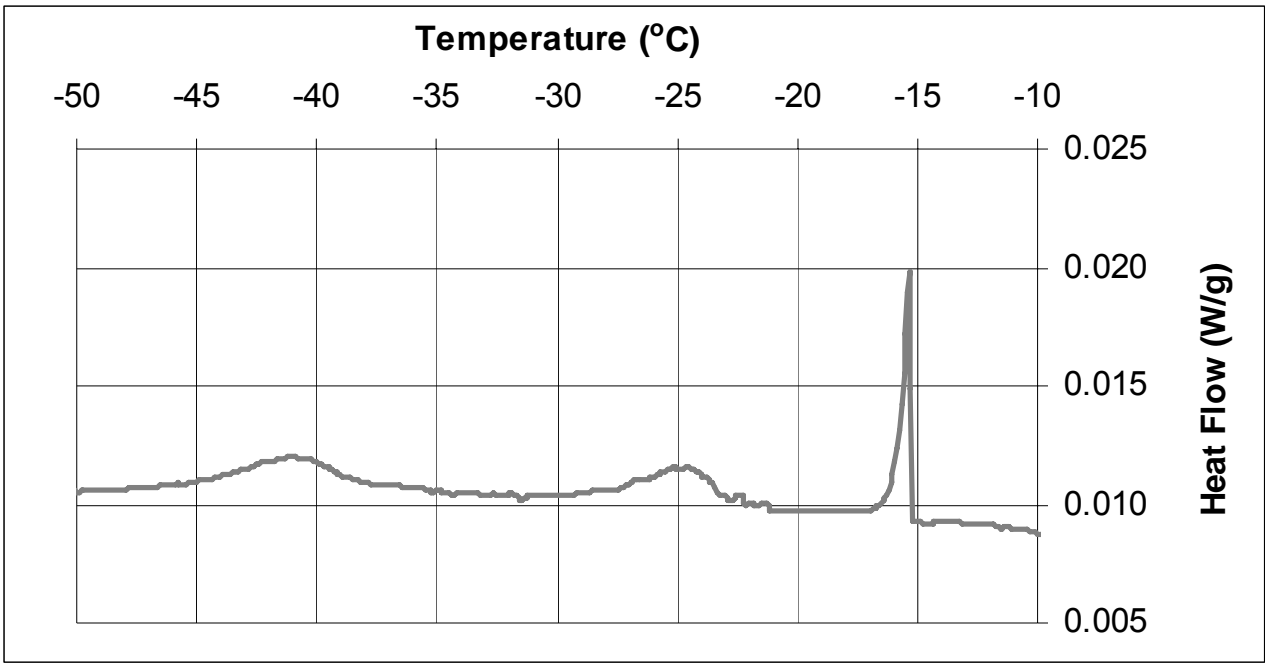

Figure $21 \mathrm{LTC}$ scan for CCRL Cement $152, w / c=0.25$, cured at $20^{\circ} \mathrm{C}$ for $21 \mathrm{~d}$ under sealed conditions, then resaturated for $1 \mathrm{~d}$. 
Cement: CCRL Cement 152

Solution: Distilled water

$w / c: 0.25$

Temperature: $20{ }^{\circ} \mathrm{C}$

Degree of hydration: 0.702
Curing: Saturated

Age when tested: $36 \mathrm{~d}$

Sample mass: $72.0 \mathrm{mg}$

Filename: c152w025T20Csat36d

Date tested: June 21, 2005

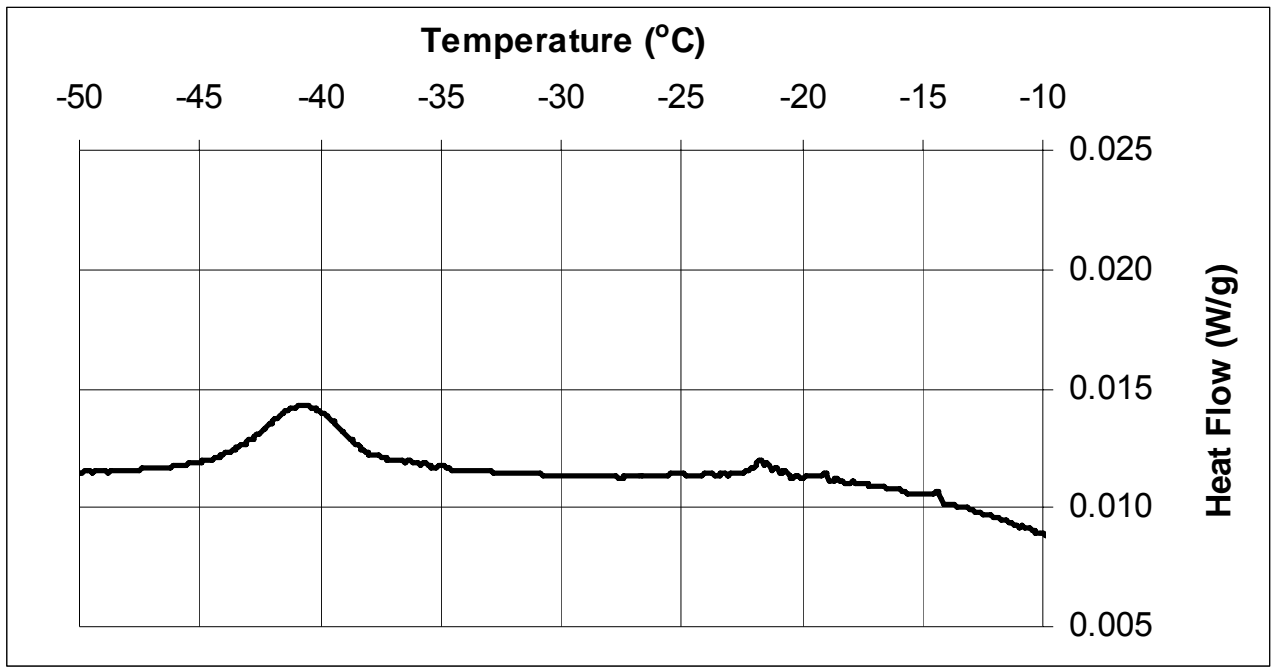

Figure $22 \mathrm{LTC}$ scan for CCRL Cement $152, w / c=0.25$, cured for $36 \mathrm{~d}$ under saturated conditions at $20{ }^{\circ} \mathrm{C}$.

Cement: CCRL Cement 152

Solution: Distilled water

w/c: 0.25

Temperature: $20{ }^{\circ} \mathrm{C}$

Degree of hydration: 0.500
Curing: Sealed

Age when tested: $37 \mathrm{~d}$

Sample mass: $59.3 \mathrm{mg}$

Filename: c152w025T20Cseal37d

Date tested: June 22, 2005

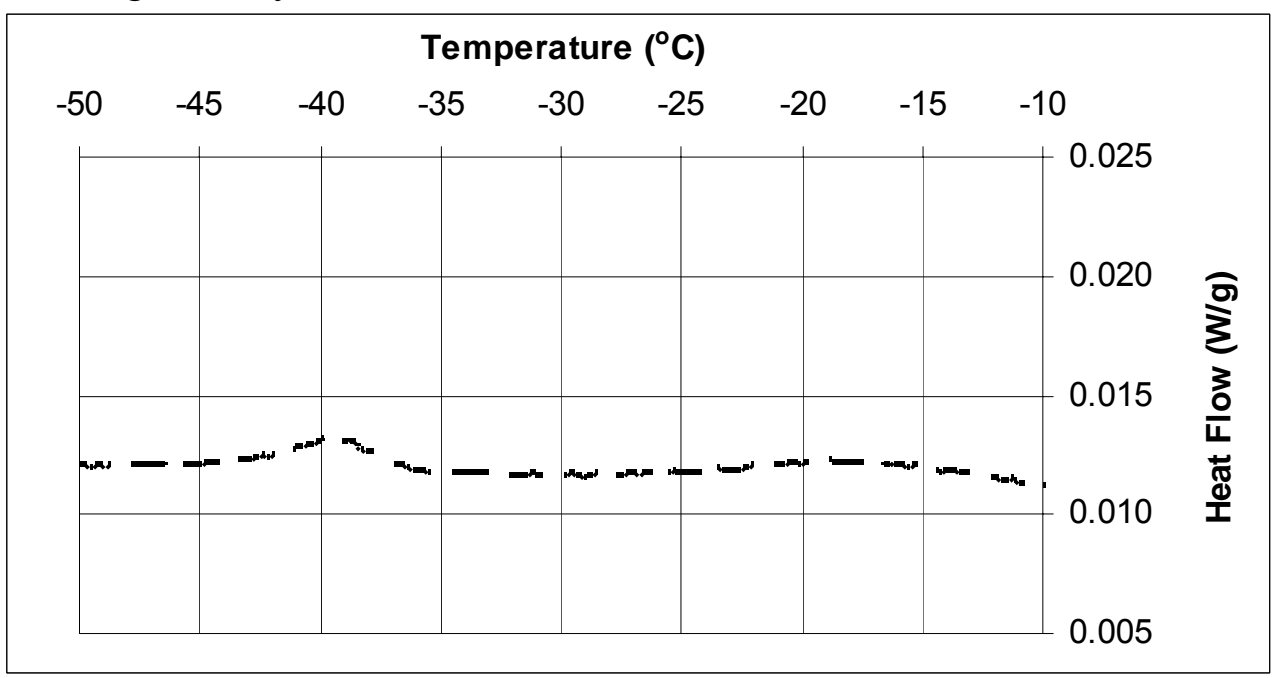

Figure $23 \mathrm{LTC}$ scan for CCRL Cement 152, w/c $=0.25$, cured for $37 \mathrm{~d}$ under sealed conditions at $20{ }^{\circ} \mathrm{C}$. 
Cement: CCRL Cement 152

Solution: Distilled water

$w / c: 0.25$

Temperature: $20{ }^{\circ} \mathrm{C}$

Degree of hydration: N/A
Curing: Sealed $37 \mathrm{~d} /$ resaturated

Age when tested: $38 \mathrm{~d}$

Sample mass: $92.1 \mathrm{mg}$

Filename: c152w025T20Csealresat37t38d

Date tested: June 23, 2005

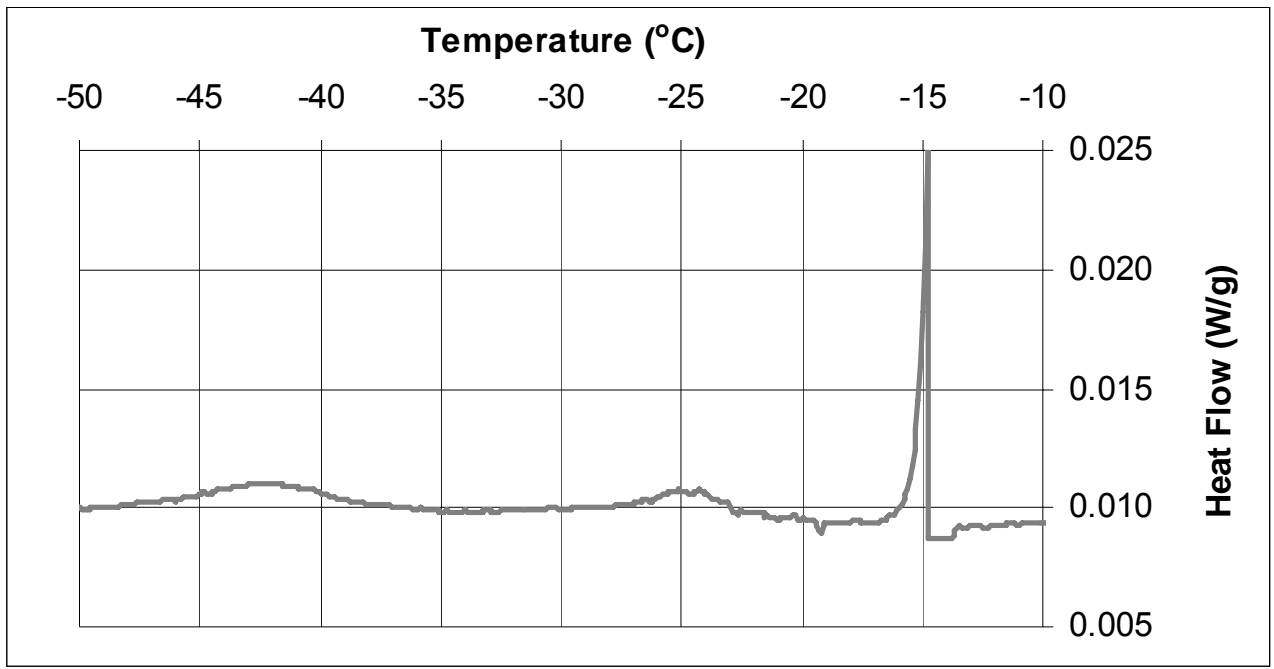

Figure 24 LTC scan for CCRL Cement $152, w / c=0.25$, cured at $20{ }^{\circ} \mathrm{C}$ for $37 \mathrm{~d}$ under sealed conditions, then resaturated for $1 \mathrm{~d}$.

Cement: CCRL Cement 152

Solution: Distilled water

$w / c: 0.25$

Temperature: $20{ }^{\circ} \mathrm{C}$

Degree of hydration: 0.708
Curing: Saturated

Age when tested: $56 \mathrm{~d}$

Sample mass: $84.3 \mathrm{mg}$

Filename: c152w025T20Csat56d

Date tested: July 11, 2005

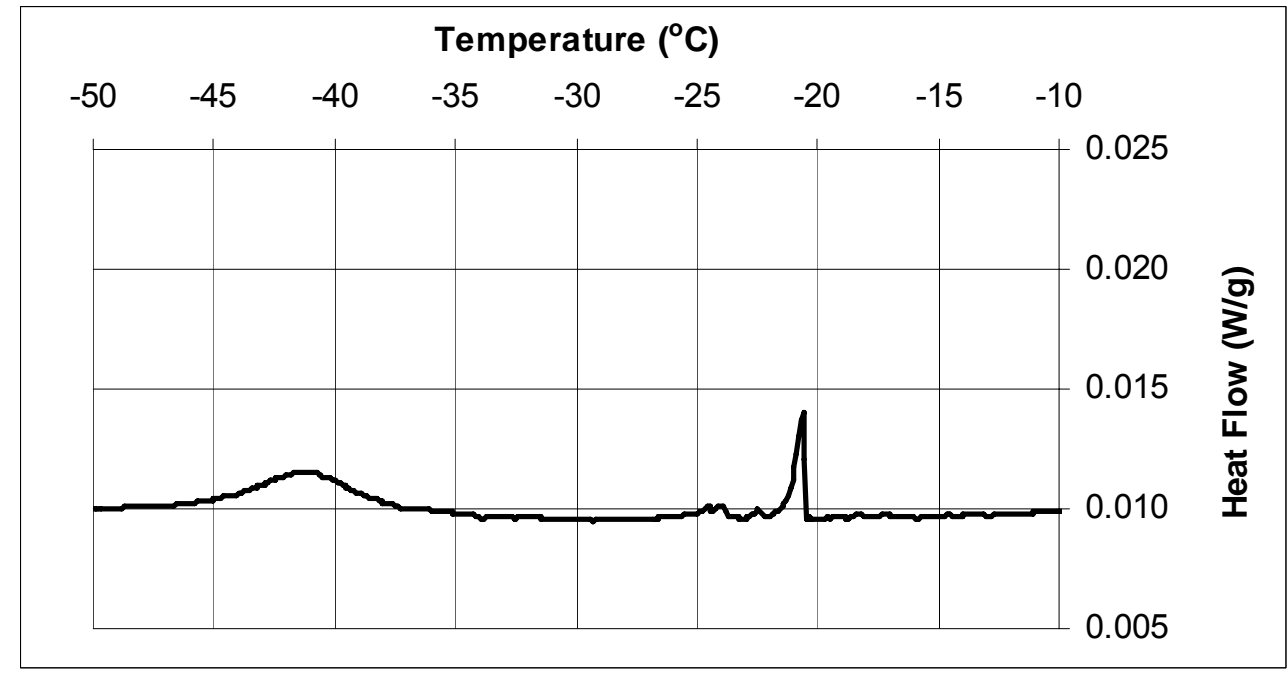

Figure $25 \mathrm{LTC}$ scan for CCRL Cement $152, w / c=0.25$, cured for $56 \mathrm{~d}$ under saturated conditions at $20{ }^{\circ} \mathrm{C}$. 
Cement: CCRL Cement 152

Solution: Distilled water

$w / c: 0.25$

Temperature: $20{ }^{\circ} \mathrm{C}$

Degree of hydration: 0.500
Curing: Sealed

Age when tested: $56 \mathrm{~d}$

Sample mass: $79.8 \mathrm{mg}$

Filename: c152w025T20Cseal56d

Date tested: July 11, 2005

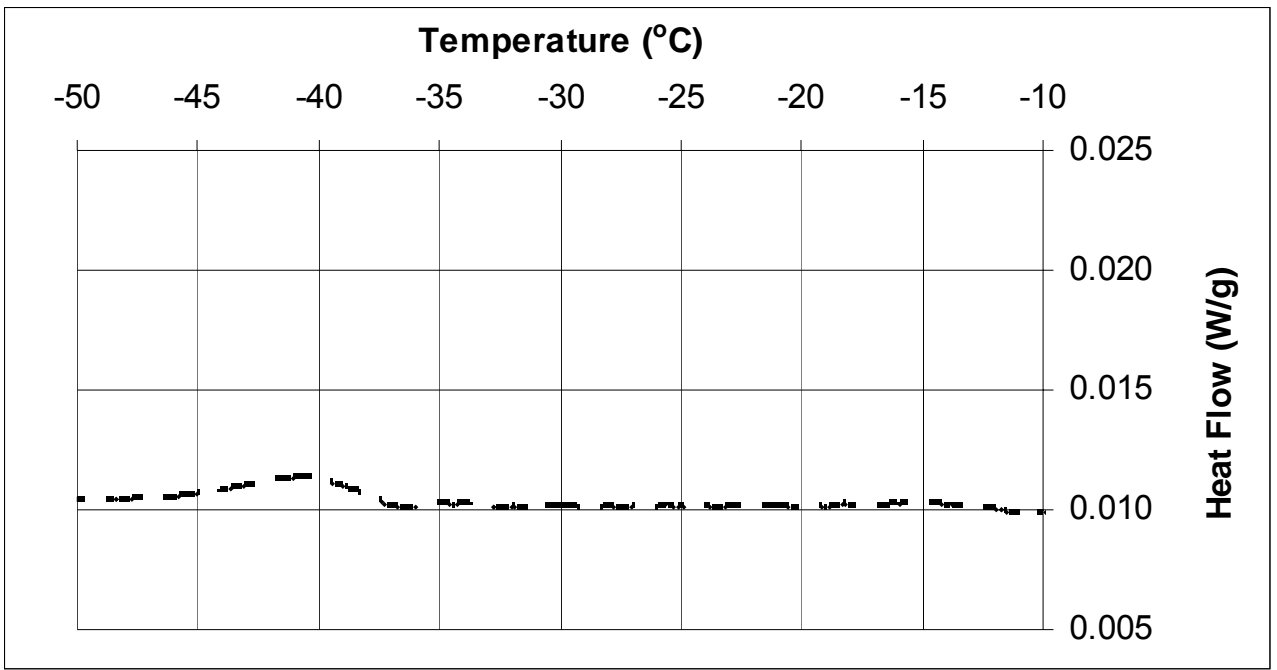

Figure $26 \mathrm{LTC}$ scan for CCRL Cement $152, w / c=0.25$, cured for $56 \mathrm{~d}$ under sealed conditions at $20{ }^{\circ} \mathrm{C}$.

Cement: CCRL Cement 152

Solution: Distilled water

$w / c: 0.25$

Temperature: $20{ }^{\circ} \mathrm{C}$

Degree of hydration: N/A
Curing: Sealed $56 \mathrm{~d} /$ resaturated

Age when tested: $57 \mathrm{~d}$

Sample mass: $69.3 \mathrm{mg}$

Filename: c152w025T20Csealresat56t57d

Date tested: July 12, 2005

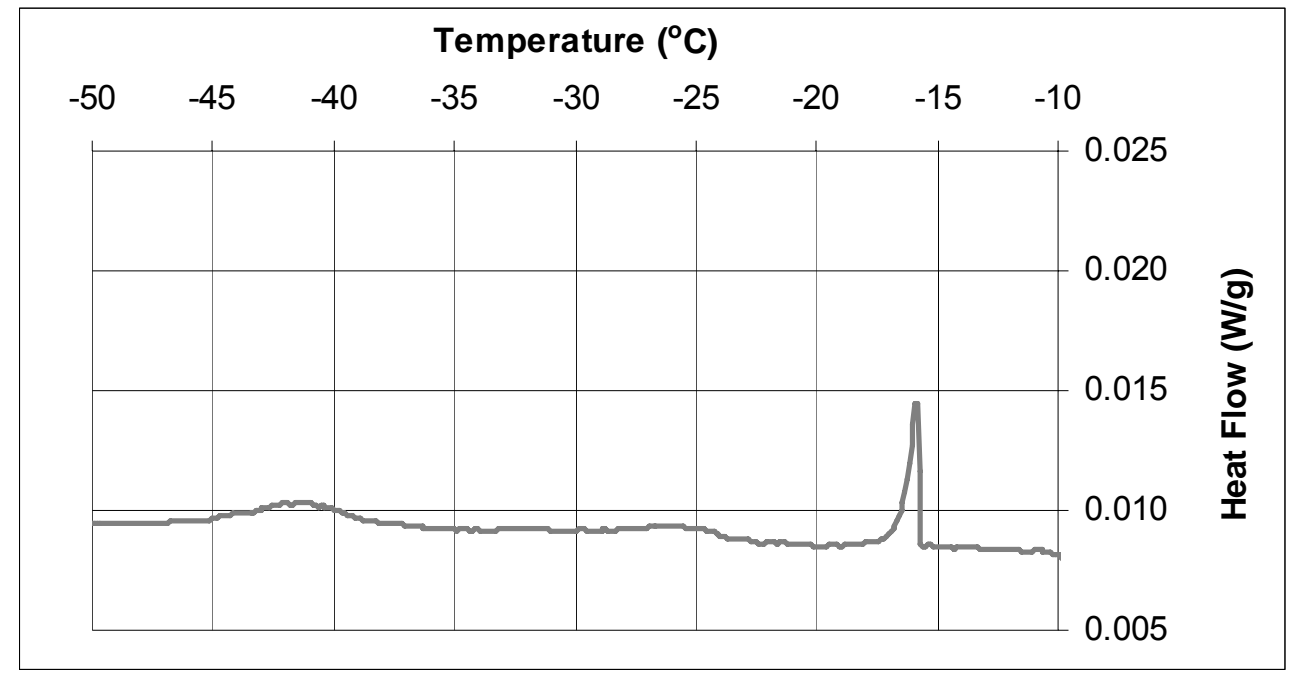

Figure $27 \mathrm{LTC}$ scan for CCRL Cement $152, w / c=0.25$, cured at $20^{\circ} \mathrm{C}$ for $56 \mathrm{~d}$ under sealed conditions, then resaturated for $1 \mathrm{~d}$. 
Cement: CCRL Cement 152

Solution: Distilled water

$w / c: 0.25$

Temperature: $20{ }^{\circ} \mathrm{C}$

Degree of hydration: 0.703
Curing: Saturated

Age when tested: $91 \mathrm{~d}$

Sample mass: $64.5 \mathrm{mg}$

Filename: c152w025T20Csat91d

Date tested: August 15, 2005

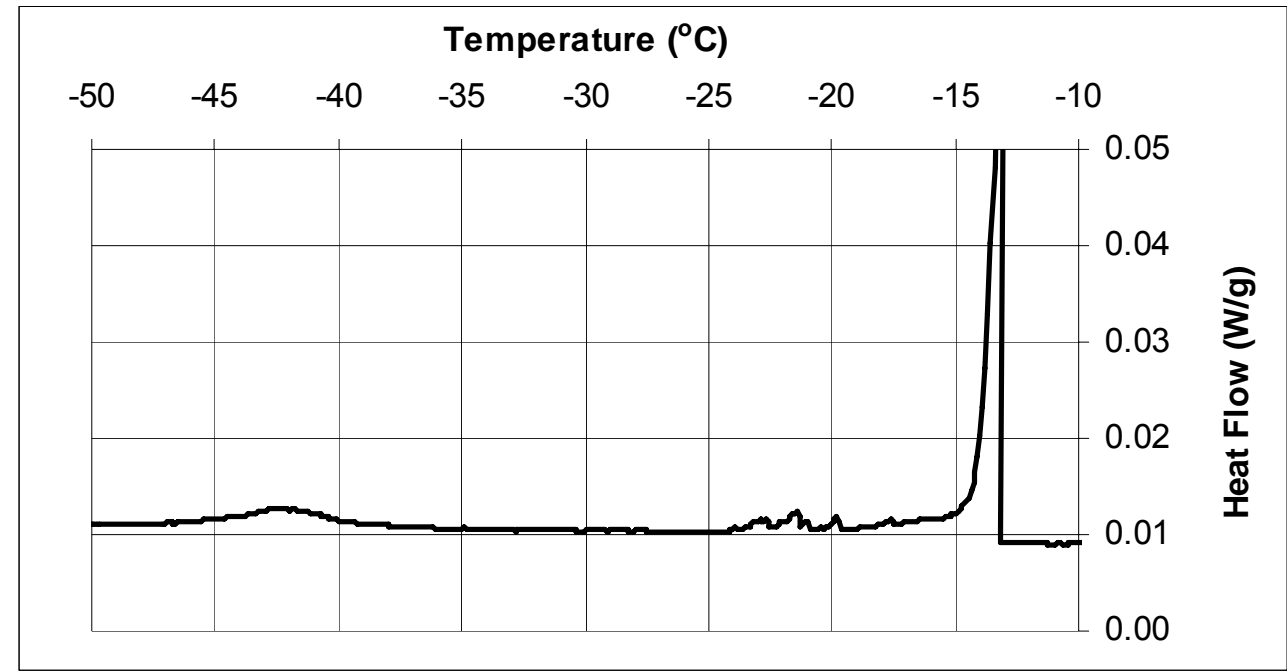

Figure $28 \mathrm{LTC}$ scan for CCRL Cement 152, w/c $=0.25$, cured for $91 \mathrm{~d}$ under saturated conditions at $20{ }^{\circ} \mathrm{C}$.

Cement: CCRL Cement 152

Solution: Distilled water

$w / c: 0.25$

Temperature: $20{ }^{\circ} \mathrm{C}$

Degree of hydration: 0.500
Curing: Sealed

Age when tested: $91 \mathrm{~d}$

Sample mass: $60.9 \mathrm{mg}$

Filename: c152w025T20Csea191d

Date tested: August 15, 2005

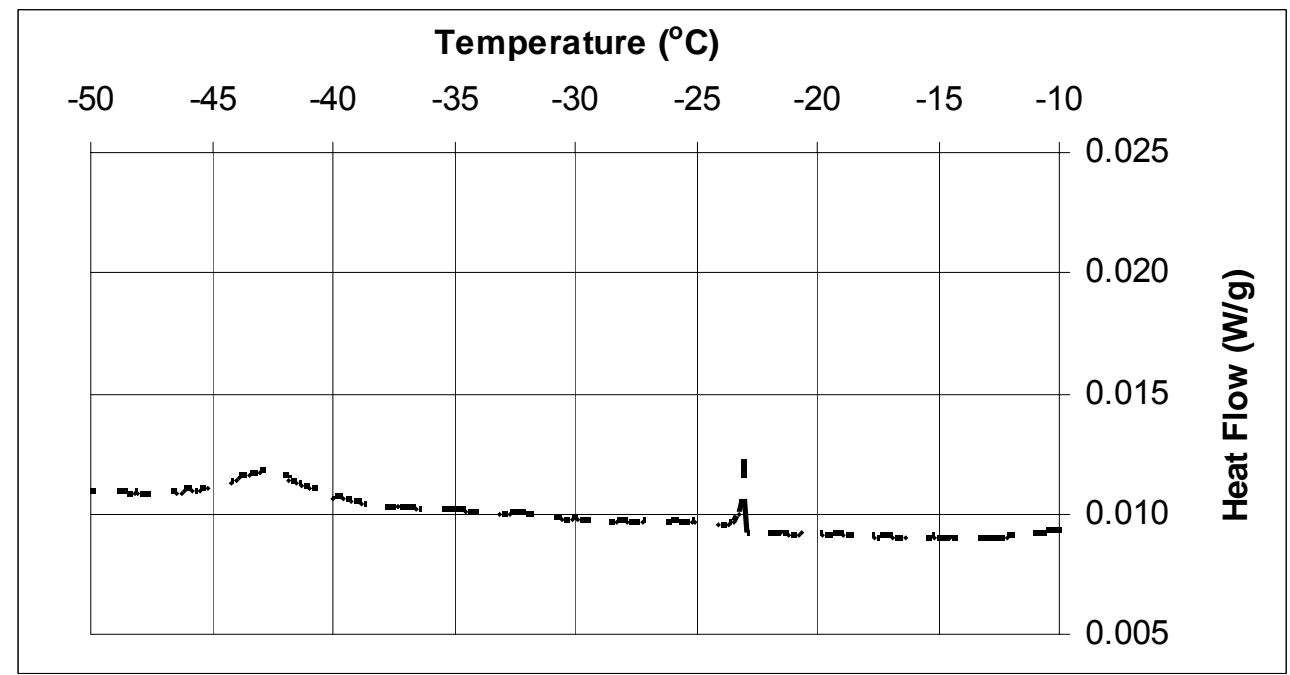

Figure $29 \mathrm{LTC}$ scan for CCRL Cement $152, w / c=0.25$, cured for $91 \mathrm{~d}$ under sealed conditions at $20{ }^{\circ} \mathrm{C}$. 
Cement: CCRL Cement 152

Solution: Distilled water

$w / c: 0.25$

Temperature: $20{ }^{\circ} \mathrm{C}$

Degree of hydration: N/A
Curing: Sealed $91 \mathrm{~d} /$ resaturated

Age when tested: $92 \mathrm{~d}$

Sample mass: $84.6 \mathrm{mg}$

Filename: c152w025T20Csealresat91t92d

Date tested: August 16, 2005

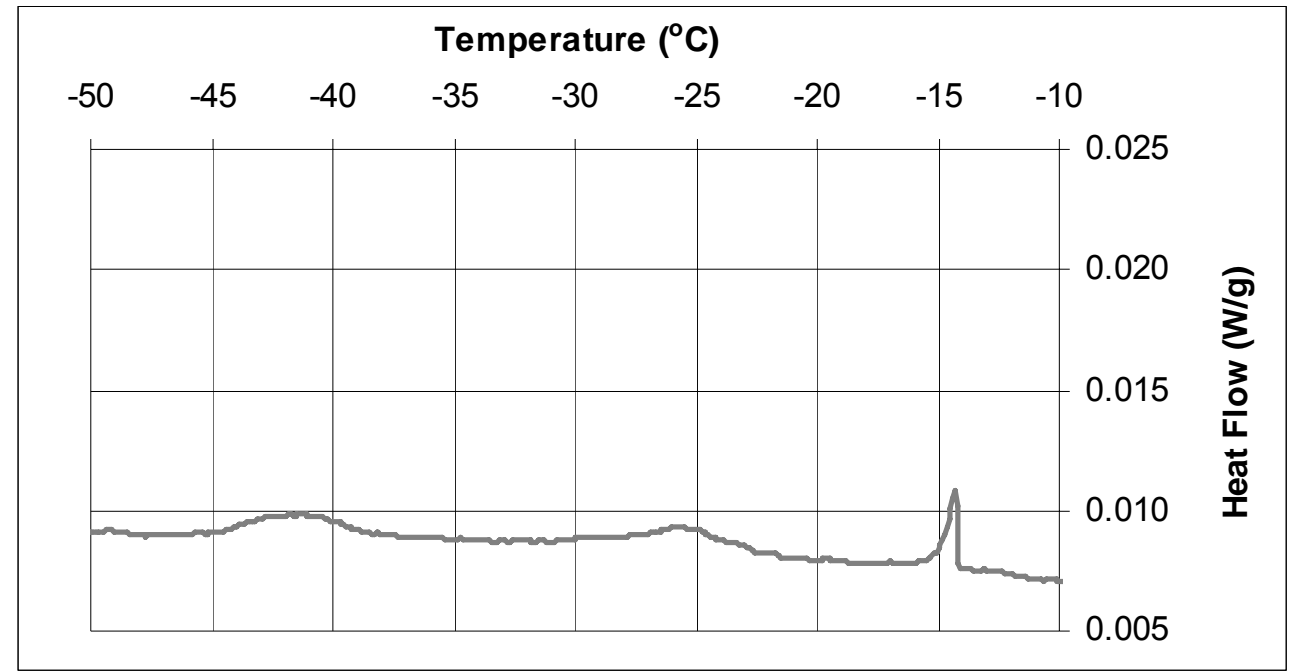

Figure $30 \mathrm{LTC}$ scan for CCRL Cement $152, w / c=0.25$, cured at $20^{\circ} \mathrm{C}$ for $91 \mathrm{~d}$ under sealed conditions, then resaturated for $1 \mathrm{~d}$. 
Cement: CCRL Cement 152

Solution: Distilled water

w/c: 0.35

Temperature: $20{ }^{\circ} \mathrm{C}$

Degree of hydration: 0.316
Curing: Saturated

Age when tested: $1 \mathrm{~d}$

Sample mass: $52.2 \mathrm{mg}$

Filename: cem152w35sat1d

Date tested: Nov. 2, 2004

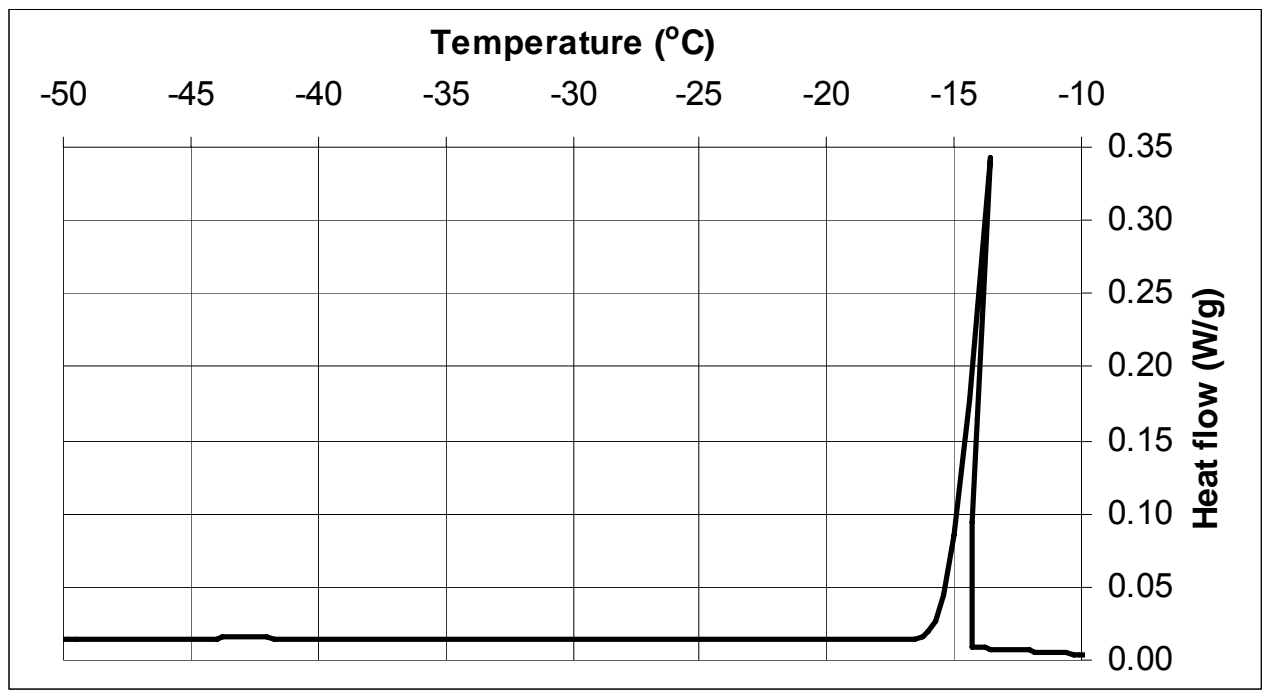

Figure $31 \mathrm{LTC}$ scan for CCRL Cement $152, w / C=0.35$, cured for $1 \mathrm{~d}$ under saturated conditions at $20^{\circ} \mathrm{C}$.

Cement: CCRL Cement 152

Solution: Distilled water

w/c: 0.35

Temperature: $20{ }^{\circ} \mathrm{C}$

Degree of hydration: 0.328
Curing: Sealed

Age when tested: $1 \mathrm{~d}$

Sample mass: $38.5 \mathrm{mg}$

Filename: cem152w35sealld

Date tested: Nov. 2, 2004

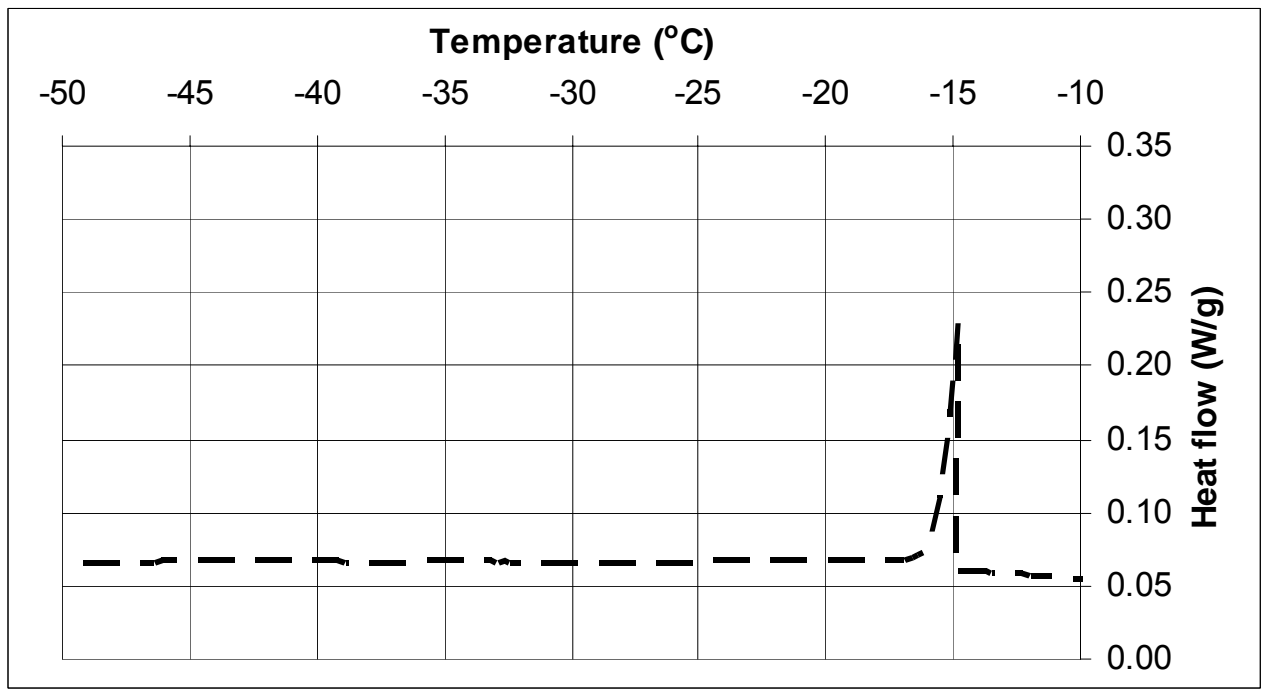

Figure $32 \mathrm{LTC}$ scan for CCRL Cement 152, $w / c=0.35$, cured for $1 \mathrm{~d}$ under sealed conditions at $20^{\circ} \mathrm{C}$. 
Cement: CCRL Cement 152

Solution: Distilled water

w/c: 0.35

Temperature: $2{ }^{\circ} \mathrm{C}$

Degree of hydration: 0.430
Curing: Saturated

Age when tested: $2 \mathrm{~d}$

Sample mass: $53.0 \mathrm{mg}$

Filename: cem152w35sat2d

Date tested: Nov. 3, 2004

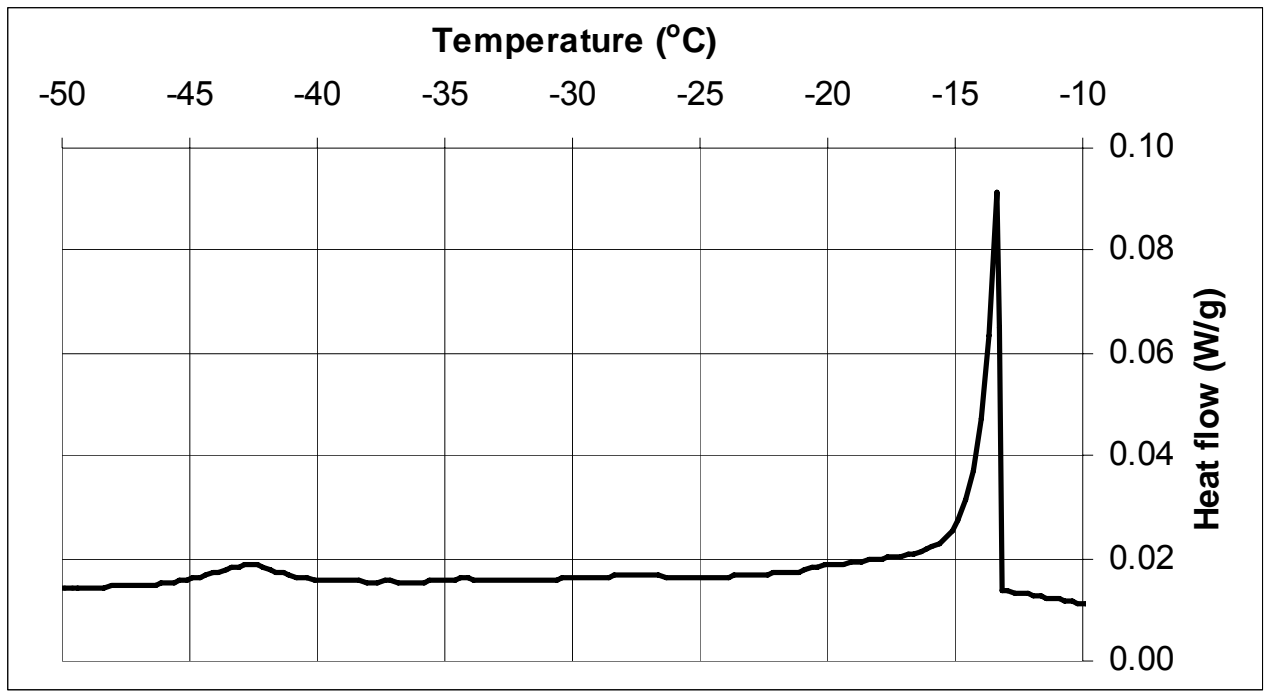

Figure $33 \mathrm{LTC}$ scan for CCRL Cement 152, w/c $=0.35$, cured for $2 \mathrm{~d}$ under saturated conditions at $20{ }^{\circ} \mathrm{C}$.

Cement: CCRL Cement 152

Solution: Distilled water

w/c: 0.35

Temperature: $20^{\circ} \mathrm{C}$

Degree of hydration: 0.439
Curing: Sealed

Age when tested: $2 \mathrm{~d}$

Sample mass: $61.2 \mathrm{mg}$

Filename: cem $152 \mathrm{w} 35 \mathrm{sea} 2 \mathrm{~d}$

Date tested: Nov. 3, 2004

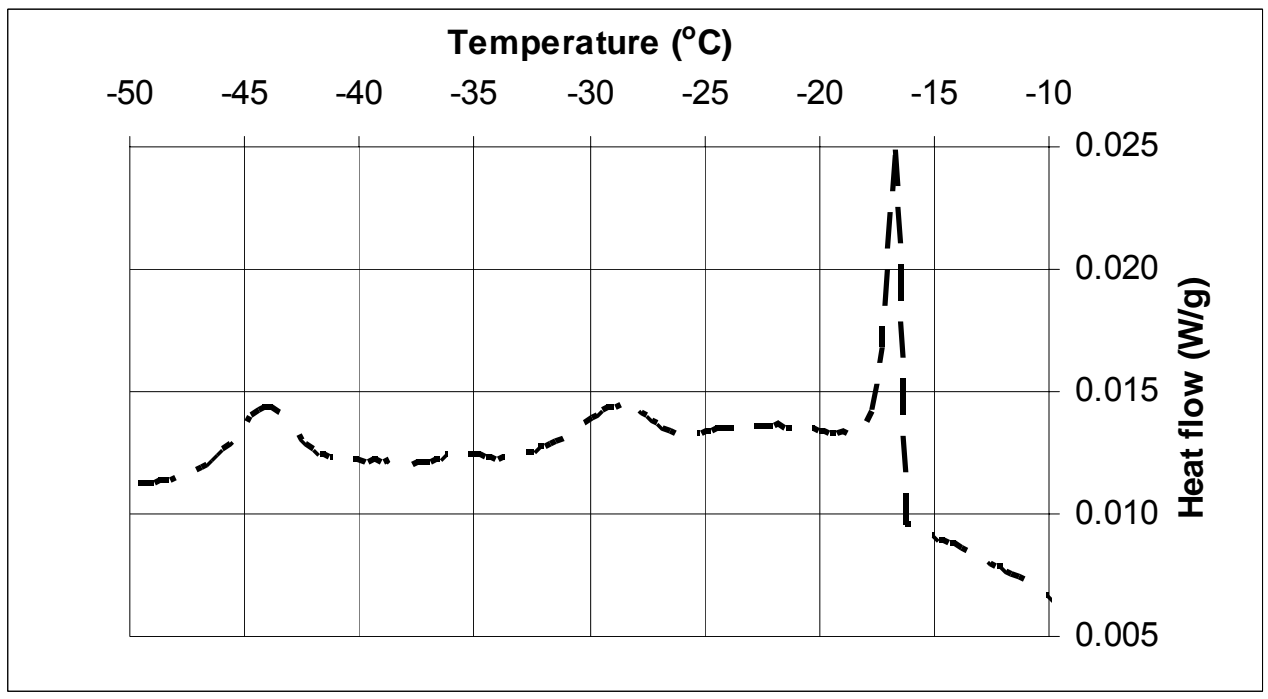

Figure $34 \mathrm{LTC}$ scan for CCRL Cement $152, w / c=0.35$, cured for $2 \mathrm{~d}$ under sealed conditions at $20^{\circ} \mathrm{C}$. 
Cement: CCRL Cement 152

Solution: Distilled water

$w / c: 0.35$

Temperature: $20{ }^{\circ} \mathrm{C}$

Degree of hydration: N/A
Curing: Saturated

Age when tested: $2 \mathrm{~d}$

Sample mass: $53.7 \mathrm{mg}$

Filename: cem152w35sat2d1221

Date tested: Dec. 22, 2004

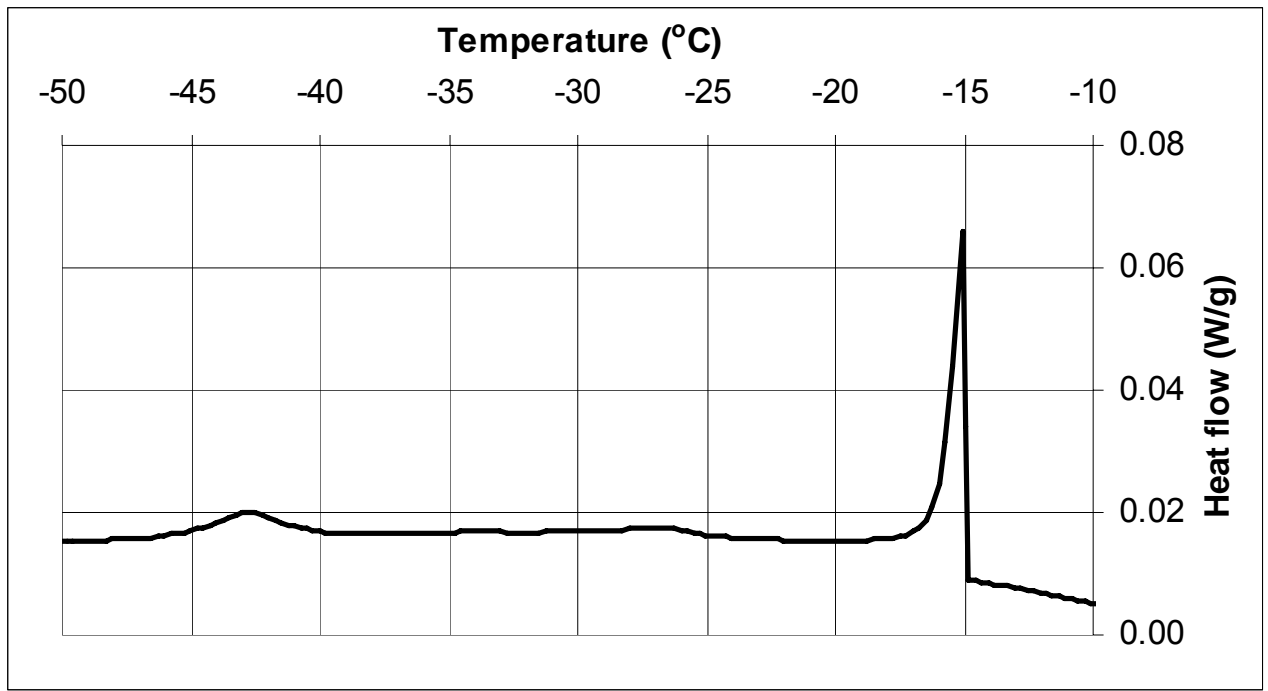

Figure $35 \mathrm{LTC}$ scan for CCRL Cement $152, w / c=0.35$, cured for $2 \mathrm{~d}$ under saturated conditions at $20^{\circ} \mathrm{C}$ (replicate mixture).

Cement: CCRL Cement 152

Solution: Distilled water

$w / c: 0.35$

Temperature: $20{ }^{\circ} \mathrm{C}$

Degree of hydration: N/A
Curing: Sealed

Age when tested: $2 \mathrm{~d}$

Sample mass: $64.2 \mathrm{mg}$

Filename: cem152w35seal2d1221

Date tested: Dec. 22, 2004

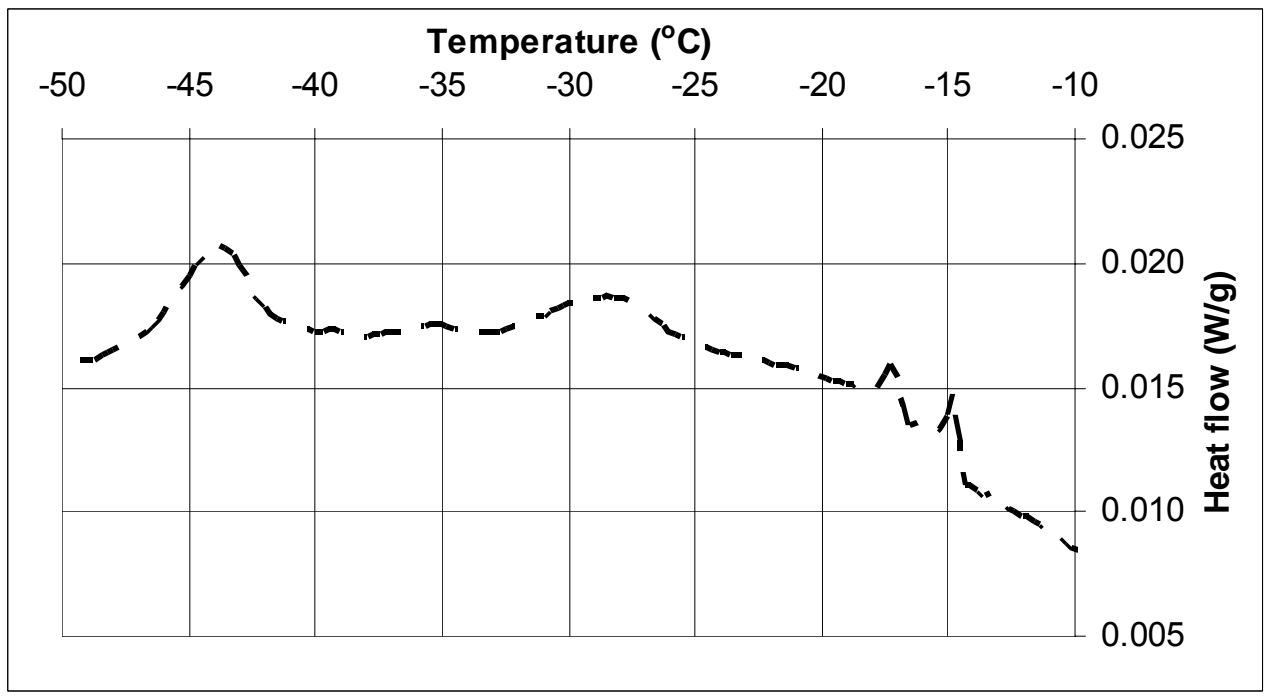

Figure $36 \mathrm{LTC}$ scan for CCRL Cement $152, w / c=0.35$, cured for $2 \mathrm{~d}$ under sealed conditions at $20{ }^{\circ} \mathrm{C}$ (replicate mixture). 
Cement: CCRL Cement 152

Solution: Distilled water

w/c: 0.35

Temperature: $20^{\circ} \mathrm{C}$

Degree of hydration: 0.502
Curing: Saturated

Age when tested: $3 \mathrm{~d}$

Sample mass: $51.1 \mathrm{mg}$

Filename: cem152w35sat3d

Date tested: Nov. 4, 2004

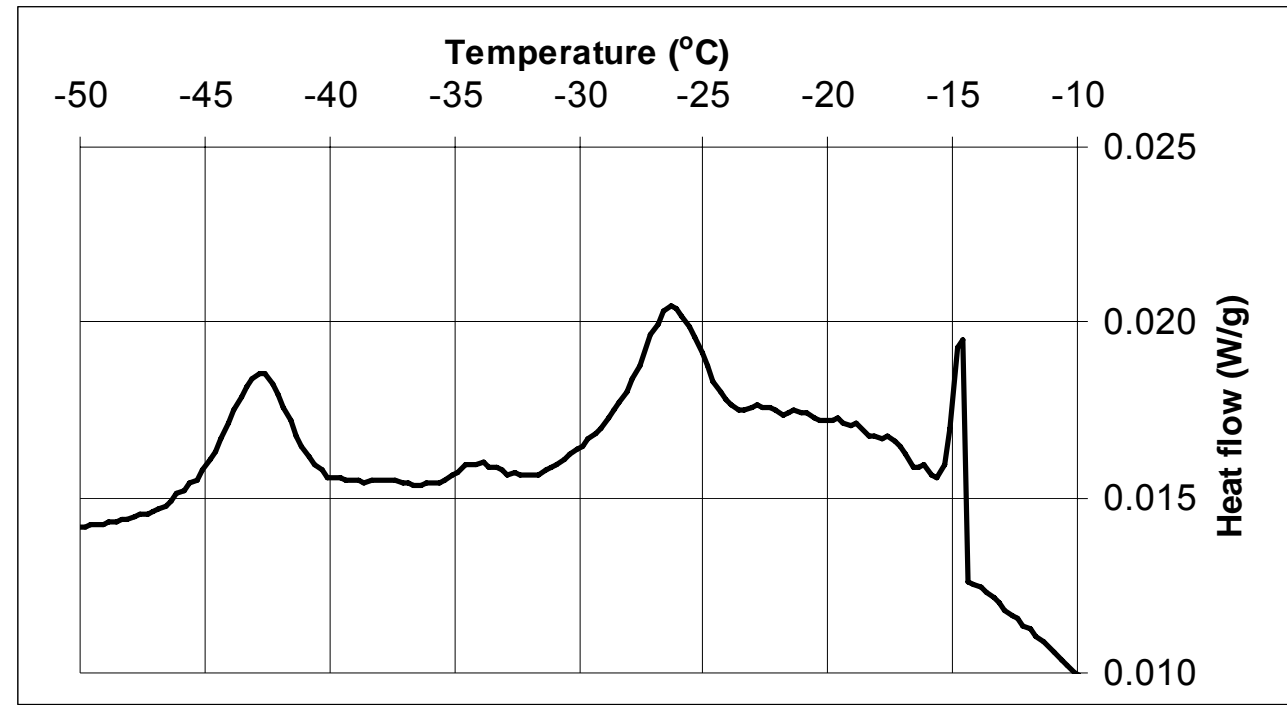

Figure 37 LTC scan for CCRL Cement 152, $w / c=0.35$, cured for $3 \mathrm{~d}$ under saturated conditions at $20{ }^{\circ} \mathrm{C}$.

Cement: CCRL Cement 152

Solution: Distilled water

w/c: 0.35

Temperature: $20{ }^{\circ} \mathrm{C}$

Degree of hydration: 0.502
Curing: Sealed

Age when tested: $3 \mathrm{~d}$

Sample mass: $56.0 \mathrm{mg}$

Filename: cem152w35seal3d

Date tested: Nov. 4, 2004

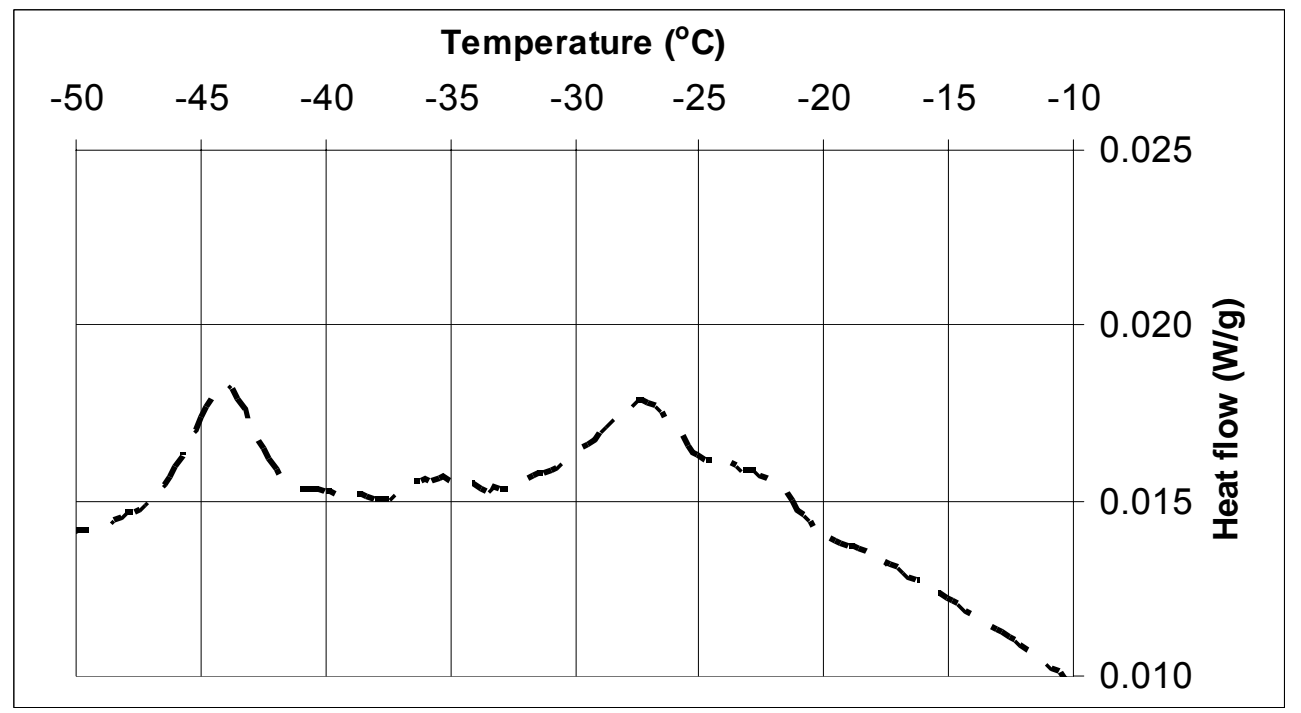

Figure $38 \mathrm{LTC}$ scan for CCRL Cement 152, $w / c=0.35$, cured for $3 \mathrm{~d}$ under sealed conditions at $20^{\circ} \mathrm{C}$. 
Cement: CCRL Cement 152

Solution: Distilled water

$w / c: 0.35$

Temperature: $20{ }^{\circ} \mathrm{C}$

Degree of hydration: N/A
Curing: Sealed $2 \mathrm{~d} /$ resaturated

Age when tested: $3 \mathrm{~d}$

Sample mass: $51.3 \mathrm{mg}$

Filename: cem $152 \mathrm{w} 35$ sealresat $2 \mathrm{~d} 1222$

Date tested: Dec. 23, 2004

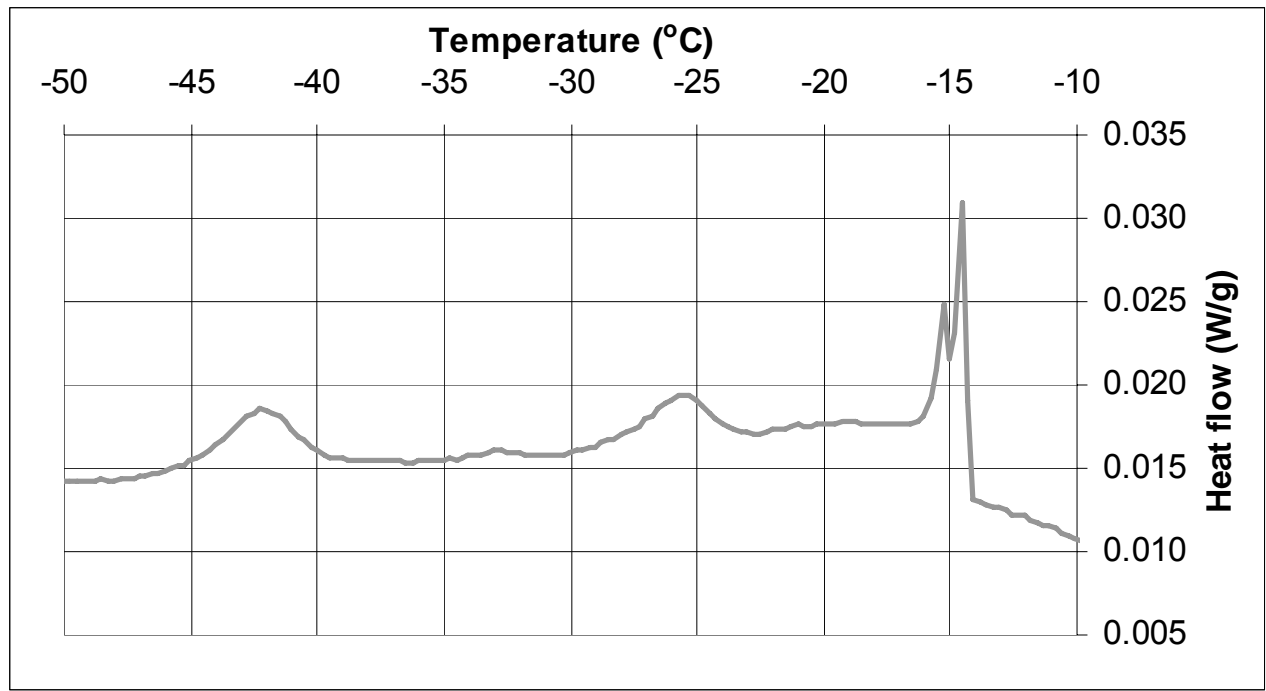

Figure 39 LTC scan for CCRL Cement $152, w / C=0.35$, cured at $20^{\circ} \mathrm{C}$ for $2 \mathrm{~d}$ under sealed conditions, then resaturated for $1 \mathrm{~d}$. 
Cement: CCRL Cement 152

Solution: Distilled water

w/c: 0.35

Temperature: $20^{\circ} \mathrm{C}$

Degree of hydration: 0.568
Curing: Saturated

Age when tested: $4 \mathrm{~d}$

Sample mass: $35.7 \mathrm{mg}$

Filename: cem152w35sat4d

Date tested: Nov. 5, 2004

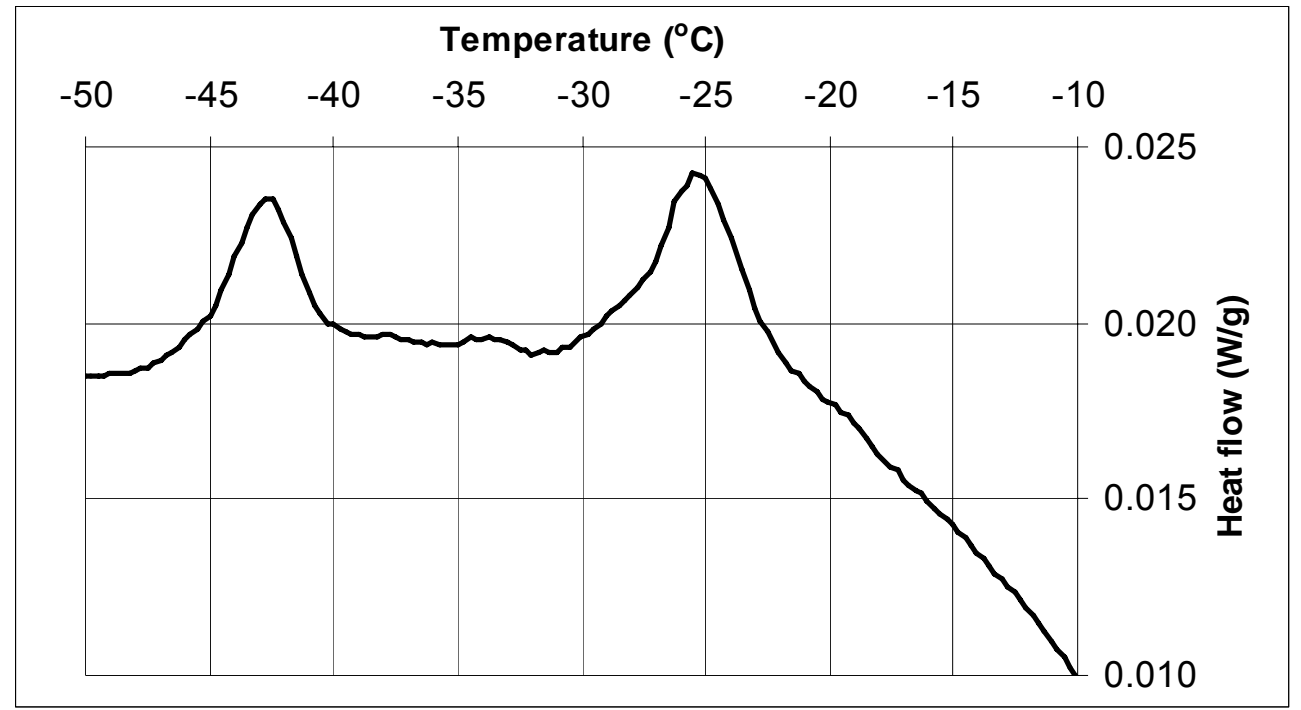

Figure $40 \mathrm{LTC}$ scan for CCRL Cement 152, $w / c=0.35$, cured for $4 \mathrm{~d}$ under saturated conditions at $20{ }^{\circ} \mathrm{C}$.

Cement: CCRL Cement 152

Solution: Distilled water

w/c: 0.35

Temperature: $20^{\circ} \mathrm{C}$

Degree of hydration: 0.554
Curing: Sealed

Age when tested: $4 \mathrm{~d}$

Sample mass: $58.6 \mathrm{mg}$

Filename: cem152w35seal4d

Date tested: Nov. 5, 2004

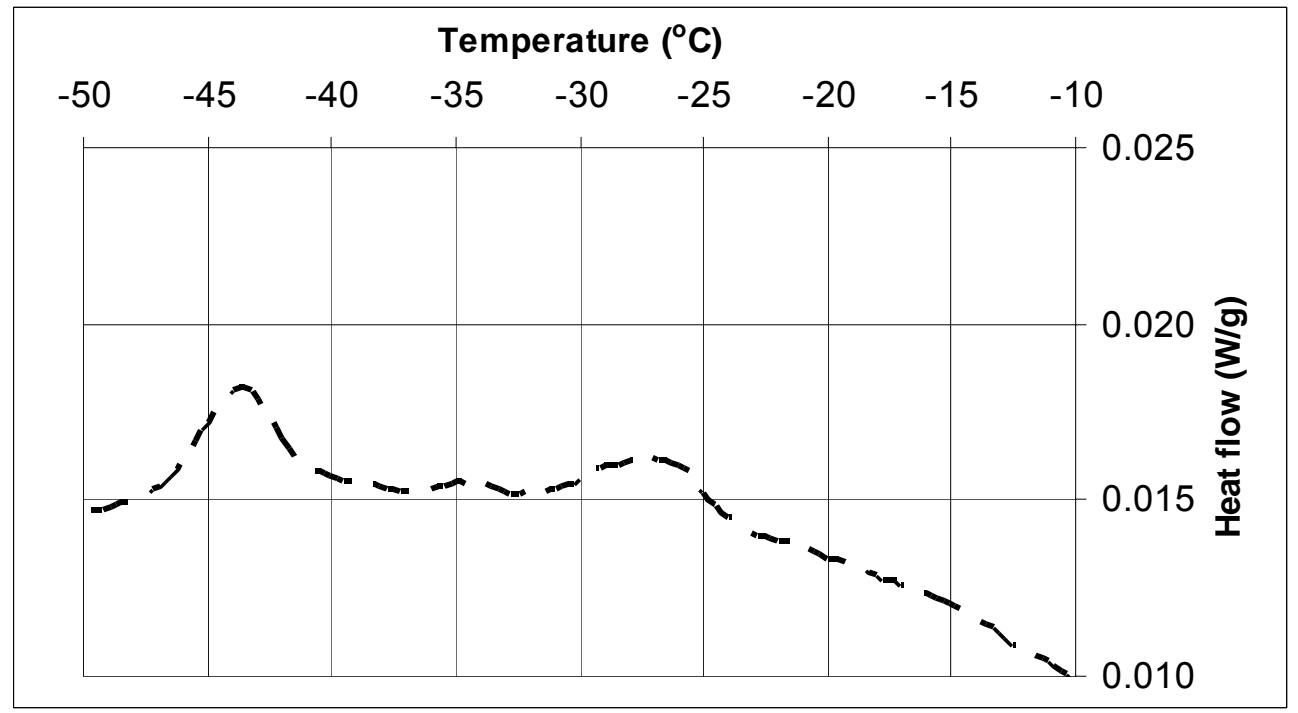

Figure $41 \mathrm{LTC}$ scan for CCRL Cement 152, w/c $=0.35$, cured for $4 \mathrm{~d}$ under sealed conditions at $20^{\circ} \mathrm{C}$. 
Cement: CCRL Cement 152

Solution: Distilled water

w/c: 0.35

Temperature: $20{ }^{\circ} \mathrm{C}$

Degree of hydration: N/A
Curing: Sealed $3 \mathrm{~d} /$ resaturated

Age when tested: $4 \mathrm{~d}$

Sample mass: $74.3 \mathrm{mg}$

Filename: cem152w35sealresat3d

Date tested: Nov. 5, 2004

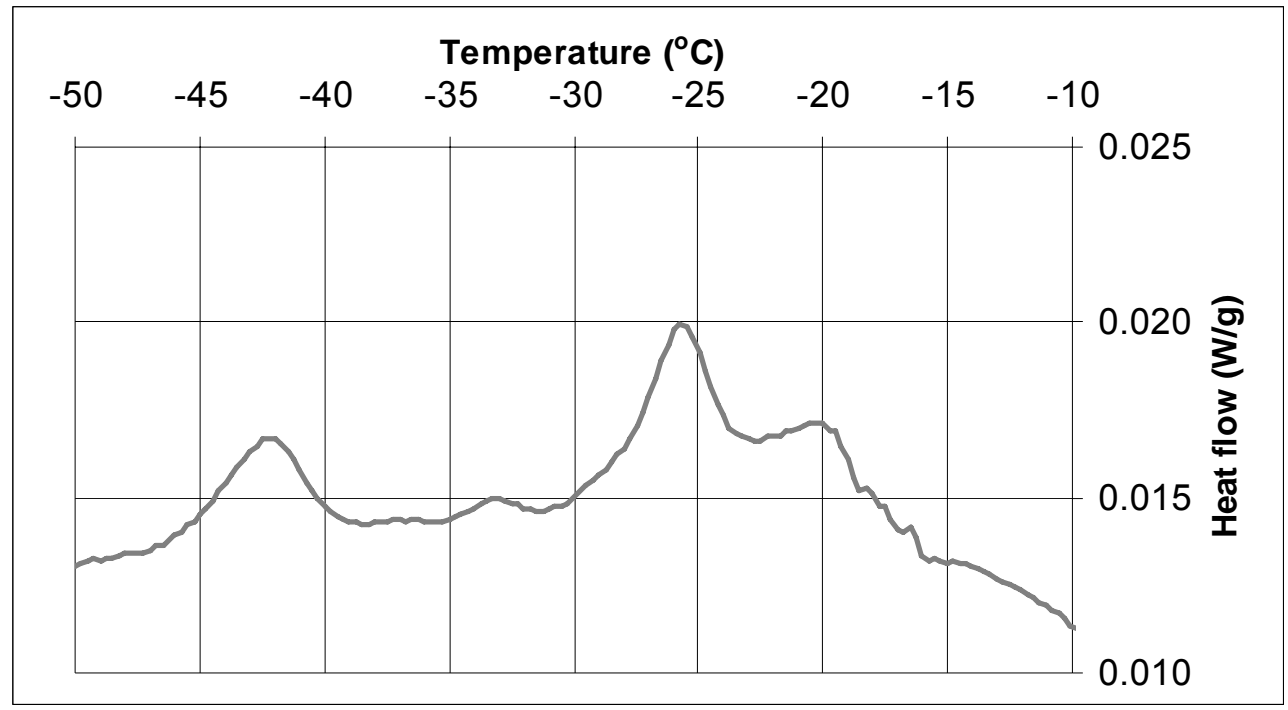

Figure $42 \mathrm{LTC}$ scan for CCRL Cement $152, w / c=0.35$, cured at $20^{\circ} \mathrm{C}$ for $3 \mathrm{~d}$ under sealed conditions, then resaturated for $1 \mathrm{~d}$.

Cement: CCRL Cement 152

Solution: Distilled water

w/c: 0.35

Temperature: $20{ }^{\circ} \mathrm{C}$

Degree of hydration: N/A
Curing: Sealed $4 \mathrm{~d} /$ resaturated

Age when tested: $5 \mathrm{~d}$

Sample mass: $58.2 \mathrm{mg}$

Filename: cem152w35sealresat $4 \mathrm{~d}$

Date tested: Nov. 6, 2004

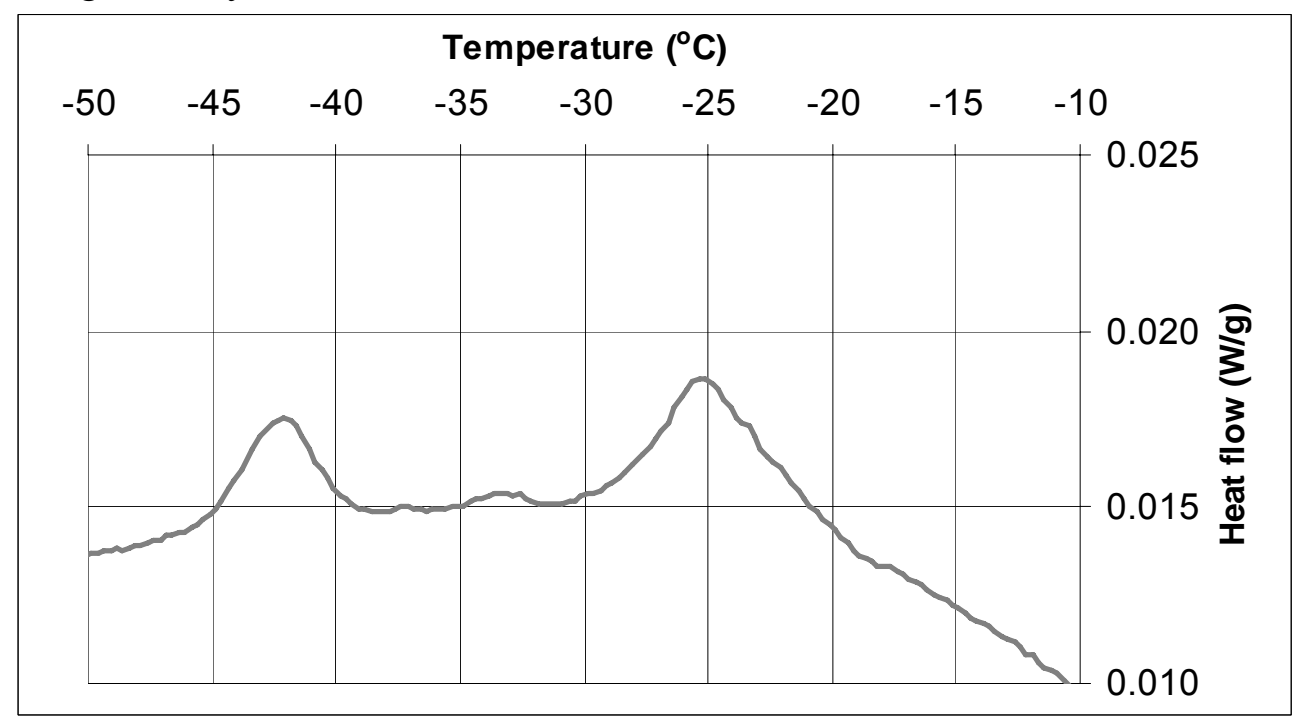

Figure $43 \mathrm{LTC}$ scan for CCRL Cement $152, w / c=0.35$, cured at $20{ }^{\circ} \mathrm{C}$ for $4 \mathrm{~d}$ under sealed conditions, then resaturated for $1 \mathrm{~d}$. 
Cement: CCRL Cement 152

Solution: Distilled water

w/c: 0.35

Temperature: $2{ }^{\circ} \mathrm{C}$

Degree of hydration: 0.597
Curing: Saturated

Age when tested: $5 \mathrm{~d}$

Sample mass: $49.9 \mathrm{mg}$

Filename: cem152w35sat5d

Date tested: Nov. 6, 2004

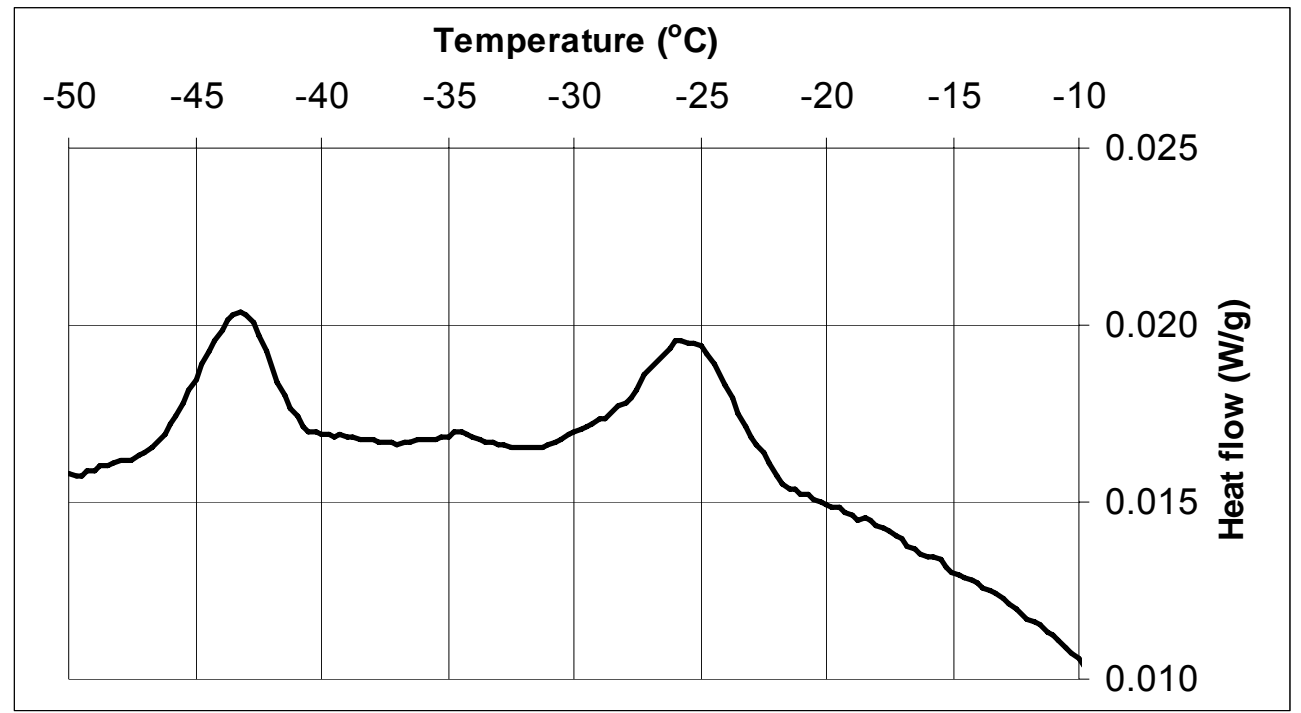

Figure $44 \mathrm{LTC}$ scan for CCRL Cement 152, w/c $=0.35$, cured for $5 \mathrm{~d}$ under saturated conditions at $20{ }^{\circ} \mathrm{C}$.

Cement: CCRL Cement 152

Solution: Distilled water

w/c: 0.35

Temperature: $20{ }^{\circ} \mathrm{C}$

Degree of hydration: 0.569
Curing: Sealed

Age when tested: $5 \mathrm{~d}$

Sample mass: $74.2 \mathrm{mg}$

Filename: cem152w35seal5d

Date tested: Nov. 6, 2004

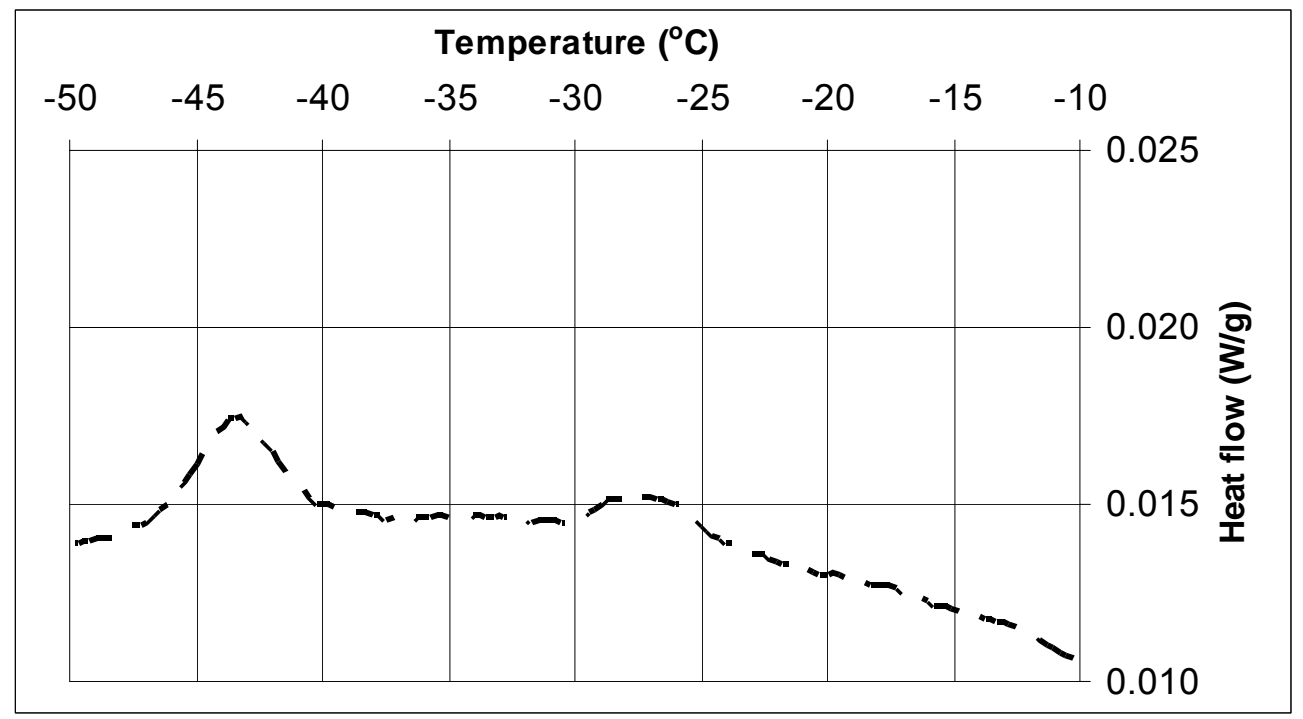

Figure $45 \mathrm{LTC}$ scan for CCRL Cement 152, $w / c=0.35$, cured for $5 \mathrm{~d}$ under sealed conditions at $20^{\circ} \mathrm{C}$. 
Cement: CCRL Cement 152

Solution: Distilled water

w/c: 0.35

Temperature: $20{ }^{\circ} \mathrm{C}$

Degree of hydration: 0.656
Curing: Saturated

Age when tested: $7 \mathrm{~d}$

Sample mass: $45.7 \mathrm{mg}$

Filename: cem152w35sat7d

Date tested: Nov. 8, 2004

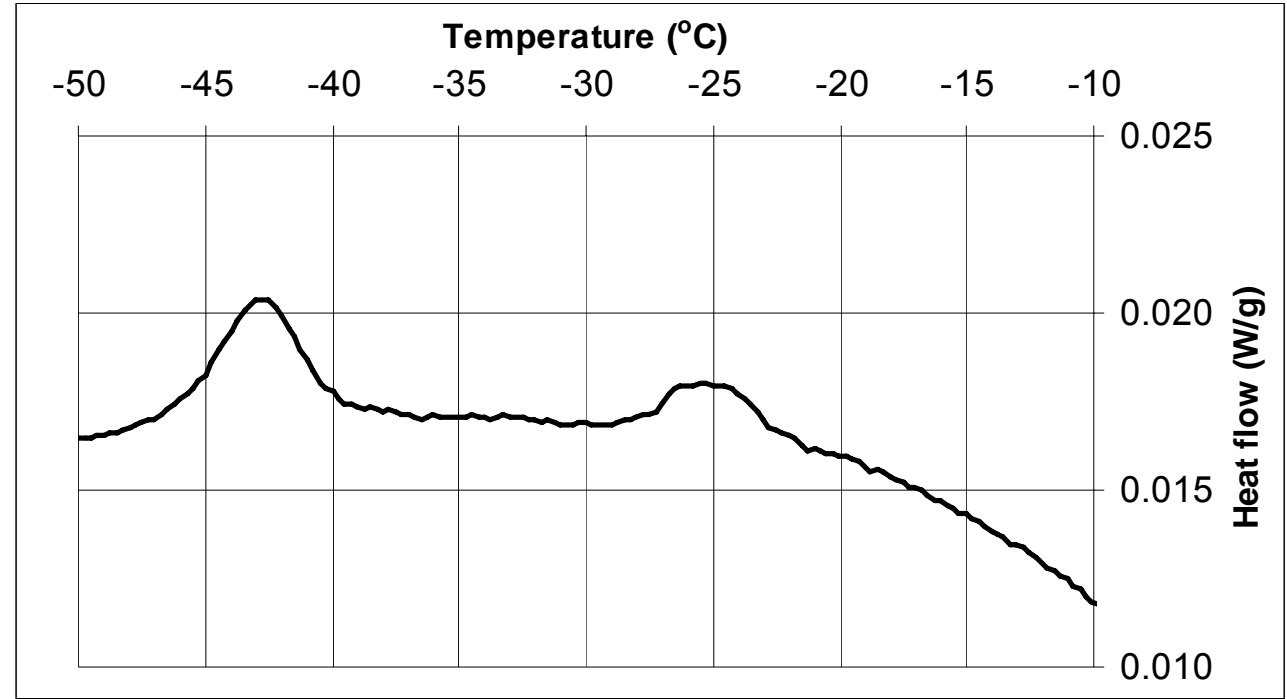

Figure $46 \mathrm{LTC}$ scan for CCRL Cement $152, w / c=0.35$, cured for $7 \mathrm{~d}$ under saturated conditions at $20^{\circ} \mathrm{C}$.

Cement: CCRL Cement 152

Solution: Distilled water

w/c: 0.35

Temperature: $20{ }^{\circ} \mathrm{C}$

Degree of hydration: 0.619
Curing: Sealed

Age when tested: $7 \mathrm{~d}$

Sample mass: $43.9 \mathrm{mg}$

Filename: cem $152 \mathrm{w} 35 \mathrm{sea} 7 \mathrm{~d}$

Date tested: Nov. 8, 2004

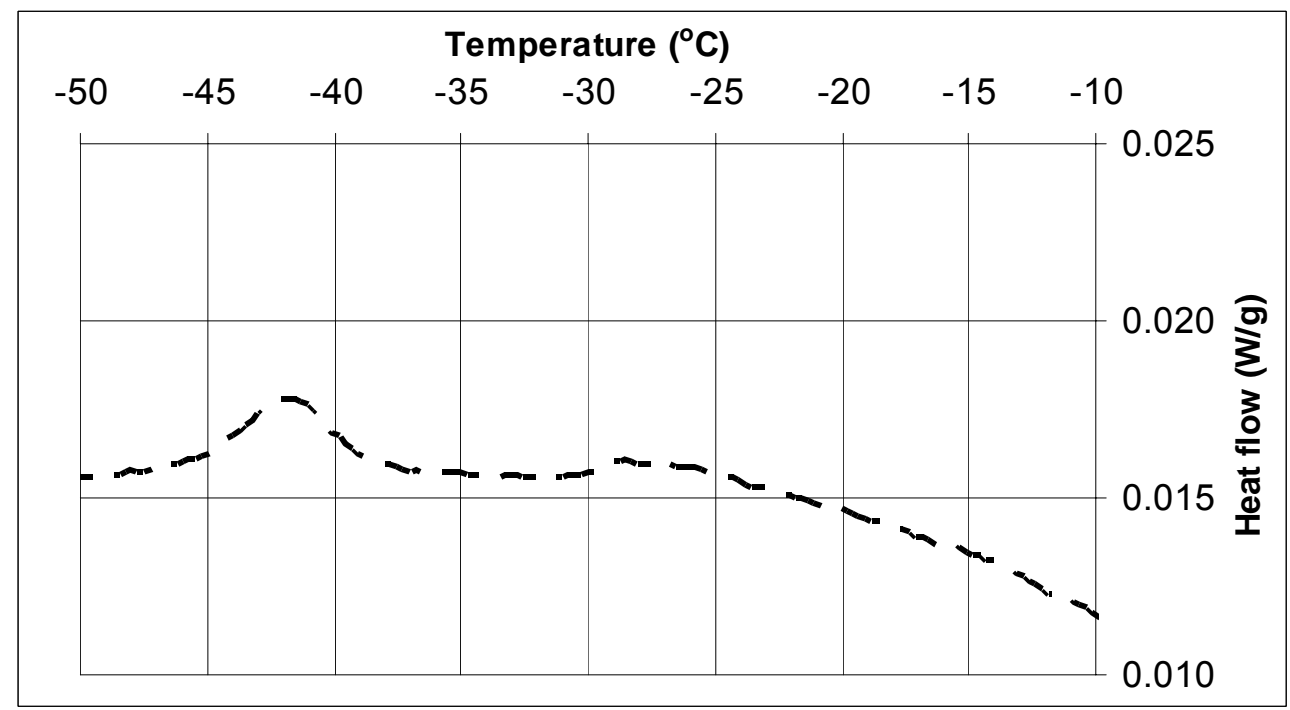

Figure $47 \mathrm{LTC}$ scan for CCRL Cement $152, w / c=0.35$, cured for $7 \mathrm{~d}$ under sealed conditions at $20^{\circ} \mathrm{C}$. 
Cement: CCRL Cement 152

Solution: Distilled water

w/c: 0.35

Temperature: $2{ }^{\circ} \mathrm{C}$

Degree of hydration: N/A
Curing: Sealed $5 \mathrm{~d} /$ resaturated

Age when tested: $7 \mathrm{~d}$

Sample mass: $60.4 \mathrm{mg}$

Filename: cem $152 \mathrm{w} 35$ sealresat $5 \mathrm{~d}$

Date tested: Nov. 8, 2004

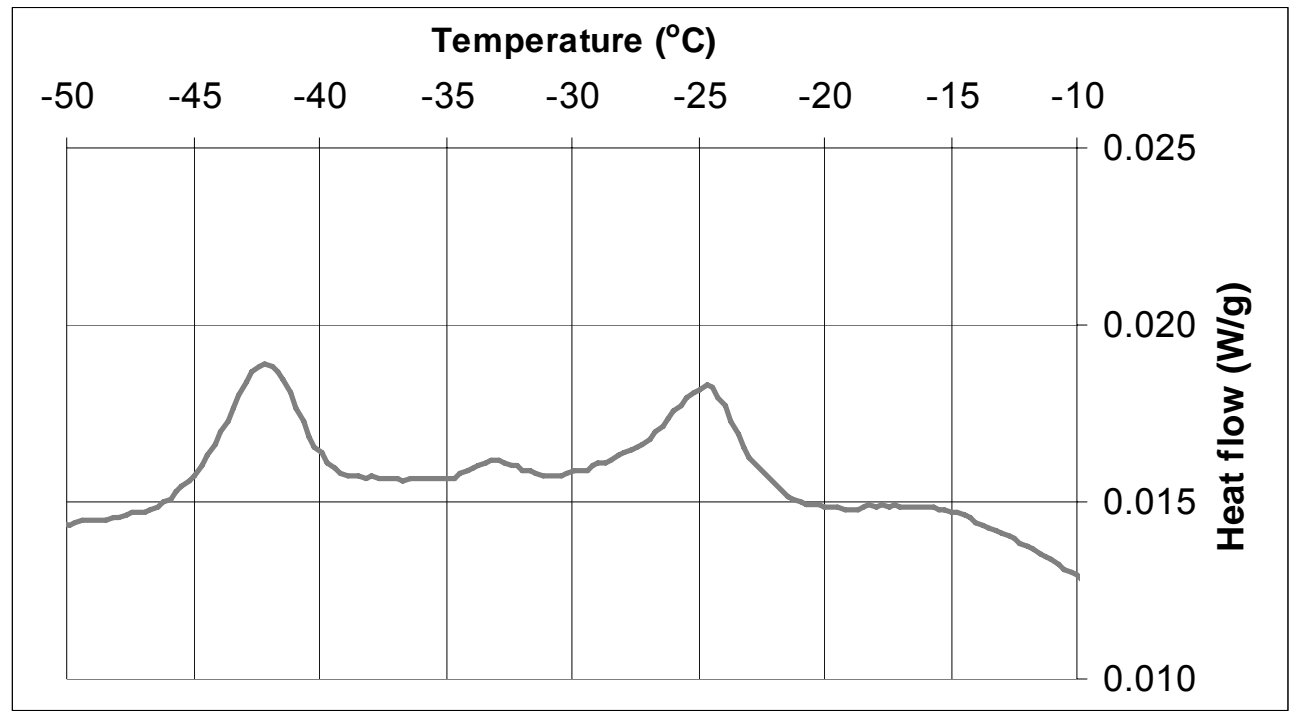

Figure $48 \mathrm{LTC}$ scan for CCRL Cement $152, w / C=0.35$, cured at $20^{\circ} \mathrm{C}$ for $5 \mathrm{~d}$ under sealed conditions, then resaturated for $2 \mathrm{~d}$.

Cement: CCRL Cement 152

Solution: Distilled water

w/c: 0.35

Temperature: $20^{\circ} \mathrm{C}$

Degree of hydration: N/A
Curing: Sealed $7 \mathrm{~d} /$ resaturated

Age when tested: $9 \mathrm{~d}$

Sample mass: $42.1 \mathrm{mg}$

Filename: cem152w35sealresat $7 \mathrm{~d}$

Date tested: Nov. 10, 2004

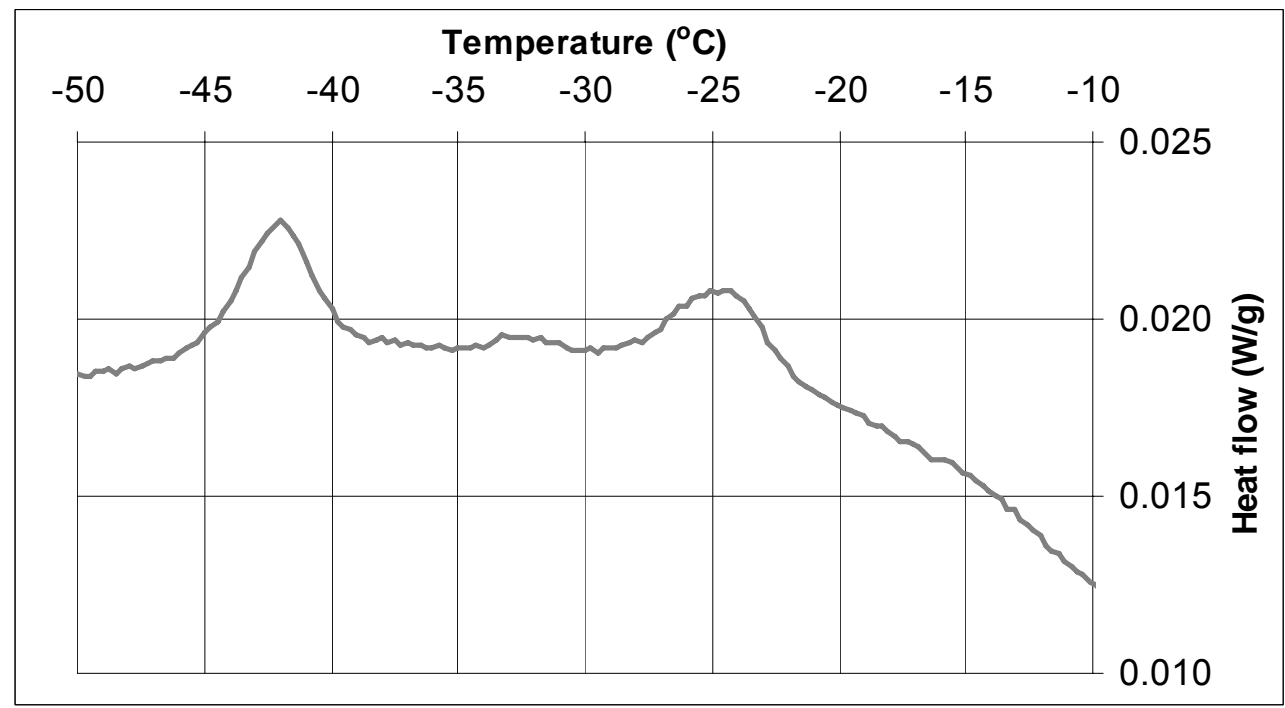

Figure $49 \mathrm{LTC}$ scan for CCRL Cement $152, w / c=0.35$, cured at $20{ }^{\circ} \mathrm{C}$ for $7 \mathrm{~d}$ under sealed conditions, then resaturated for $2 \mathrm{~d}$. 
Cement: CCRL Cement 152

Solution: Distilled water

w/c: 0.35

Temperature: $20{ }^{\circ} \mathrm{C}$

Degree of hydration: N/A
Curing: Sealed $7 \mathrm{~d} /$ frozen/resaturated Age when tested: $8+\mathrm{d}$ Sample mass: $44.4 \mathrm{mg}$ Filename: cem152w35sealresatfr7d Date tested: Nov. 9, 2004

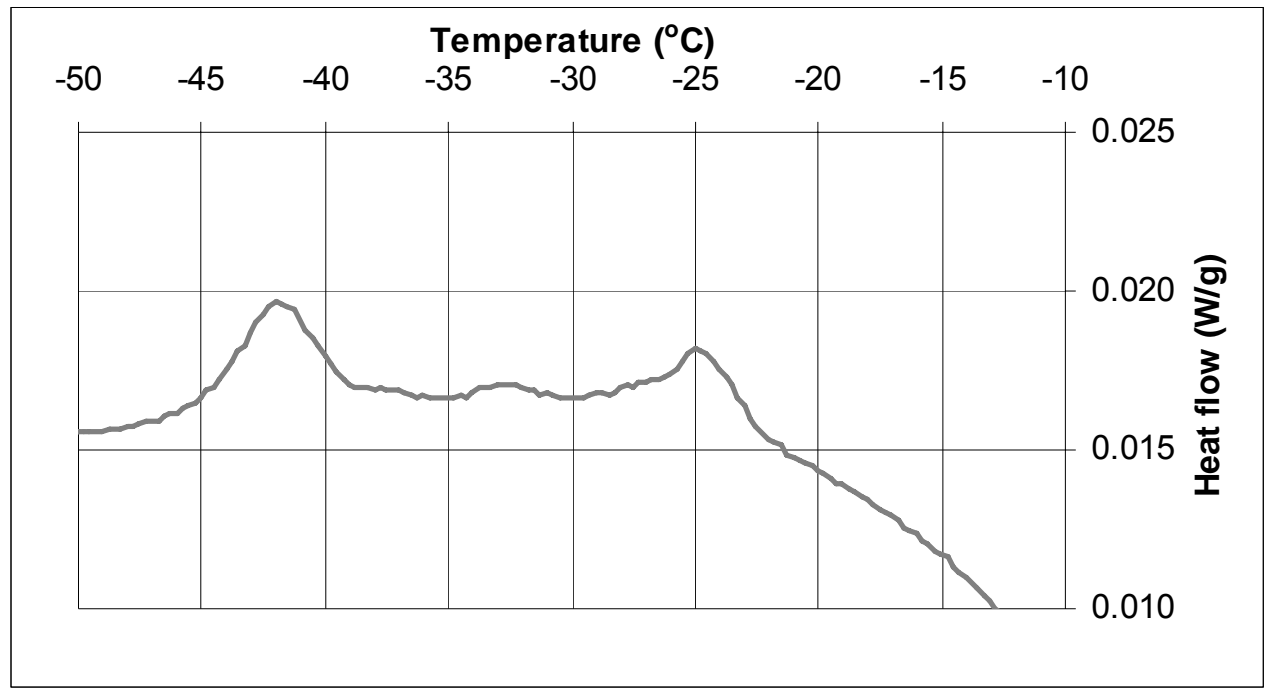

Figure $50 \mathrm{LTC}$ scan for CCRL Cement $152, w / C=0.35$, cured at $20{ }^{\circ} \mathrm{C}$ for $7 \mathrm{~d}$ under sealed conditions, frozen during an LTC scan (Figure 17), then resaturated for $1 \mathrm{~d}$. 
Cement: CCRL Cement 152

Solution: Distilled water

w/c: 0.35

Temperature: $20{ }^{\circ} \mathrm{C}$

Degree of hydration: N/A
Curing: Saturated

Age when tested: $9 \mathrm{~d}$

Sample mass: $61.1 \mathrm{mg}$

Filename: cem152w35sat9d

Date tested: Nov. 10, 2004

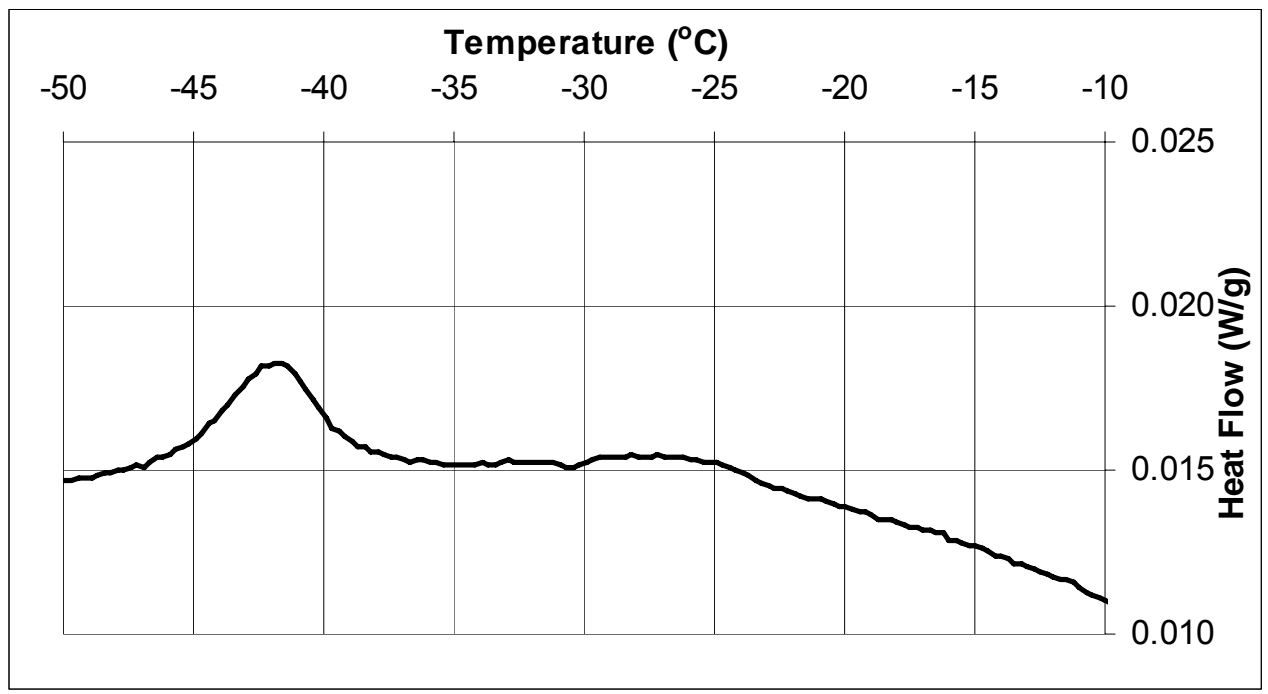

Figure $51 \mathrm{LTC}$ scan for CCRL Cement 152, w/c $=0.35$, cured for $9 \mathrm{~d}$ under saturated conditions at $20{ }^{\circ} \mathrm{C}$.

Cement: CCRL Cement 152

Solution: Distilled water

w/c: 0.35

Temperature: $20{ }^{\circ} \mathrm{C}$

Degree of hydration: N/A
Curing: Sealed

Age when tested: $9 \mathrm{~d}$

Sample mass: $50.1 \mathrm{mg}$

Filename: cem152w35seal9d

Date tested: Nov. 10, 2004

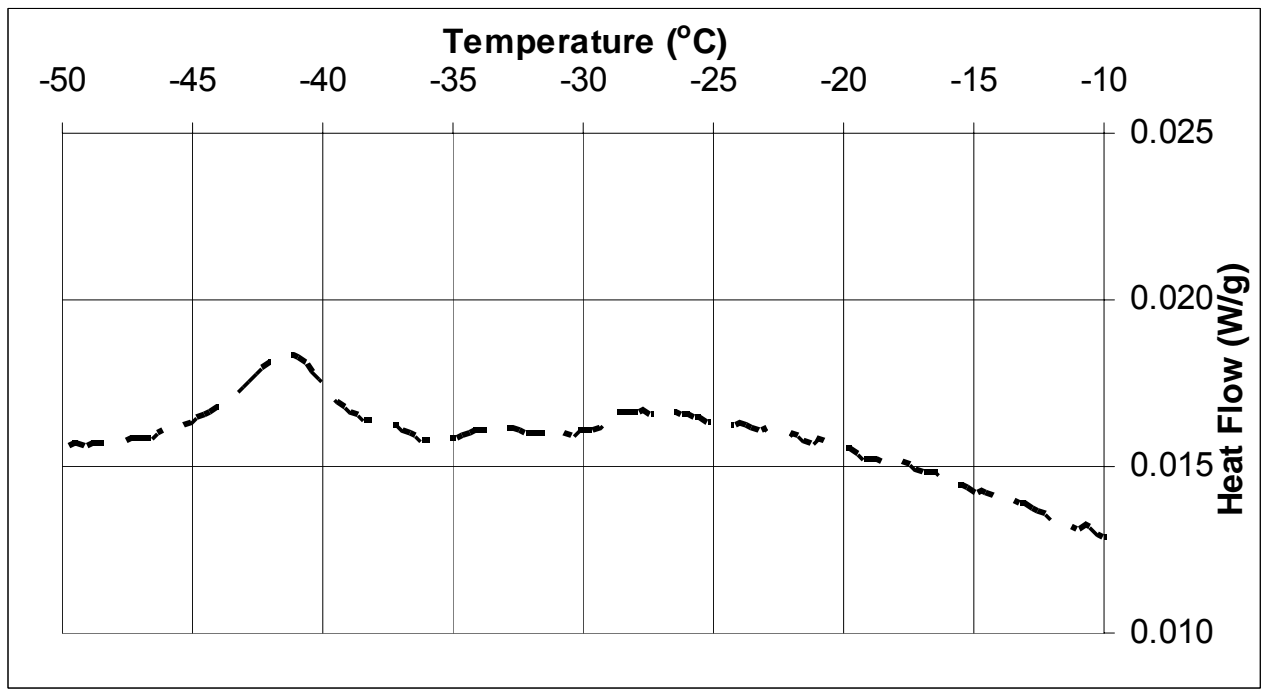

Figure $52 \mathrm{LTC}$ scan for CCRL Cement 152, $w / c=0.35$, cured for $9 \mathrm{~d}$ under sealed conditions at $20^{\circ} \mathrm{C}$. 
Cement: CCRL Cement 152

Solution: Distilled water

$w / c: 0.35$

Temperature: $20{ }^{\circ} \mathrm{C}$

Degree of hydration: 0.715
Curing: Saturated

Age when tested: $14 \mathrm{~d}$

Sample mass: $49.3 \mathrm{mg}$

Filename: cem152w35sat14d

Date tested: Nov. 15, 2004

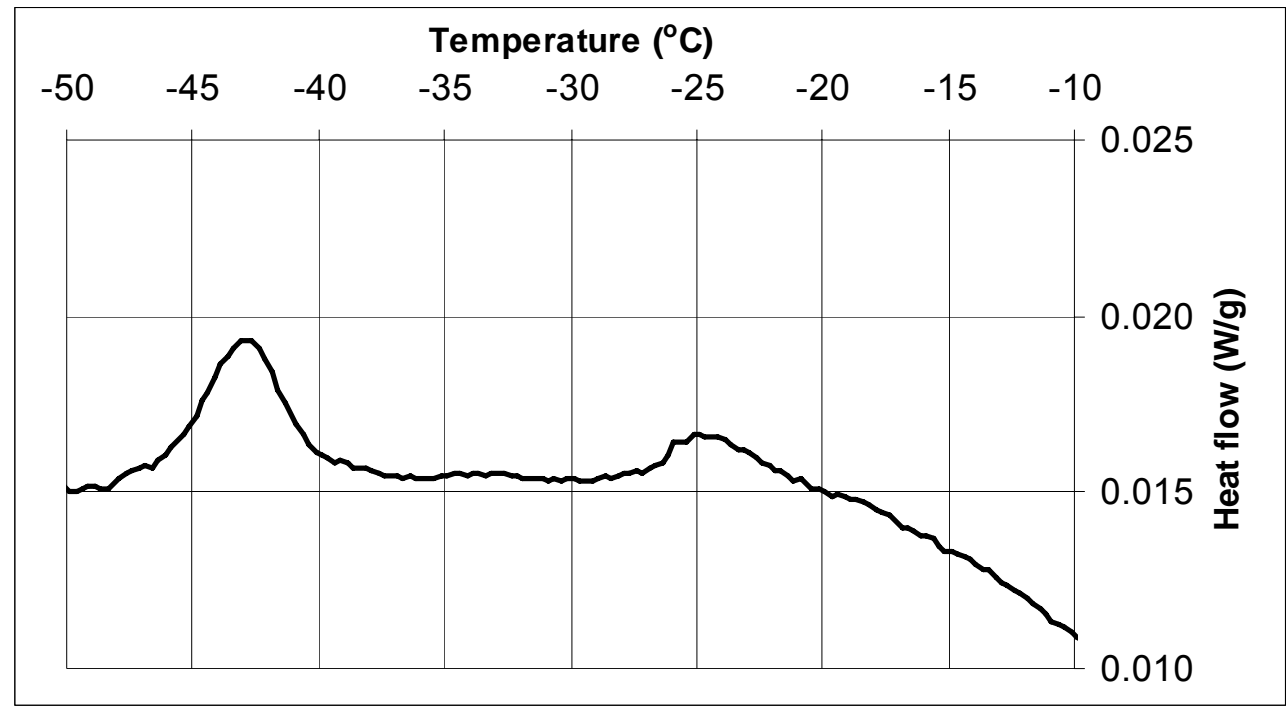

Figure $53 \mathrm{LTC}$ scan for CCRL Cement $152, w / c=0.35$, cured for $14 \mathrm{~d}$ under saturated conditions at $20{ }^{\circ} \mathrm{C}$.

Cement: CCRL Cement 152

Solution: Distilled water w/c: 0.35

Temperature: $20{ }^{\circ} \mathrm{C}$

Degree of hydration: 0.658
Curing: Sealed

Age when tested: $14 \mathrm{~d}$

Sample mass: $46.7 \mathrm{mg}$

Filename: cem152w35seal14d

Date tested: Nov. 15, 2004

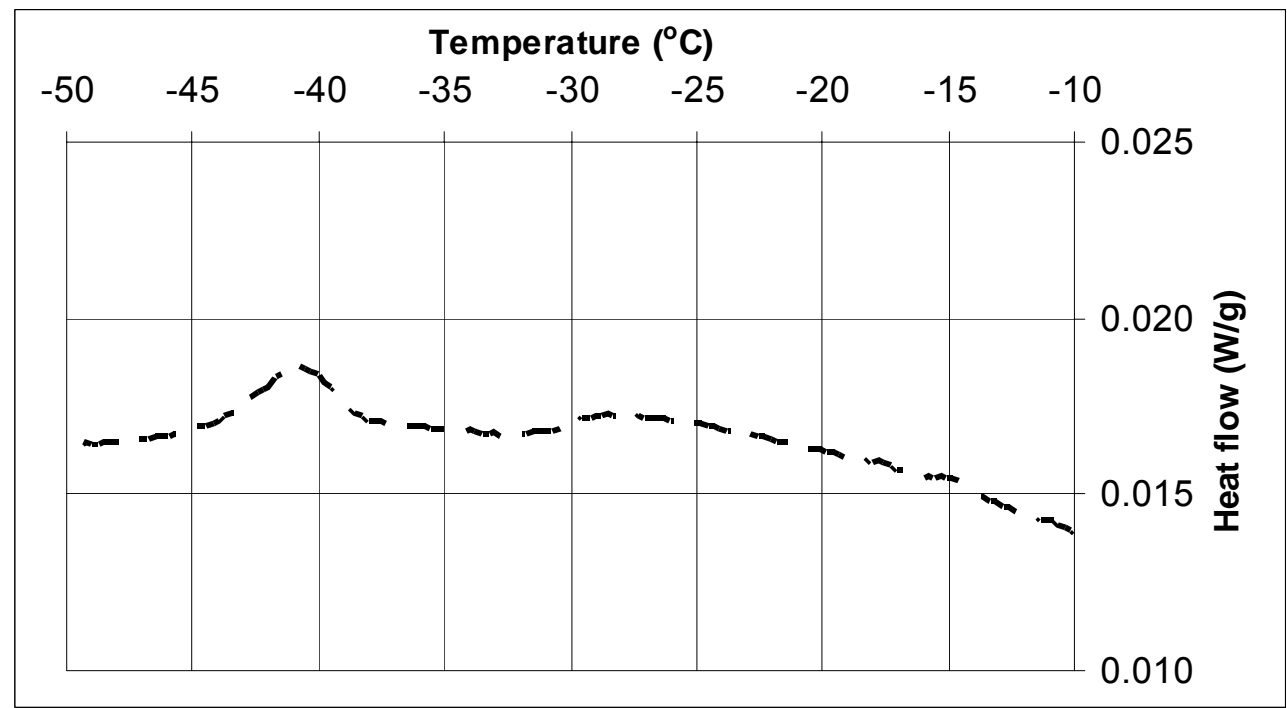

Figure $54 \mathrm{LTC}$ scan for CCRL Cement 152, w/c $=0.35$, cured for $14 \mathrm{~d}$ under sealed conditions at $20{ }^{\circ} \mathrm{C}$. 
Cement: CCRL Cement 152

Solution: Distilled water

w/c: 0.35

Temperature: $20{ }^{\circ} \mathrm{C}$

Degree of hydration: N/A
Curing: Sealed $14 \mathrm{~d} /$ resaturated

Age when tested: $15 \mathrm{~d}$

Sample mass: $59.0 \mathrm{mg}$

Filename: cem152w35sealresat $14 \mathrm{~d}$

Date tested: Nov. 16, 2004

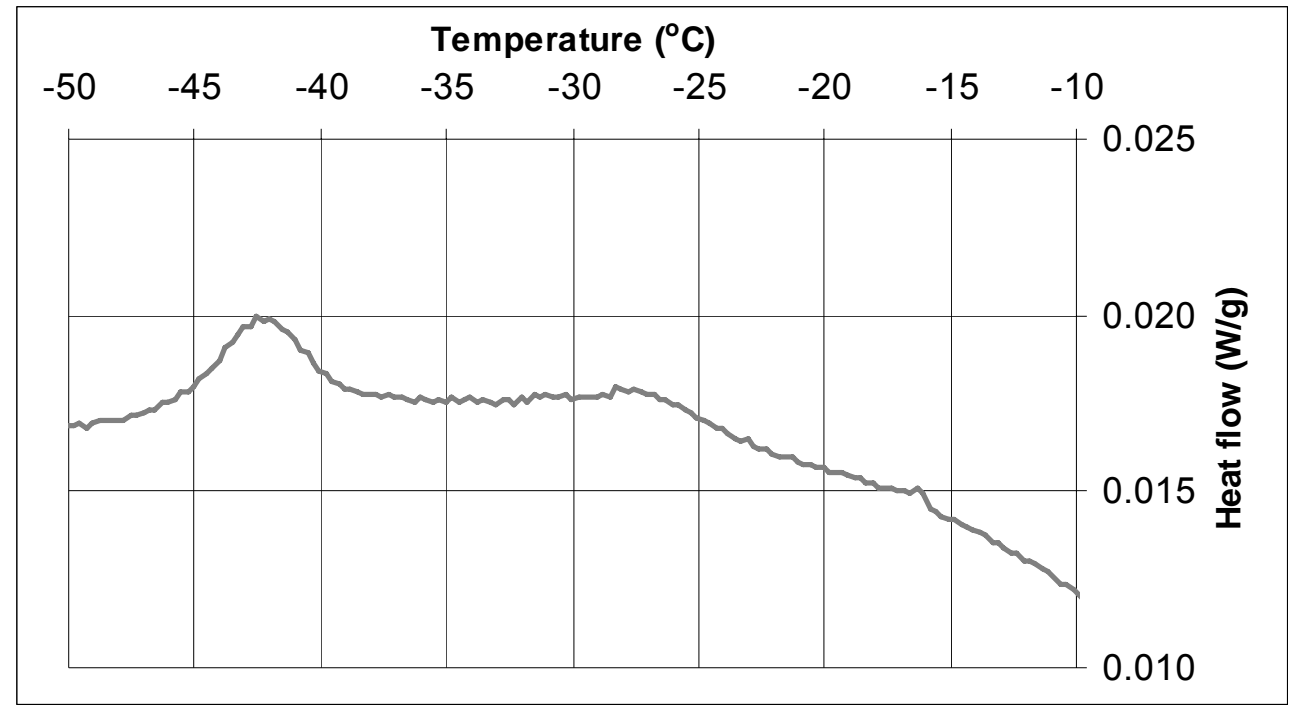

Figure $55 \mathrm{LTC}$ scan for CCRL Cement $152, w / c=0.35$, cured at $20{ }^{\circ} \mathrm{C}$ for $14 \mathrm{~d}$ under sealed conditions, then resaturated for $1 \mathrm{~d}$.

Cement: CCRL Cement 152

Solution: Distilled water

$w / c: 0.35$

Temperature: $20^{\circ} \mathrm{C}$

Degree of hydration: N/A
Curing: Sealed $14 \mathrm{~d} /$ resaturated

Age when tested: $18 \mathrm{~d}$

Sample mass: $35.3 \mathrm{mg}$

Filename: cem152w35sealresatb14d

Date tested: Nov. 19, 2004

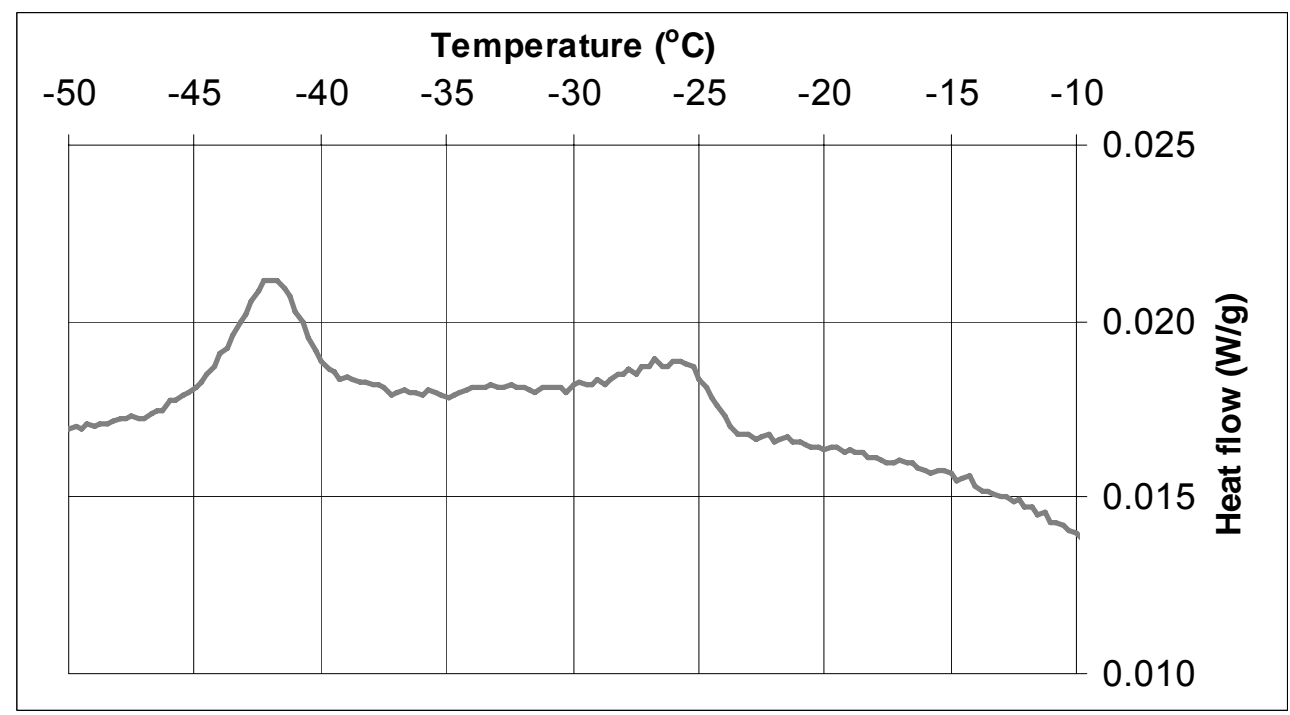

Figure $56 \mathrm{LTC}$ scan for CCRL Cement $152, w / \mathrm{c}=0.35$, cured at $20{ }^{\circ} \mathrm{C}$ for $14 \mathrm{~d}$ under sealed conditions, then resaturated for $4 \mathrm{~d}$. 
Cement: CCRL Cement 152

Solution: Distilled water

$w / c: 0.35$

Temperature: $20{ }^{\circ} \mathrm{C}$

Degree of hydration: N/A
Curing: Saturated

Age when tested: $18 \mathrm{~d}$

Sample mass: $80.9 \mathrm{mg}$

Filename: cem152w35sat18d

Date tested: Jan. 7, 2005

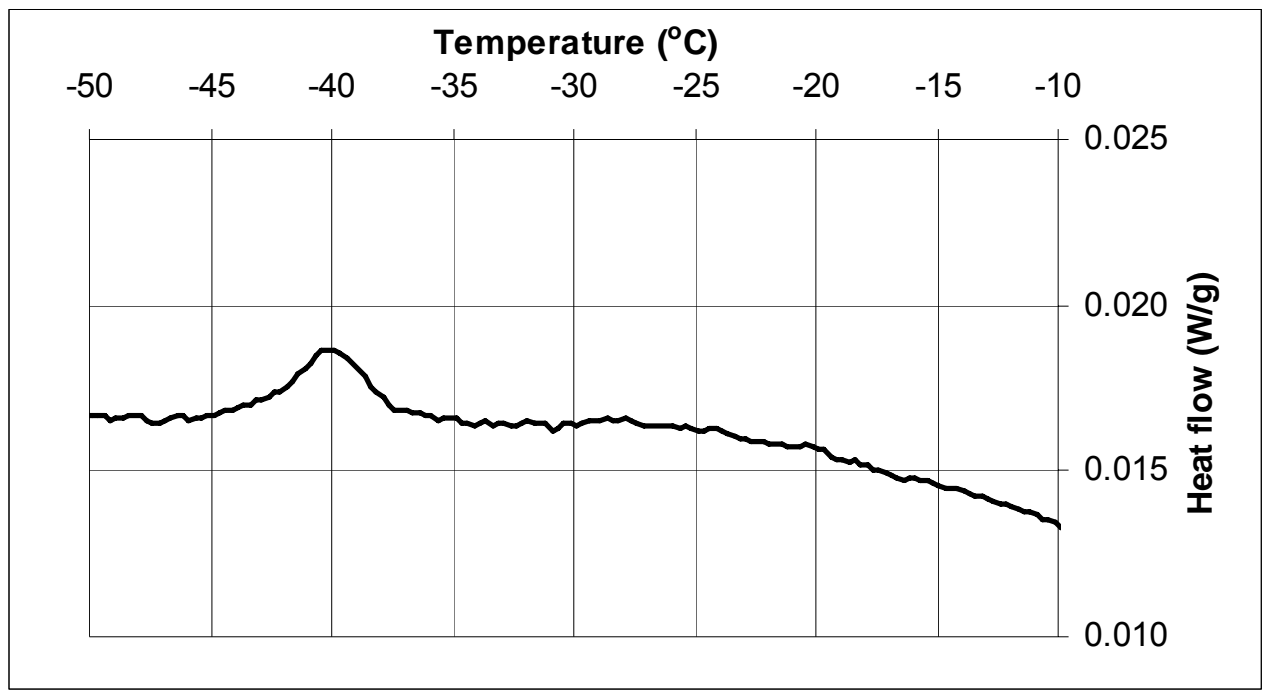

Figure $57 \mathrm{LTC}$ scan for CCRL Cement $152, w / c=0.35$, cured for $18 \mathrm{~d}$ under saturated conditions at $20{ }^{\circ} \mathrm{C}$.

Cement: CCRL Cement 152

Solution: Distilled water

$w / c: 0.35$

Temperature: $20{ }^{\circ} \mathrm{C}$

Degree of hydration: N/A
Curing: Sealed

Age when tested: $18 \mathrm{~d}$

Sample mass: $47.3 \mathrm{mg}$

Filename: cem152w35seal18d

Date tested: Jan. 7, 2005

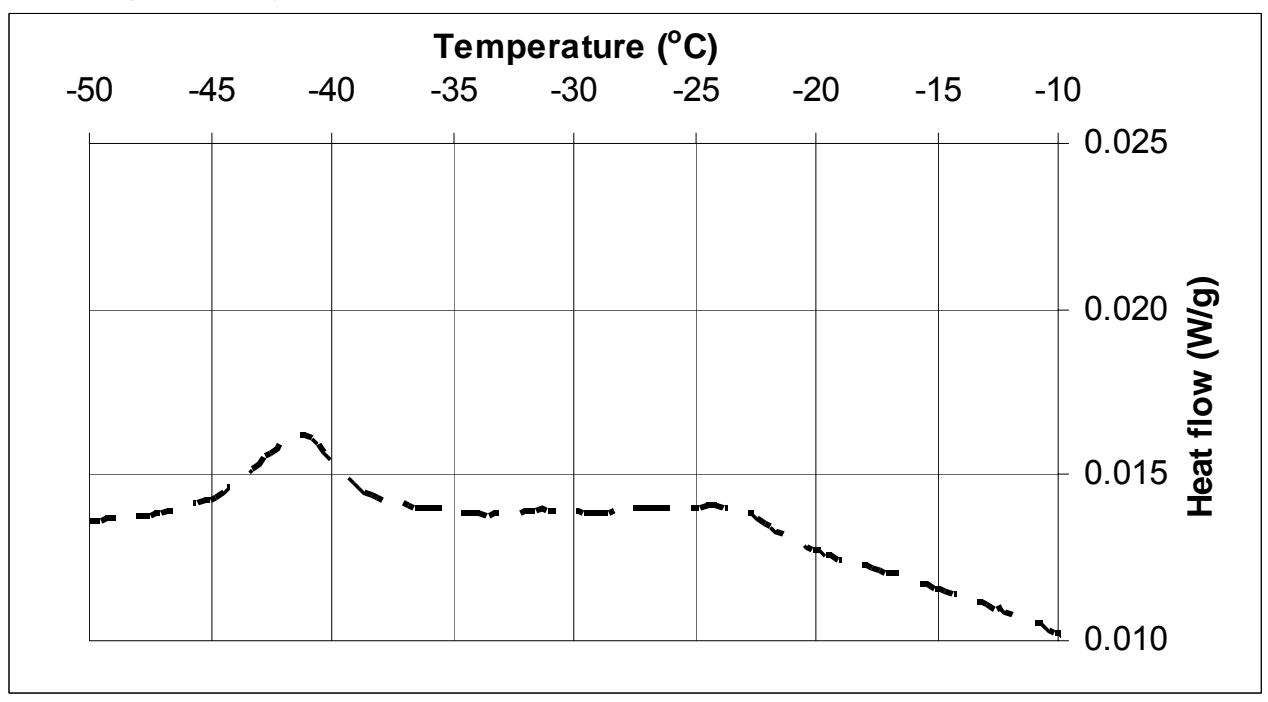

Figure $58 \mathrm{LTC}$ scan for CCRL Cement 152, w/c $=0.35$, cured for $18 \mathrm{~d}$ under sealed conditions at $20^{\circ} \mathrm{C}$. 
Cement: CCRL Cement 152

Solution: Distilled water

w/c: 0.35

Temperature: $20{ }^{\circ} \mathrm{C}$

Degree of hydration: N/A
Curing: Sealed $17 \mathrm{~d} /$ resaturated

Age when tested: $18 \mathrm{~d}$

Sample mass: $69.0 \mathrm{mg}$

Filename: cem $152 \mathrm{w} 35$ sealresat $18 \mathrm{~d}$

Date tested: Jan. 7, 2005

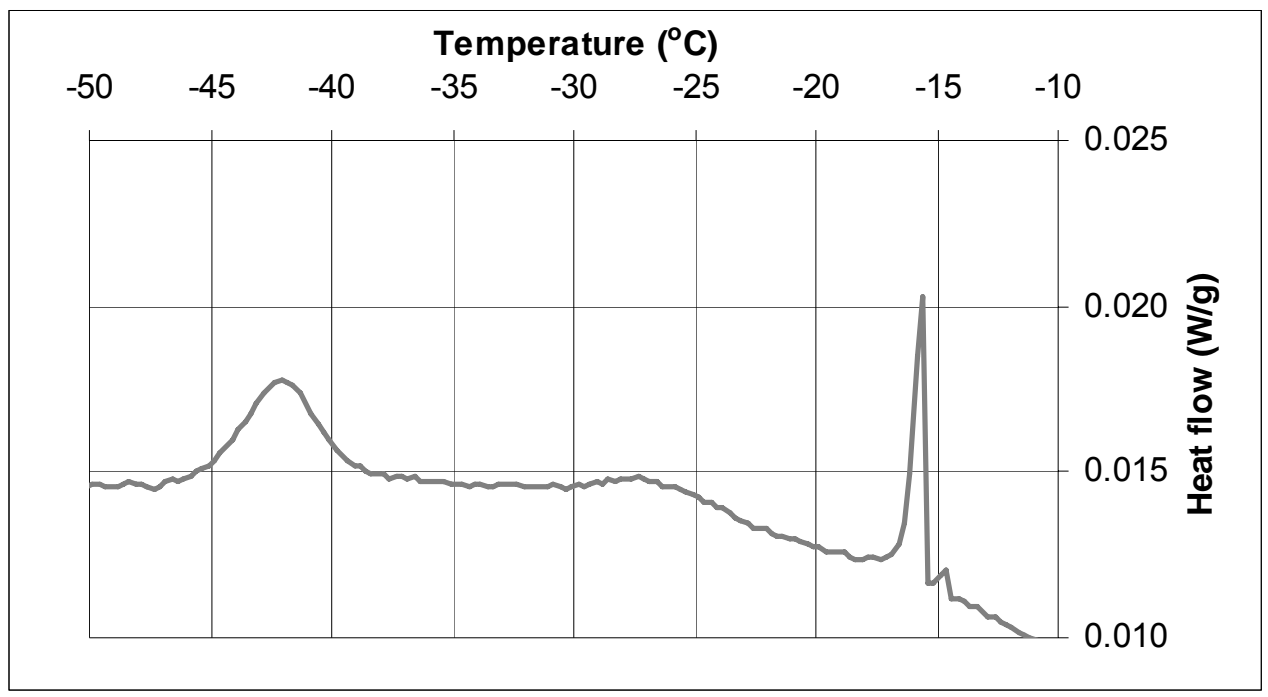

Figure 59 LTC scan for CCRL Cement $152, w / c=0.35$, cured at $20{ }^{\circ} \mathrm{C}$ for $17 \mathrm{~d}$ under sealed conditions, then resaturated for $1 \mathrm{~d}$.

Cement: CCRL Cement 152

Solution: Distilled water

w/c: 0.35

Temperature: $20{ }^{\circ} \mathrm{C}$

Degree of hydration: N/A
Curing: Sealed $14 \mathrm{~d} /$ resaturated

Age when tested: $21 \mathrm{~d}$

Sample mass: $43.6 \mathrm{mg}$

Filename: cem 152 w35sealresatc14d

Date tested: Nov. 22, 2004

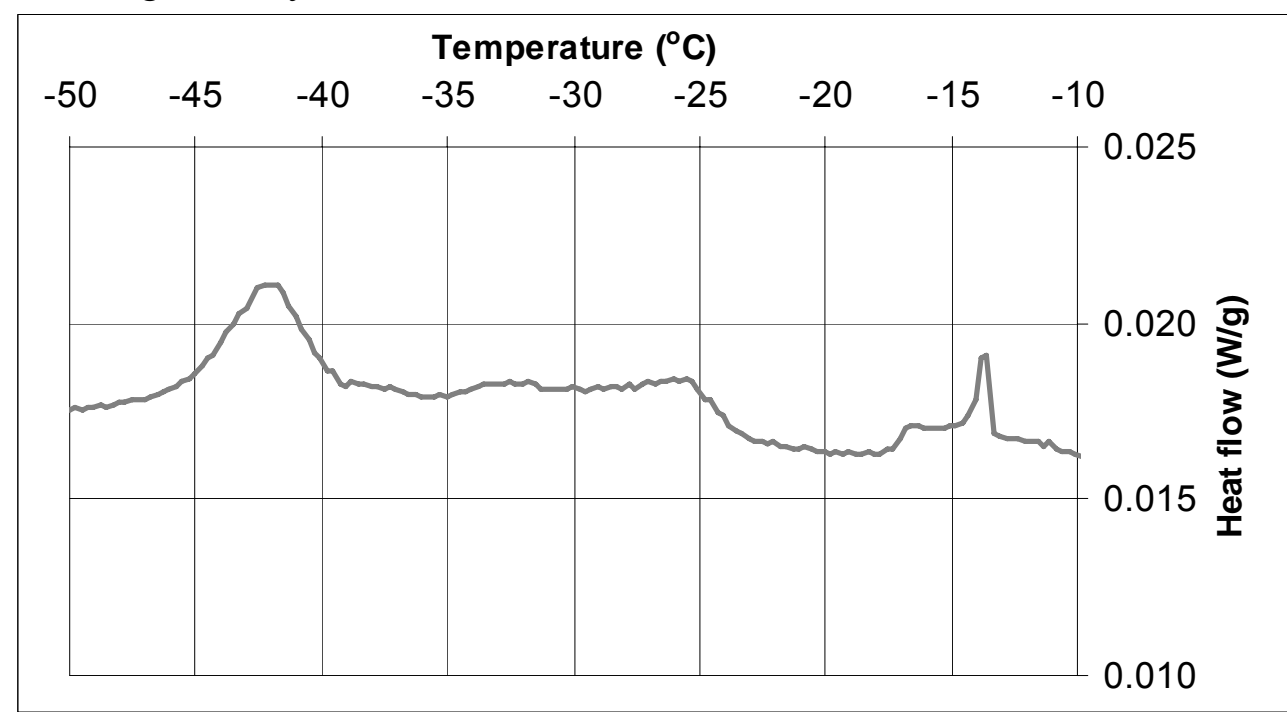

Figure $60 \mathrm{LTC}$ scan for CCRL Cement $152, w / c=0.35$, cured at $20{ }^{\circ} \mathrm{C}$ for $14 \mathrm{~d}$ under sealed conditions, then resaturated for $7 \mathrm{~d}$. 
Cement: CCRL Cement 152

Solution: Distilled water

$w / c: 0.35$

Temperature: $20{ }^{\circ} \mathrm{C}$

Degree of hydration: N/A
Curing: Sealed $14 \mathrm{~d} /$ resaturated

Age when tested: $29 \mathrm{~d}$

Sample mass: $66.5 \mathrm{mg}$

Filename: cem152w35sealresatd14d

Date tested: Nov. 30, 2004

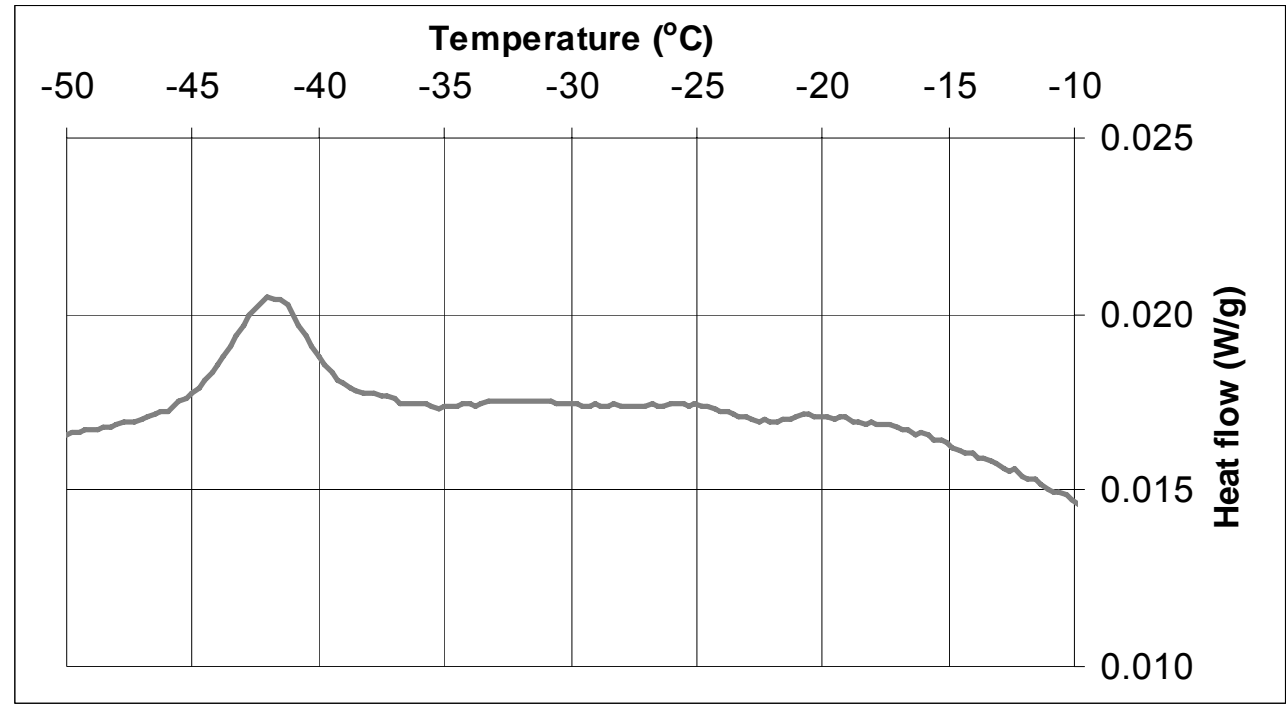

Figure $61 \mathrm{LTC}$ scan for CCRL Cement $152, w / c=0.35$, cured at $20{ }^{\circ} \mathrm{C}$ for $14 \mathrm{~d}$ under sealed conditions, then resaturated for $15 \mathrm{~d}$. 
Cement: CCRL Cement 152

Solution: Distilled water

w/c: 0.35

Temperature: $20{ }^{\circ} \mathrm{C}$

Degree of hydration: 0.759
Curing: Saturated

Age when tested: $30 \mathrm{~d}$

Sample mass: $64.3 \mathrm{mg}$

Filename: cem152w35sat30d

Date tested: Dec. 1, 2004

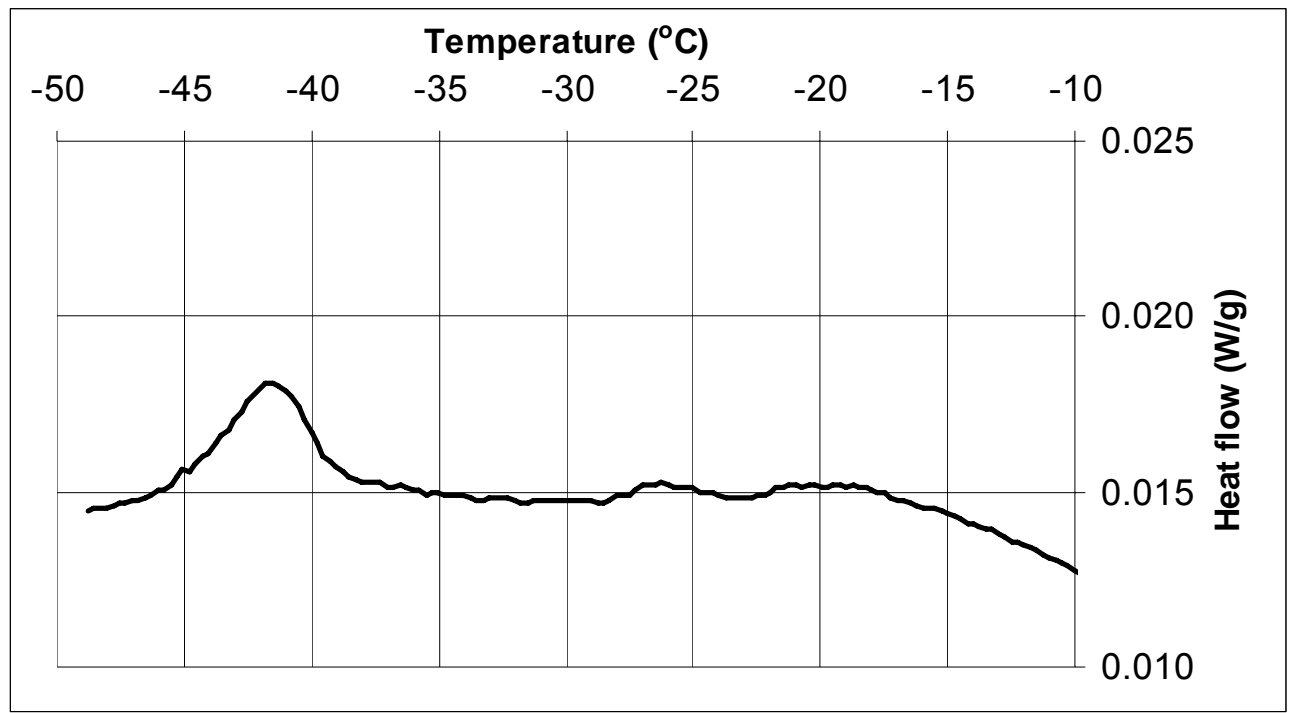

Figure $62 \mathrm{LTC}$ scan for CCRL Cement 152, w/c $=0.35$, cured for $30 \mathrm{~d}$ under saturated conditions at $20{ }^{\circ} \mathrm{C}$.

Cement: CCRL Cement 152

Solution: Distilled water

w/c: 0.35

Temperature: $20{ }^{\circ} \mathrm{C}$

Degree of hydration: 0.674
Curing: Sealed

Age when tested: $30 \mathrm{~d}$

Sample mass: $43.0 \mathrm{mg}$

Filename: cem152w35seal30d

Date tested: Dec. 1, 2004

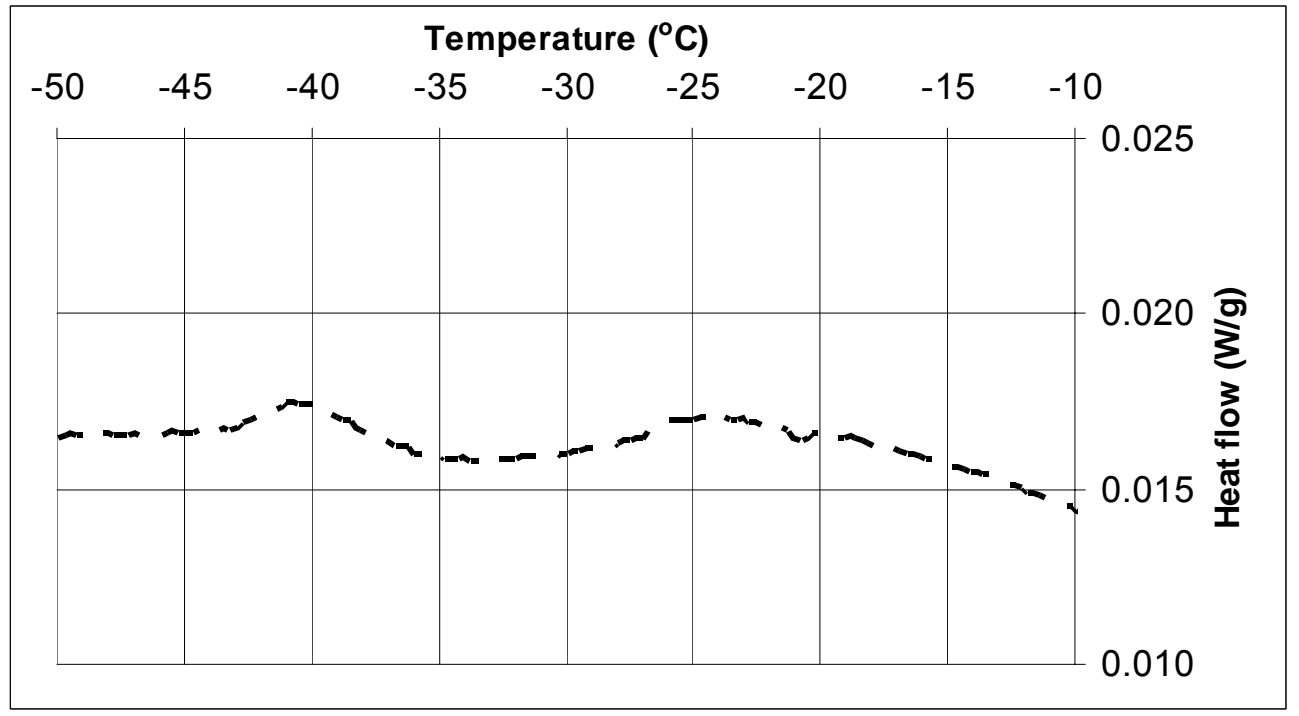

Figure $63 \mathrm{LTC}$ scan for CCRL Cement 152, $w / c=0.35$, cured for $30 \mathrm{~d}$ under sealed conditions at $20{ }^{\circ} \mathrm{C}$. 
Cement: CCRL Cement 152

Solution: Distilled water

w/c: 0.35

Temperature: $20{ }^{\circ} \mathrm{C}$

Degree of hydration: N/A
Curing: Sealed $30 \mathrm{~d} /$ resaturated

Age when tested: $32 \mathrm{~d}$

Sample mass: $59.9 \mathrm{mg}$

Filename: cem152w35sealresat30d

Date tested: Dec. 3, 2004

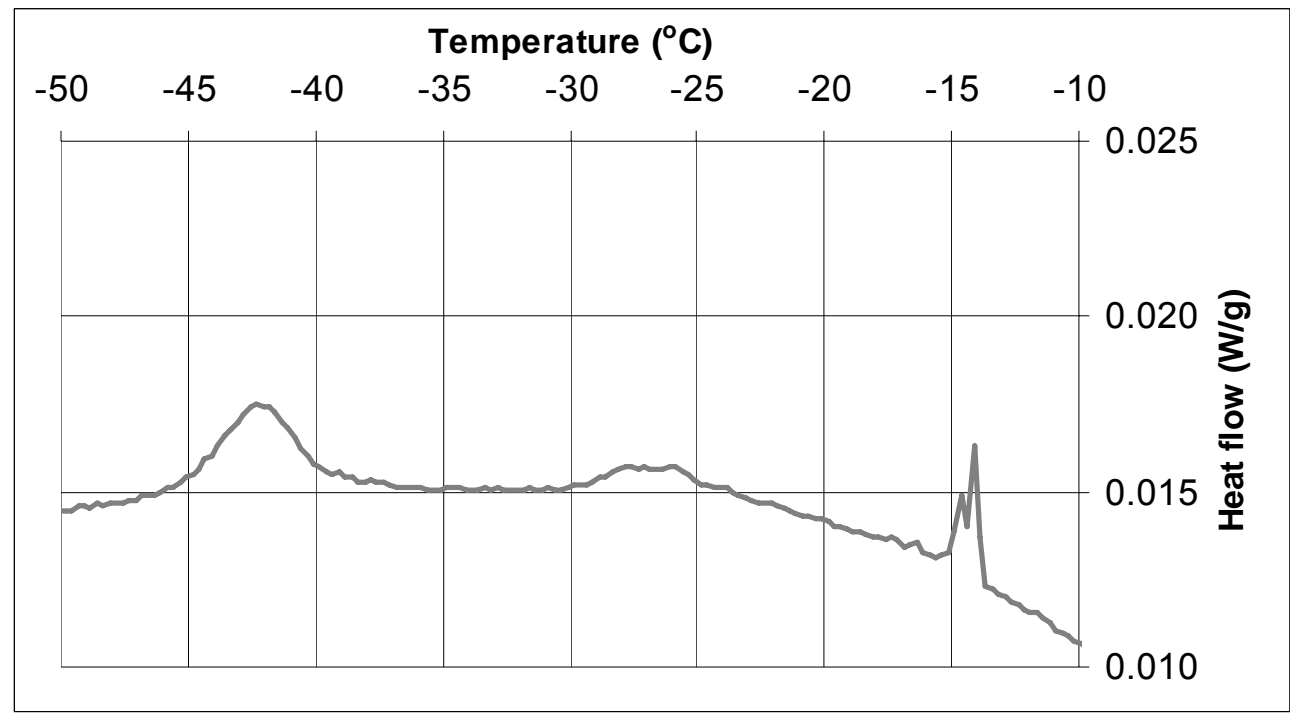

Figure $64 \mathrm{LTC}$ scan for CCRL Cement $152, w / c=0.35$, cured at $20{ }^{\circ} \mathrm{C}$ for $30 \mathrm{~d}$ under sealed conditions, then resaturated for $2 \mathrm{~d}$.

Cement: CCRL Cement 152

Solution: Distilled water

w/c: 0.35

Temperature: $20^{\circ} \mathrm{C}$

Degree of hydration: N/A
Curing: Sealed $30 \mathrm{~d} / \mathrm{resaturated}$

Age when tested: $35 \mathrm{~d}$

Sample mass: $91.4 \mathrm{mg}$

Filename: cem152w35sealresatb30d

Date tested: Dec. 6, 2004

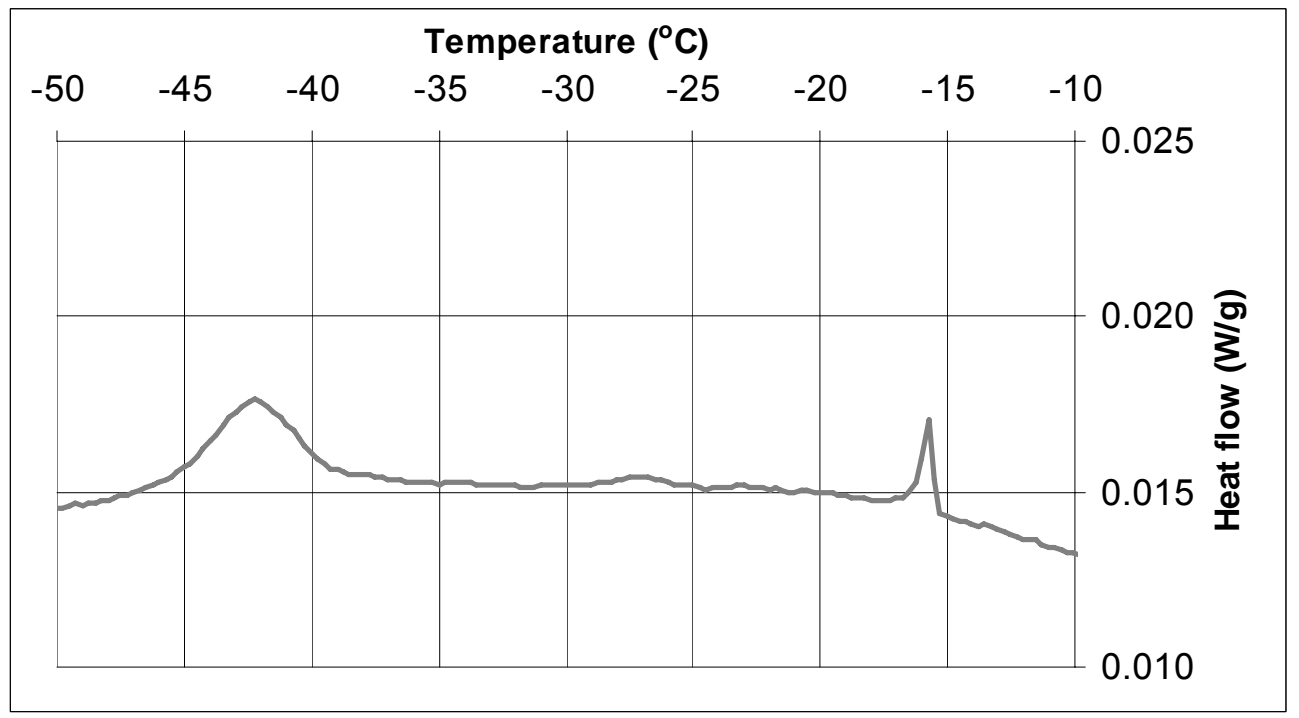

Figure $65 \mathrm{LTC}$ scan for CCRL Cement $152, w / c=0.35$, cured at $20{ }^{\circ} \mathrm{C}$ for $30 \mathrm{~d}$ under sealed conditions, then resaturated for $5 \mathrm{~d}$. 
Cement: CCRL Cement 152

Solution: Distilled water

w/c: 0.35

Temperature: $20{ }^{\circ} \mathrm{C}$

Degree of hydration: N/A
Curing: Sealed $30 \mathrm{~d} /$ resaturated

Age when tested: $42 \mathrm{~d}$

Sample mass: $34.1 \mathrm{mg}$

Filename: cem 152 w35sealresatd30d

Date tested: Dec. 13, 2004

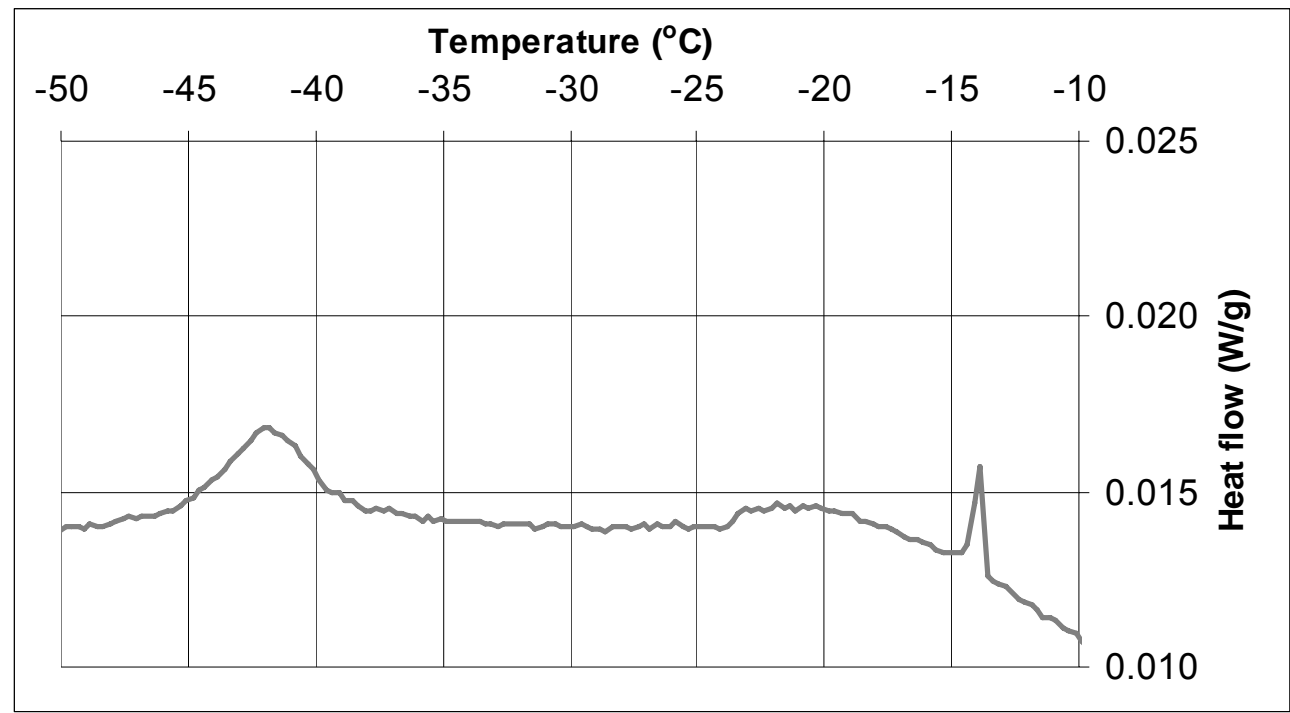

Figure $66 \mathrm{LTC}$ scan for CCRL Cement $152, w / c=0.35$, cured at $20{ }^{\circ} \mathrm{C}$ for $30 \mathrm{~d}$ under sealed conditions, then resaturated for $12 \mathrm{~d}$.

Cement: CCRL Cement 152

Solution: Distilled water

w/c: 0.35

Temperature: $20^{\circ} \mathrm{C}$

Degree of hydration: N/A
Curing: Sealed $30 \mathrm{~d} /$ resaturated

Age when tested: $49 \mathrm{~d}$

Sample mass: $74.2 \mathrm{mg}$

Filename: cem152w35sealresate30d

Date tested: Dec. 20, 2004

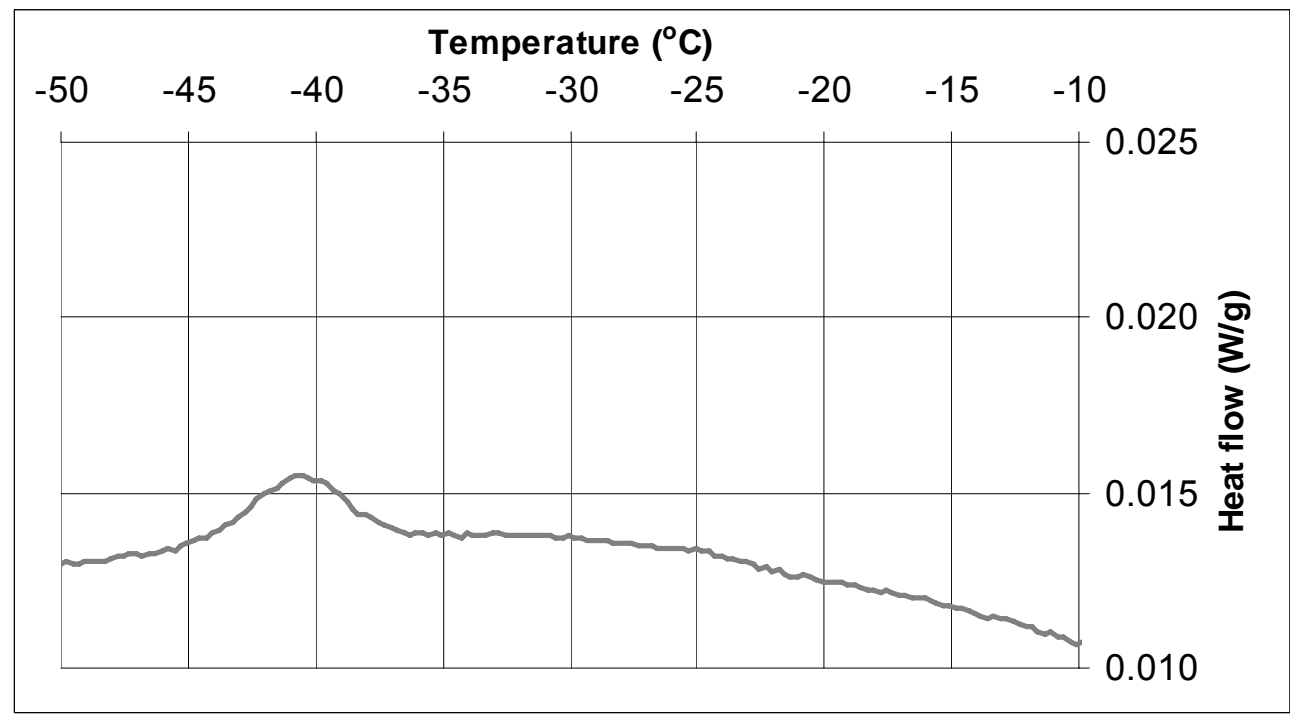

Figure $67 \mathrm{LTC}$ scan for CCRL Cement $152, w / c=0.35$, cured at $20^{\circ} \mathrm{C}$ for $30 \mathrm{~d}$ under sealed conditions, then resaturated for $19 \mathrm{~d}$. 
Cement: CCRL Cement 152

Solution: Distilled water

$w / c: 0.35$

Temperature: $20{ }^{\circ} \mathrm{C}$

Degree of hydration: N/A
Curing: Saturated

Age when tested: $50 \mathrm{~d}$

Sample mass: $72.5 \mathrm{mg}$

Filename: cem152w35sat50d

Date tested: Dec. 21, 2004

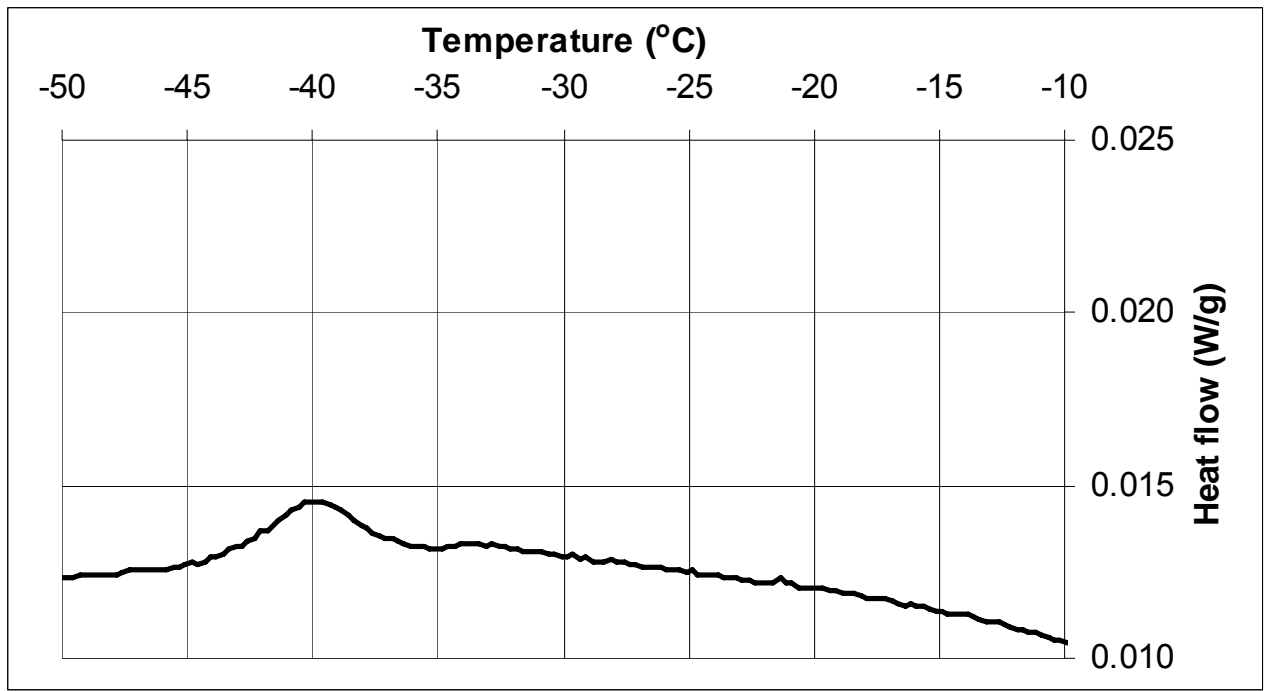

Figure $68 \mathrm{LTC}$ scan for CCRL Cement $152, w / c=0.35$, cured for $50 \mathrm{~d}$ under saturated conditions at $20{ }^{\circ} \mathrm{C}$.

Cement: CCRL Cement 152

Solution: Distilled water

$w / c: 0.35$

Temperature: $20{ }^{\circ} \mathrm{C}$

Degree of hydration: N/A
Curing: Sealed

Age when tested: $50 \mathrm{~d}$

Sample mass: $75.1 \mathrm{mg}$

Filename: cem152w35seal50d

Date tested: Dec. 21, 2004

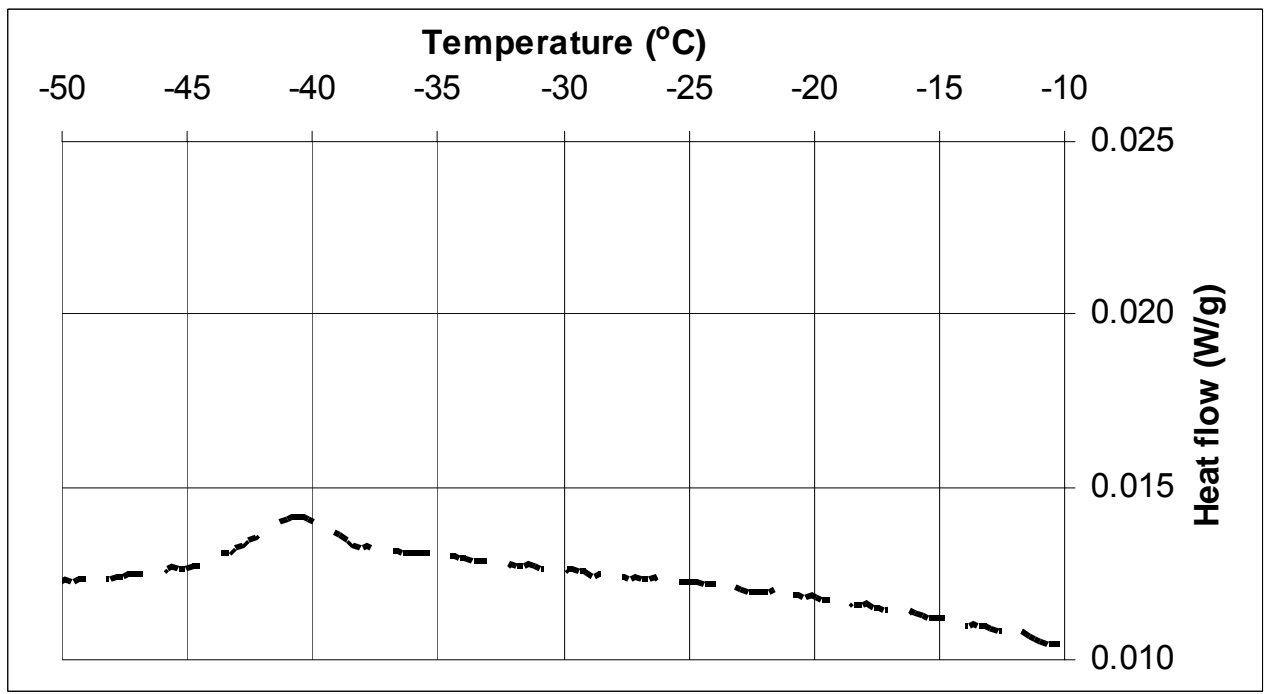

Figure $69 \mathrm{LTC}$ scan for CCRL Cement $152, w / c=0.35$, cured for $50 \mathrm{~d}$ under sealed conditions at $20{ }^{\circ} \mathrm{C}$. 
Cement: CCRL Cement 152

Solution: Distilled water

w/c: 0.35

Temperature: $20{ }^{\circ} \mathrm{C}$

Degree of hydration: N/A
Curing: Sealed $50 \mathrm{~d} /$ resaturated

Age when tested: $51 \mathrm{~d}$

Sample mass: $80.5 \mathrm{mg}$

Filename: cem152w35sealresat50d

Date tested: Dec. 22, 2004

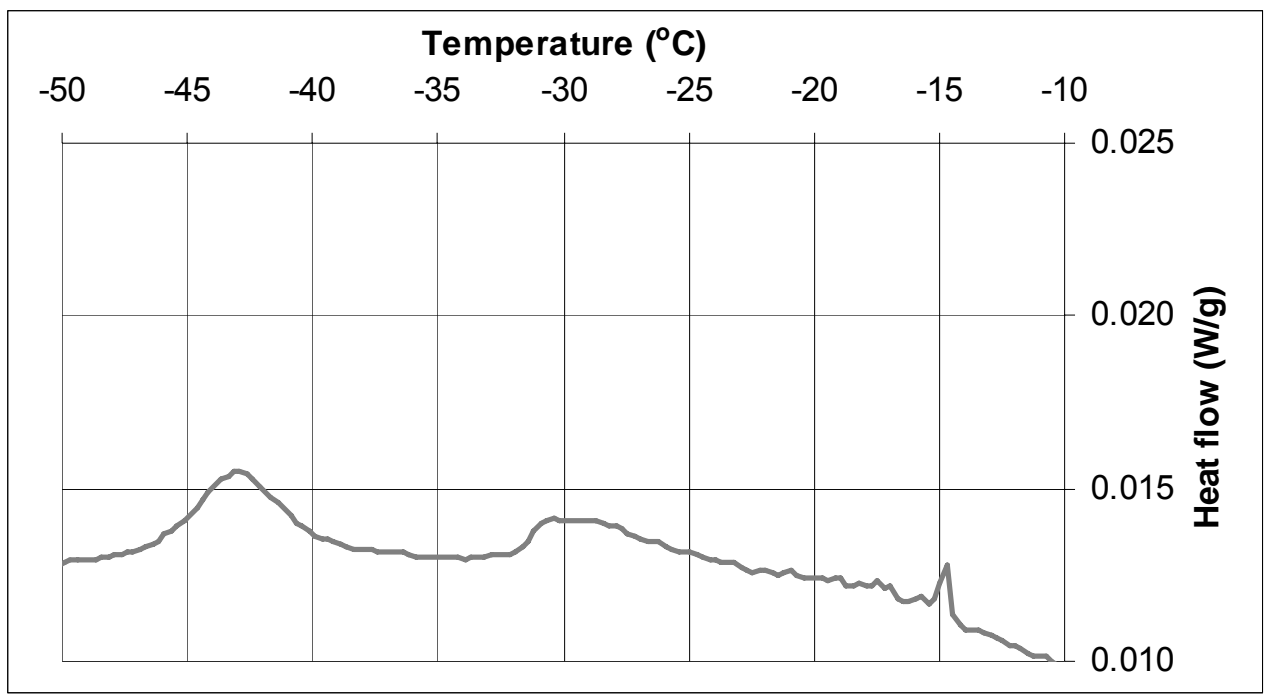

Figure $70 \mathrm{LTC}$ scan for CCRL Cement $152, w / \mathrm{c}=0.35$, cured at $20^{\circ} \mathrm{C}$ for $50 \mathrm{~d}$ under sealed conditions, then resaturated for $1 \mathrm{~d}$.

Cement: CCRL Cement 152

Solution: Distilled water

w/c: 0.35

Temperature: $20^{\circ} \mathrm{C}$

Degree of hydration: N/A
Curing: Sealed $50 \mathrm{~d} /$ resaturated

Age when tested: $52 \mathrm{~d}$

Sample mass: $50.2 \mathrm{mg}$

Filename: cem $152 \mathrm{w} 35$ sealresatb50d

Date tested: Dec. 23, 2004

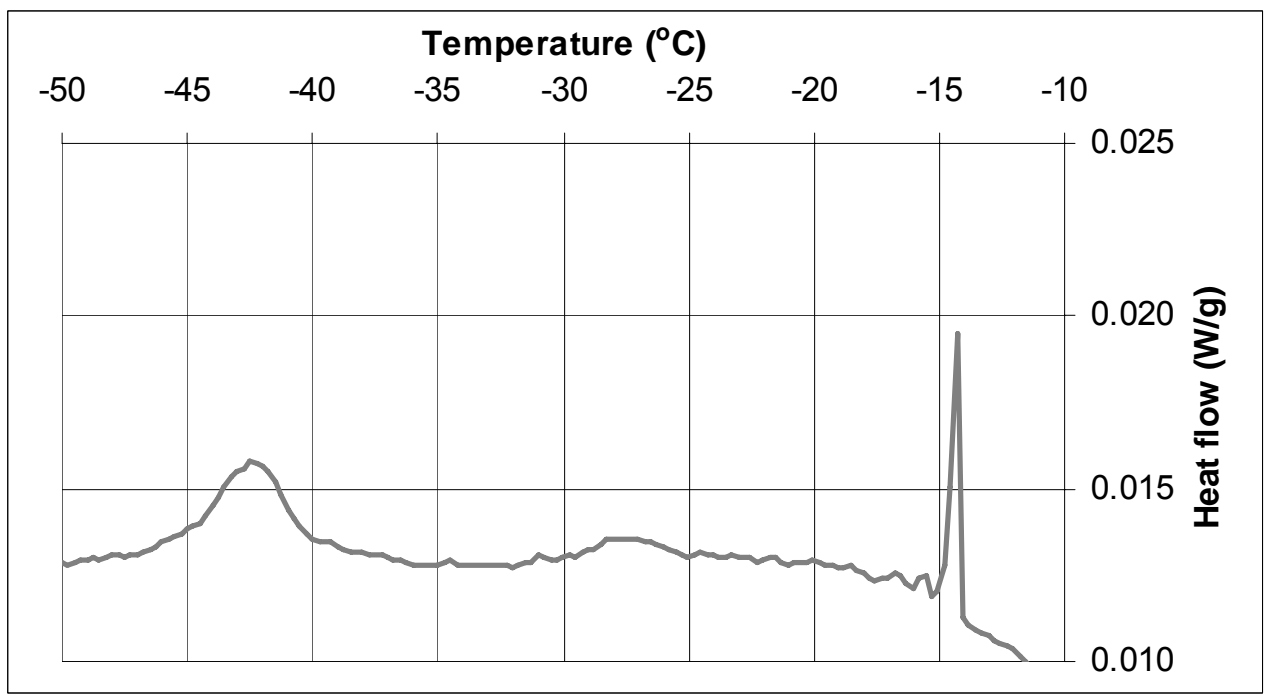

Figure $71 \mathrm{LTC}$ scan for CCRL Cement $152, w / c=0.35$, cured at $20{ }^{\circ} \mathrm{C}$ for $50 \mathrm{~d}$ under sealed conditions, then resaturated for $2 \mathrm{~d}$. 
Cement: CCRL Cement 152

Solution: Distilled water

w/c: 0.35

Temperature: $20{ }^{\circ} \mathrm{C}$

Degree of hydration: N/A
Curing: Sealed $50 \mathrm{~d} /$ resaturated

Age when tested: $63 \mathrm{~d}$

Sample mass: $40.3 \mathrm{mg}$

Filename: cem 152 w35sealresatc50d

Date tested: Jan. 3, 2005

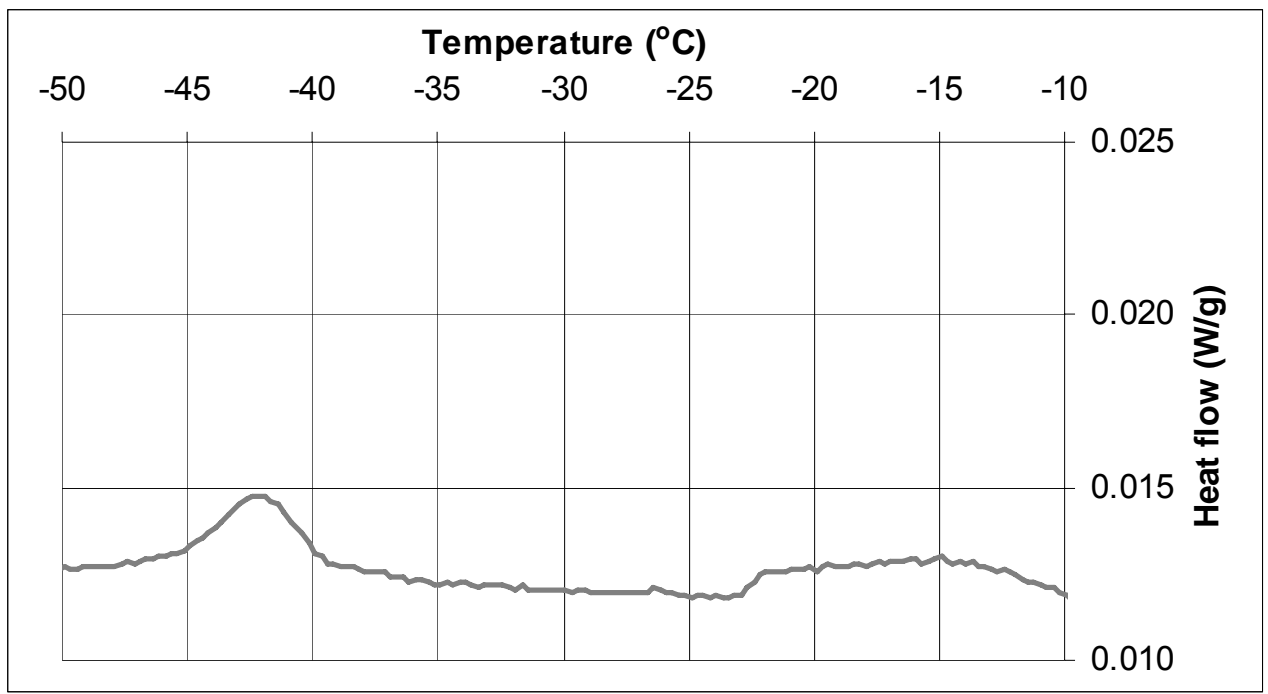

Figure $72 \mathrm{LTC}$ scan for CCRL Cement $152, w / c=0.35$, cured at $20{ }^{\circ} \mathrm{C}$ for $50 \mathrm{~d}$ under sealed conditions, then resaturated for $13 \mathrm{~d}$.

Cement: CCRL Cement 152

Solution: Distilled water

w/c: 0.35

Temperature: $20^{\circ} \mathrm{C}$

Degree of hydration: N/A
Curing: Sealed $88 \mathrm{~d} /$ resaturated

Age when tested: $91 \mathrm{~d}$

Sample mass: $52.2 \mathrm{mg}$

Filename: cem152w35sealresat91d

Date tested: Jan. 31, 2005

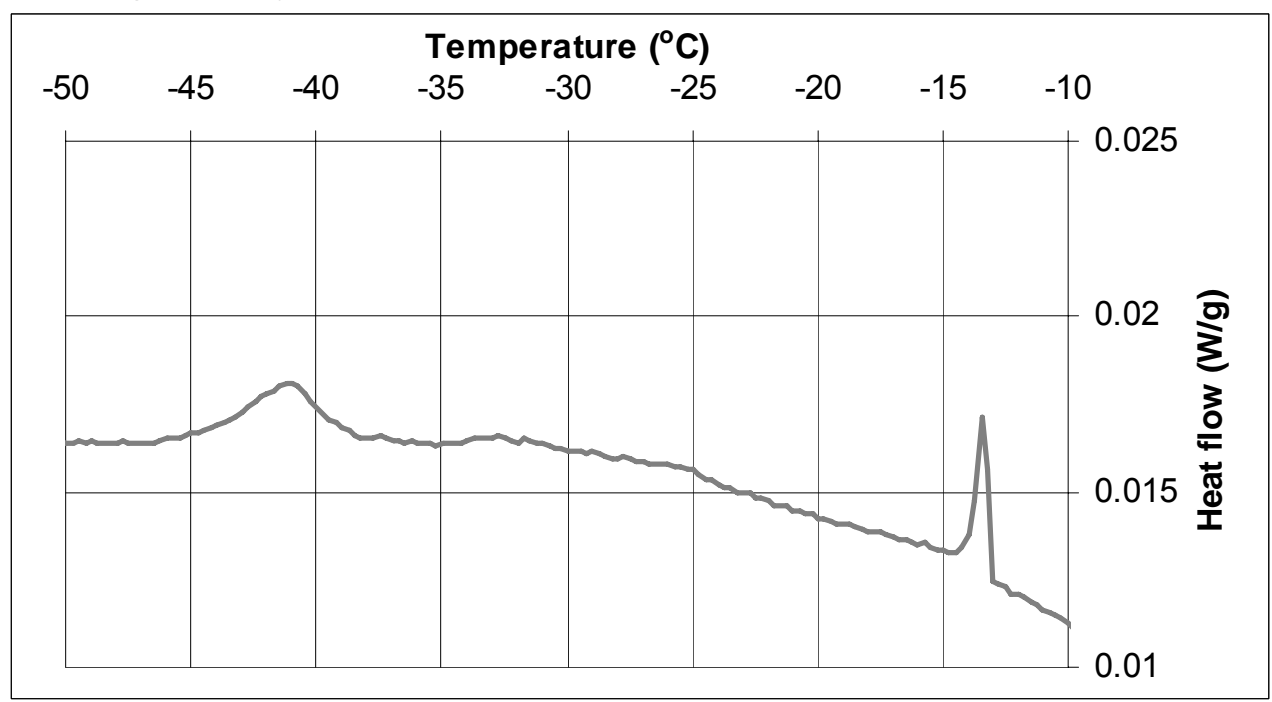

Figure $73 \mathrm{LTC}$ scan for CCRL Cement $152, w / c=0.35$, cured at $20{ }^{\circ} \mathrm{C}$ for $88 \mathrm{~d}$ under sealed conditions, then resaturated for $3 \mathrm{~d}$. 
Cement: CCRL Cement 152

Solution: Distilled water

$w / c: 0.35$

Temperature: $20{ }^{\circ} \mathrm{C}$

Degree of hydration: N/A
Curing: Saturated

Age when tested: $91 \mathrm{~d}$

Sample mass: $68.7 \mathrm{mg}$

Filename: cem152w35sat91d

Date tested: Jan. 31, 2005

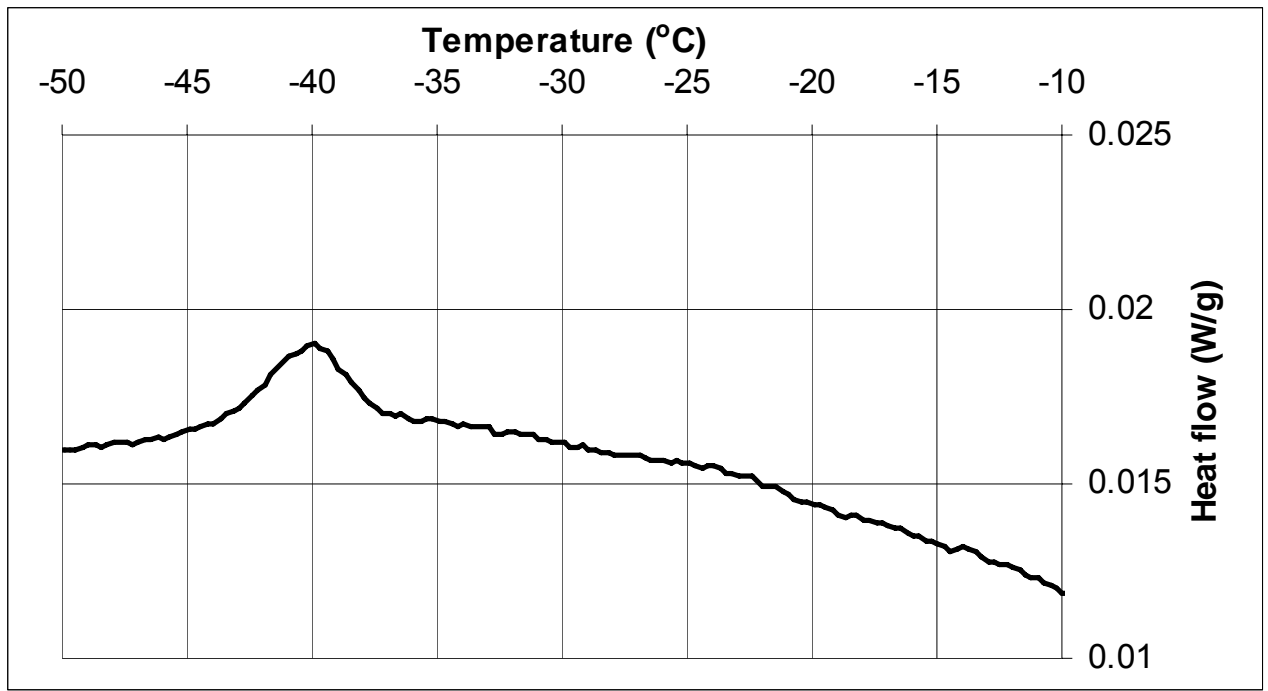

Figure $74 \mathrm{LTC}$ scan for CCRL Cement $152, w / c=0.35$, cured for $90 \mathrm{~d}$ under saturated conditions at $20{ }^{\circ} \mathrm{C}$.

Cement: CCRL Cement 152

Solution: Distilled water

$w / c: 0.35$

Temperature: $20{ }^{\circ} \mathrm{C}$

Degree of hydration: N/A
Curing: Sealed

Age when tested: $91 \mathrm{~d}$

Sample mass: $91.3 \mathrm{mg}$

Filename: cem152w35sealb91d

Date tested: Jan. 31, 2005

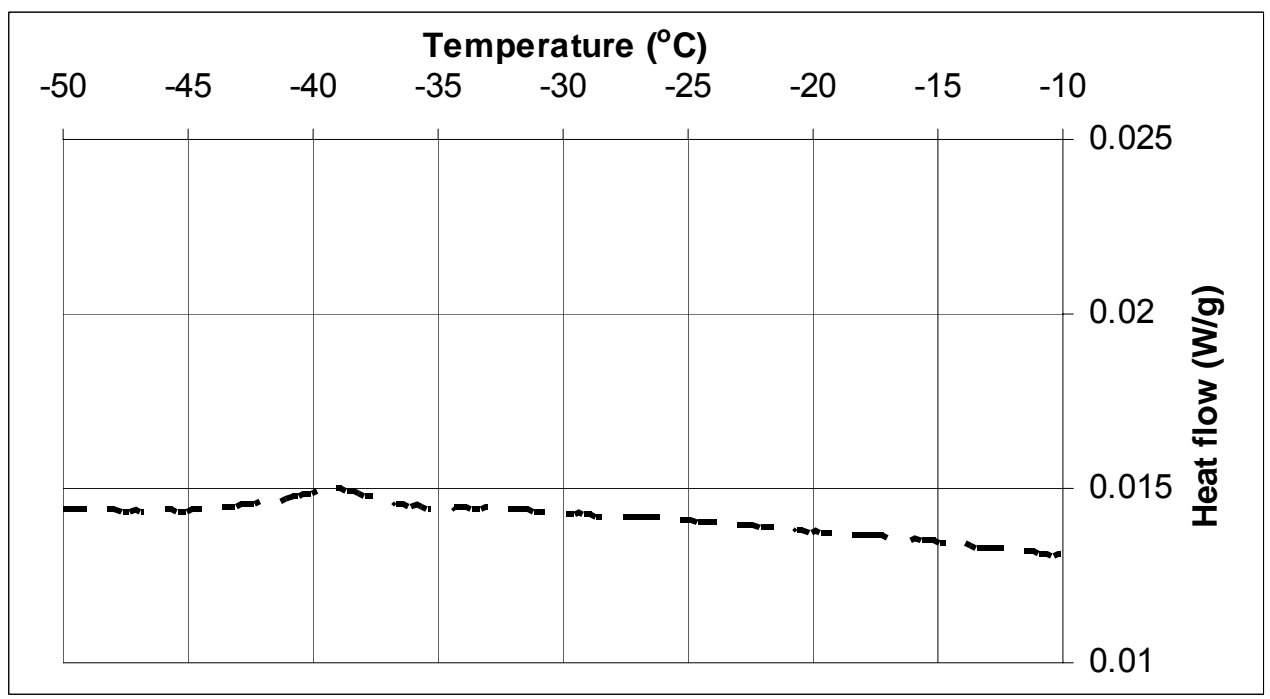

Figure 75 LTC scan for CCRL Cement 152, $w / c=0.35$, cured for $90 \mathrm{~d}$ under sealed conditions at $20{ }^{\circ} \mathrm{C}$. 
Cement: CCRL Cement 152

Solution: Distilled water

w/c: 0.35

Temperature: $2{ }^{\circ} \mathrm{C}$

Degree of hydration: 0.844
Curing: Saturated

Age when tested: $182 \mathrm{~d}$

Sample mass: $70.8 \mathrm{mg}$

Filename: cem152182dsat

Date tested: Oct. 25, 2004

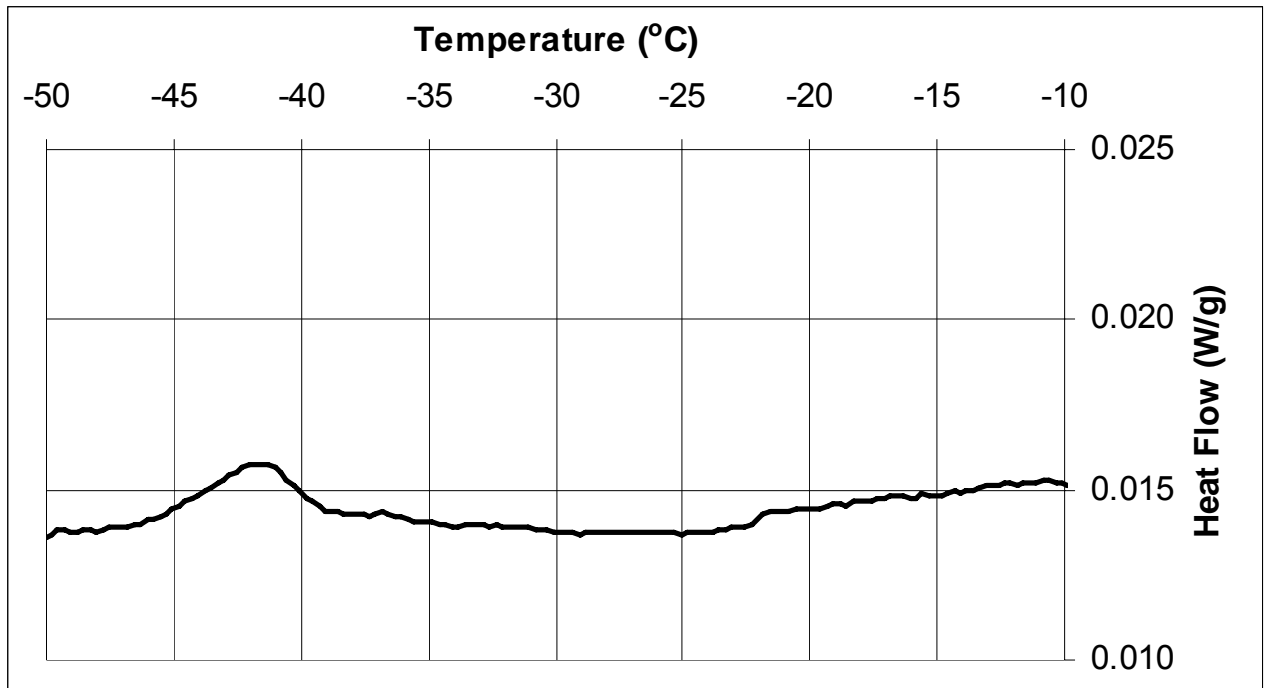

Figure 76 LTC scan for CCRL Cement $152, w / c=0.35$, cured for $182 \mathrm{~d}$ at $20{ }^{\circ} \mathrm{C}$ under saturated conditions.

Cement: CCRL Cement 152

Solution: Distilled water

w/c: 0.35

Temperature: $20^{\circ} \mathrm{C}$

Degree of hydration: 0.757
Curing: Sealed

Age when tested: $182 \mathrm{~d}$

Sample mass: $53.4 \mathrm{mg}$

Filename: cem152182dseal

Date tested: Oct. 25, 2004

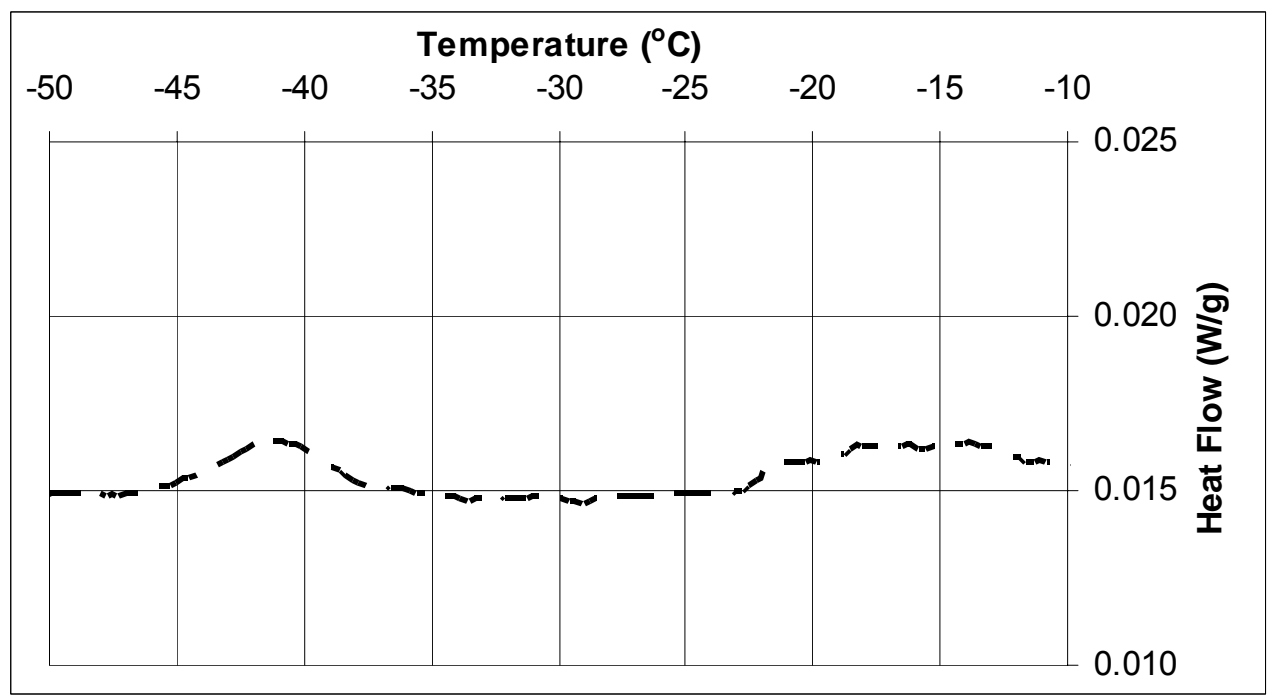

Figure 77 LTC scan for CCRL Cement $152, w / C=0.35$, cured for $182 \mathrm{~d}$ at $20{ }^{\circ} \mathrm{C}$ under sealed conditions. 
Cement: CCRL Cement 152

Solution: Distilled water

w/c: 0.35

Temperature: $20{ }^{\circ} \mathrm{C}$

Degree of hydration: 0.836
Curing: Sealed $7 \mathrm{~d} /$ resaturated

Age when tested: $182 \mathrm{~d}$

Sample mass: $58.6 \mathrm{mg}$

Filename: cem152182dsealsat

Date tested: Oct. 25, 2004

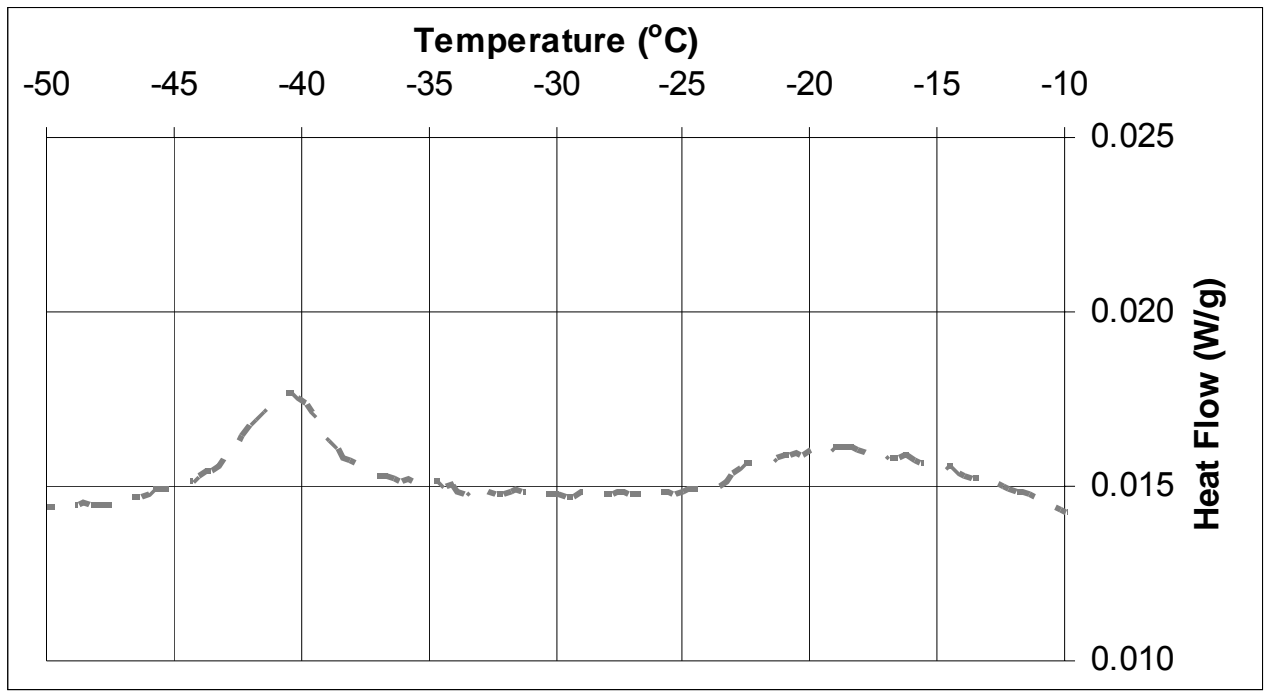

Figure $78 \mathrm{LTC}$ scan for CCRL Cement $152, w / C=0.35$, cured at $20^{\circ} \mathrm{C}$ for $7 \mathrm{~d}$ under sealed conditions, then resaturated for $175 \mathrm{~d}$.

Cement: CCRL Cement 152

Solution: Distilled water

w/c: 0.35

Temperature: $20^{\circ} \mathrm{C}$

Degree of hydration: N/A
Curing: Sealed $182 \mathrm{~d} /$ resaturated

Age when tested: $183 \mathrm{~d}$

Sample mass: $54.3 \mathrm{mg}$

Filename: cem152182dsealresat

Date tested: Oct. 26, 2004

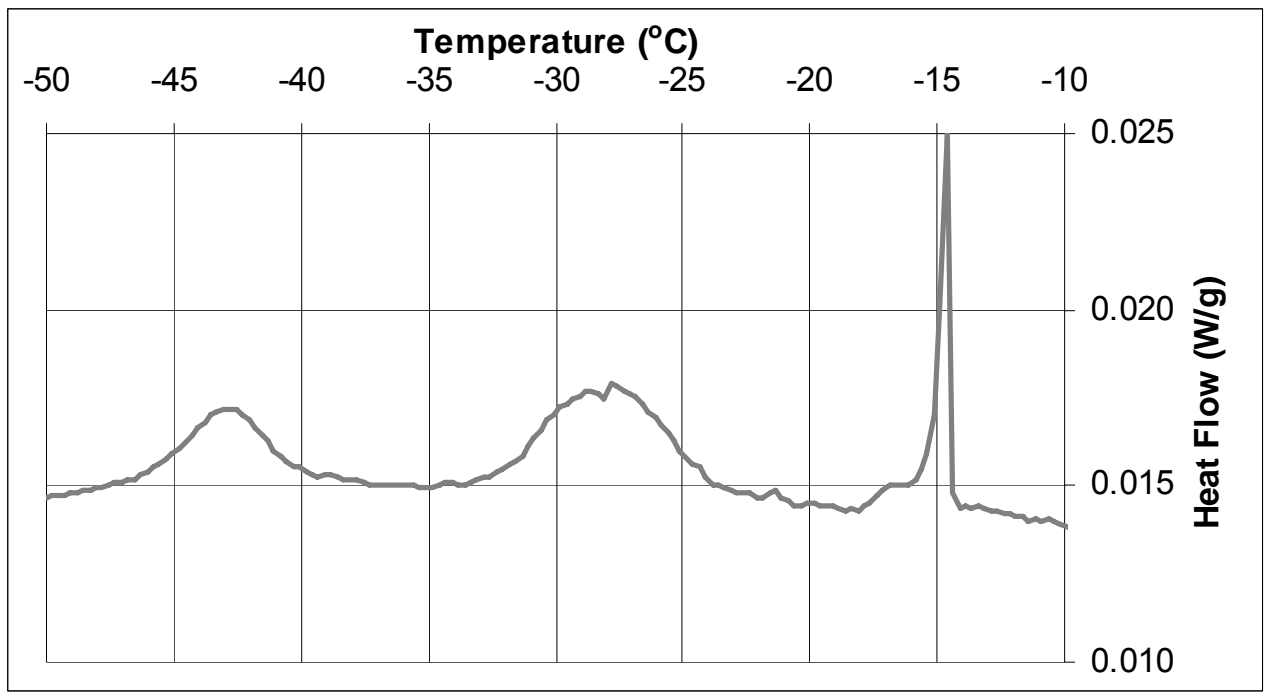

Figure $79 \mathrm{LTC}$ scan for CCRL Cement $152, w / c=0.35$, cured at $20{ }^{\circ} \mathrm{C}$ for $182 \mathrm{~d}$ under sealed conditions, then resaturated for $1 \mathrm{~d}$. 
Cement: CCRL Cement 152

Solution: Distilled water

$w / c: 0.35$

Temperature: $20{ }^{\circ} \mathrm{C}$

Degree of hydration: N/A
Curing: Sealed

Age when tested: $204 \mathrm{~d}$

Sample mass: $90.5 \mathrm{mg}$

Filename: c152w35seal204d

Date tested: Nov. 16, 2004

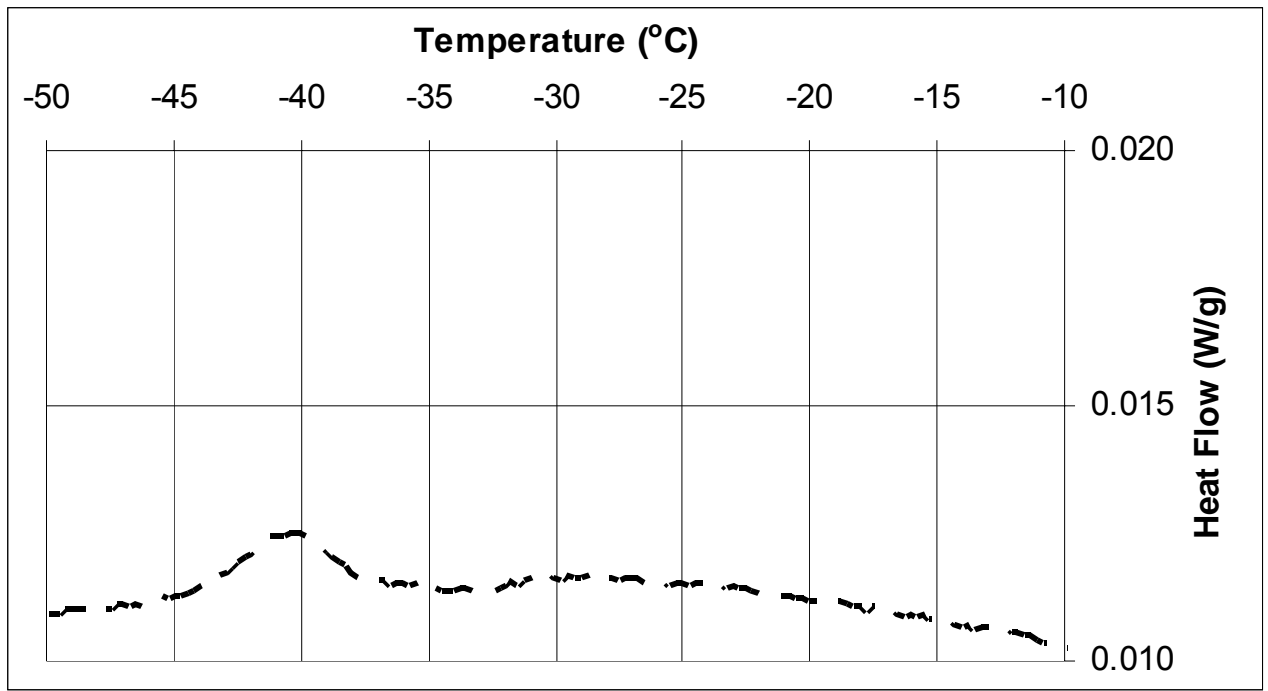

Figure $80 \mathrm{LTC}$ scan for CCRL Cement $152, w / c=0.35$, cured for $204 \mathrm{~d}$ at $20{ }^{\circ} \mathrm{C}$ under sealed conditions.

Cement: CCRL Cement 152

Solution: Distilled water

$w / c: 0.35$

Temperature: $20{ }^{\circ} \mathrm{C}$

Degree of hydration: N/A
Curing: Sealed $203 \mathrm{~d} /$ resaturated

Age when tested: $204 \mathrm{~d}$

Sample mass: $51.1 \mathrm{mg}$

Filename: c152w35sealresat204d

Date tested: Nov. 16, 2004

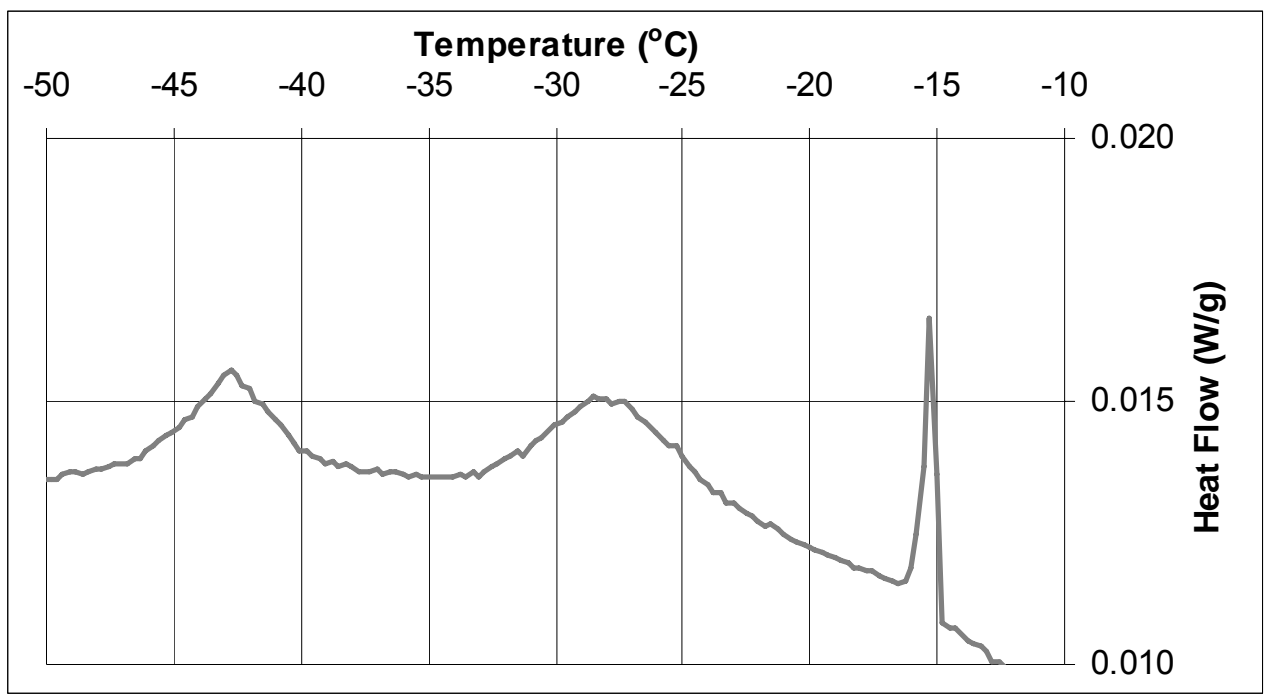

Figure $81 \mathrm{LTC}$ scan for CCRL Cement $152, w / C=0.35$, cured at $20{ }^{\circ} \mathrm{C}$ for $203 \mathrm{~d}$ under sealed conditions, then resaturated for $1 \mathrm{~d}$. 
Cement: CCRL Cement 152

Solution: Distilled water

w/c: 0.35

Temperature: $20{ }^{\circ} \mathrm{C}$

Degree of hydration: N/A
Curing: Sealed $203 \mathrm{~d} /$ resaturated

Age when tested: $207 \mathrm{~d}$

Sample mass: $51.0 \mathrm{mg}$

Filename: c152w35sealresatb204d

Date tested: Nov. 19, 2004

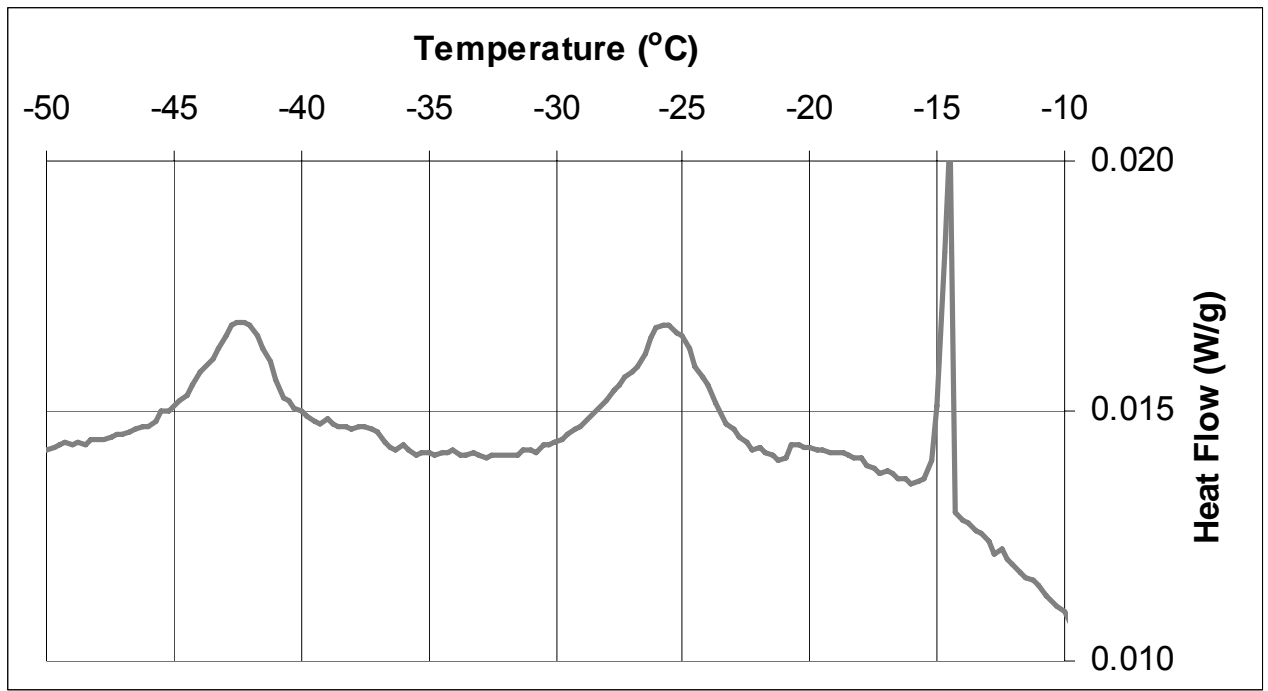

Figure $82 \mathrm{LTC}$ scan for CCRL Cement $152, w / c=0.35$, cured at $20{ }^{\circ} \mathrm{C}$ for $203 \mathrm{~d}$ under sealed conditions, then resaturated for $4 \mathrm{~d}$.

Cement: CCRL Cement 152

Solution: Distilled water

w/c: 0.35

Temperature: $20^{\circ} \mathrm{C}$

Degree of hydration: 0.799
Curing: Sealed $203 \mathrm{~d} /$ resaturated

Age when tested: $224 \mathrm{~d}$

Sample mass: $66.0 \mathrm{mg}$

Filename: c152w35sealresatc204d

Date tested: Dec. 6, 2004

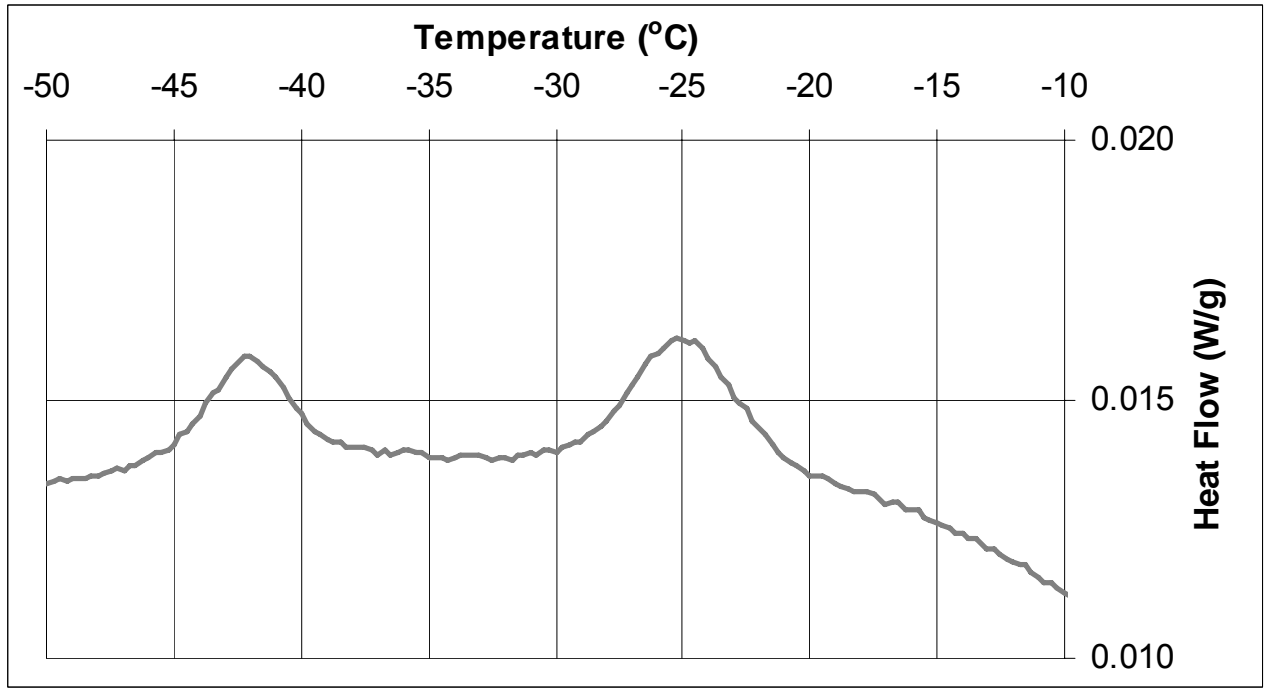

Figure $83 \mathrm{LTC}$ scan for CCRL Cement $152, w / c=0.35$, cured at $20{ }^{\circ} \mathrm{C}$ for $203 \mathrm{~d}$ under sealed conditions, then resaturated for $21 \mathrm{~d}$. 
Cement: CCRL Cement 152

Solution: Distilled water

w/c: 0.35

Temperature: $20{ }^{\circ} \mathrm{C}$

Degree of hydration: N/A
Curing: Sealed $203 \mathrm{~d} /$ resaturated

Age when tested: $238 \mathrm{~d}$

Sample mass: $75.3 \mathrm{mg}$

Filename: c152w35seal204resat2384d

Date tested: Dec. 20, 2004

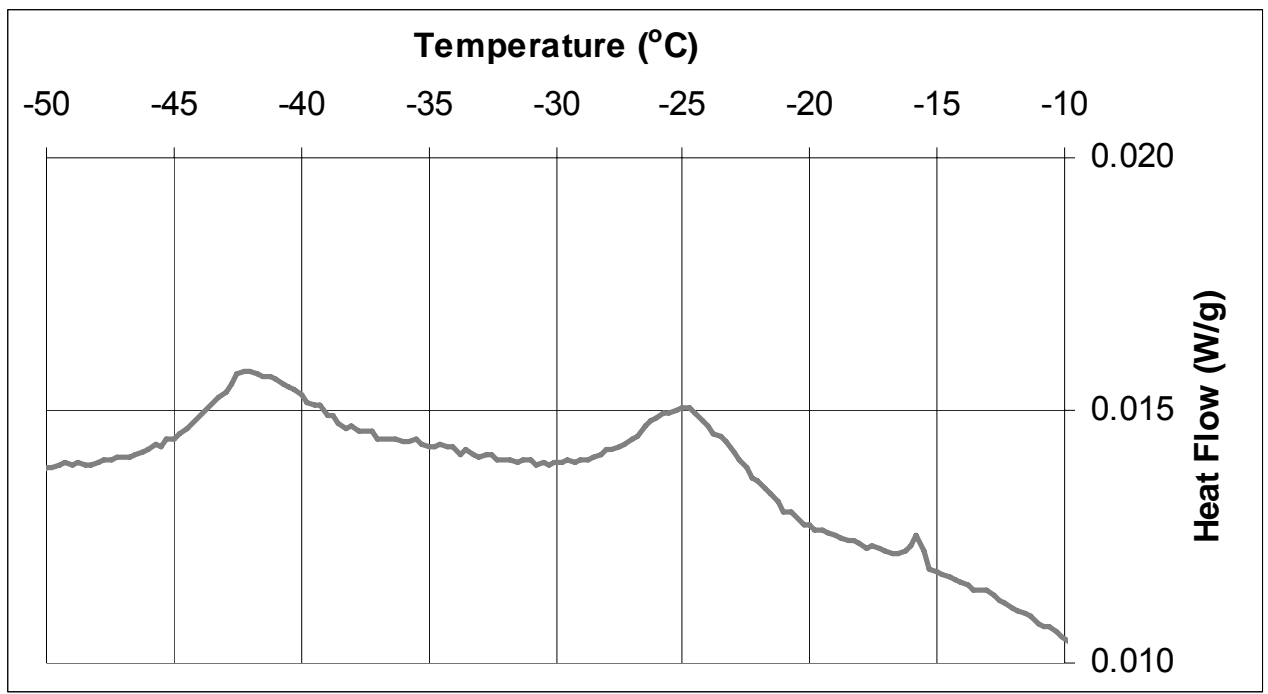

Figure $84 \mathrm{LTC}$ scan for CCRL Cement $152, w / C=0.35$, cured at $20{ }^{\circ} \mathrm{C}$ for $203 \mathrm{~d}$ under sealed conditions, then resaturated for $35 \mathrm{~d}$. 
Cement: CCRL Cement 152

Solution: Distilled water

$w / c: 0.35$

Temperature: $20{ }^{\circ} \mathrm{C}$

Degree of hydration: N/A
Curing: Saturated

Age when tested: $228 \mathrm{~d}$

Sample mass: $52.9 \mathrm{mg}$

Filename: c152w35sat228d

Date tested: Dec. 10, 2004

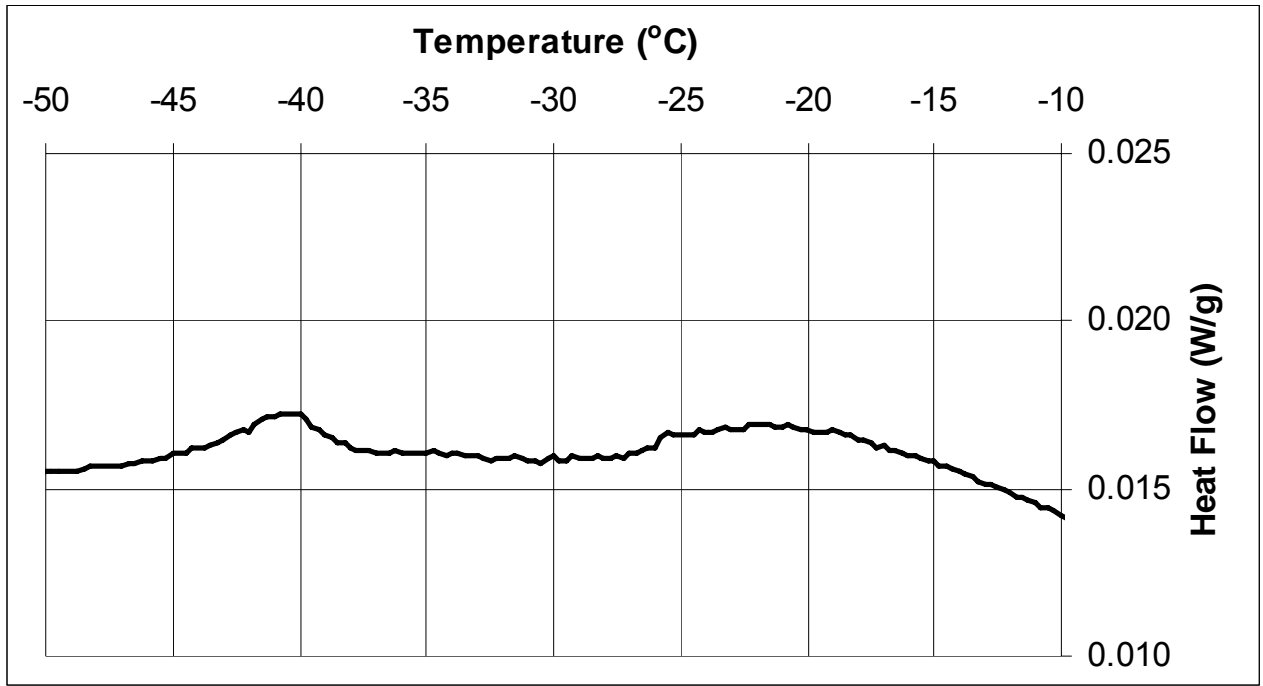

Figure $85 \mathrm{LTC}$ scan for CCRL Cement $152, w / c=0.35$, cured for $228 \mathrm{~d}$ at $20{ }^{\circ} \mathrm{C}$ under saturated conditions.

Cement: CCRL Cement 152

Solution: Distilled water

$w / c: 0.35$

Temperature: $20{ }^{\circ} \mathrm{C}$

Degree of hydration: N/A
Curing: Sealed $7 \mathrm{~d} /$ resaturated

Age when tested: $228 \mathrm{~d}$

Sample mass: $68.1 \mathrm{mg}$

Filename: c152w35sealsat228d

Date tested: Dec. 10, 2004

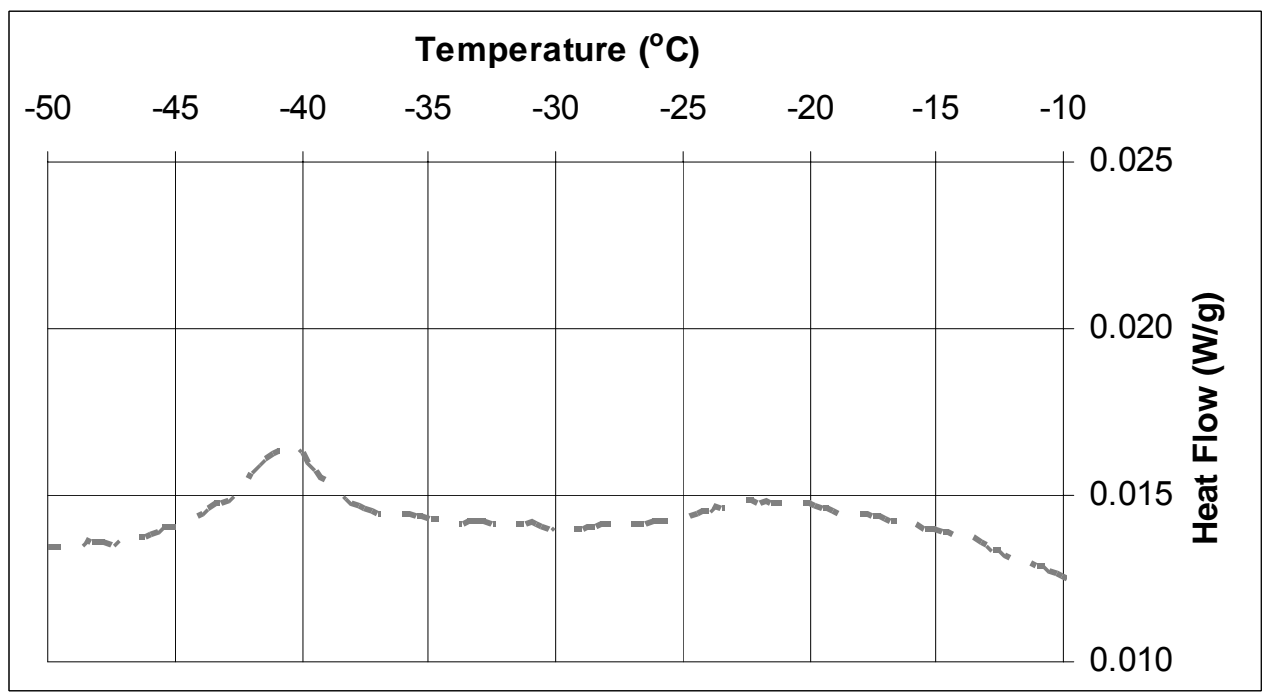

Figure $86 \mathrm{LTC}$ scan for CCRL Cement $152, w / C=0.35$, cured for $7 \mathrm{~d}$ at $20{ }^{\circ} \mathrm{C}$ under sealed conditions, then resaturated for $221 \mathrm{~d}$. 
Cement: CCRL Cement 152

Solution: Distilled water

$w / c: 0.435$

Temperature: $20{ }^{\circ} \mathrm{C}$

Degree of hydration: N/A
Curing: Saturated

Age when tested: $214 \mathrm{~d}$

Sample mass: $48.7 \mathrm{mg}$

Filename: c152w45sat214d

Date tested: Oct. 29, 2004

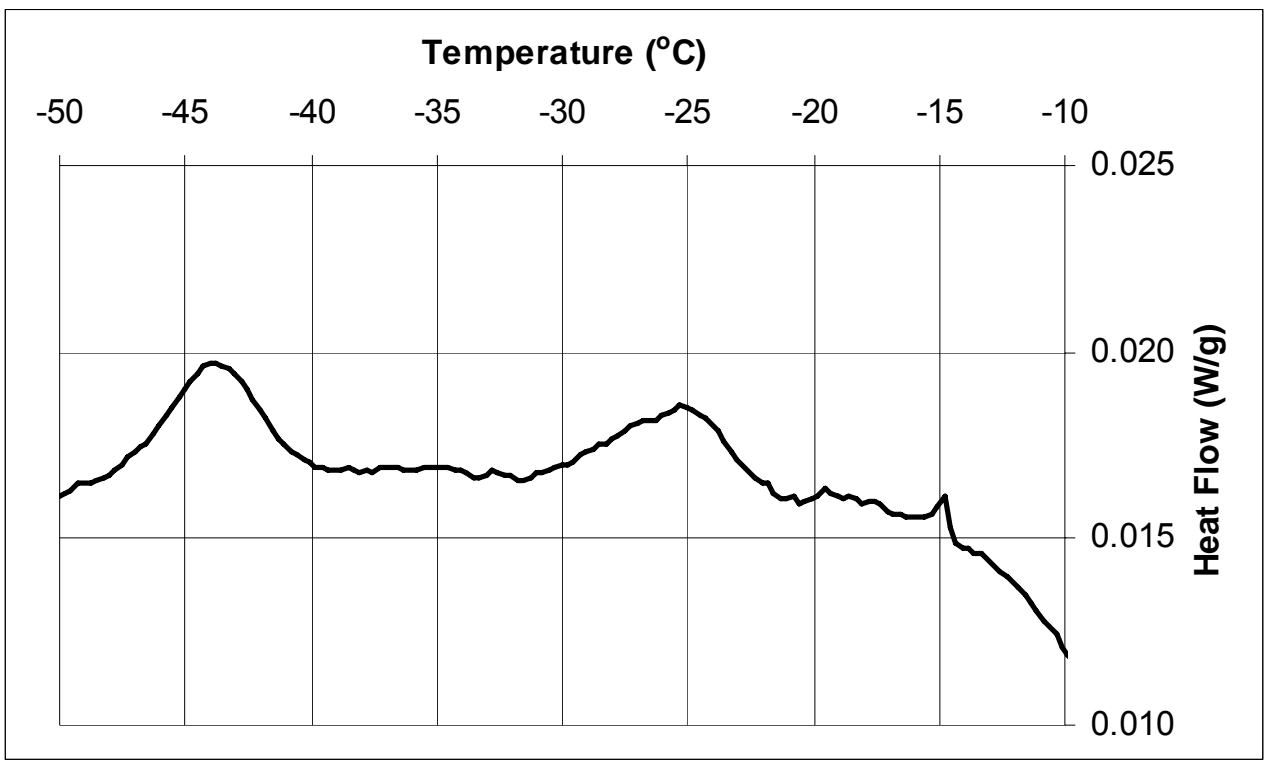

Figure 87 LTC scan for CCRL Cement $152, w / c=0.435$, cured for $214 \mathrm{~d}$ at $20{ }^{\circ} \mathrm{C}$ under saturated conditions.

Cement: CCRL Cement 152

Solution: Distilled water

$w / c: 0.435$

Temperature: $20{ }^{\circ} \mathrm{C}$

Degree of hydration: N/A
Curing: Sealed

Age when tested: $214 \mathrm{~d}$

Sample mass: $55.2 \mathrm{mg}$

Filename: c152w45seal214d

Date tested: Oct. 29, 2004

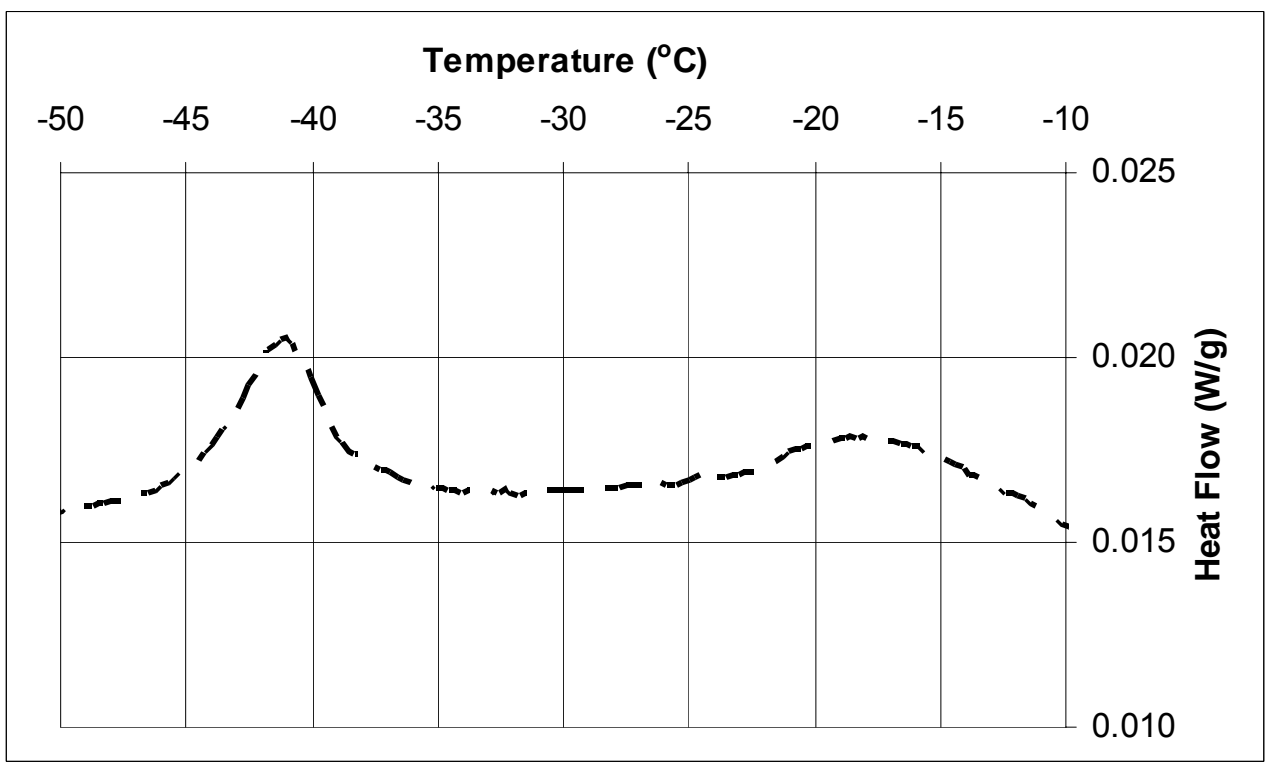

Figure $88 \mathrm{LTC}$ scan for CCRL Cement $152, w / c=0.435$, cured for $214 \mathrm{~d}$ at $20{ }^{\circ} \mathrm{C}$ under sealed conditions. 
Cement: CCRL Cement 152

Solution: Distilled water

$w / c: 0.435$

Temperature: $20{ }^{\circ} \mathrm{C}$

Degree of hydration: N/A
Curing: Sealed $7 \mathrm{~d} /$ resaturated

Age when tested: $214 \mathrm{~d}$

Sample mass: $54.0 \mathrm{mg}$

Filename: c152w45sealsat214d

Date tested: Oct. 29, 2004

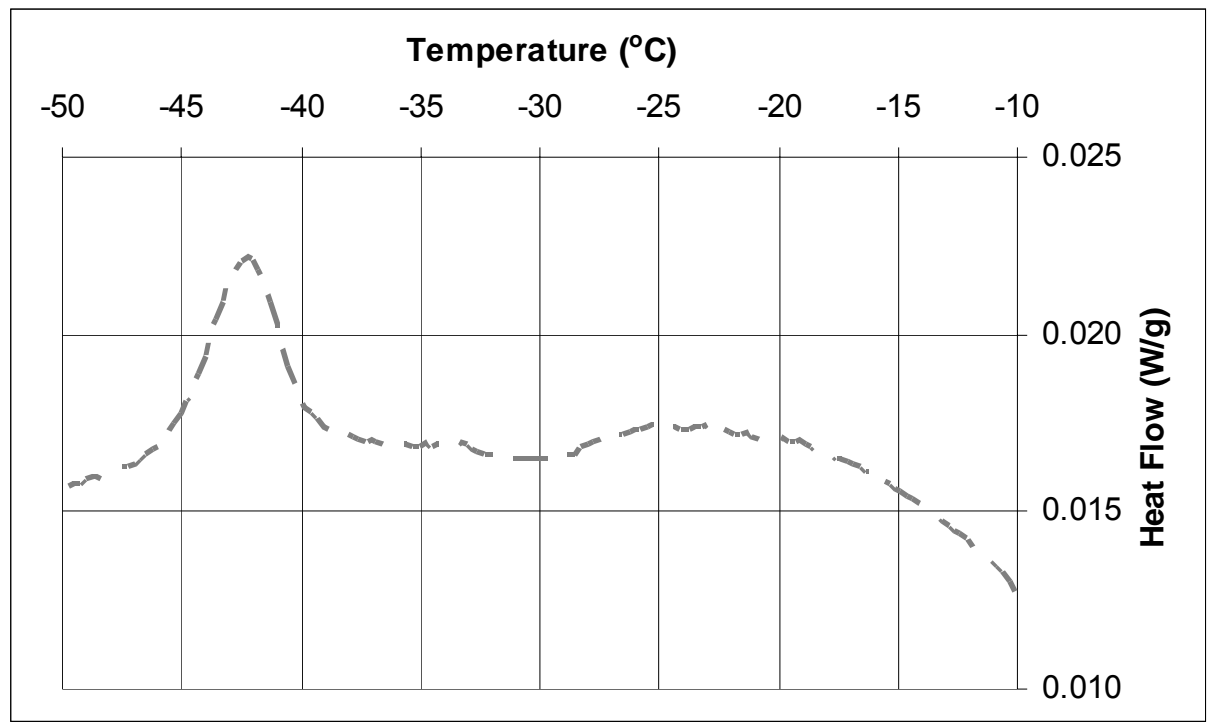

Figure $89 \mathrm{LTC}$ scan for CCRL Cement $152, w / c=0.435$, cured for $7 \mathrm{~d}$ at $20{ }^{\circ} \mathrm{C}$ under sealed conditions, then resaturated for $207 \mathrm{~d}$.

Cement: CCRL Cement 152

Solution: Distilled water

$w / c: 0.435$

Temperature: $20{ }^{\circ} \mathrm{C}$

Degree of hydration: N/A
Curing: Sealed $214 \mathrm{~d} /$ resaturated

Age when tested: $218 \mathrm{~d}$

Sample mass: $60.0 \mathrm{mg}$

Filename: c152w45sealresat214d

Date tested: Nov. 2, 2004

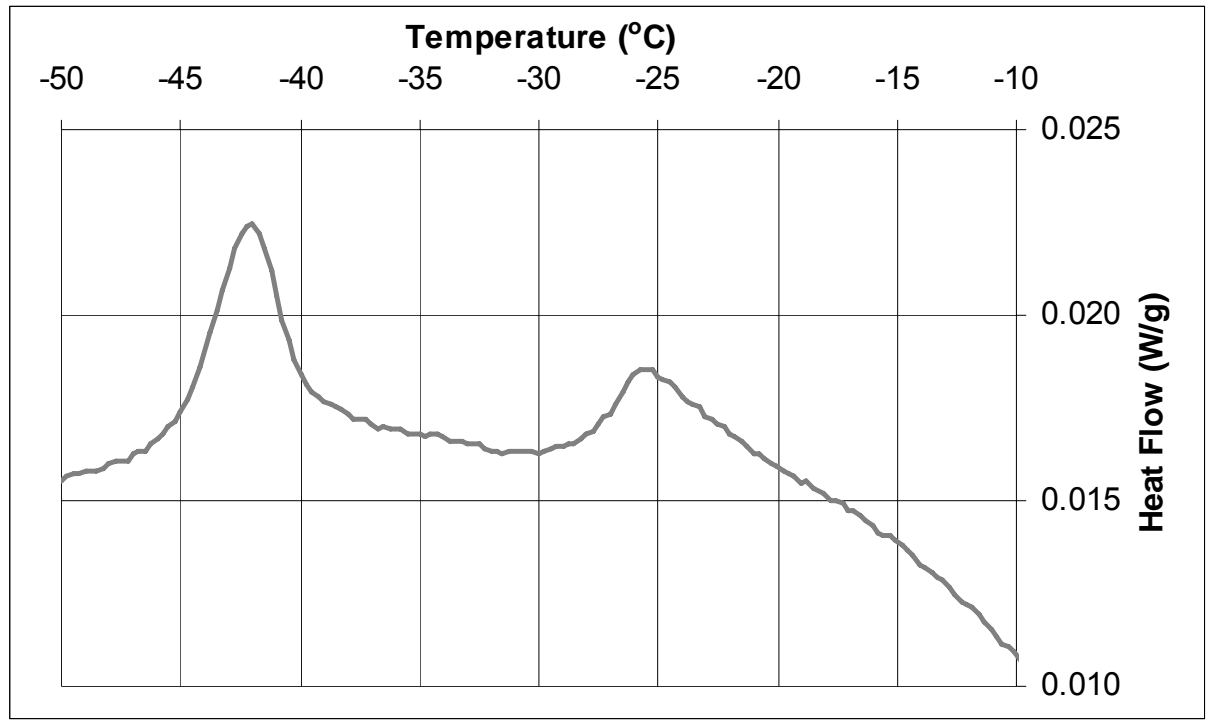

Figure $90 \mathrm{LTC}$ scan for CCRL Cement $152, w / c=0.435$, cured for $214 \mathrm{~d}$ at $20{ }^{\circ} \mathrm{C}$ under sealed conditions, then resaturated for $4 \mathrm{~d}$. 
Cement: CCRL Cement 152

Solution: Distilled water

$w / c: 0.435$

Temperature: $20{ }^{\circ} \mathrm{C}$

Degree of hydration: N/A
Curing: Sealed $214 \mathrm{~d} /$ resaturated

Age when tested: $255 \mathrm{~d}$

Sample mass: $51.6 \mathrm{mg}$

Filename: c152w45sealresatb214d

Date tested: Dec. 9, 2004

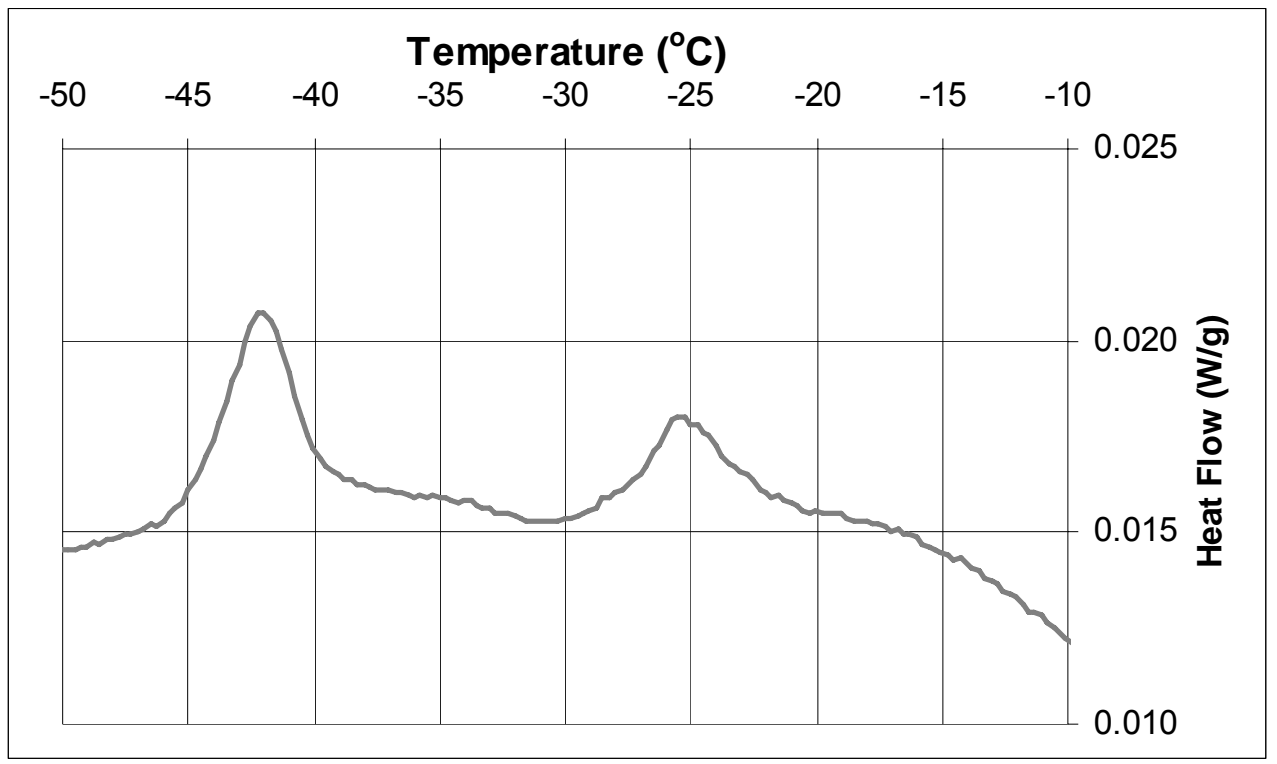

Figure $91 \mathrm{LTC}$ scan for CCRL Cement $152, w / c=0.435$, cured for $214 \mathrm{~d}$ at $20{ }^{\circ} \mathrm{C}$ under sealed conditions, then resaturated for $41 \mathrm{~d}$.

Cement: CCRL Cement 152

Solution: Distilled water

$w / c: 0.435$

Temperature: $20{ }^{\circ} \mathrm{C}$

Degree of hydration: N/A
Curing: Sealed $204 \mathrm{~d} /$ resaturated

Age when tested: $238 \mathrm{~d}$

Sample mass: $75.3 \mathrm{mg}$

Filename: c152w35seal204resat238d

Date tested: Dec. 20, 2004

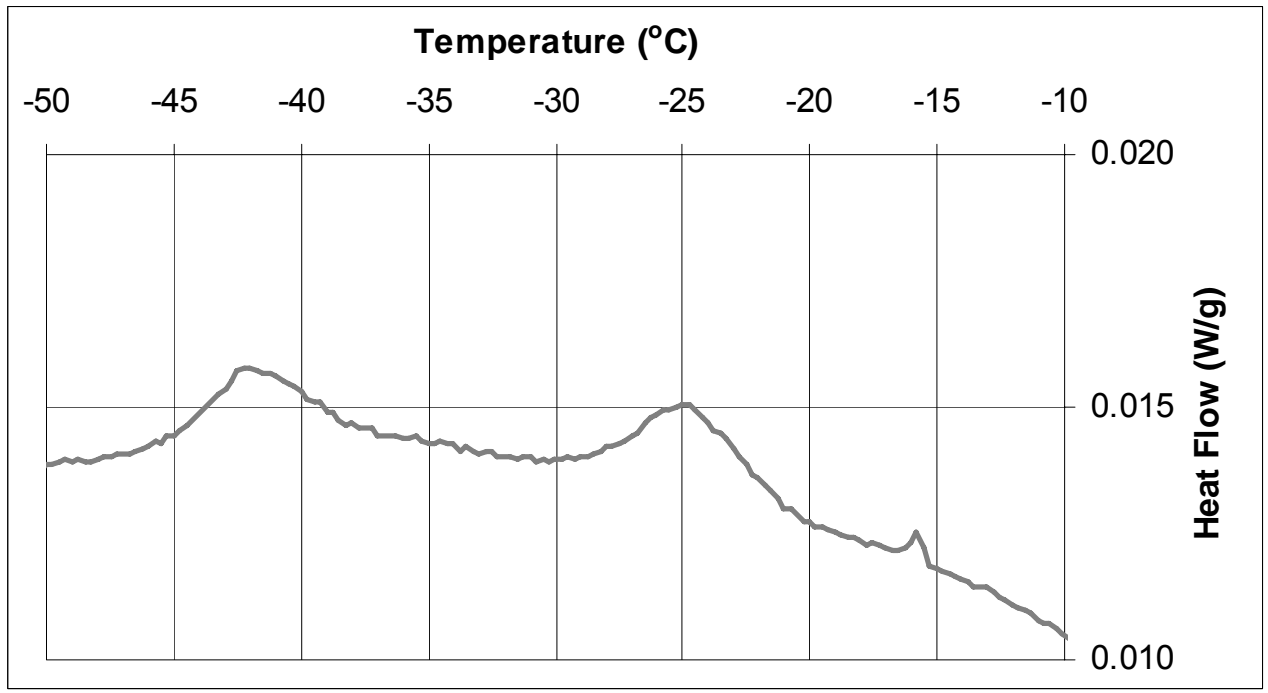

Figure $92 \mathrm{LTC}$ scan for CCRL Cement 152, w/c $=0.435$, cured for $204 \mathrm{~d}$ at $20{ }^{\circ} \mathrm{C}$ under sealed conditions, then resaturated for $34 \mathrm{~d}$. 
Cement: CCRL Cement 152

Solution: Distilled water

$w / c: 0.435$

Temperature: $20{ }^{\circ} \mathrm{C}$

Degree of hydration: N/A
Curing: Sealed

Age when tested: $256 \mathrm{~d}$

Sample mass: $44.0 \mathrm{mg}$

Filename: c152w435seal256d

Date tested: Dec. 10, 2004

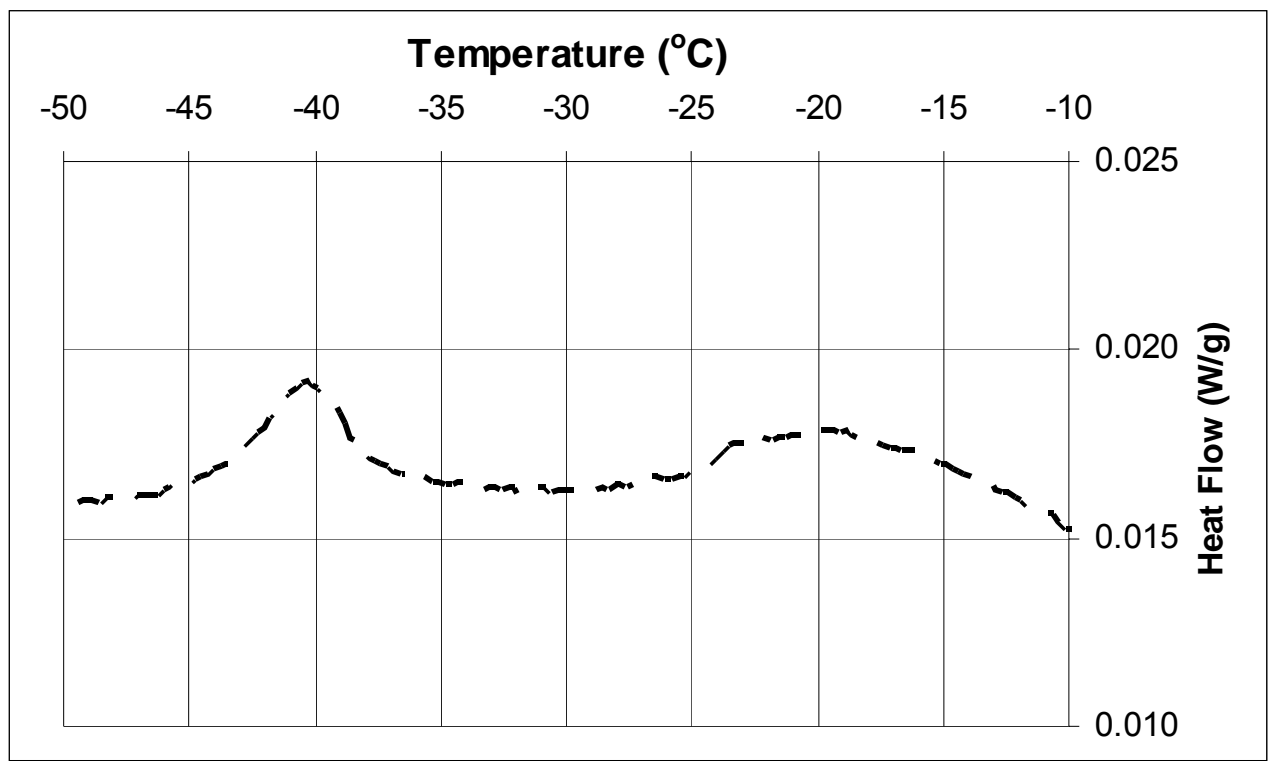

Figure $93 \mathrm{LTC}$ scan for CCRL Cement 152, $w / c=0.435$, cured for $256 \mathrm{~d}$ at $20{ }^{\circ} \mathrm{C}$ under sealed conditions.

Cement: CCRL Cement 152

Solution: Distilled water

$w / c: 0.435$

Temperature: $20{ }^{\circ} \mathrm{C}$

Degree of hydration: N/A
Curing: Saturated

Age when tested: $276 \mathrm{~d}$

Sample mass: $62.2 \mathrm{mg}$

Filename: c152w435sat276d

Date tested: Dec. 29, 2004

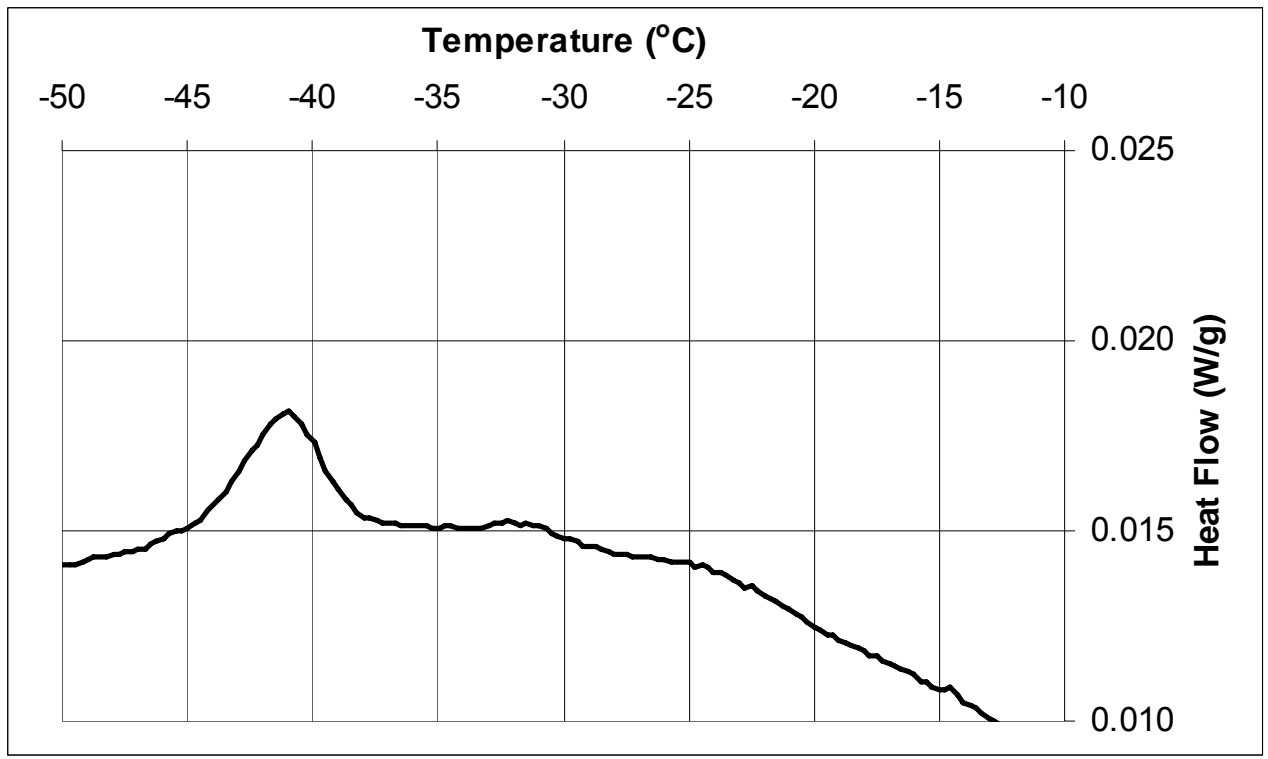

Figure $94 \mathrm{LTC}$ scan for CCRL Cement $152, w / c=0.435$, cured for $276 \mathrm{~d}$ at $20{ }^{\circ} \mathrm{C}$ under saturated conditions. 
Cement: Cement $152+20 \%$ limestone

Solution: Distilled water

w/s: 0.35

Temperature: $20{ }^{\circ} \mathrm{C}$

Degree of hydration: 0.855
Curing: Saturated

Age when tested: $91 \mathrm{~d}$

Sample mass: $59.6 \mathrm{mg}$

Filename: c152w35lf20sat91d

Date tested: Jan. 24, 2005

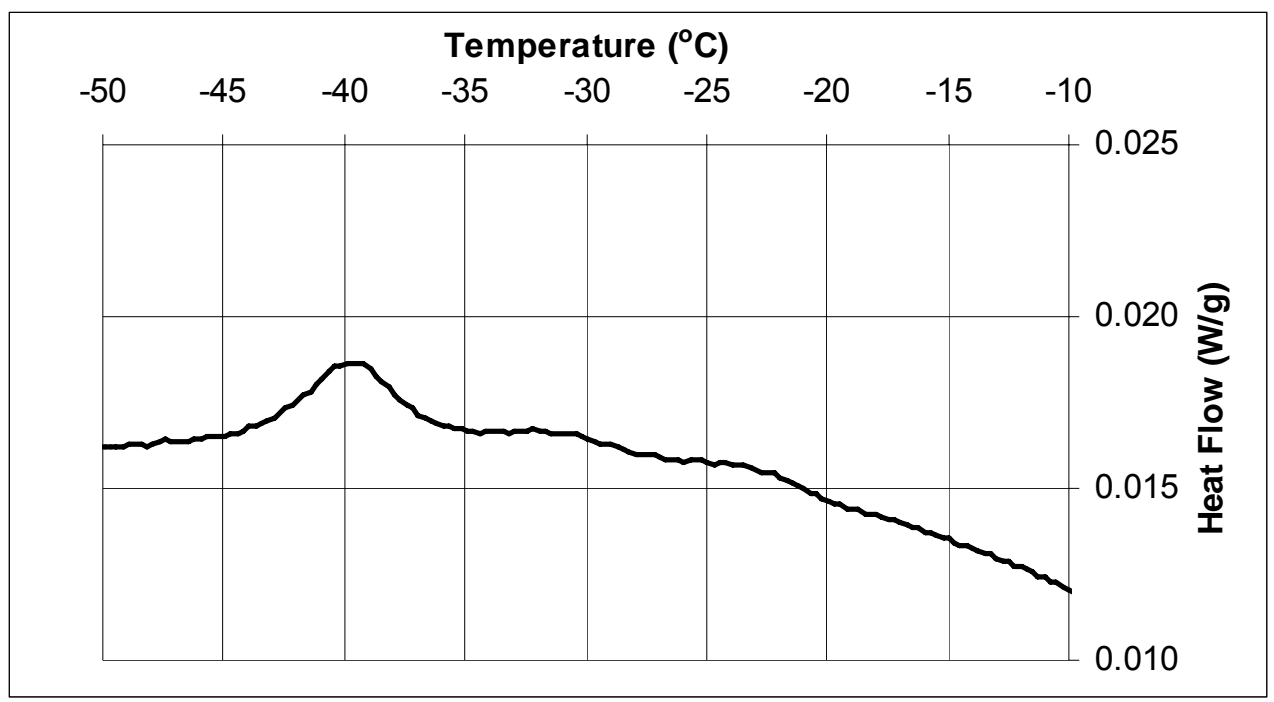

Figure 95 LTC scan for CCRL Cement 152 with $20 \%$ limestone filler substitution, $w / s=0.35$, cured for $91 \mathrm{~d}$ at $20{ }^{\circ} \mathrm{C}$ under saturated conditions.

Cement: Cement $152+20 \%$ limestone

Solution: Distilled water

w/s: 0.35

Temperature: $20{ }^{\circ} \mathrm{C}$

Degree of hydration: 0.763
Curing: Sealed

Age when tested: $91 \mathrm{~d}$

Sample mass: $36.5 \mathrm{mg}$

Filename: c152w351f20sea191d

Date tested: Jan. 24, 2005

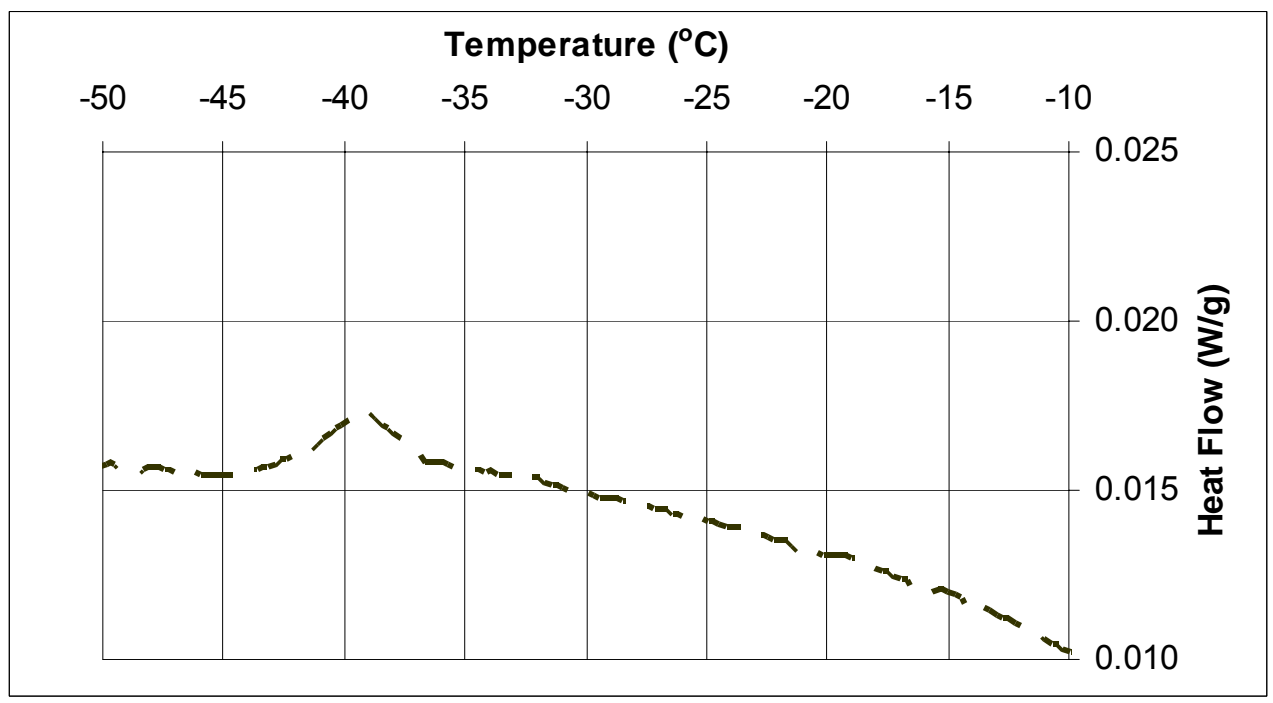

Figure $96 \mathrm{LTC}$ scan for CCRL Cement 152 with $20 \%$ limestone filler substitution, $w / s=0.35$, cured for $91 \mathrm{~d}$ at $20{ }^{\circ} \mathrm{C}$ under sealed conditions. 
Cement: Cement $152+20 \%$ limestone

Solution: Distilled water

w/s: 0.35

Temperature: $20{ }^{\circ} \mathrm{C}$

Degree of hydration: N/A
Curing: Sealed $91 \mathrm{~d} /$ resaturated Age when tested: $92 \mathrm{~d}$ Sample mass: $64.7 \mathrm{mg}$ Filename: c152w35lf20sealresat91d Date tested: Jan. 25, 2005

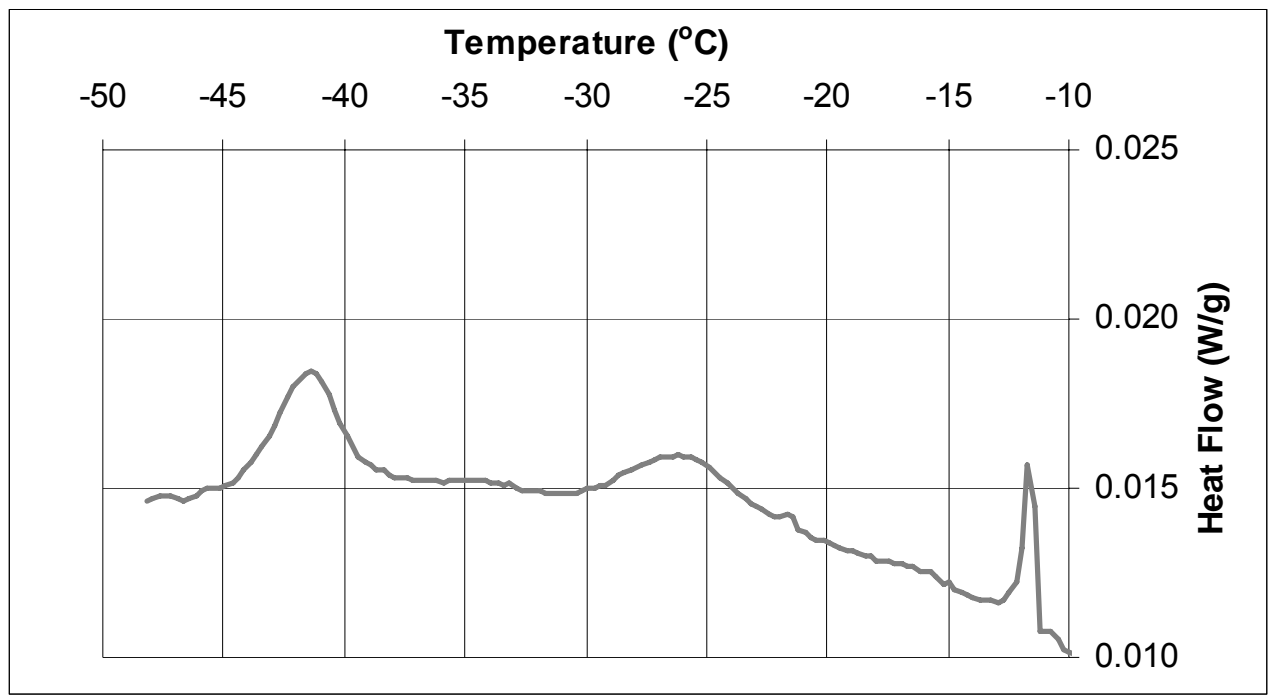

Figure 97 LTC scan for CCRL Cement 152 with $20 \%$ limestone filler substitution, $w / s=0.35$, cured under sealed conditions for $91 \mathrm{~d}$ at $20^{\circ} \mathrm{C}$, then resaturated for $1 \mathrm{~d}$.

Cement: Cement $152+20 \%$ limestone

Solution: Distilled water

w/s: 0.35

Temperature: $20{ }^{\circ} \mathrm{C}$

Degree of hydration: N/A
Curing: Sealed $91 \mathrm{~d} /$ resaturated Age when tested: $183 \mathrm{~d}$

Sample mass: $40.5 \mathrm{mg}$

Filename: c152lf20w35sealresat91t182d

Date tested: April 26, 2005

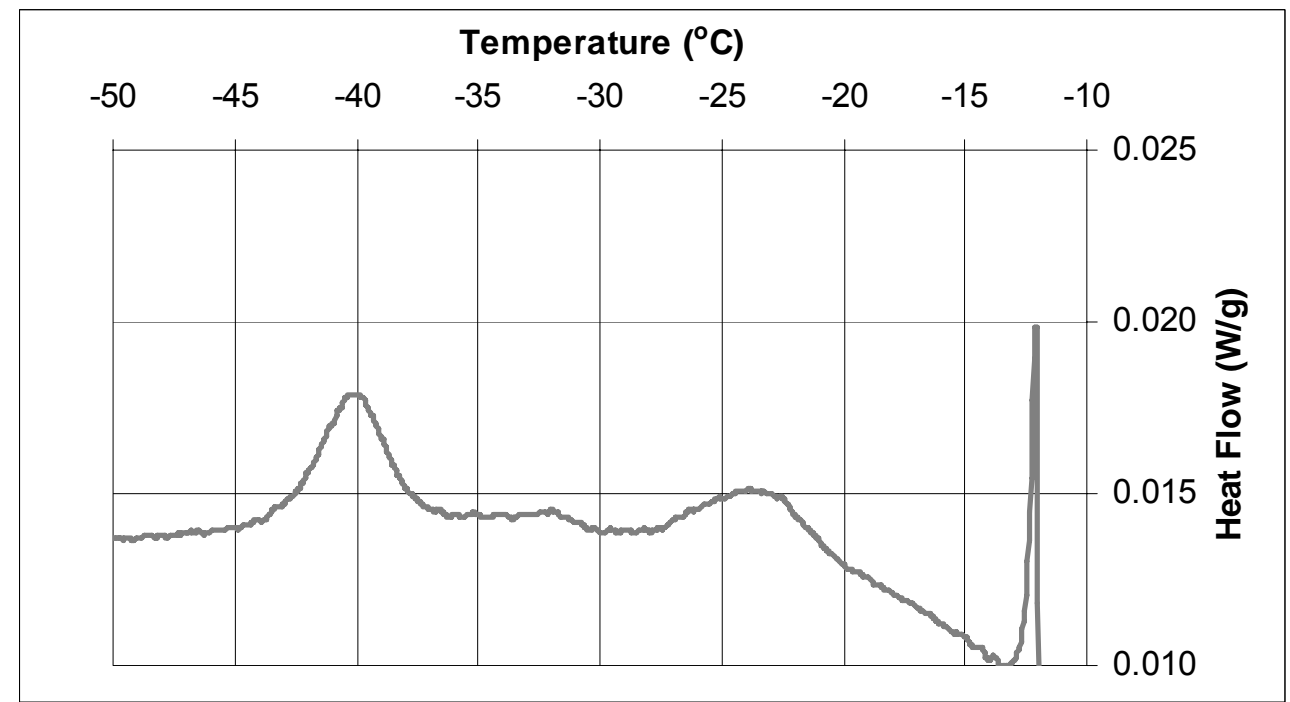

Figure $98 \mathrm{LTC}$ scan for CCRL Cement 152 with $20 \%$ limestone filler substitution, $w / s=0.35$, cured under sealed conditions for $91 \mathrm{~d}$ at $20{ }^{\circ} \mathrm{C}$, then resaturated for $92 \mathrm{~d}$. 
Cement: Cement $152+20 \%$ limestone

Solution: Distilled water

w/s: 0.35

Temperature: $20{ }^{\circ} \mathrm{C}$

Degree of hydration: 0.907
Curing: Saturated

Age when tested: $183 \mathrm{~d}$

Sample mass: $38.9 \mathrm{mg}$

Filename: c1521f20w35sat182d

Date tested: April 26, 2005

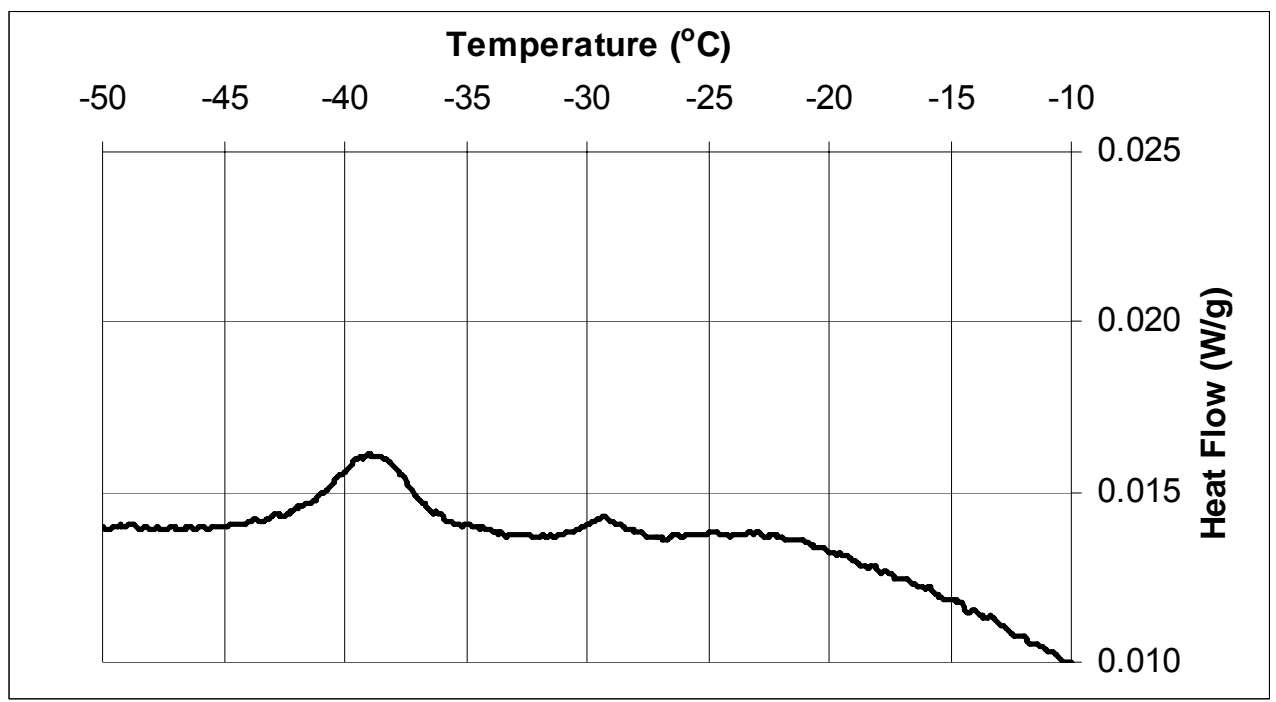

Figure $99 \mathrm{LTC}$ scan for CCRL Cement 152 with $20 \%$ limestone filler substitution, $w / s=0.35$, cured for $183 \mathrm{~d}$ at $20^{\circ} \mathrm{C}$ under saturated conditions.

Cement: Cement $152+20 \%$ limestone

Solution: Distilled water

$w / s: 0.35$

Temperature: $20{ }^{\circ} \mathrm{C}$

Degree of hydration: 0.828
Curing: Sealed

Age when tested: $183 \mathrm{~d}$

Sample mass: $65.8 \mathrm{mg}$

Filename: c152lf20w35seal182d

Date tested: April 26, 2005

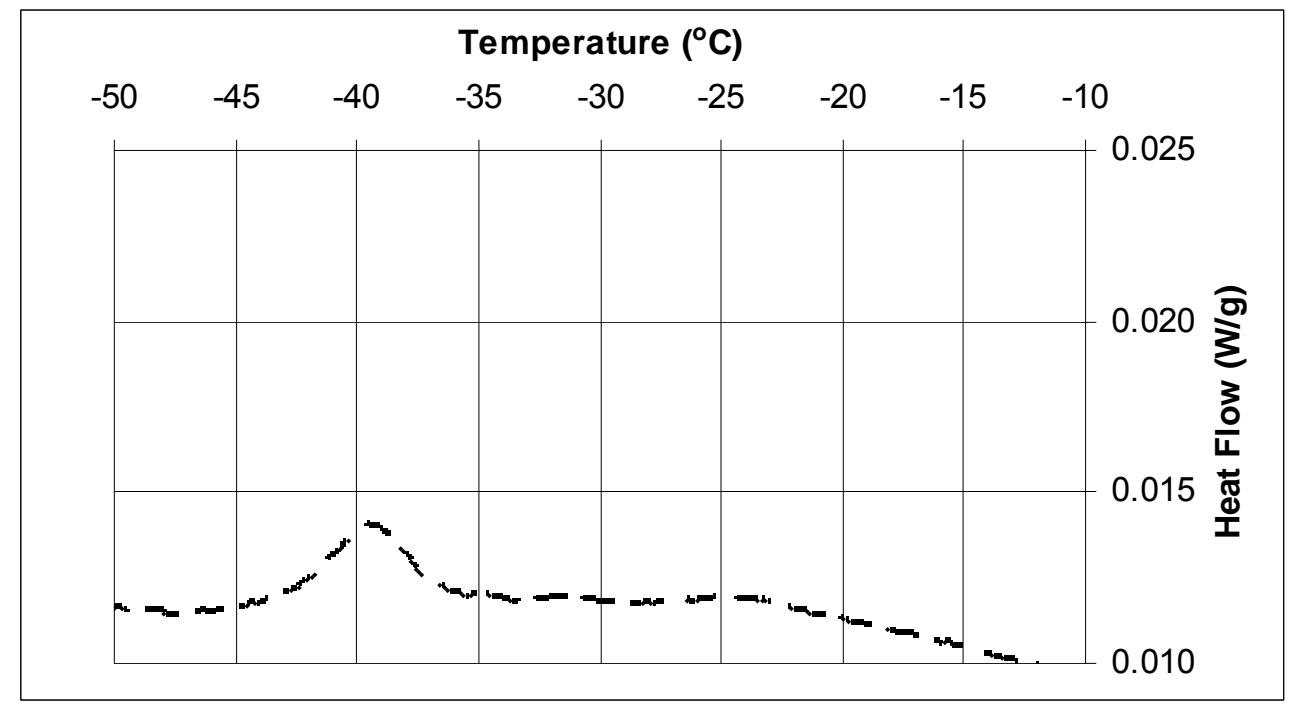

Figure $100 \mathrm{LTC}$ scan for CCRL Cement 152 with $20 \%$ limestone filler substitution, $w / s=0.35$, cured for $183 \mathrm{~d}$ at $20^{\circ} \mathrm{C}$ under sealed conditions. 
Cement: Cement $152+20 \%$ limestone Solution: Distilled water w/s: 0.35

Temperature: $20{ }^{\circ} \mathrm{C}$

Degree of hydration: N/A
Curing: Sealed 183 d/resaturated Age when tested: $184 \mathrm{~d}$ Sample mass: $64.7 \mathrm{mg}$ Filename: c152lf20w35sealresat182t183d Date tested: April 27, 2005

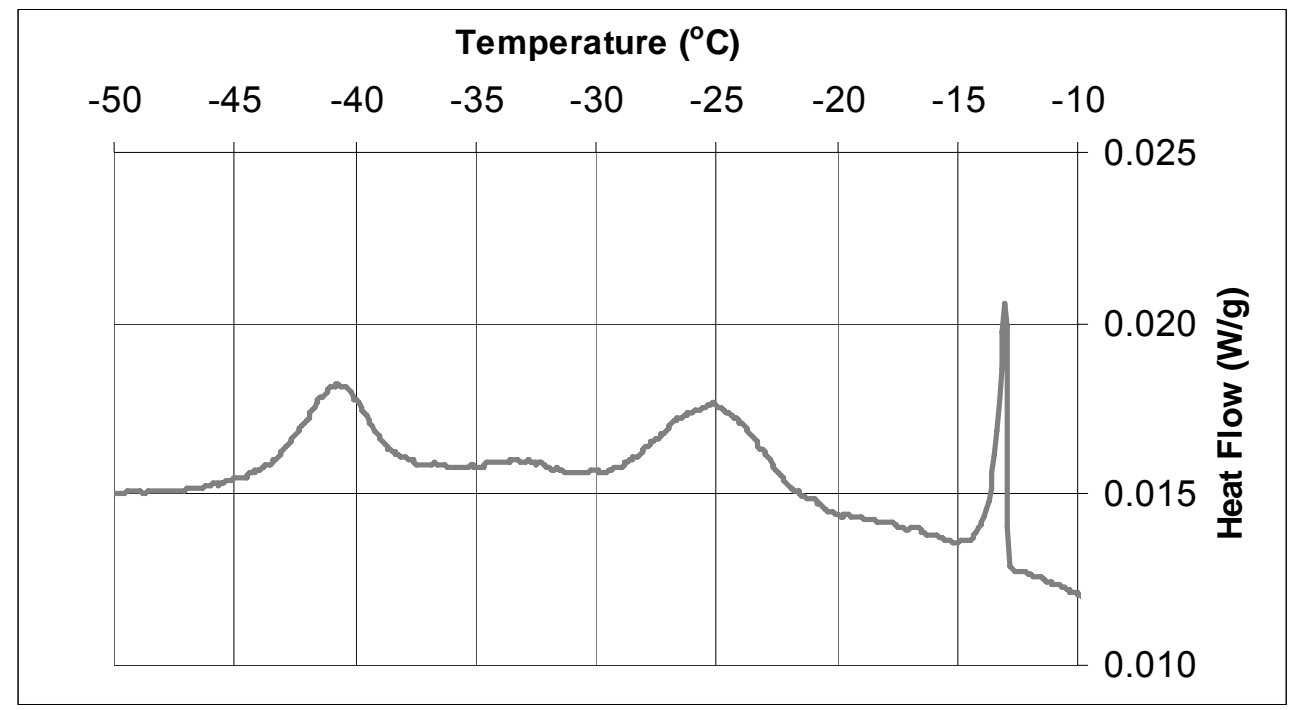

Figure 101 LTC scan for CCRL Cement 152 with $20 \%$ limestone filler substitution, $w / s=0.35$, cured under sealed conditions for $183 \mathrm{~d}$ at $20{ }^{\circ} \mathrm{C}$, then resaturated for $1 \mathrm{~d}$.

Cement: Cement $152+20 \%$ limestone

Solution: Distilled water

w/s: 0.435

Temperature: $20{ }^{\circ} \mathrm{C}$

Degree of hydration: N/A
Curing: Saturated

Age when tested: $213 \mathrm{~d}$

Sample mass: $55.0 \mathrm{mg}$

Filename: c152w451f20sat213d

Date tested: Dec. 23, 2004

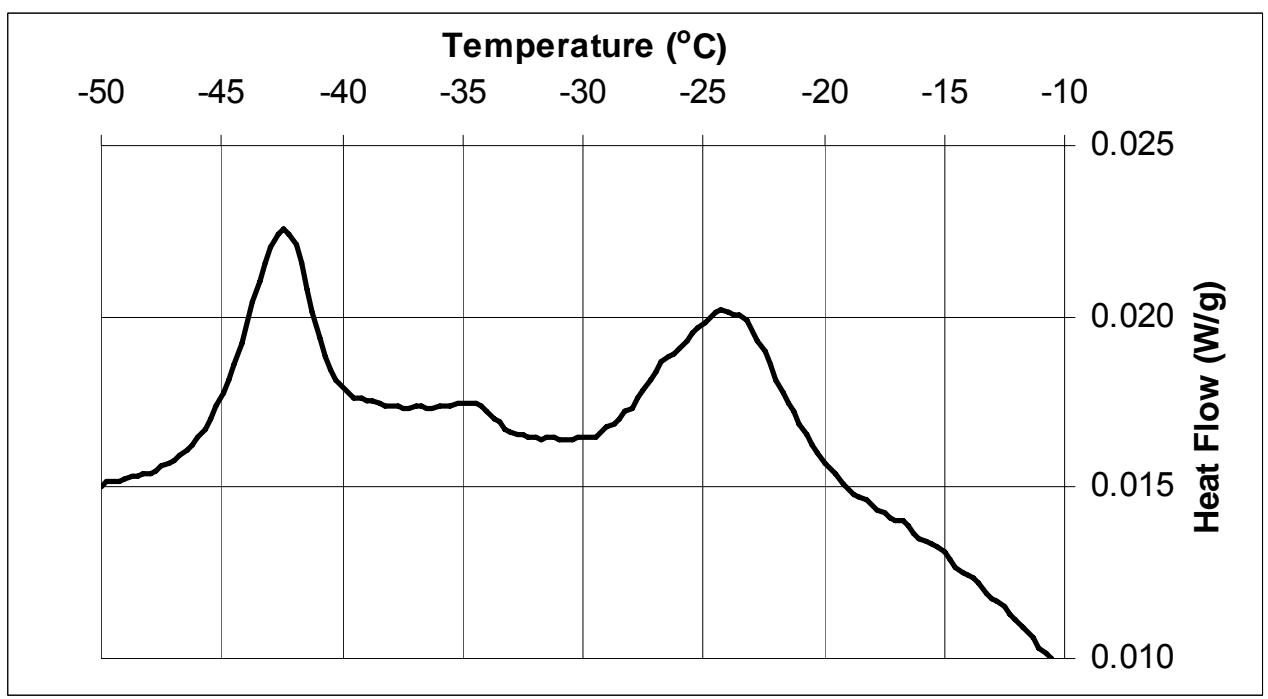

Figure $102 \mathrm{LTC}$ scan for CCRL Cement 152 with $20 \%$ limestone filler substitution, $w / s=0.435$, cured for $213 \mathrm{~d}$ at $20{ }^{\circ} \mathrm{C}$ under saturated conditions. 
Cement: Cement $152+20 \%$ limestone

Solution: Distilled water

w/s: 0.435

Temperature: $20{ }^{\circ} \mathrm{C}$

Degree of hydration: N/A
Curing: Sealed

Age when tested: $219 \mathrm{~d}$

Sample mass: $57.9 \mathrm{mg}$

Filename: c152w45lfseal219d

Date tested: Dec. 29, 2004

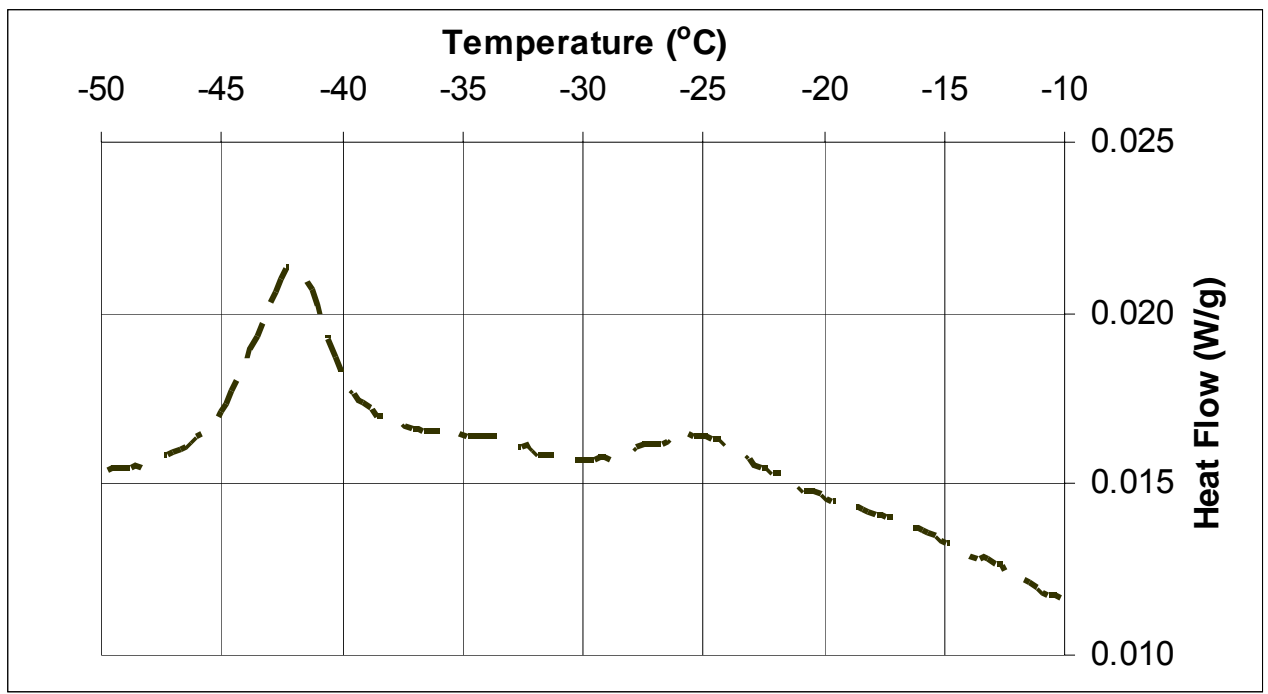

Figure $103 \mathrm{LTC}$ scan for CCRL Cement 152 with $20 \%$ limestone filler substitution, $w / s=0.435$, cured for $219 \mathrm{~d}$ at $20{ }^{\circ} \mathrm{C}$ under sealed conditions.

Cement: Cement $152+20 \%$ limestone Solution: Distilled water w/s: 0.435

Temperature: $20{ }^{\circ} \mathrm{C}$

Degree of hydration: N/A
Curing: Sealed $218 \mathrm{~d} /$ resaturated Age when tested: $220 \mathrm{~d}$

Sample mass: $67.5 \mathrm{mg}$ Filename: c152w451fseal219d

Date tested: Dec. 29, 2004

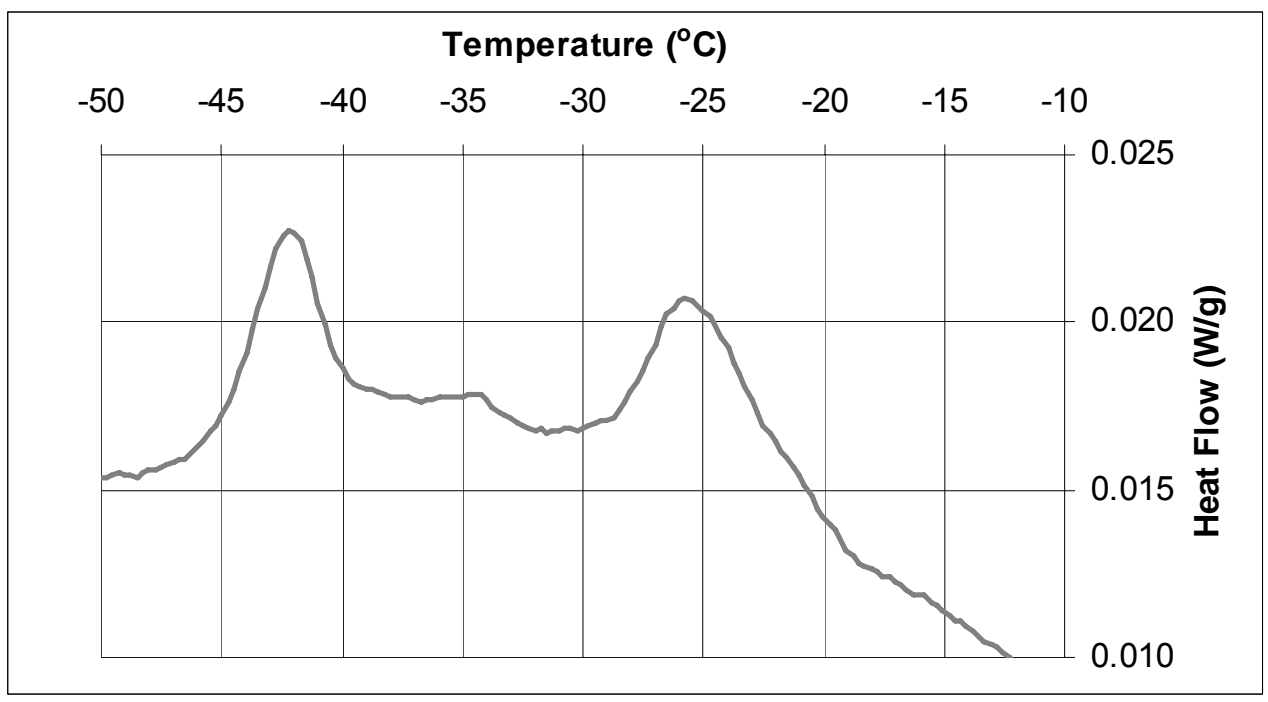

Figure $104 \mathrm{LTC}$ scan for CCRL Cement 152 with $20 \%$ limestone filler substitution, $w / s=0.435$, cured under sealed conditions for $218 \mathrm{~d}$ at $20^{\circ} \mathrm{C}$, then resaturated for $1 \mathrm{~d}$. 
Cement: CCRL Cement 152

Solution: Distilled water

$w / c: 0.25$

Temperature: $40{ }^{\circ} \mathrm{C}$

Degree of hydration: 0.303
Curing: Saturated

Age when tested: $8 \mathrm{~h}$

Sample mass: $96.4 \mathrm{mg}$

Filename: c152w025T40Csat8h

Date tested: June 8, 2005

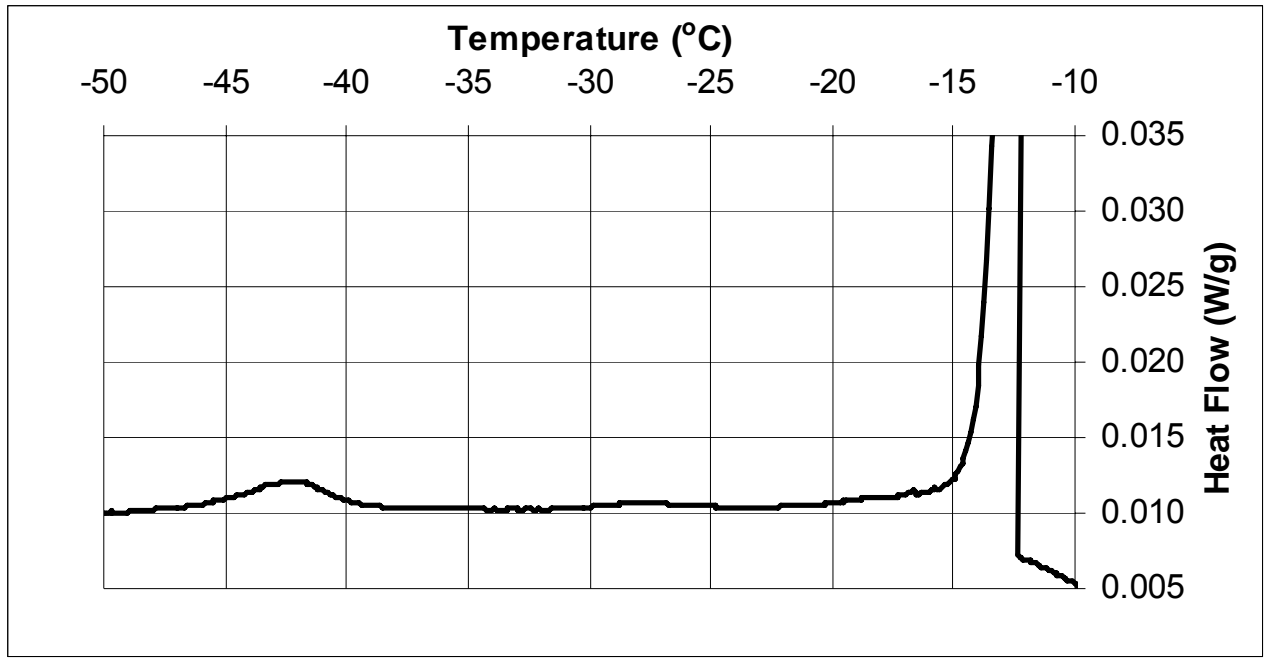

Figure 105 LTC scan for CCRL Cement 152, w/c $=0.25$, cured for $8 \mathrm{~h}$ under saturated conditions at $40{ }^{\circ} \mathrm{C}$.

Cement: CCRL Cement 152

Solution: Distilled water

w/c: 0.25

Temperature: $40{ }^{\circ} \mathrm{C}$

Degree of hydration: 0.516
Curing: Saturated

Age when tested: $1 \mathrm{~d}$

Sample mass: $56.8 \mathrm{mg}$

Filename: c152w025T40Csat1d

Date tested: June 1, 2005

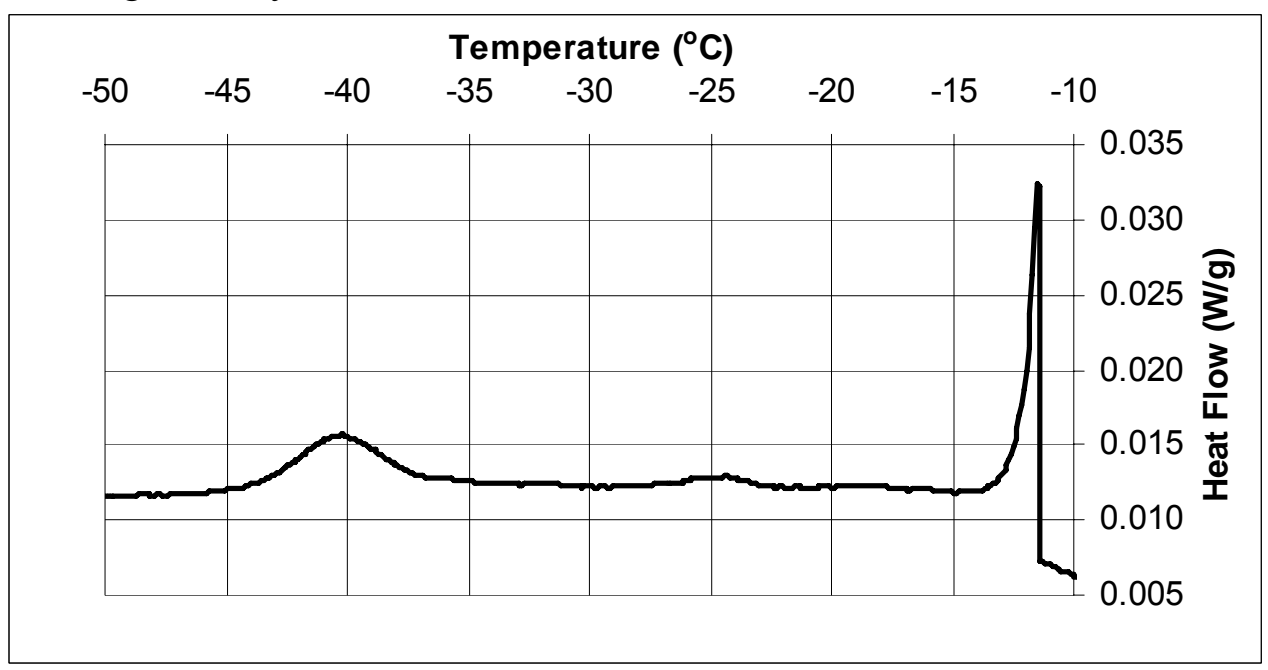

Figure $106 \mathrm{LTC}$ scan for CCRL Cement $152, w / c=0.25$, cured for $1 \mathrm{~d}$ under saturated conditions at $40{ }^{\circ} \mathrm{C}$. 
Cement: CCRL Cement 152

Solution: Distilled water

$w / c: 0.25$

Temperature: $40{ }^{\circ} \mathrm{C}$

Degree of hydration: 0.439
Curing: Sealed

Age when tested: $1 \mathrm{~d}$

Sample mass: $55.5 \mathrm{mg}$

Filename: c152w025T40Csealld

Date tested: June 1, 2005

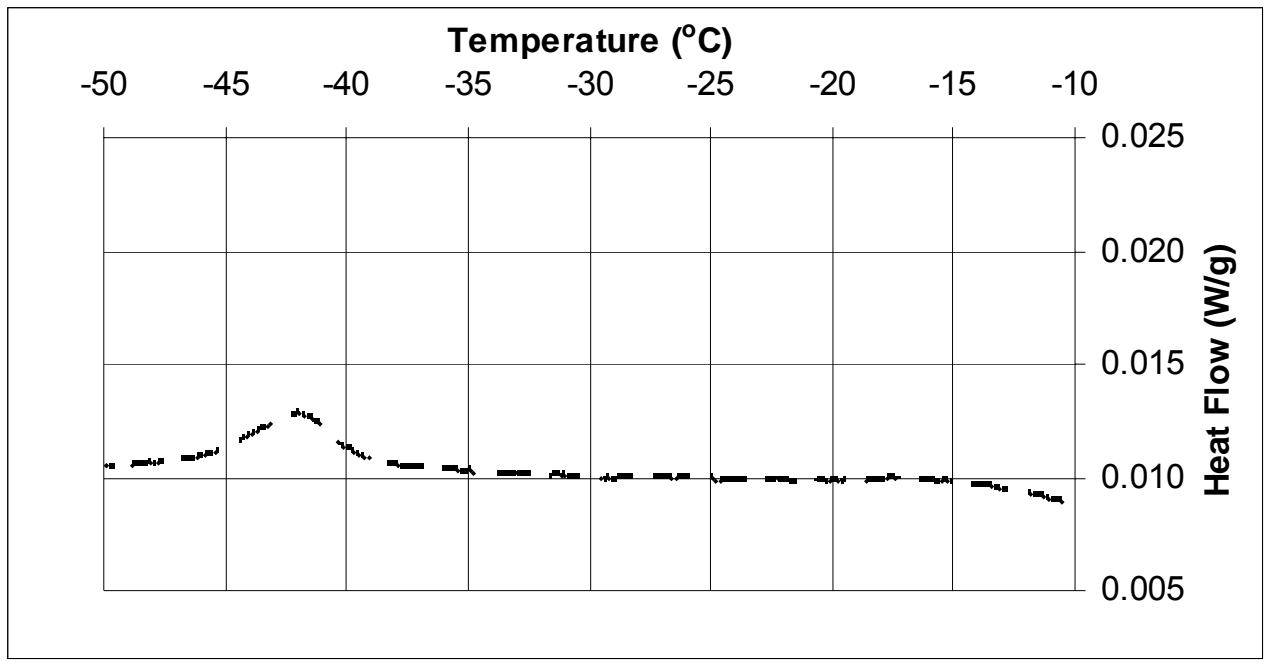

Figure $107 \mathrm{LTC}$ scan for CCRL Cement $152, w / c=0.25$, cured for $1 \mathrm{~d}$ under sealed conditions at $40{ }^{\circ} \mathrm{C}$.

Cement: CCRL Cement 152

Solution: Distilled water

w/c: 0.25

Temperature: $40{ }^{\circ} \mathrm{C}$

Degree of hydration: 0.596
Curing: Saturated

Age when tested: $2 \mathrm{~d}$

Sample mass: $56.3 \mathrm{mg}$

Filename: c152w025T40Csat2d

Date tested: June 2, 2005

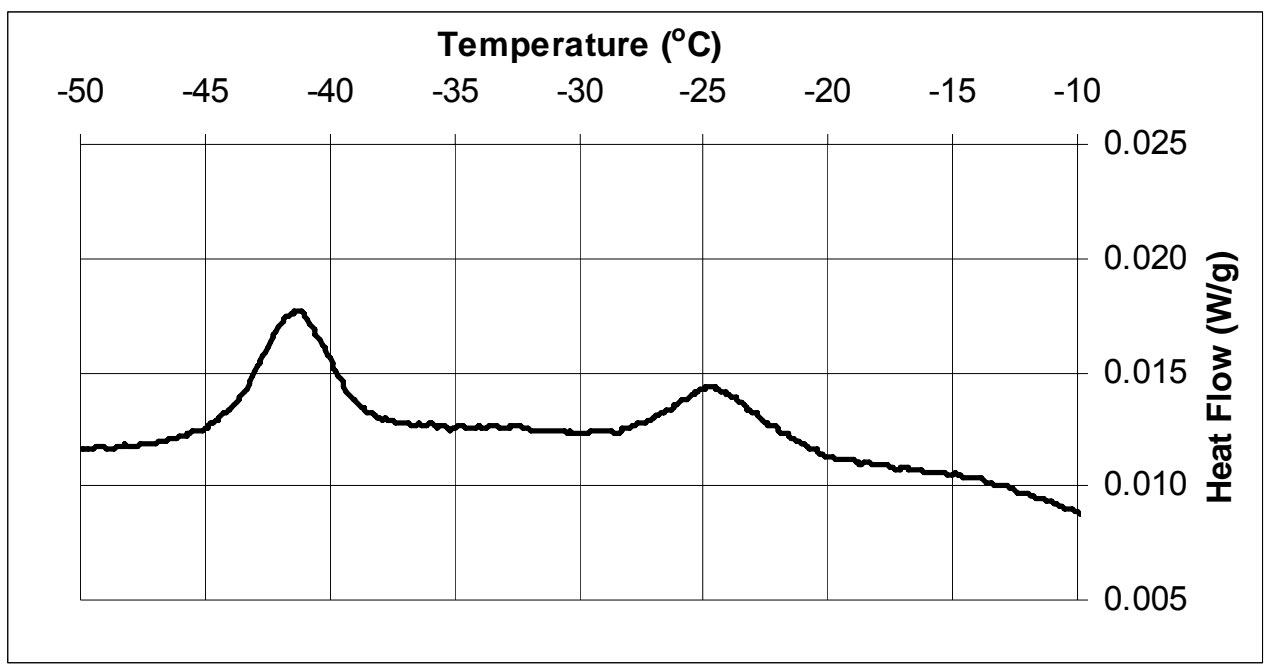

Figure $108 \mathrm{LTC}$ scan for CCRL Cement $152, w / c=0.25$, cured for $2 \mathrm{~d}$ under saturated conditions at $40{ }^{\circ} \mathrm{C}$. 
Cement: CCRL Cement 152

Solution: Distilled water

$w / c: 0.25$

Temperature: $40{ }^{\circ} \mathrm{C}$

Degree of hydration: 0.451
Curing: Sealed

Age when tested: $2 \mathrm{~d}$

Sample mass: $32.4 \mathrm{mg}$

Filename: c152w025T40Cseal2d

Date tested: June 2, 2005

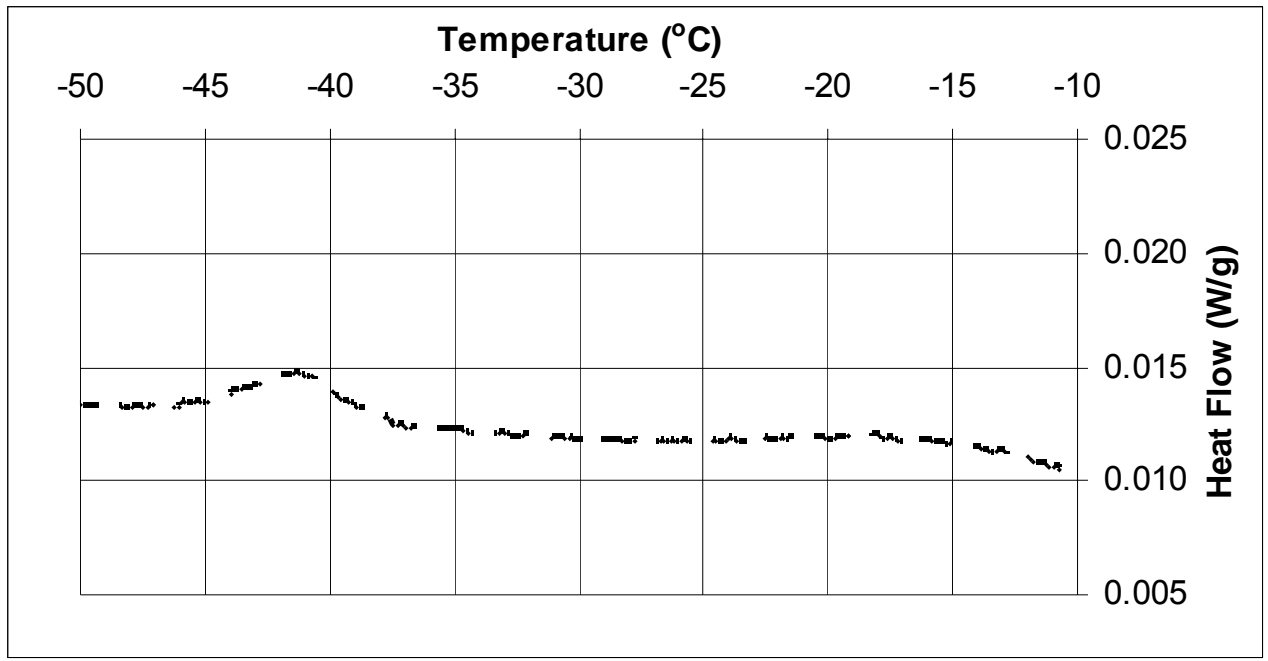

Figure $109 \mathrm{LTC}$ scan for CCRL Cement 152, w/c $=0.25$, cured for $2 \mathrm{~d}$ under sealed conditions at $40{ }^{\circ} \mathrm{C}$.

Cement: CCRL Cement 152

Solution: Distilled water

w/c: 0.25

Temperature: $40{ }^{\circ} \mathrm{C}$

Degree of hydration: N/A
Curing: Sealed $1 \mathrm{~d}$ /resaturated

Age when tested: $2 \mathrm{~d}$

Sample mass: $50.5 \mathrm{mg}$

Filename: c152w025T40Csealresat1t2d

Date tested: June 2, 2005

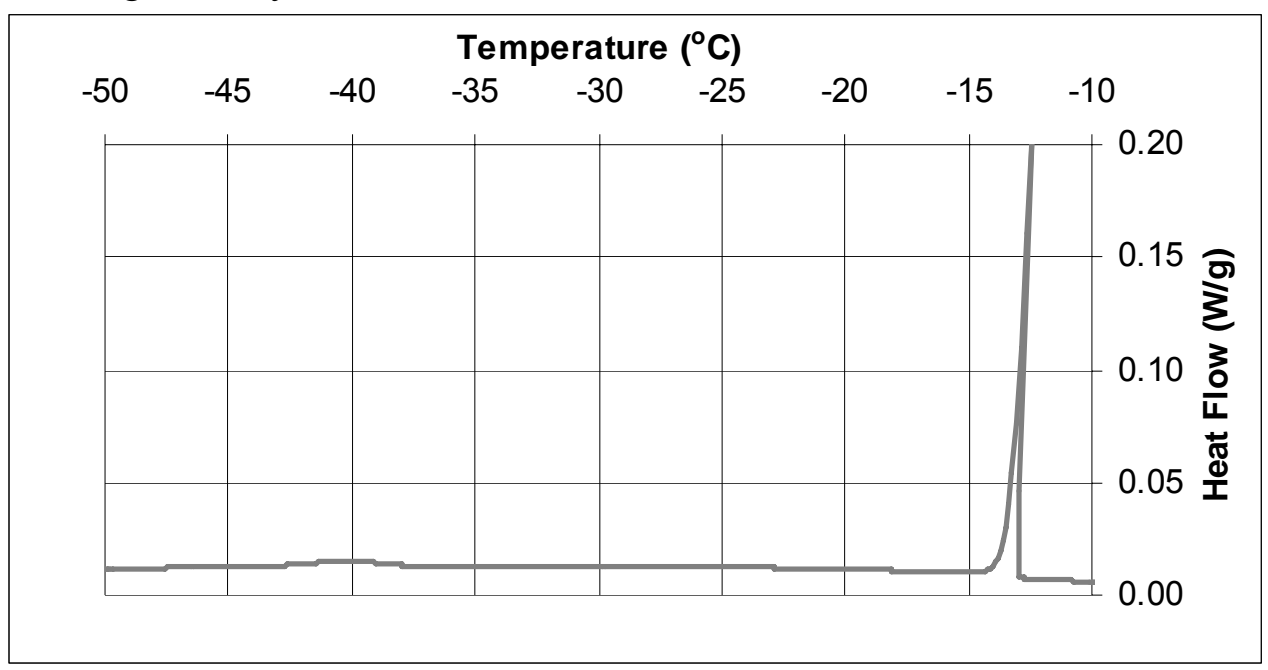

Figure $110 \mathrm{LTC}$ scan for CCRL Cement $152, w / c=0.25$, cured for $1 \mathrm{~d}$ at $40^{\circ} \mathrm{C}$ under sealed conditions, then resaturated for $1 \mathrm{~d}$. 
Cement: CCRL Cement 152

Solution: Distilled water

$w / c: 0.25$

Temperature: $40{ }^{\circ} \mathrm{C}$

Degree of hydration: 0.620
Curing: Saturated

Age when tested: $3 \mathrm{~d}$

Sample mass: $44.0 \mathrm{mg}$

Filename: c152w025T40Csat3d

Date tested: June 3, 2005

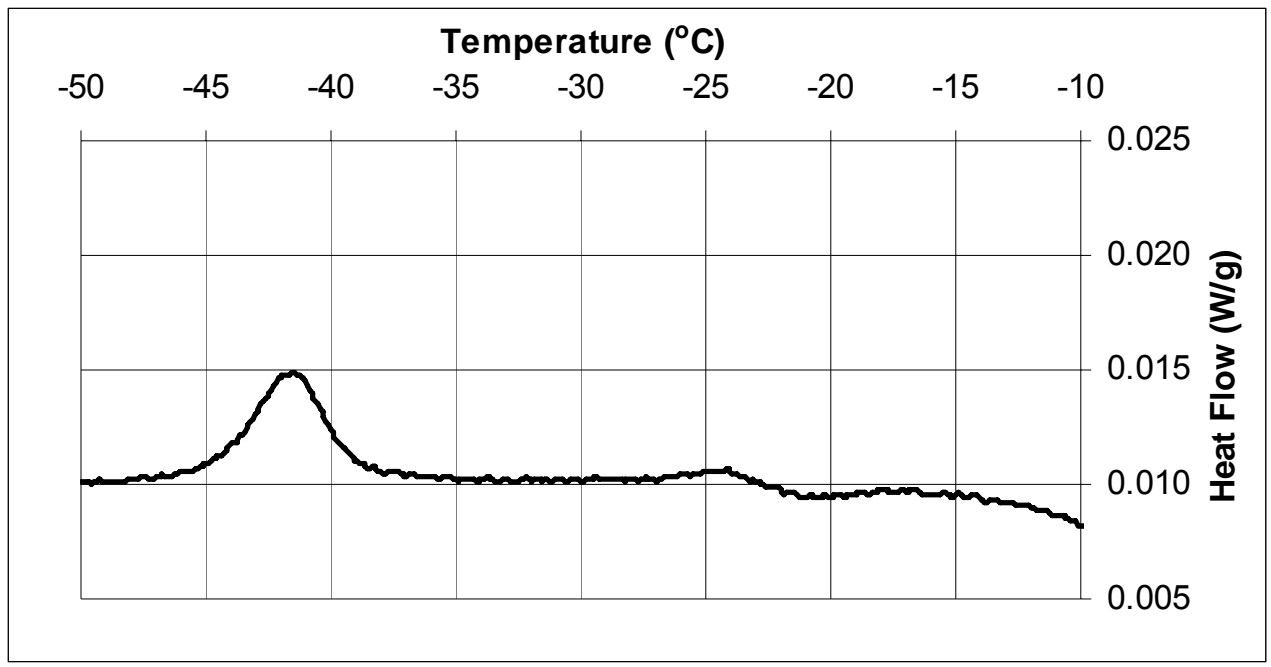

Figure $111 \mathrm{LTC}$ scan for CCRL Cement 152, w/c $=0.25$, cured for $3 \mathrm{~d}$ under saturated conditions at $40{ }^{\circ} \mathrm{C}$.

Cement: CCRL Cement 152

Solution: Distilled water

$w / c: 0.25$

Temperature: $40{ }^{\circ} \mathrm{C}$

Degree of hydration: 0.467
Curing: Sealed

Age when tested: $3 \mathrm{~d}$

Sample mass: $40.0 \mathrm{mg}$

Filename: c152w025T40Cseal3d

Date tested: June 3, 2005

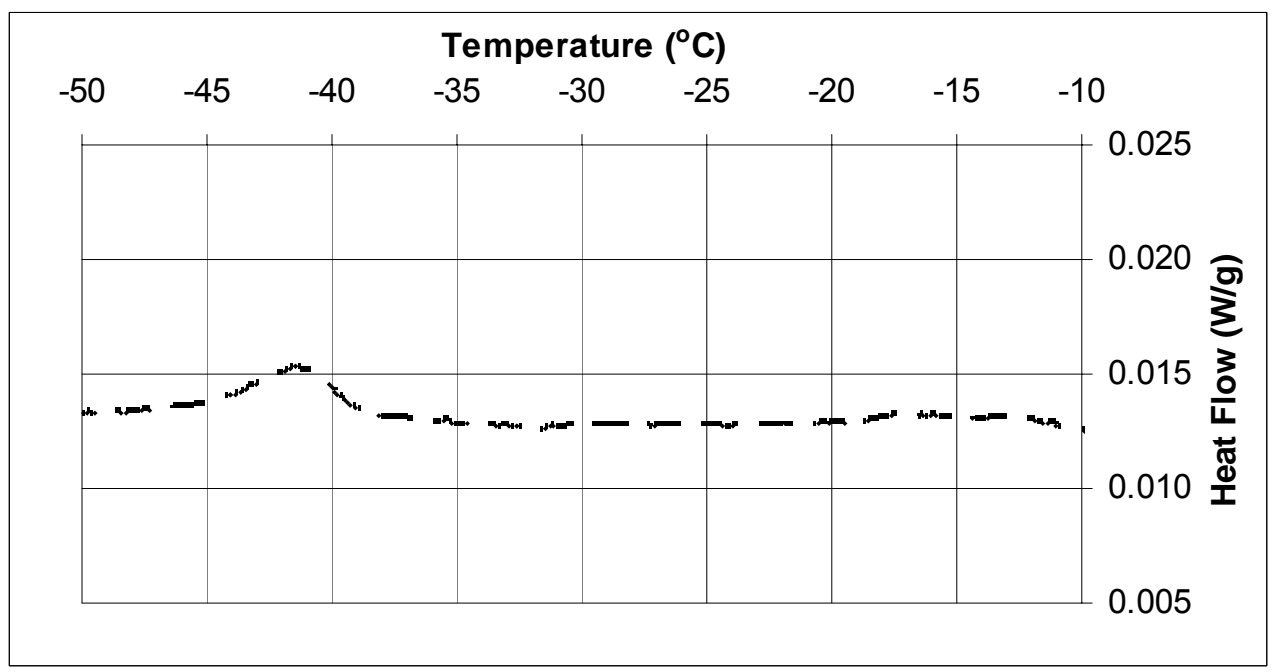

Figure $112 \mathrm{LTC}$ scan for CCRL Cement 152, w/c $=0.25$, cured for $3 \mathrm{~d}$ under sealed conditions at $40{ }^{\circ} \mathrm{C}$. 
Cement: CCRL Cement 152

Solution: Distilled water

$w / c: 0.25$

Temperature: $40{ }^{\circ} \mathrm{C}$

Degree of hydration: N/A
Curing: Sealed $2 \mathrm{~d} /$ resaturated

Age when tested: $3 \mathrm{~d}$

Sample mass: $40.3 \mathrm{mg}$

Filename: c152w025T40Csealresat2t3d

Date tested: June 3, 2005

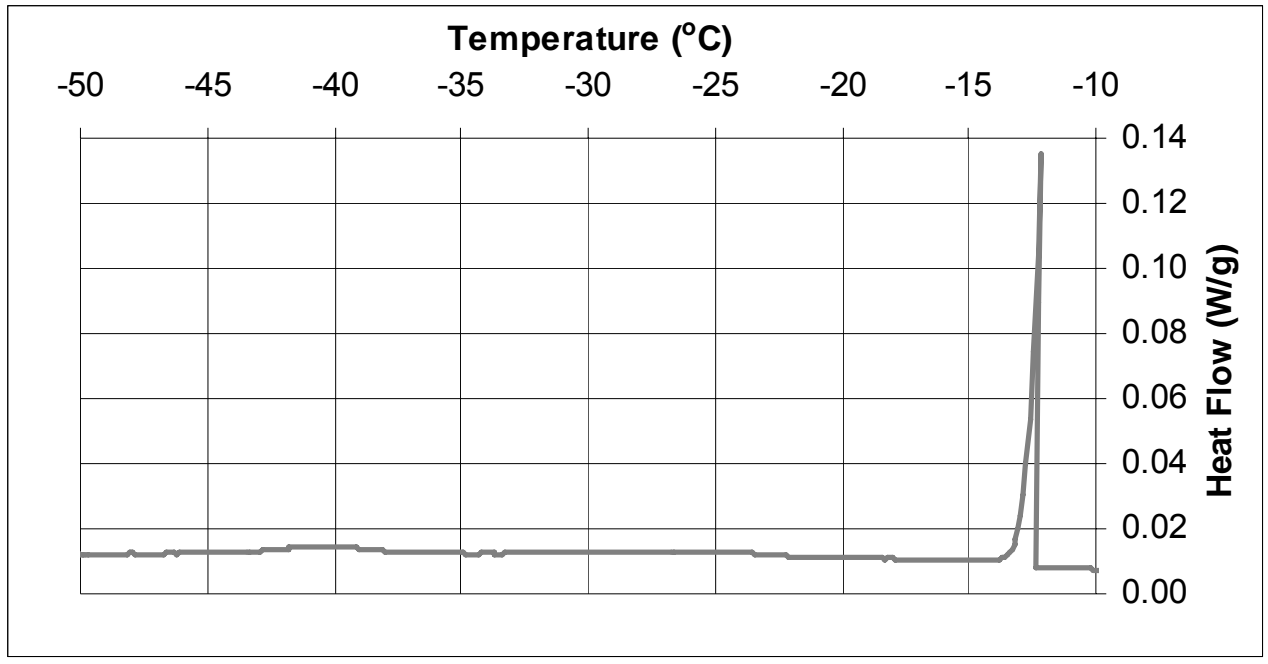

Figure $113 \mathrm{LTC}$ scan for CCRL Cement $152, w / c=0.25$, cured for $2 \mathrm{~d}$ at $40{ }^{\circ} \mathrm{C}$ under sealed conditions, then resaturated for $1 \mathrm{~d}$.

Cement: CCRL Cement 152

Solution: Distilled water

$w / c: 0.25$

Temperature: $40{ }^{\circ} \mathrm{C}$

Degree of hydration: N/A
Curing: Sealed $3 \mathrm{~d} /$ resaturated

Age when tested: $4 \mathrm{~d}$

Sample mass: $35.2 \mathrm{mg}$

Filename: c152w025T40Csealresat3t4d

Date tested: June 4, 2005

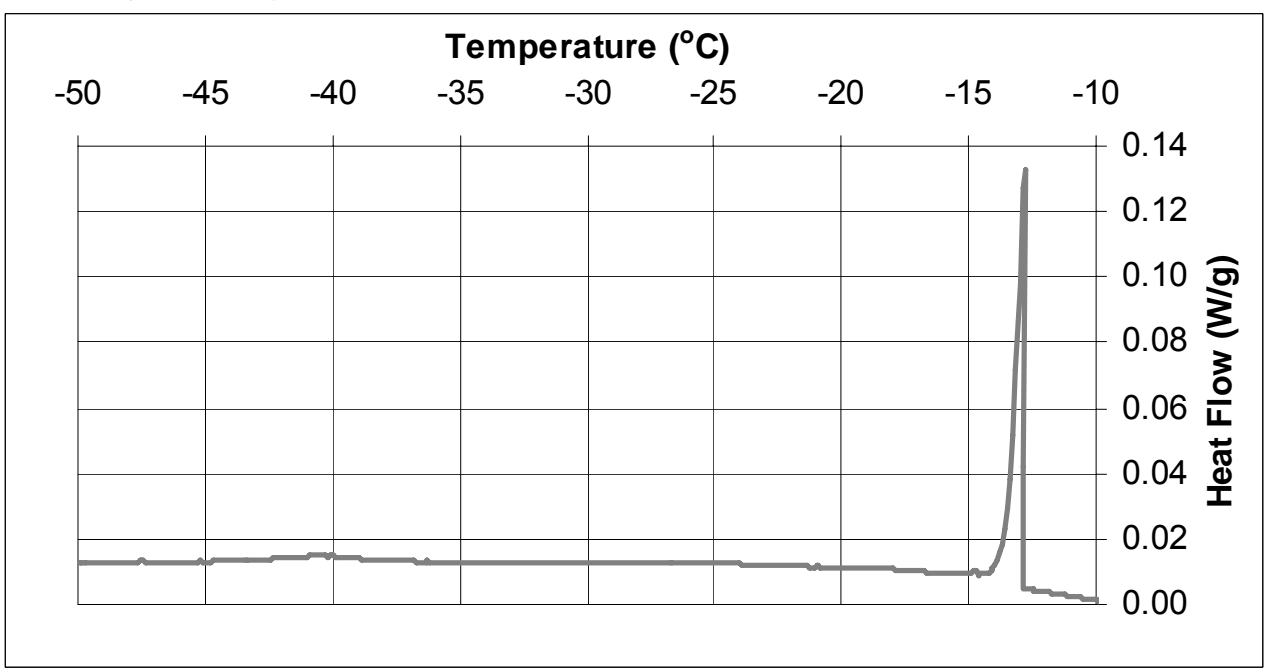

Figure $114 \mathrm{LTC}$ scan for CCRL Cement $152, w / c=0.25$, cured for $3 \mathrm{~d}$ at $40{ }^{\circ} \mathrm{C}$ under sealed conditions, then resaturated for $1 \mathrm{~d}$. 
Cement: CCRL Cement 152

Solution: Distilled water

$w / c: 0.25$

Temperature: $40{ }^{\circ} \mathrm{C}$

Degree of hydration: N/A
Curing: Saturated

Age when tested: $14 \mathrm{~d}$

Sample mass: $48.9 \mathrm{mg}$

Filename: c152w025T40Csat14d

Date tested: June 22, 2005

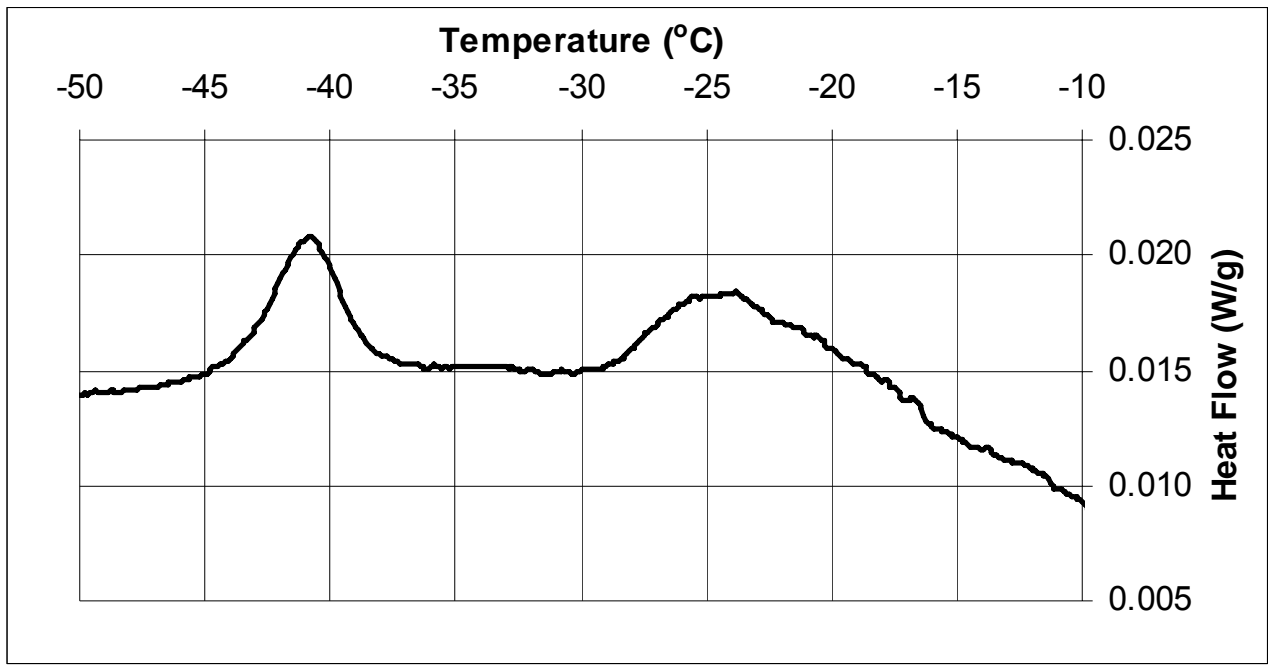

Figure $115 \mathrm{LTC}$ scan for CCRL Cement $152, w / c=0.25$, cured for $14 \mathrm{~d}$ under saturated conditions at 40 ${ }^{\circ} \mathrm{C}$.

Cement: CCRL Cement 152

Solution: Distilled water

$w / c: 0.25$

Temperature: $40{ }^{\circ} \mathrm{C}$

Degree of hydration: N/A
Curing: Sealed

Age when tested: $14 \mathrm{~d}$

Sample mass: $55.0 \mathrm{mg}$

Filename: c152w025T40Cseal14d

Date tested: June 22, 2005

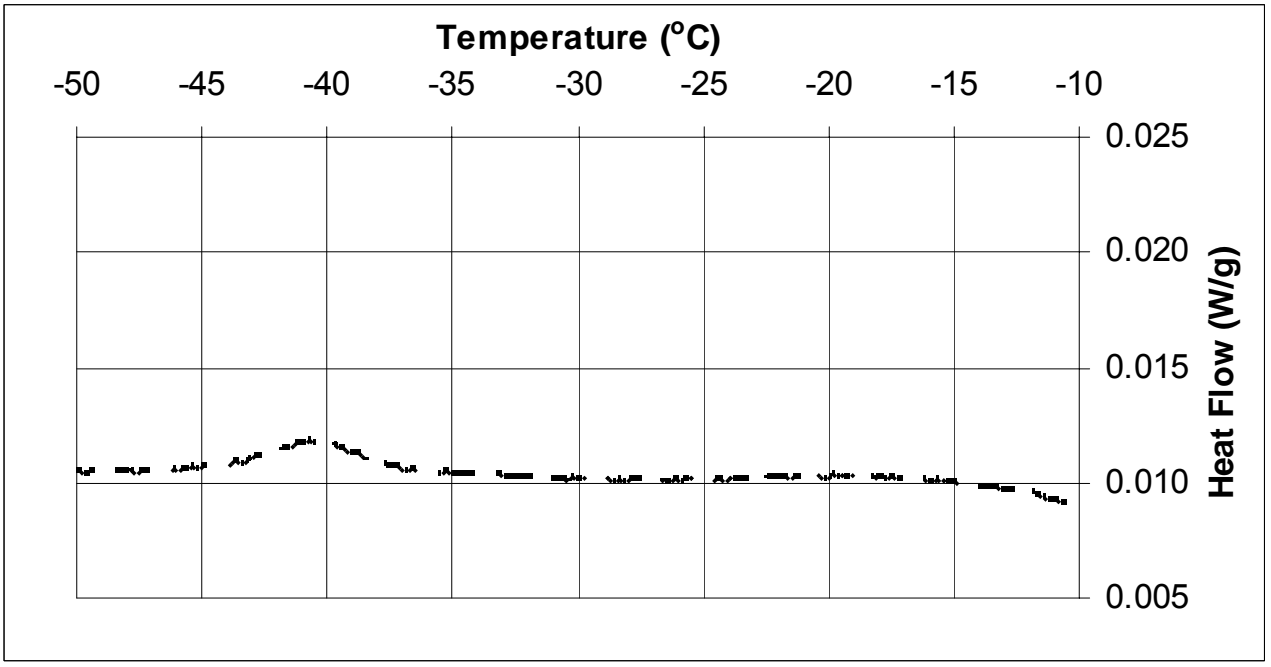

Figure $116 \mathrm{LTC}$ scan for CCRL Cement $152, w / c=0.25$, cured for $14 \mathrm{~d}$ under sealed conditions at $40{ }^{\circ} \mathrm{C}$. 
Cement: CCRL Cement 152

Solution: Distilled water

$w / c: 0.25$

Temperature: $40{ }^{\circ} \mathrm{C}$

Degree of hydration: N/A
Curing: Sealed $14 \mathrm{~d} /$ resaturated

Age when tested: $15 \mathrm{~d}$

Sample mass: $58.7 \mathrm{mg}$

Filename: c152w025T40Csealresat14t15d

Date tested: June 23, 2005

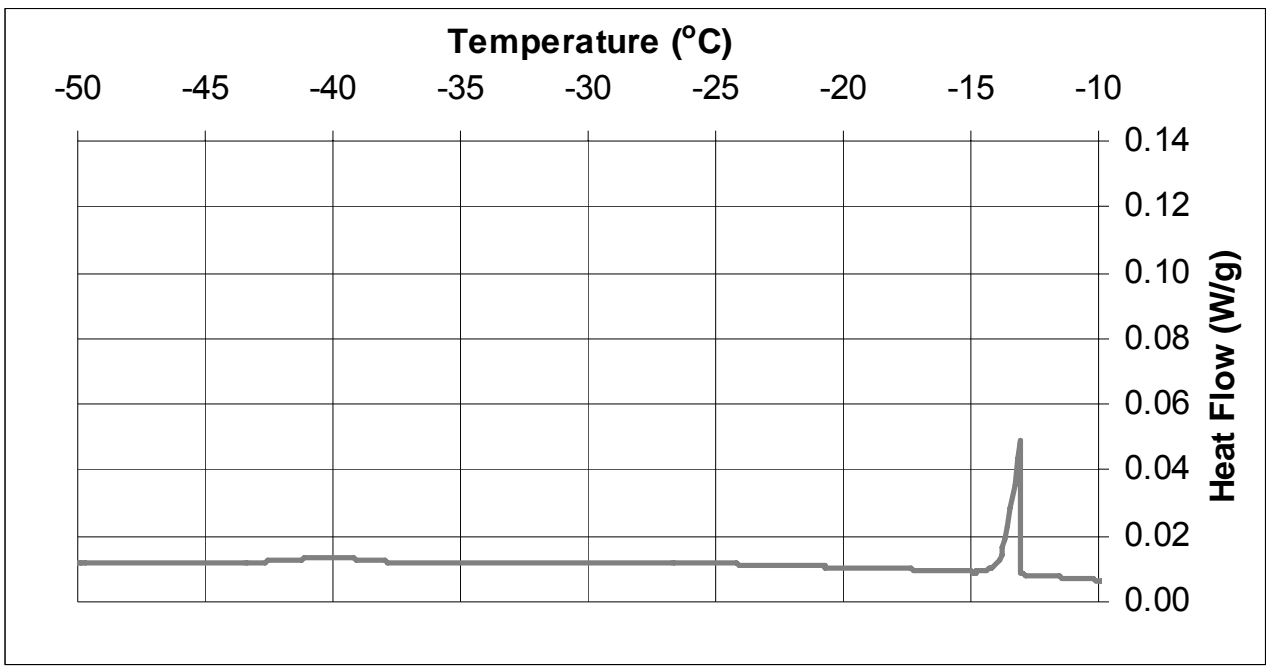

Figure $117 \mathrm{LTC}$ scan for CCRL Cement $152, w / c=0.25$, cured for $14 \mathrm{~d}$ at $40{ }^{\circ} \mathrm{C}$ under sealed conditions, then resaturated for $1 \mathrm{~d}$.

Cement: CCRL Cement 152

Solution: Distilled water

$w / c: 0.25$

Temperature: $40{ }^{\circ} \mathrm{C}$

Degree of hydration: N/A
Curing: Saturated

Age when tested: $28 \mathrm{~d}$

Sample mass: $61.8 \mathrm{mg}$

Filename: c152w025T40Csat28d

Date tested: July 6, 2005

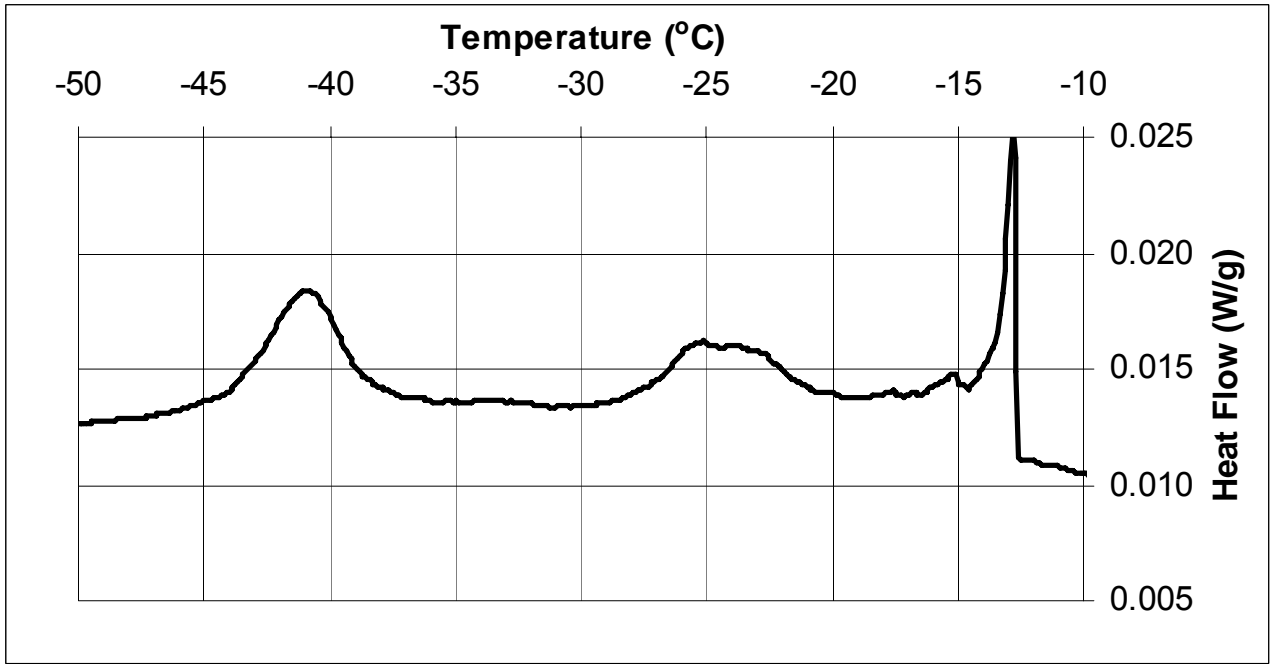

Figure $118 \mathrm{LTC}$ scan for CCRL Cement $152, w / c=0.25$, cured for $28 \mathrm{~d}$ under saturated conditions at 40 ${ }^{\circ} \mathrm{C}$. 
Cement: CCRL Cement 152

Solution: Distilled water

$w / c: 0.25$

Temperature: $40{ }^{\circ} \mathrm{C}$

Degree of hydration: N/A
Curing: Sealed

Age when tested: $28 \mathrm{~d}$

Sample mass: $43.4 \mathrm{mg}$

Filename: c152w025T40Cseal28d

Date tested: July 6, 2005

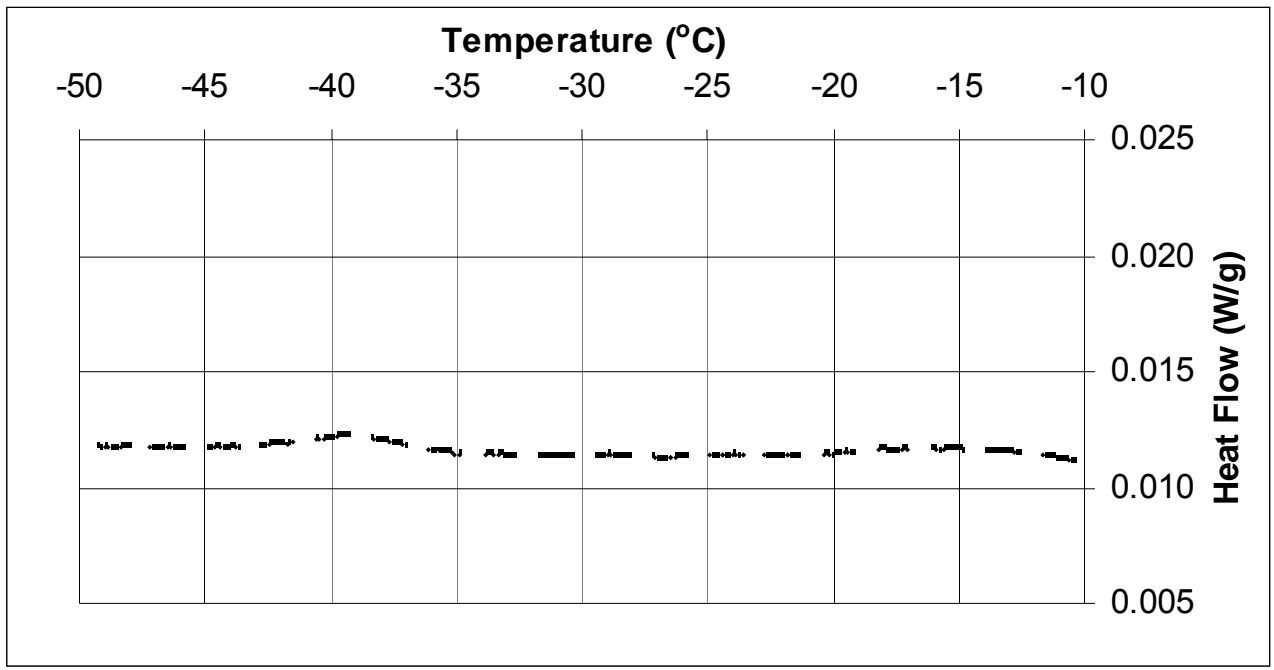

Figure 119 LTC scan for CCRL Cement $152, w / c=0.25$, cured for $28 \mathrm{~d}$ under sealed conditions at $40{ }^{\circ} \mathrm{C}$.

Cement: CCRL Cement 152

Solution: Distilled water

$w / c: 0.25$

Temperature: $40{ }^{\circ} \mathrm{C}$

Degree of hydration: N/A
Curing: Sealed $28 \mathrm{~d} /$ resaturated

Age when tested: $29 \mathrm{~d}$

Sample mass: $59.8 \mathrm{mg}$

Filename: c152w025T40Csealresat28t29d

Date tested: July 7, 2005

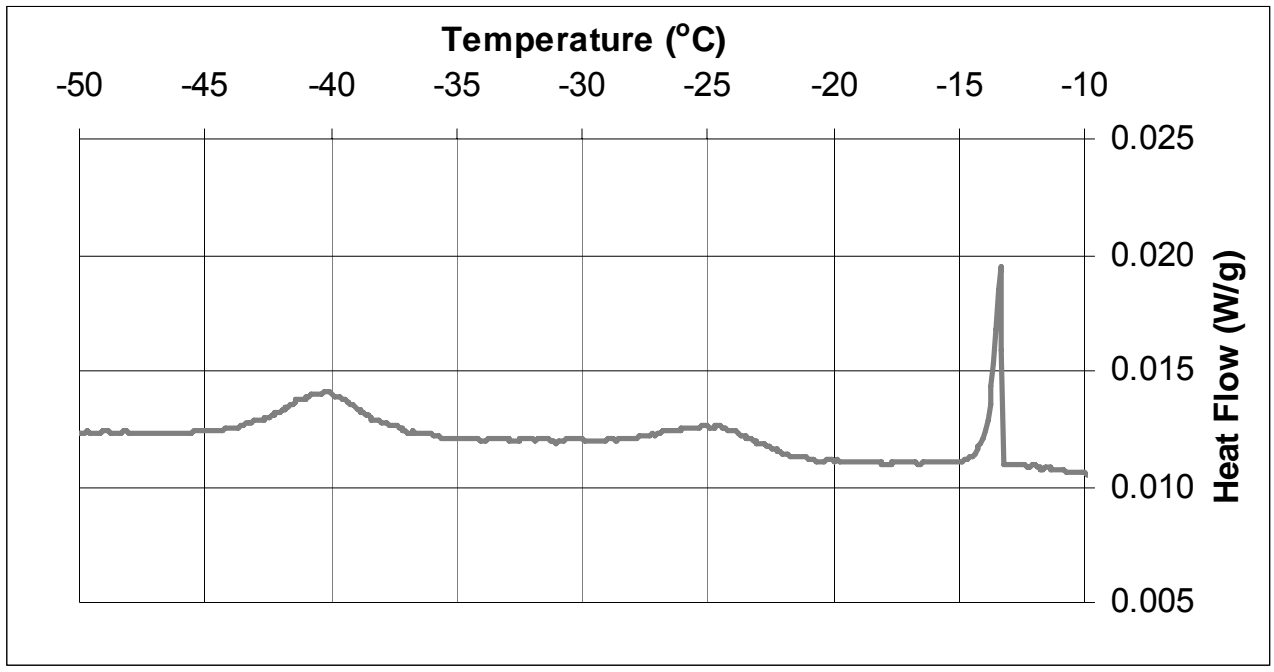

Figure $120 \mathrm{LTC}$ scan for CCRL Cement $152, w / C=0.25$, cured for $28 \mathrm{~d}$ at $40{ }^{\circ} \mathrm{C}$ under sealed conditions, then resaturated for $1 \mathrm{~d}$. 
Cement: CCRL Cement 152

Solution: Distilled water

w/c: 0.35

Temperature: $40{ }^{\circ} \mathrm{C}$

Degree of hydration: 0.516
Curing: Saturated

Age when tested: $1 \mathrm{~d}$

Sample mass: $70.0 \mathrm{mg}$

Filename: c152w35T40sat 1d

Date tested: Jan. 12, 2005

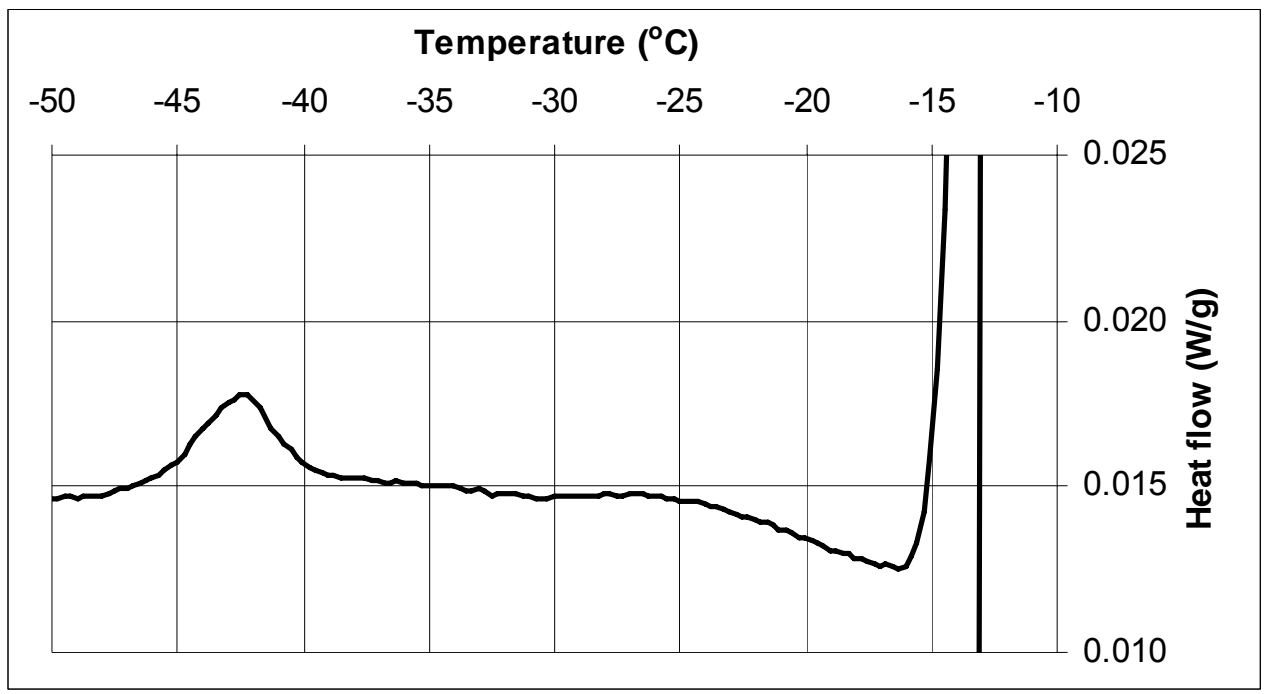

Figure $121 \mathrm{LTC}$ scan for CCRL Cement $152, w / C=0.35$, cured for $1 \mathrm{~d}$ under saturated conditions at $40{ }^{\circ} \mathrm{C}$.

Cement: CCRL Cement 152

Solution: Distilled water w/c: 0.35

Temperature: $40{ }^{\circ} \mathrm{C}$

Degree of hydration: 0.504
Curing: Sealed

Age when tested: $1 \mathrm{~d}$

Sample mass: $43.5 \mathrm{mg}$

Filename: c152w35T40sealld

Date tested: Jan. 12, 2005

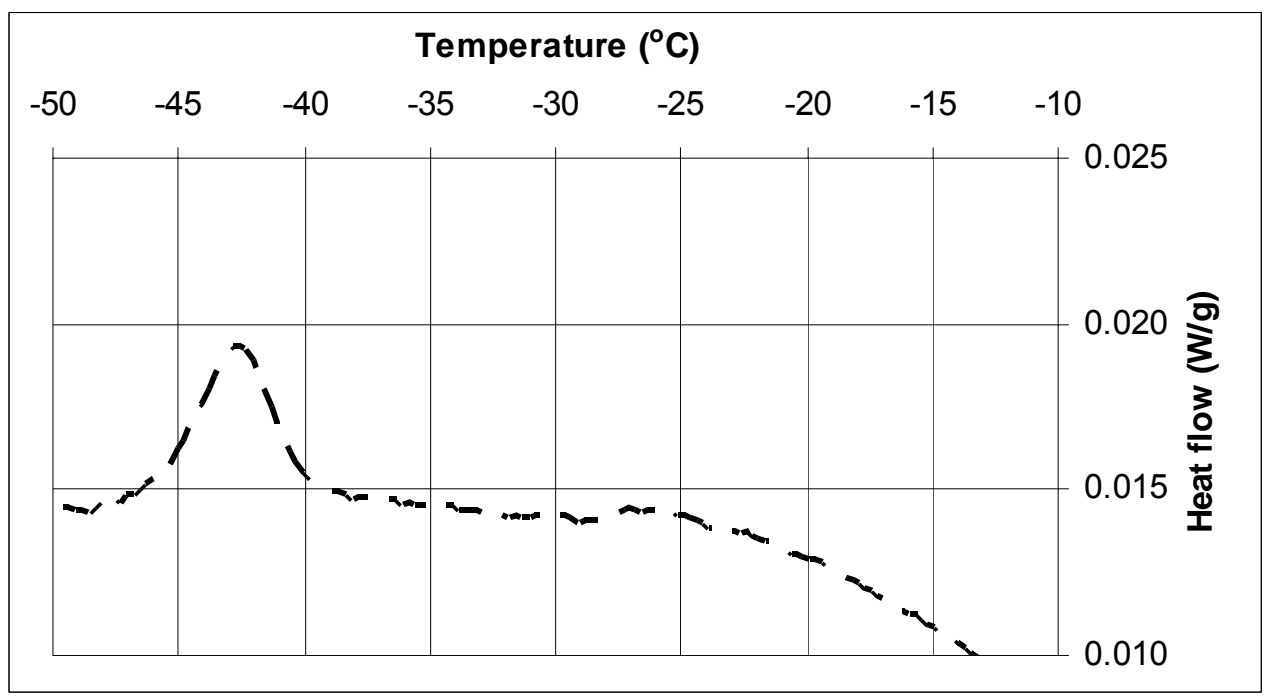

Figure $122 \mathrm{LTC}$ scan for CCRL Cement 152, w/c $=0.35$, cured for $1 \mathrm{~d}$ under sealed conditions at $40{ }^{\circ} \mathrm{C}$. 
Cement: CCRL Cement 152

Solution: Distilled water

w/c: 0.35

Temperature: $40{ }^{\circ} \mathrm{C}$

Degree of hydration: N/A
Curing: Sealed $1 \mathrm{~d} /$ resaturated

Age when tested: $2 \mathrm{~d}$

Sample mass: $38.3 \mathrm{mg}$

Filename: c152w35T40sealresat1d

Date tested: Jan. 13, 2005

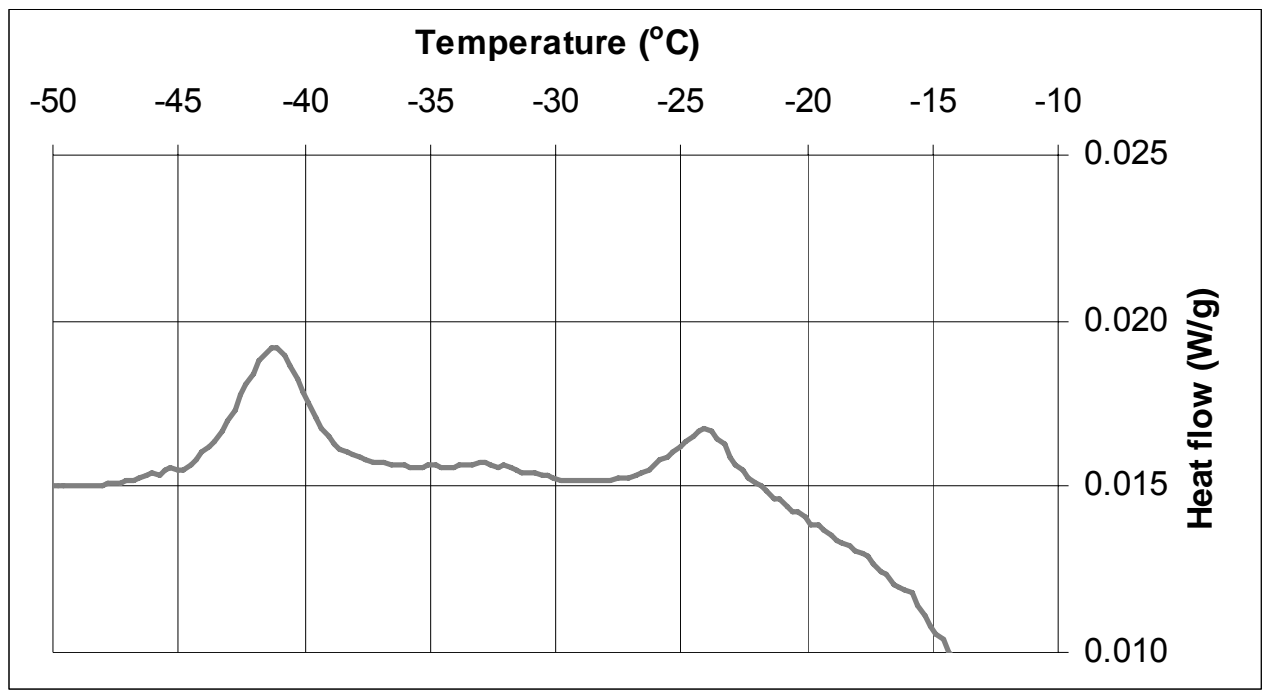

Figure $123 \mathrm{LTC}$ scan for CCRL Cement $152, w / c=0.35$, cured for $1 \mathrm{~d}$ at $40{ }^{\circ} \mathrm{C}$ under sealed conditions, then resaturated for $1 \mathrm{~d}$.

Cement: CCRL Cement 152

Solution: Distilled water

w/c: 0.35

Temperature: $40{ }^{\circ} \mathrm{C}$

Degree of hydration: N/A
Curing: Sealed $1 \mathrm{~d} /$ resaturated

Age when tested: $3 \mathrm{~d}$

Sample mass: $85.7 \mathrm{mg}$

Filename: c152w35T40sealresatb1d

Date tested: Jan. 14, 2005

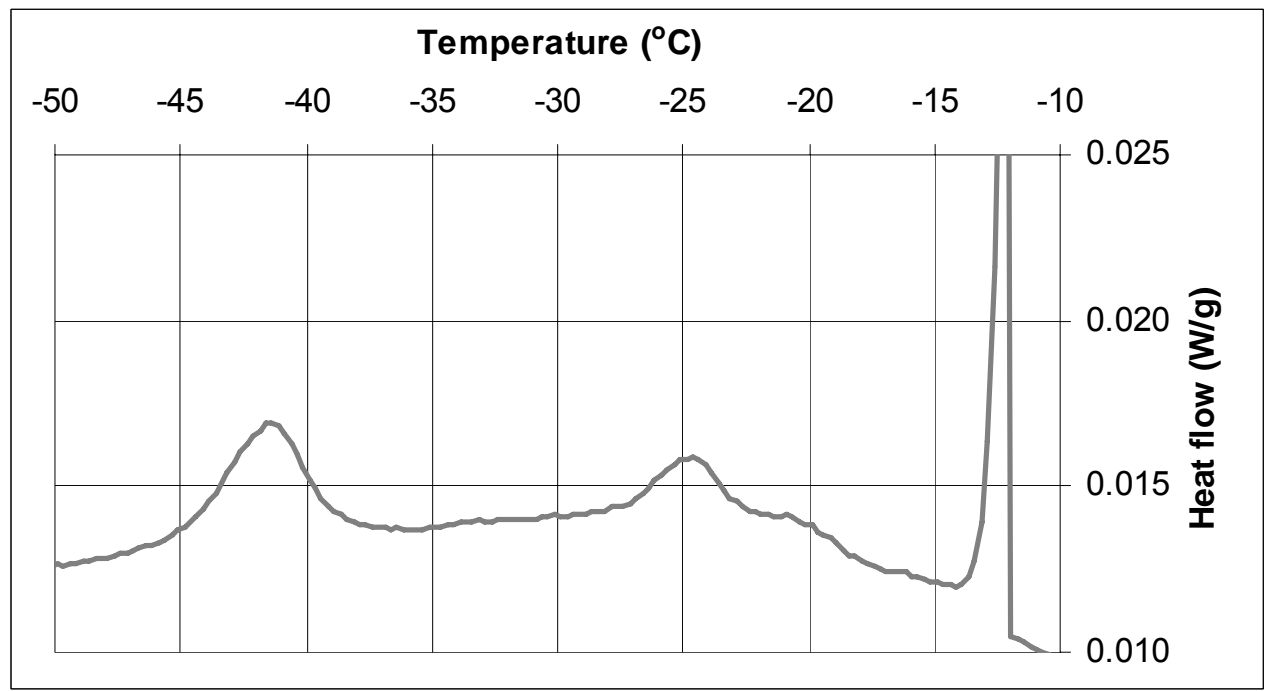

Figure $124 \mathrm{LTC}$ scan for CCRL Cement $152, w / c=0.35$, cured for $1 \mathrm{~d}$ at $40{ }^{\circ} \mathrm{C}$ under sealed conditions, then resaturated for $2 \mathrm{~d}$. 
Cement: CCRL Cement 152

Solution: Distilled water

w/c: 0.35

Temperature: $40{ }^{\circ} \mathrm{C}$

Degree of hydration: 0.655
Curing: Saturated

Age when tested: $2 \mathrm{~d}$

Sample mass: $52.8 \mathrm{mg}$

Filename: c152w35T40sat2d

Date tested: Jan. 13, 2005

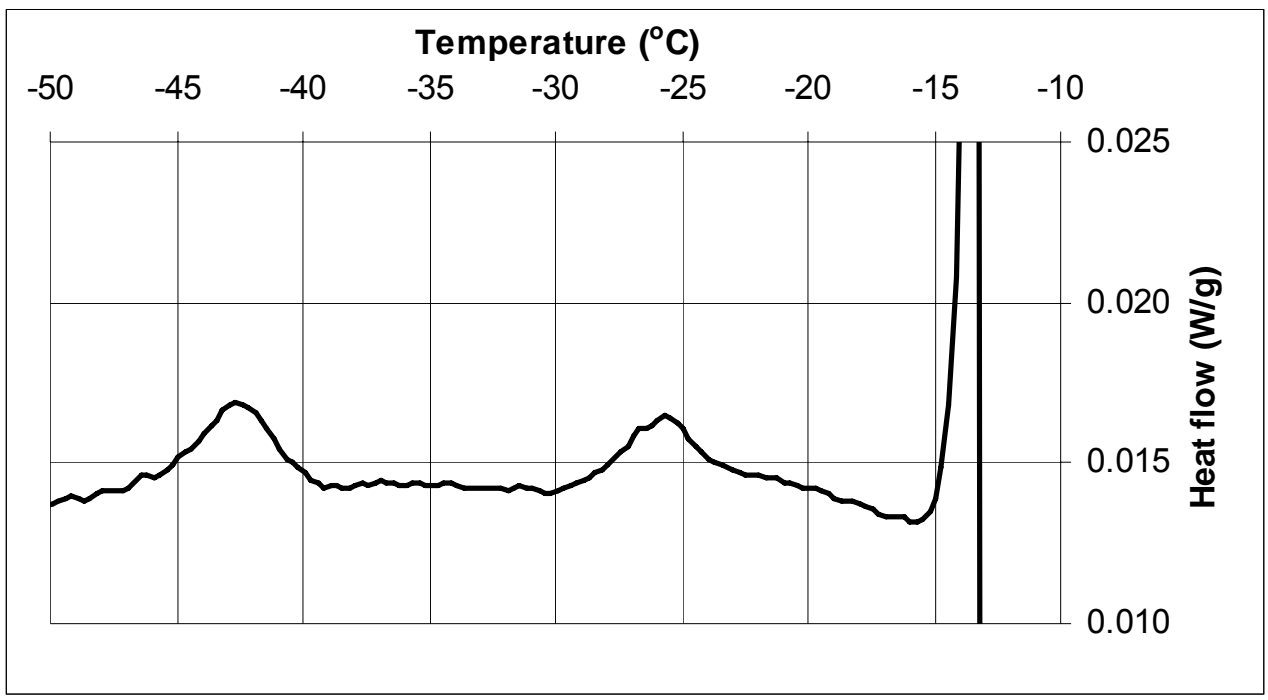

Figure $125 \mathrm{LTC}$ scan for CCRL Cement $152, w / c=0.35$, cured for $2 \mathrm{~d}$ under saturated conditions at $40{ }^{\circ} \mathrm{C}$.

Cement: CCRL Cement 152

Solution: Distilled water

w/c: 0.35

Temperature: $40{ }^{\circ} \mathrm{C}$

Degree of hydration: 0.589
Curing: Sealed

Age when tested: $2 \mathrm{~d}$

Sample mass: $77.3 \mathrm{mg}$

Filename: c152w35T40seal2d

Date tested: Jan. 13, 2005

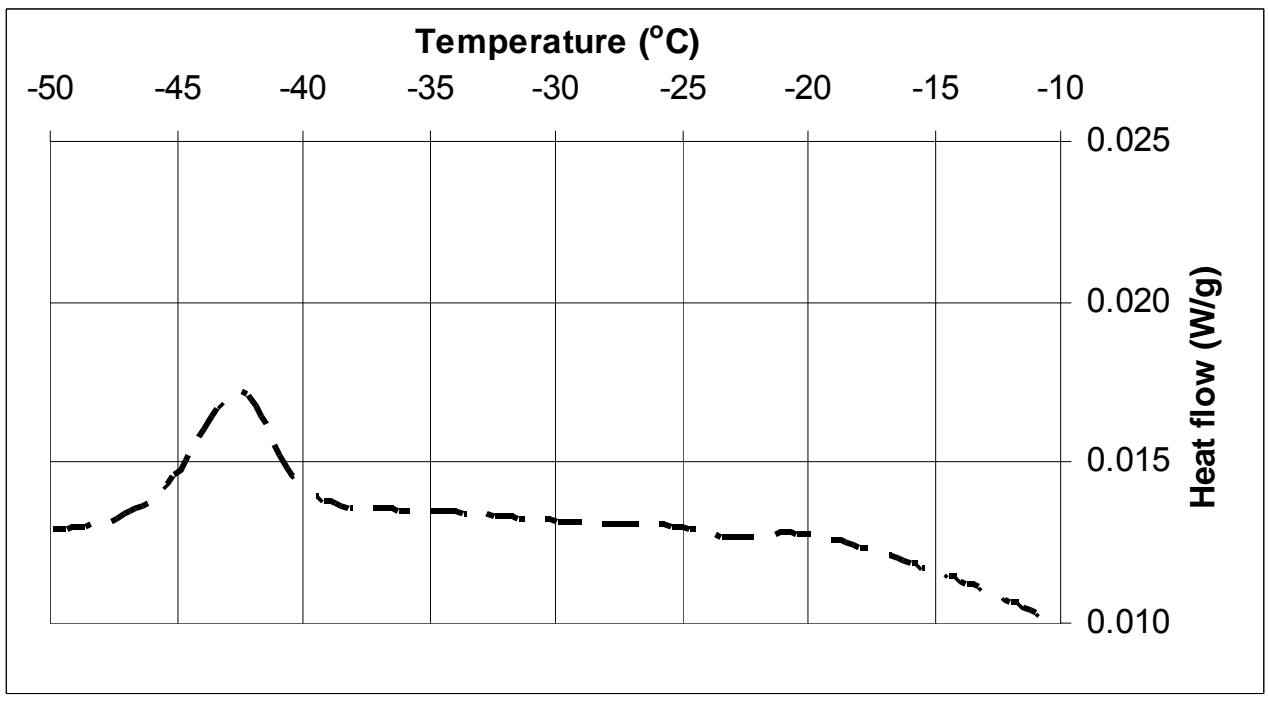

Figure $126 \mathrm{LTC}$ scan for CCRL Cement $152, w / c=0.35$, cured for $2 \mathrm{~d}$ under sealed conditions at $40{ }^{\circ} \mathrm{C}$. 
Cement: CCRL Cement 152

Solution: Distilled water

w/c: 0.35

Temperature: $40{ }^{\circ} \mathrm{C}$

Degree of hydration: 0.738
Curing: Saturated

Age when tested: $7 \mathrm{~d}$

Sample mass: $77.3 \mathrm{mg}$

Filename: c152w35T40sat7d

Date tested: Jan. 18, 2005

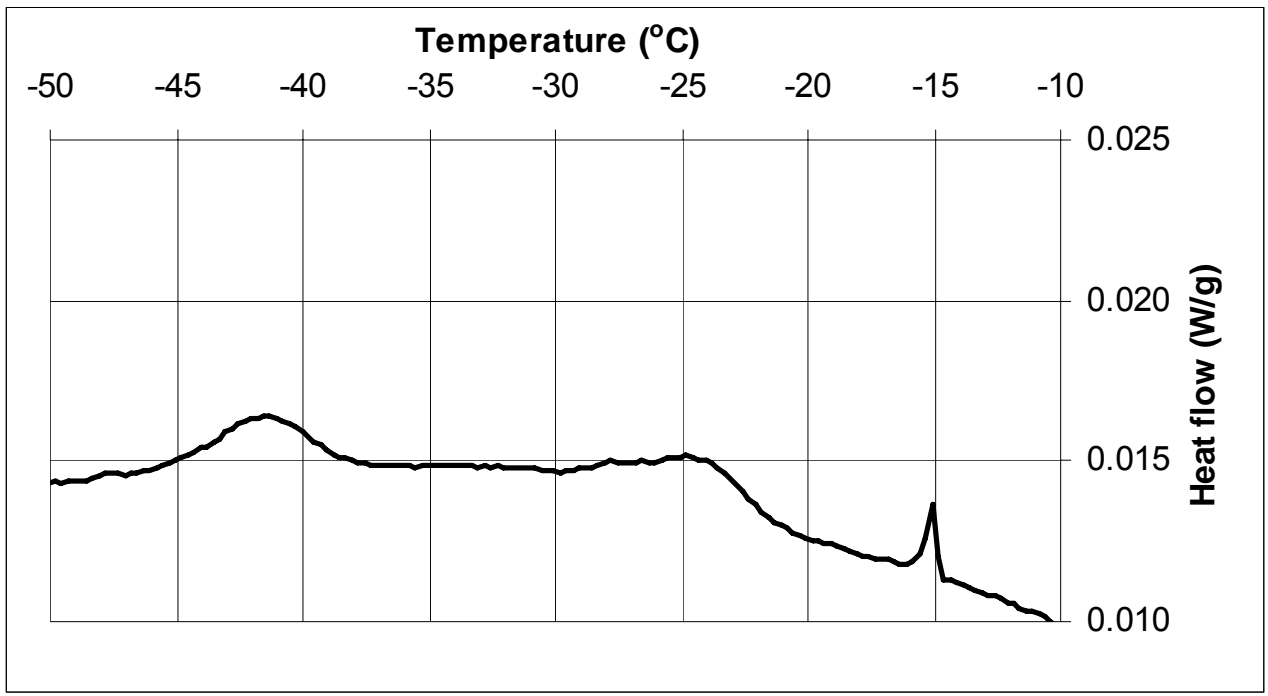

Figure $127 \mathrm{LTC}$ scan for CCRL Cement $152, w / c=0.35$, cured for $7 \mathrm{~d}$ under saturated conditions at $40{ }^{\circ} \mathrm{C}$.

Cement: CCRL Cement 152

Solution: Distilled water

w/c: 0.35

Temperature: $40{ }^{\circ} \mathrm{C}$

Degree of hydration: 0.642
Curing: Sealed

Age when tested: $7 \mathrm{~d}$

Sample mass: $50.9 \mathrm{mg}$

Filename: c152w35T40seal7d

Date tested: Jan. 18, 2005

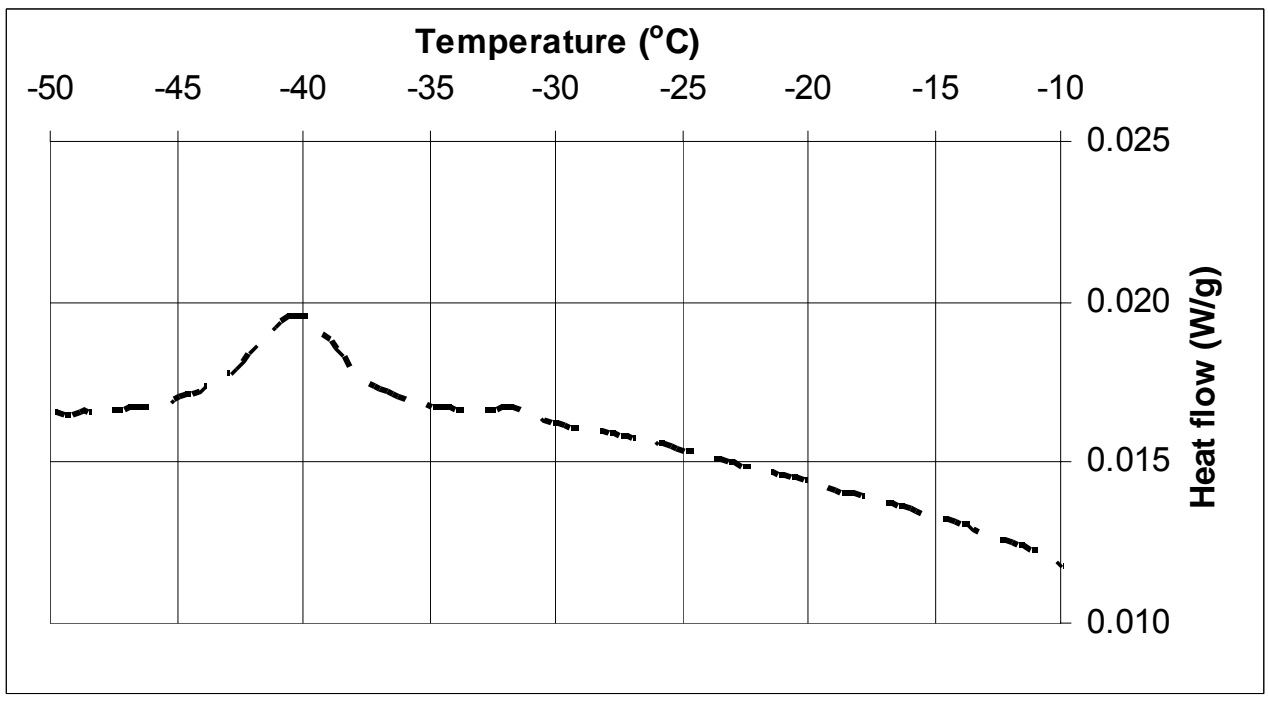

Figure $128 \mathrm{LTC}$ scan for CCRL Cement $152, w / c=0.35$, cured for $7 \mathrm{~d}$ under sealed conditions at $40{ }^{\circ} \mathrm{C}$. 
Cement: CCRL Cement 152

Solution: Distilled water

w/c: 0.35

Temperature: $40{ }^{\circ} \mathrm{C}$

Degree of hydration: N/A
Curing: Sealed $2 \mathrm{~d} /$ resaturated

Age when tested: $7 \mathrm{~d}$

Sample mass: $76.8 \mathrm{mg}$

Filename: c152w35T40sealresat2t7d

Date tested: Jan. 18, 2005

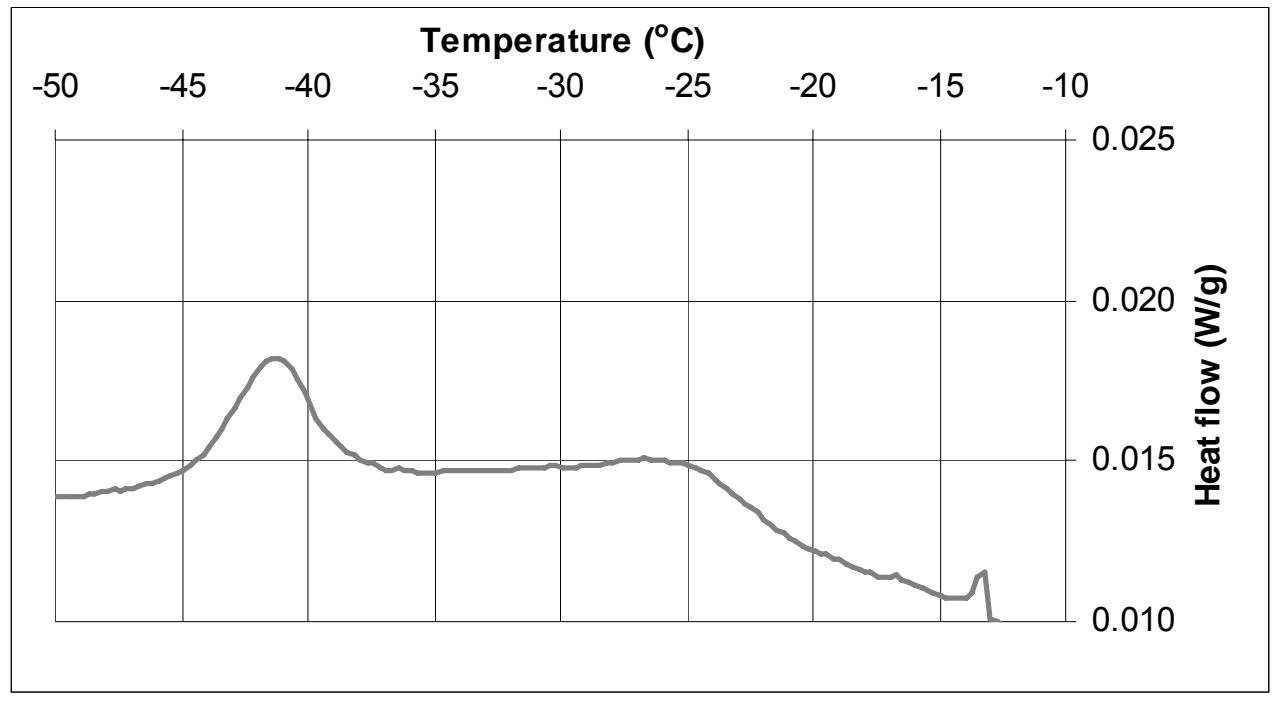

Figure $129 \mathrm{LTC}$ scan for CCRL Cement $152, w / c=0.35$, cured for $2 \mathrm{~d}$ under sealed conditions at $40{ }^{\circ} \mathrm{C}$, then resaturated for $5 \mathrm{~d}$.

Cement: CCRL Cement 152

Solution: Distilled water

w/c: 0.35

Temperature: $40{ }^{\circ} \mathrm{C}$

Degree of hydration: N/A
Curing: Sealed $7 \mathrm{~d} /$ resaturated

Age when tested: $13 \mathrm{~d}$

Sample mass: $52.7 \mathrm{mg}$

Filename: c152w35T40sealresat7t13d

Date tested: Jan. 24, 2005

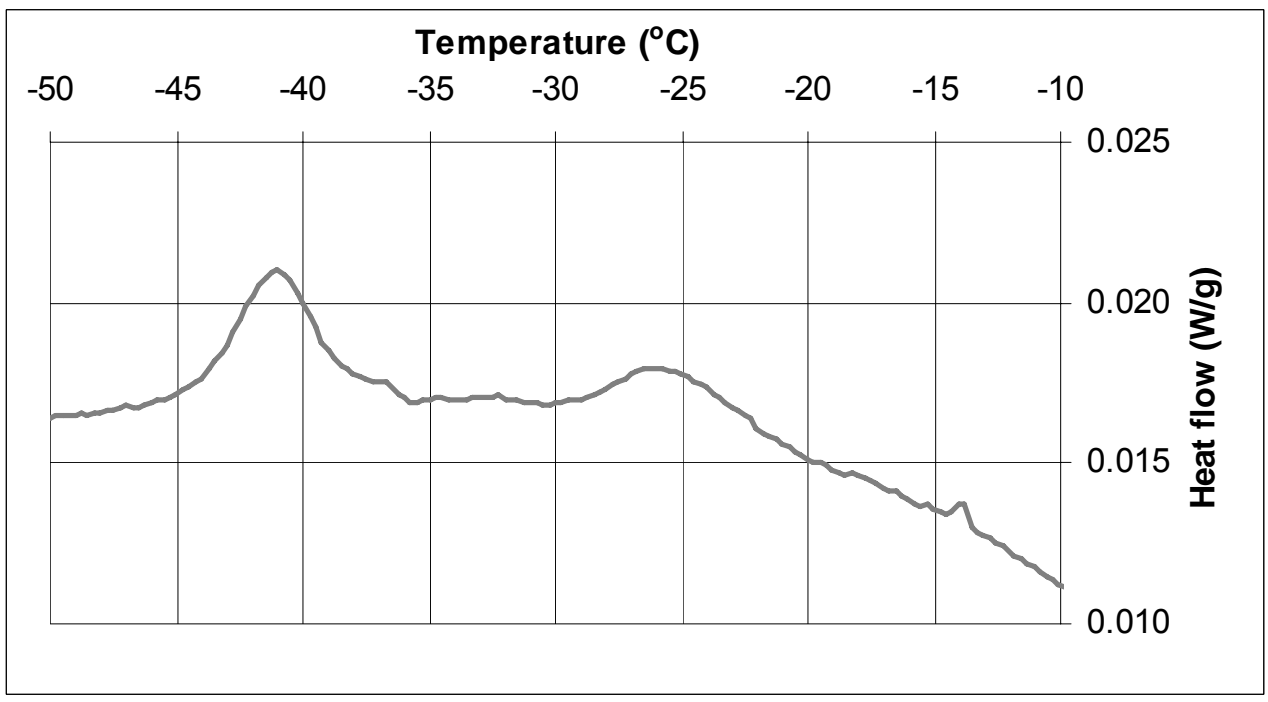

Figure $130 \mathrm{LTC}$ scan for CCRL Cement $152, w / c=0.35$, cured for $7 \mathrm{~d}$ under sealed conditions at $40{ }^{\circ} \mathrm{C}$, then resaturated for $6 \mathrm{~d}$. 
Cement: CCRL Cement 152

Solution: Distilled water

$w / c: 0.35$

Temperature: $40{ }^{\circ} \mathrm{C}$

Degree of hydration: 0.761
Curing: Saturated

Age when tested: $14 \mathrm{~d}$

Sample mass: $60.8 \mathrm{mg}$

Filename: c152w35T40sat14d

Date tested: Jan. 25, 2005

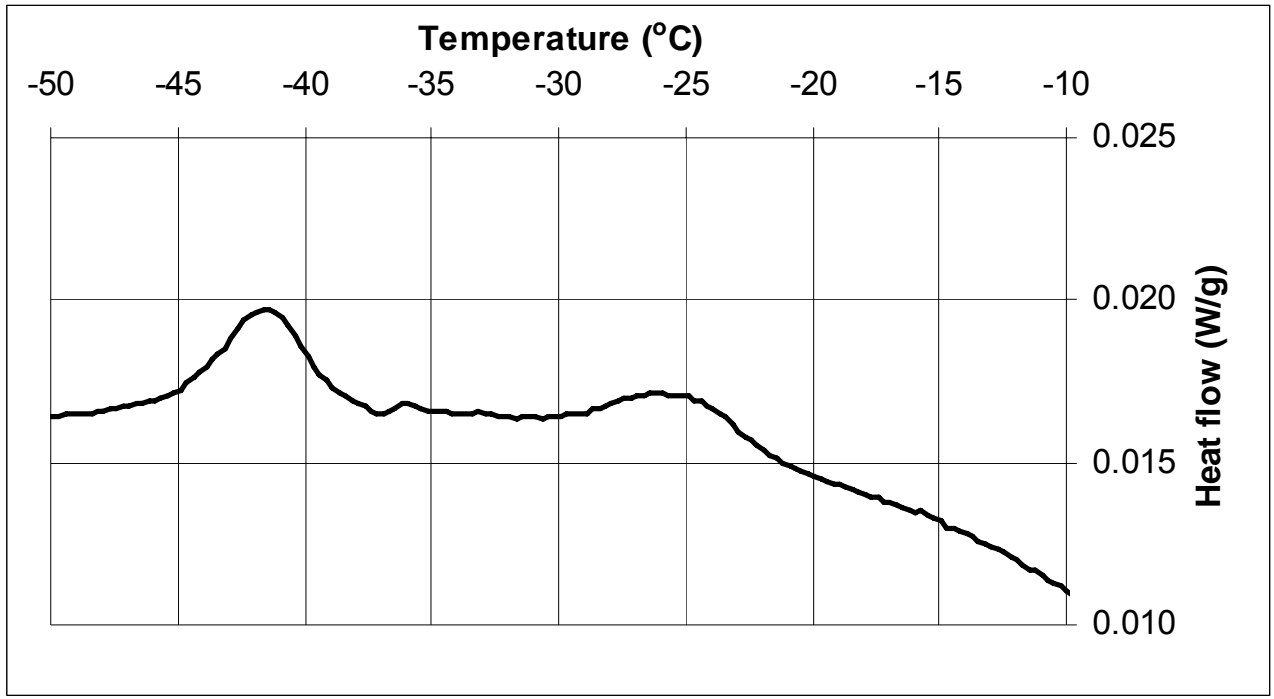

Figure $131 \mathrm{LTC}$ scan for CCRL Cement $152, w / c=0.35$, cured for $14 \mathrm{~d}$ under saturated conditions at 40 ${ }^{\circ} \mathrm{C}$.

Cement: CCRL Cement 152

Solution: Distilled water

w/c: 0.35

Temperature: $40{ }^{\circ} \mathrm{C}$

Degree of hydration: 0.645
Curing: Sealed

Age when tested: $14 \mathrm{~d}$

Sample mass: $62.7 \mathrm{mg}$

Filename: c152w35T40seal14d

Date tested: Jan. 25, 2005

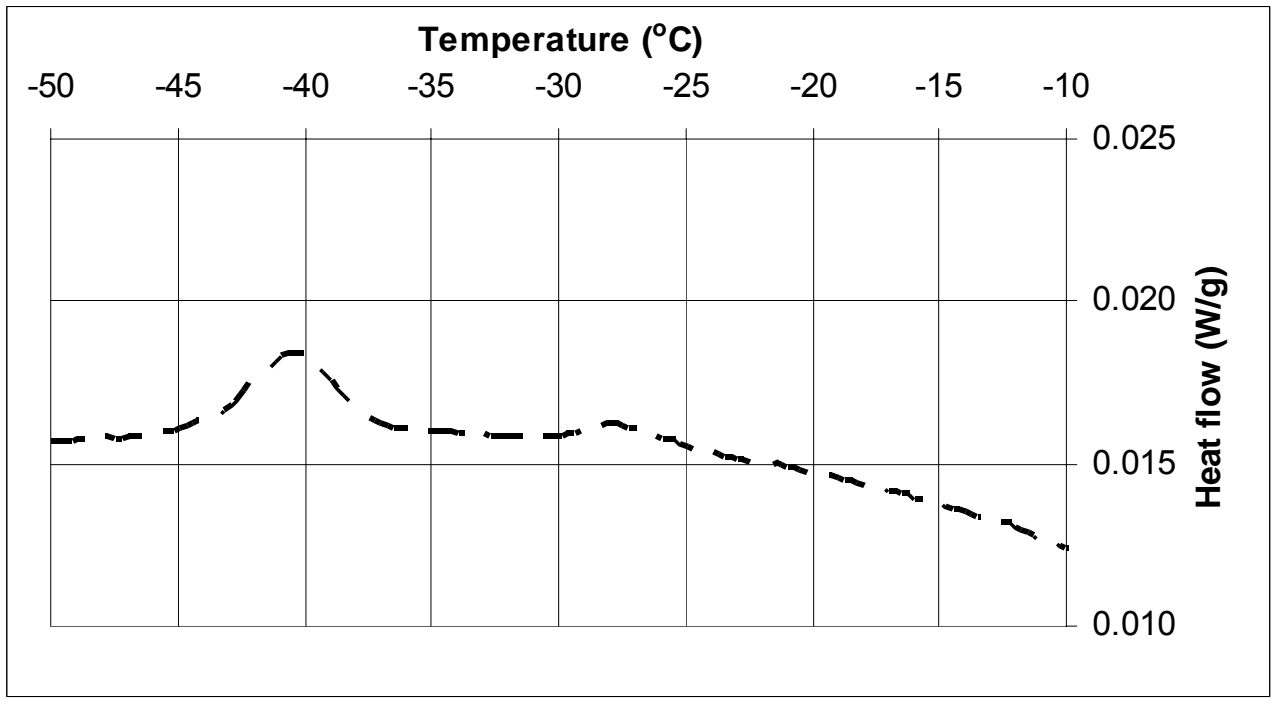

Figure $132 \mathrm{LTC}$ scan for CCRL Cement $152, w / c=0.35$, cured for $14 \mathrm{~d}$ under sealed conditions at $40{ }^{\circ} \mathrm{C}$. 
Cement: CCRL Cement 152

Solution: Distilled water

w/c: 0.35

Temperature: $40{ }^{\circ} \mathrm{C}$

Degree of hydration: 0.824
Curing: Saturated

Age when tested: $28 \mathrm{~d}$

Sample mass: $97.0 \mathrm{mg}$

Filename: c152w35T40sat28d

Date tested: Feb. 8, 2005

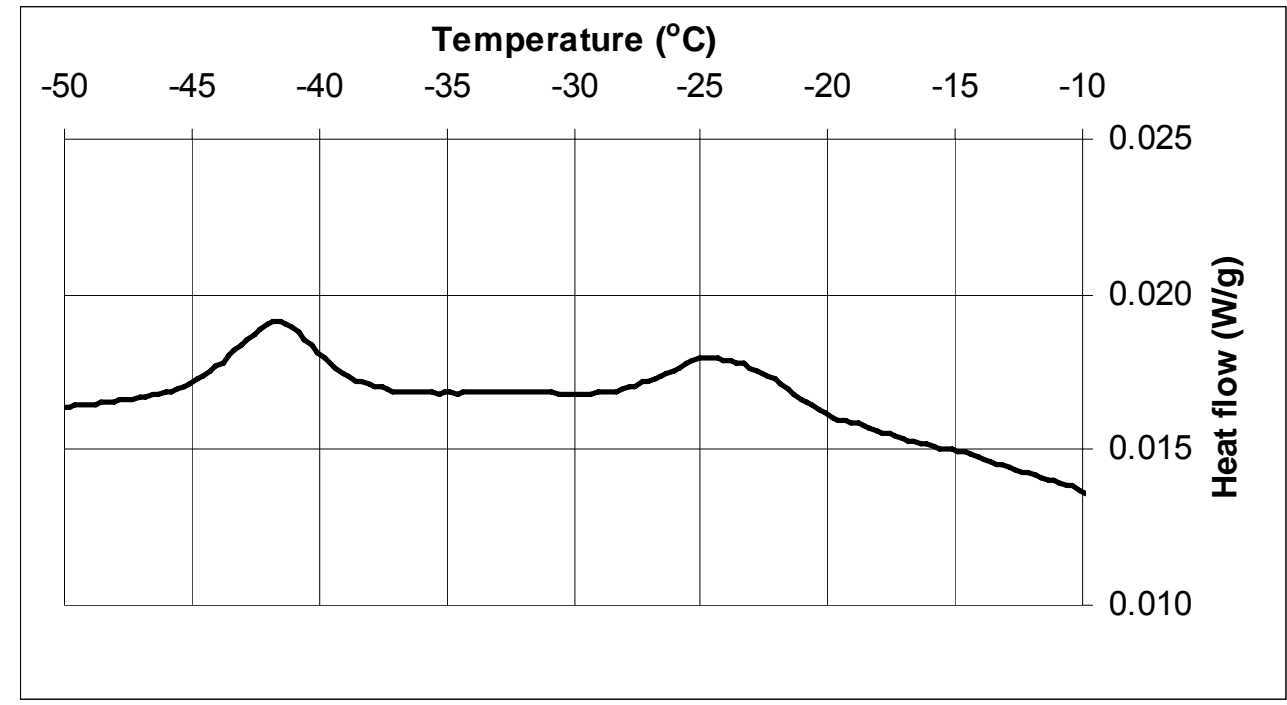

Figure $133 \mathrm{LTC}$ scan for CCRL Cement $152, w / c=0.35$, cured for $28 \mathrm{~d}$ under saturated conditions at 40 ${ }^{\circ} \mathrm{C}$.

Cement: CCRL Cement 152

Solution: Distilled water

$w / c: 0.35$

Temperature: $40{ }^{\circ} \mathrm{C}$

Degree of hydration: 0.681
Curing: Sealed

Age when tested: $28 \mathrm{~d}$

Sample mass: $80.2 \mathrm{mg}$

Filename: c152w035a40Cseal28d

Date tested: Feb. 8, 2005

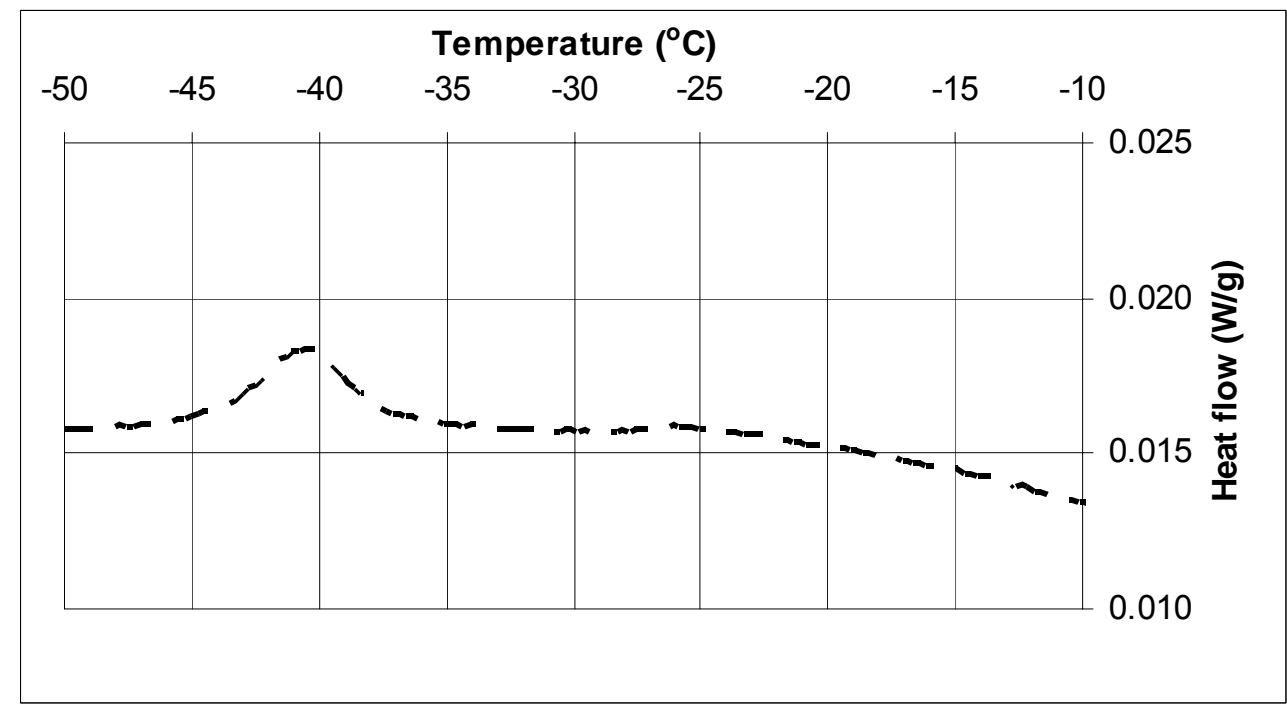

Figure $134 \mathrm{LTC}$ scan for CCRL Cement 152, w/C $=0.35$, cured for $28 \mathrm{~d}$ under sealed conditions at $40{ }^{\circ} \mathrm{C}$. 
Cement: CCRL Cement 152

Solution: Distilled water

w/c: 0.35

Temperature: $40{ }^{\circ} \mathrm{C}$

Degree of hydration: N/A
Curing: Sealed $14 \mathrm{~d} /$ resaturated

Age when tested: $29 \mathrm{~d}$

Sample mass: $51.3 \mathrm{mg}$

Filename: c152w35T40seal14resat29d

Date tested: Feb. 9, 2005

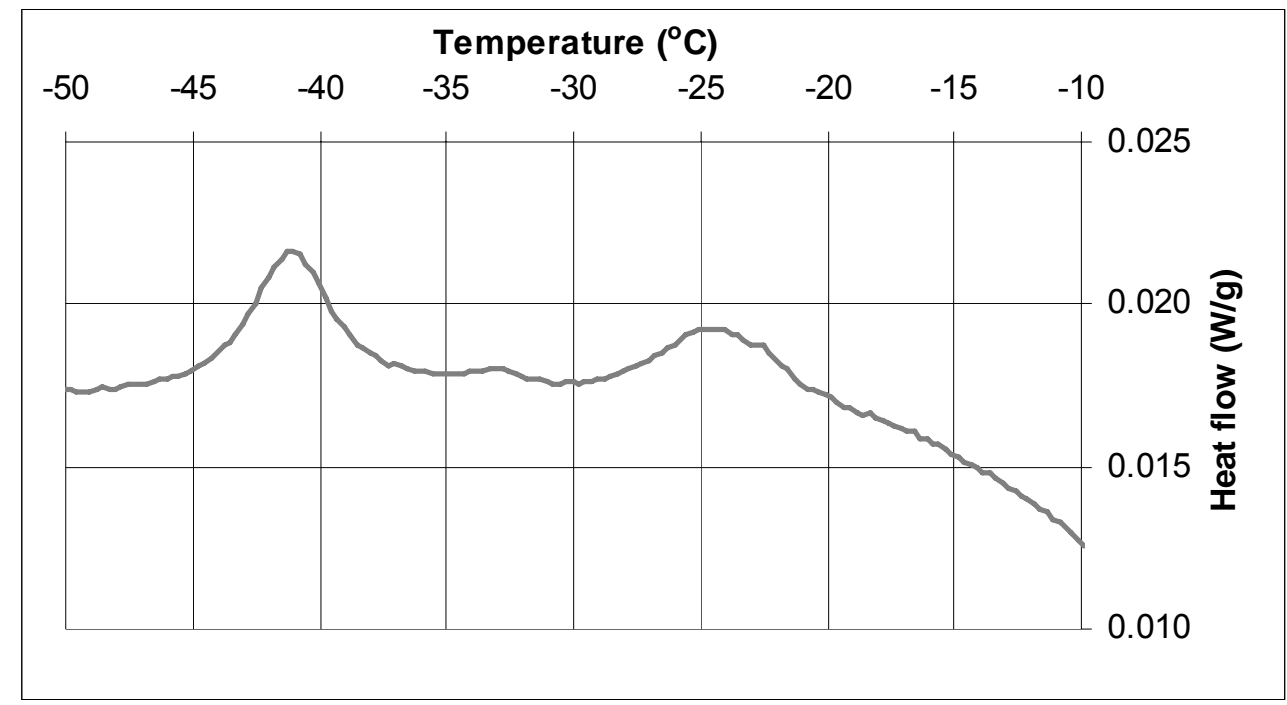

Figure $135 \mathrm{LTC}$ scan for CCRL Cement $152, w / c=0.35$, cured for $14 \mathrm{~d}$ under sealed conditions at $40{ }^{\circ} \mathrm{C}$, then resaturated for $15 \mathrm{~d}$.

Cement: CCRL Cement 152

Solution: Distilled water

$w / c: 0.35$

Temperature: $40{ }^{\circ} \mathrm{C}$

Degree of hydration: N/A
Curing: Sealed $28 \mathrm{~d} /$ resaturated

Age when tested: $29 \mathrm{~d}$

Sample mass: $61.5 \mathrm{mg}$

Filename: c152w35T40Csealresat28d

Date tested: Feb. 9, 2005

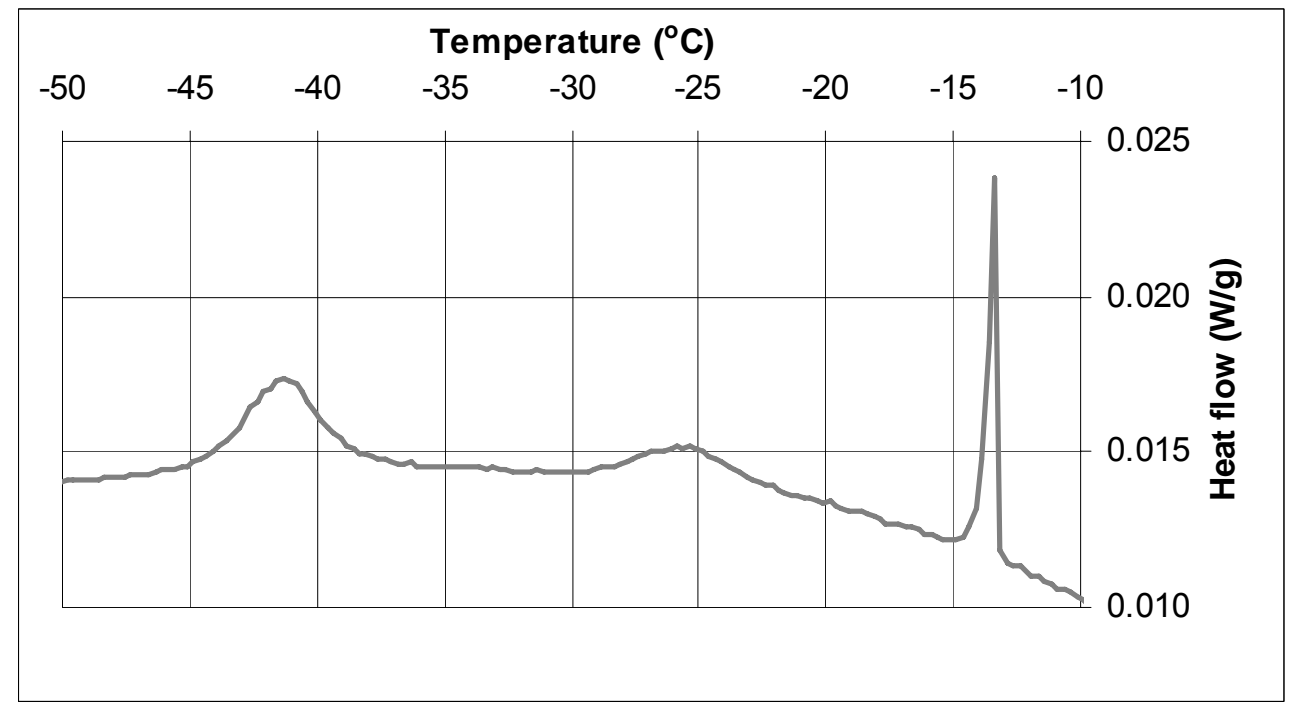

Figure $136 \mathrm{LTC}$ scan for CCRL Cement $152, w / c=0.35$, cured for $28 \mathrm{~d}$ under sealed conditions at $40{ }^{\circ} \mathrm{C}$, then resaturated for $1 \mathrm{~d}$. 
Cement: CCRL Cement 152

Solution: Distilled water

w/c: 0.35

Temperature: $40{ }^{\circ} \mathrm{C}$

Degree of hydration: 0.794
Curing: Saturated

Age when tested: $58 \mathrm{~d}$

Sample mass: $57.3 \mathrm{mg}$

Filename: c152w035T40Csat58d

Date tested: March 10, 2005

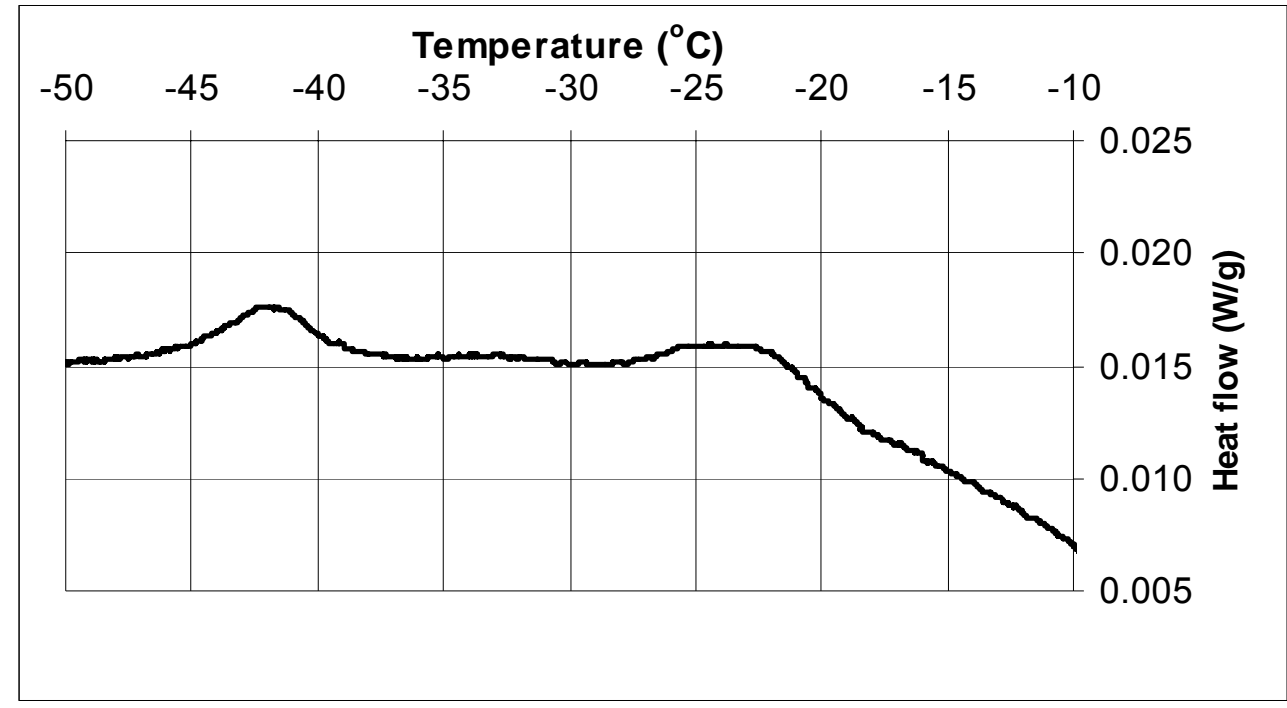

Figure $137 \mathrm{LTC}$ scan for CCRL Cement $152, w / c=0.35$, cured for $58 \mathrm{~d}$ under saturated conditions at 40 ${ }^{\circ} \mathrm{C}$.

Cement: CCRL Cement 152

Solution: Distilled water

w/c: 0.35

Temperature: $40{ }^{\circ} \mathrm{C}$

Degree of hydration: 0.743
Curing: Sealed

Age when tested: $58 \mathrm{~d}$

Sample mass: $51.3 \mathrm{mg}$

Filename: c152w035T40Cseal58d

Date tested: March 10, 2005

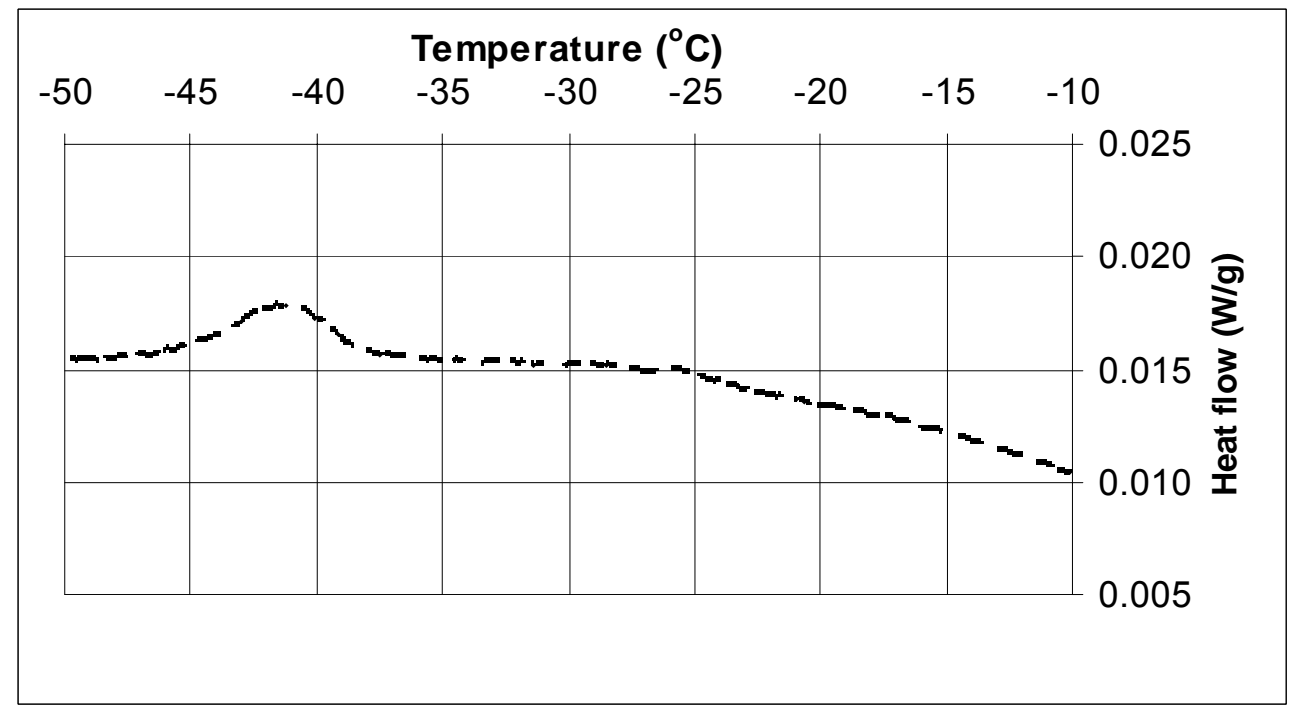

Figure $138 \mathrm{LTC}$ scan for CCRL Cement 152, w/C $=0.35$, cured for $58 \mathrm{~d}$ under sealed conditions at $40{ }^{\circ} \mathrm{C}$. 
Cement: CCRL Cement 152

Solution: Distilled water

w/c: 0.35

Temperature: $40{ }^{\circ} \mathrm{C}$

Degree of hydration: N/A
Curing: Sealed $57 \mathrm{~d} /$ resaturated

Age when tested: $58 \mathrm{~d}$

Sample mass: $62.1 \mathrm{mg}$

Filename: c152w035T40Csealresat58d

Date tested: March 10, 2005

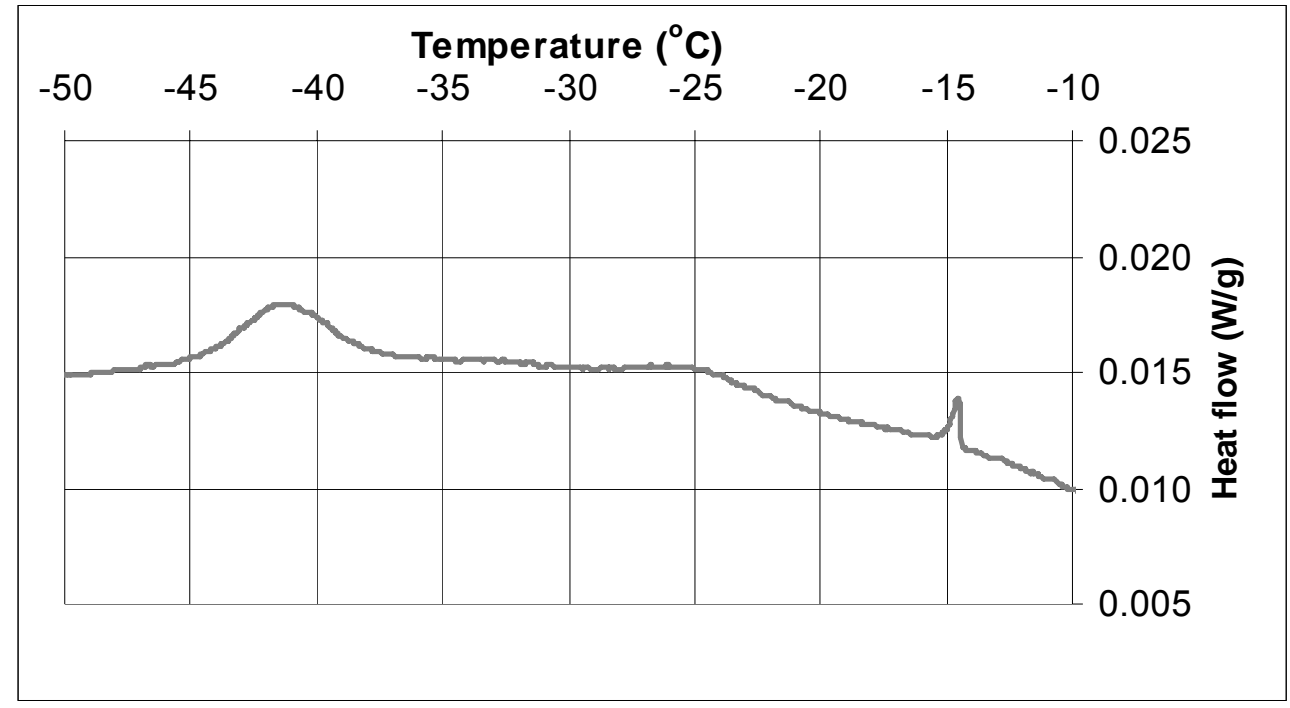

Figure $139 \mathrm{LTC}$ scan for CCRL Cement $152, w / c=0.35$, cured for $57 \mathrm{~d}$ under sealed conditions at $40{ }^{\circ} \mathrm{C}$, then resaturated for $1 \mathrm{~d}$.

Cement: CCRL Cement 152

Solution: Distilled water

w/c: 0.35

Temperature: $40{ }^{\circ} \mathrm{C}$

Degree of hydration: N/A
Curing: Sealed $57 \mathrm{~d} /$ resaturated

Age when tested: $63 \mathrm{~d}$

Sample mass: $71.5 \mathrm{mg}$

Filename: c152w035T40Cresat58t63d

Date tested: March 15, 2005

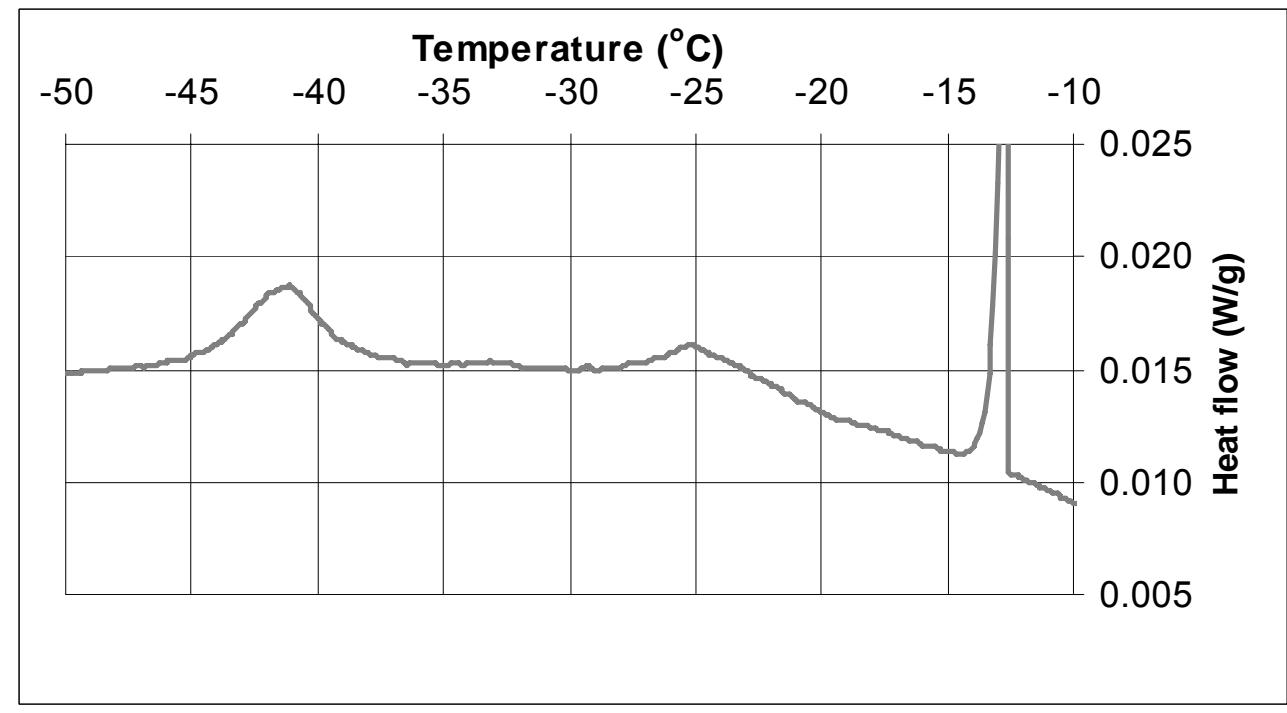

Figure $140 \mathrm{LTC}$ scan for CCRL Cement $152, w / C=0.35$, cured for $57 \mathrm{~d}$ under sealed conditions at $40{ }^{\circ} \mathrm{C}$, then resaturated for $6 \mathrm{~d}$. 
Cement: CCRL Cement 152

Solution: Distilled water

w/c: 0.45

Temperature: $40{ }^{\circ} \mathrm{C}$

Degree of hydration: N/A
Curing: Saturated

Age when tested: $3 \mathrm{~d}$

Sample mass: $55.2 \mathrm{mg}$

Filename: c152w45T40Csat3d

Date tested: Feb. 17, 2005

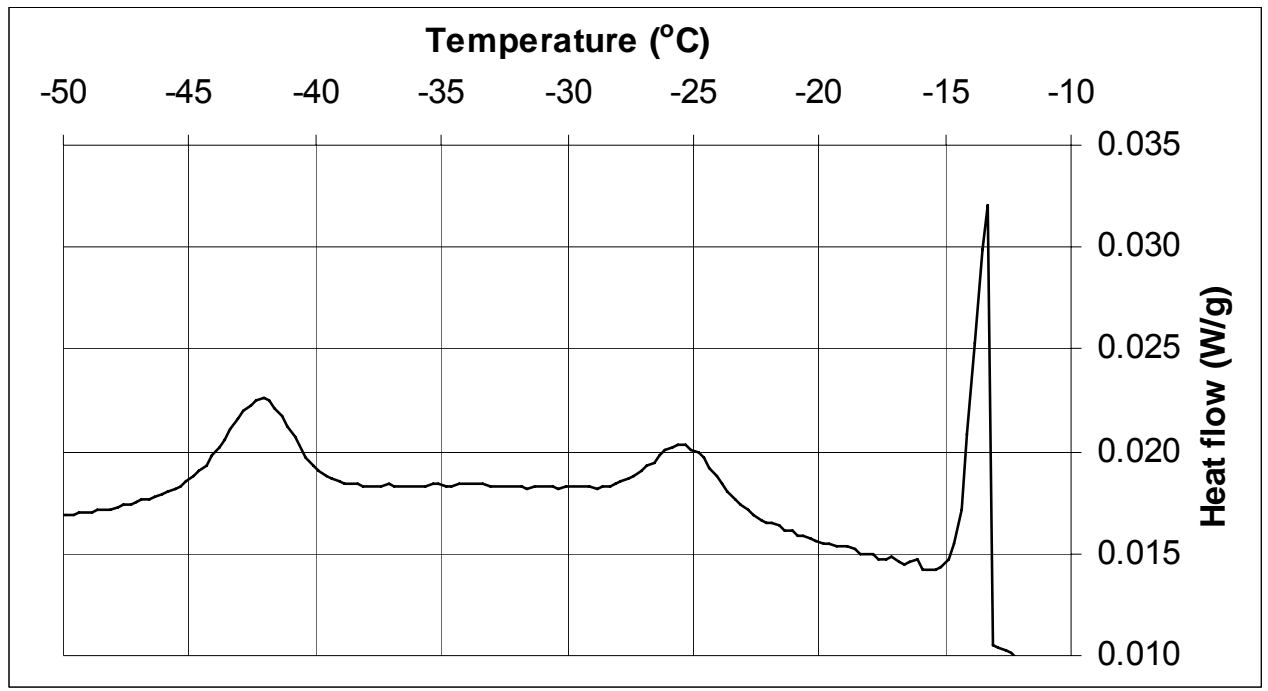

Figure $141 \mathrm{LTC}$ scan for CCRL Cement $152, w / C=0.45$, cured for $3 \mathrm{~d}$ under saturated conditions at $40{ }^{\circ} \mathrm{C}$.

Cement: CCRL Cement 152

Solution: Distilled water

w/c: 0.45

Temperature: $40{ }^{\circ} \mathrm{C}$

Degree of hydration: N/A
Curing: Sealed

Age when tested: $3 \mathrm{~d}$

Sample mass: $55.2 \mathrm{mg}$

Filename: c152w45T40Cseal3d

Date tested: Feb. 17, 2005

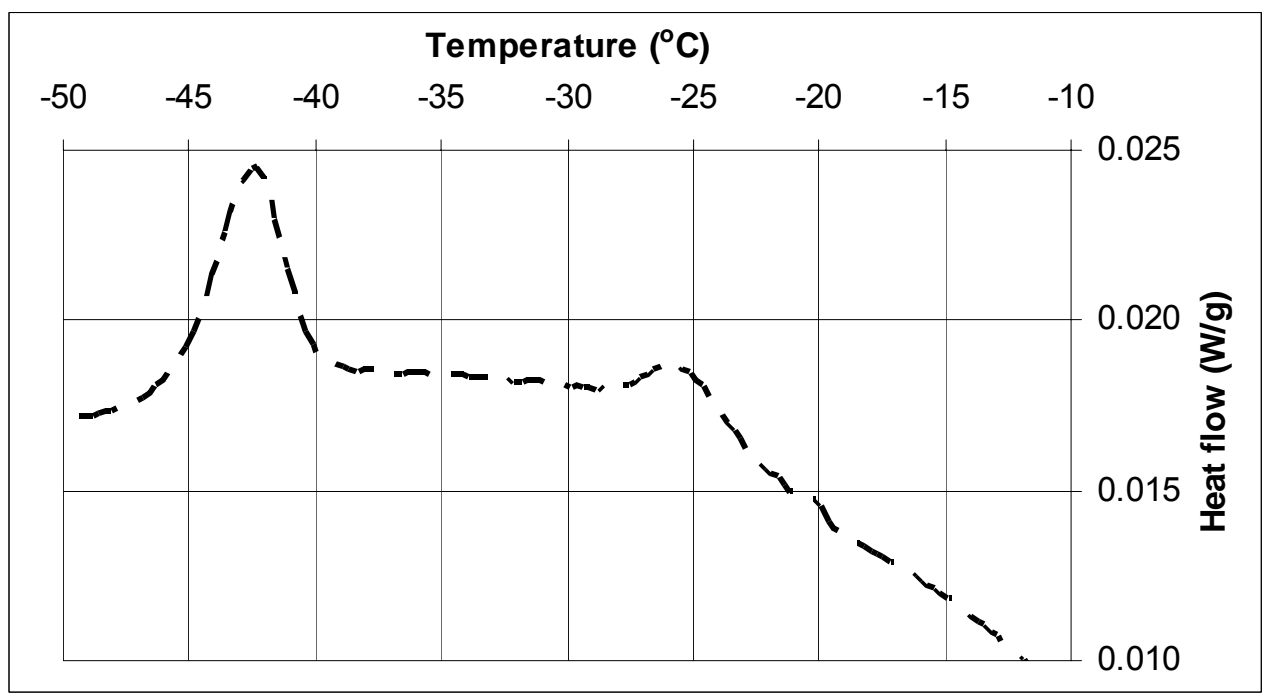

Figure $142 \mathrm{LTC}$ scan for CCRL Cement $152, w / c=0.45$, cured for $3 \mathrm{~d}$ under sealed conditions at $40{ }^{\circ} \mathrm{C}$. 
Cement: CCRL Cement 152

Solution: Distilled water

w/c: 0.45

Temperature: $40{ }^{\circ} \mathrm{C}$

Degree of hydration: 0.822
Curing: Saturated

Age when tested: $8 \mathrm{~d}$

Sample mass: $69.1 \mathrm{mg}$

Filename: c152w45T40Csat8d

Date tested: Feb. 22, 2005

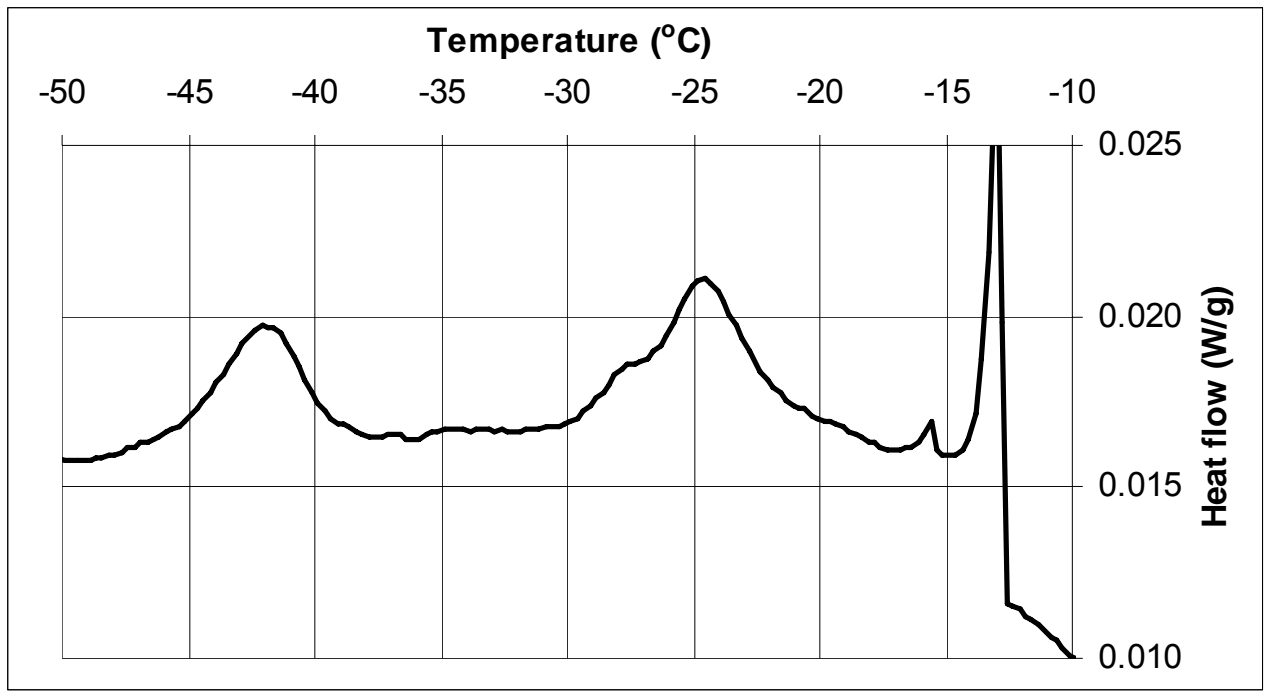

Figure $143 \mathrm{LTC}$ scan for CCRL Cement $152, w / c=0.45$, cured for $8 \mathrm{~d}$ under saturated conditions at $40{ }^{\circ} \mathrm{C}$.

Cement: CCRL Cement 152

Solution: Distilled water w/c: 0.45

Temperature: $40{ }^{\circ} \mathrm{C}$

Degree of hydration: 0.786
Curing: Sealed

Age when tested: $8 \mathrm{~d}$

Sample mass: $51.4 \mathrm{mg}$

Filename: c152w45T40Cseal8d

Date tested: Feb. 22, 2005

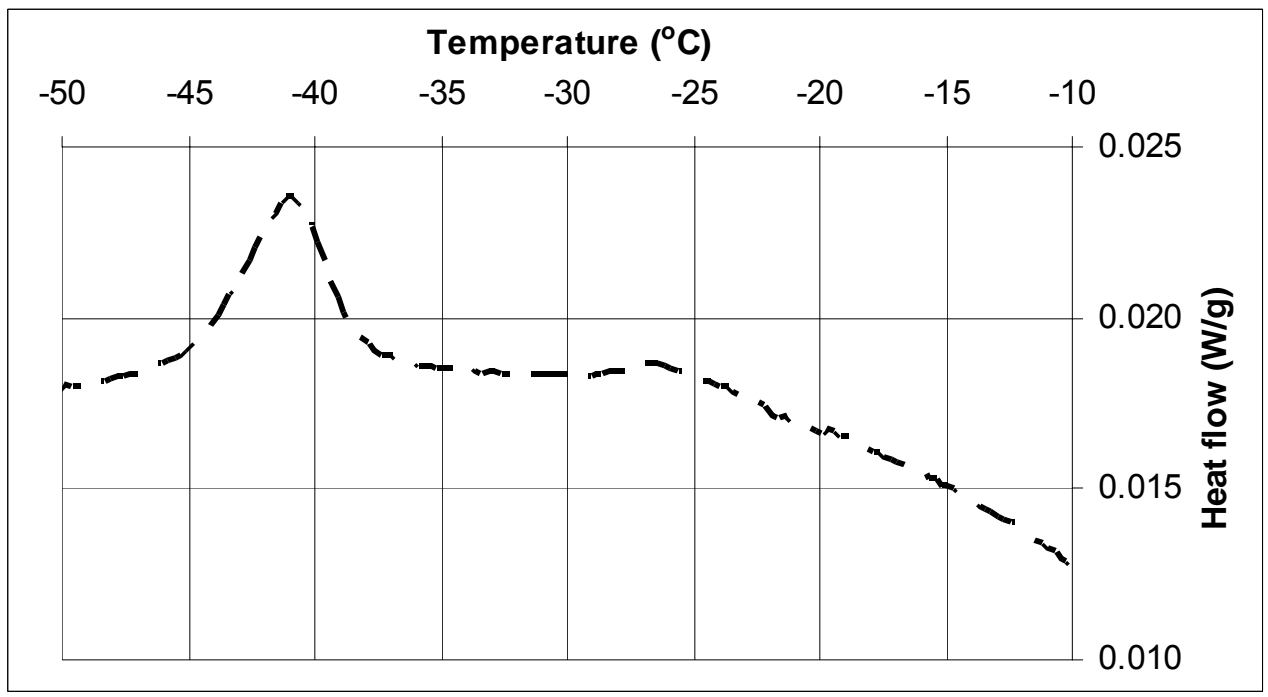

Figure $144 \mathrm{LTC}$ scan for CCRL Cement $152, w / c=0.45$, cured for $8 \mathrm{~d}$ under sealed conditions at $40^{\circ} \mathrm{C}$. 
Cement: CCRL Cement 152

Solution: Distilled water

w/c: 0.45

Temperature: $40{ }^{\circ} \mathrm{C}$

Degree of hydration: N/A
Curing: Sealed $3 \mathrm{~d} /$ resaturated

Age when tested: $8 \mathrm{~d}$

Sample mass: $45.2 \mathrm{mg}$

Filename: c152w45T40sealresat3t8d

Date tested: Feb. 22, 2005

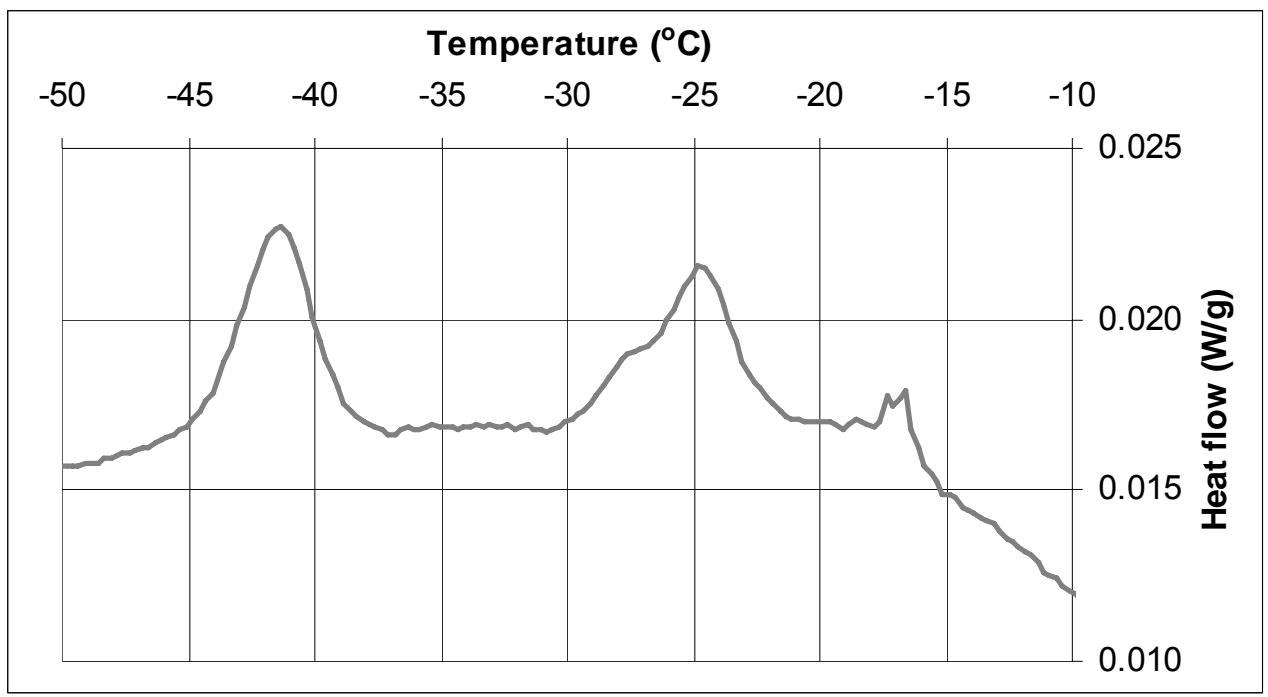

Figure $145 \mathrm{LTC}$ scan for CCRL Cement $152, w / c=0.45$, cured for $3 \mathrm{~d}$ under sealed conditions at $40{ }^{\circ} \mathrm{C}$, then resaturated for $5 \mathrm{~d}$. 
Cement: CCRL Cement 152

Solution: Distilled water

$w / c: 0.45$

Temperature: $40{ }^{\circ} \mathrm{C}$

Degree of hydration: 0.883
Curing: Saturated

Age when tested: $14 \mathrm{~d}$

Sample mass: $58.3 \mathrm{mg}$

Filename: c152w45T40Csat14d

Date tested: Feb. 28, 2005

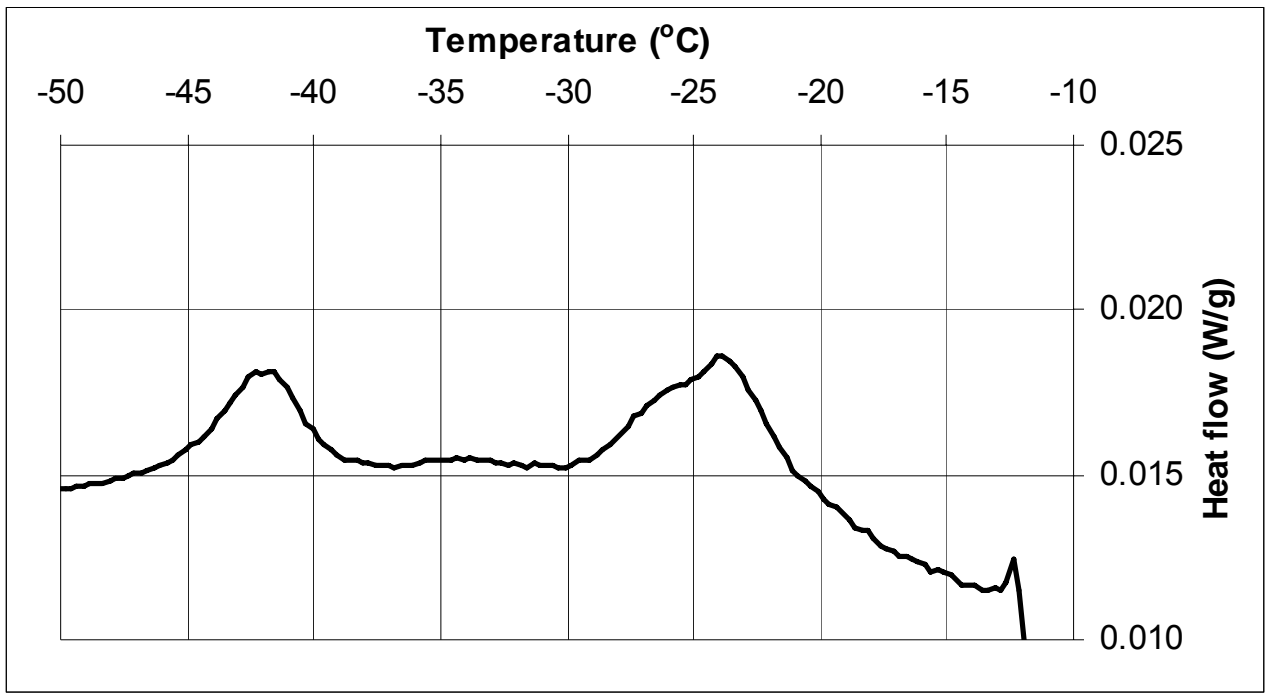

Figure $146 \mathrm{LTC}$ scan for CCRL Cement $152, w / c=0.45$, cured for $14 \mathrm{~d}$ under saturated conditions at 40 ${ }^{\circ} \mathrm{C}$.

Cement: CCRL Cement 152

Solution: Distilled water

$w / c: 0.45$

Temperature: $40{ }^{\circ} \mathrm{C}$

Degree of hydration: 0.799
Curing: Sealed

Age when tested: $14 \mathrm{~d}$

Sample mass: $44.7 \mathrm{mg}$

Filename: c152w45T40Cseal14d

Date tested: Feb. 28, 2005

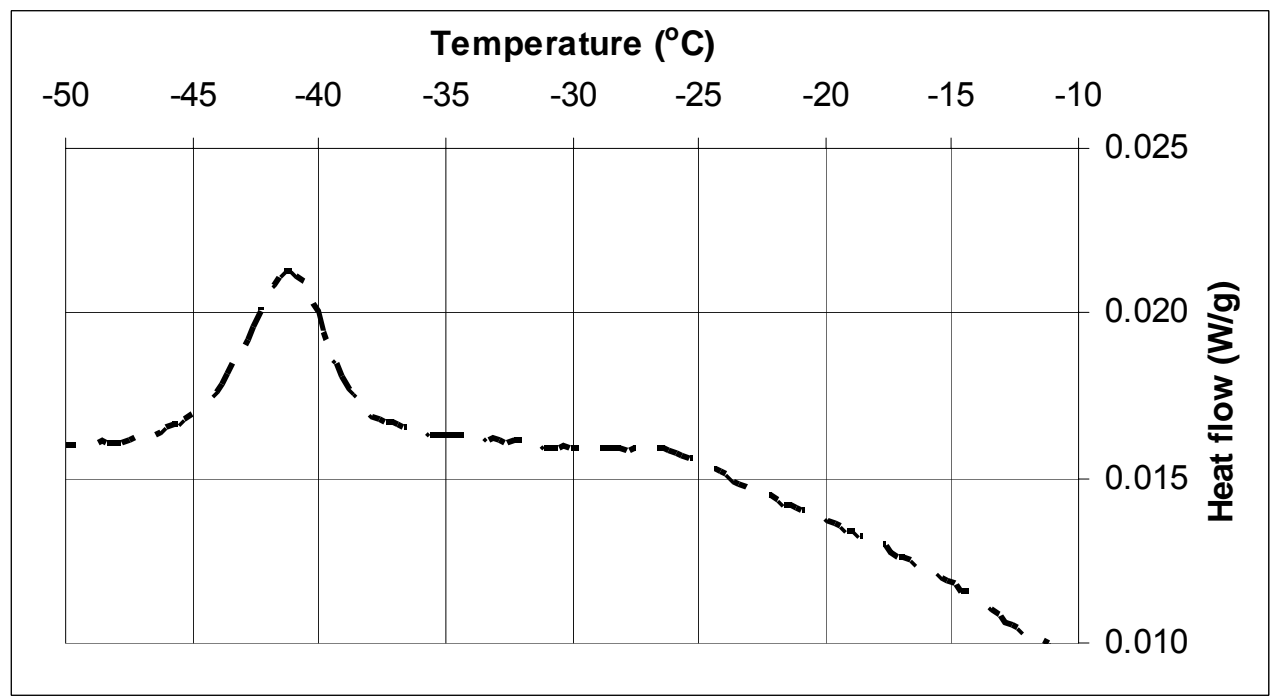

Figure 147 LTC scan for CCRL Cement $152, w / c=0.45$, cured for $14 \mathrm{~d}$ under sealed conditions at $40{ }^{\circ} \mathrm{C}$. 
Cement: CCRL Cement 152

Solution: Distilled water

w/c: 0.45

Temperature: $40{ }^{\circ} \mathrm{C}$

Degree of hydration: N/A
Curing: Sealed $3 \mathrm{~d} /$ resaturated

Age when tested: $14 \mathrm{~d}$

Sample mass: $61.8 \mathrm{mg}$

Filename: c152w45T40sealres3t14d

Date tested: Feb. 28, 2005

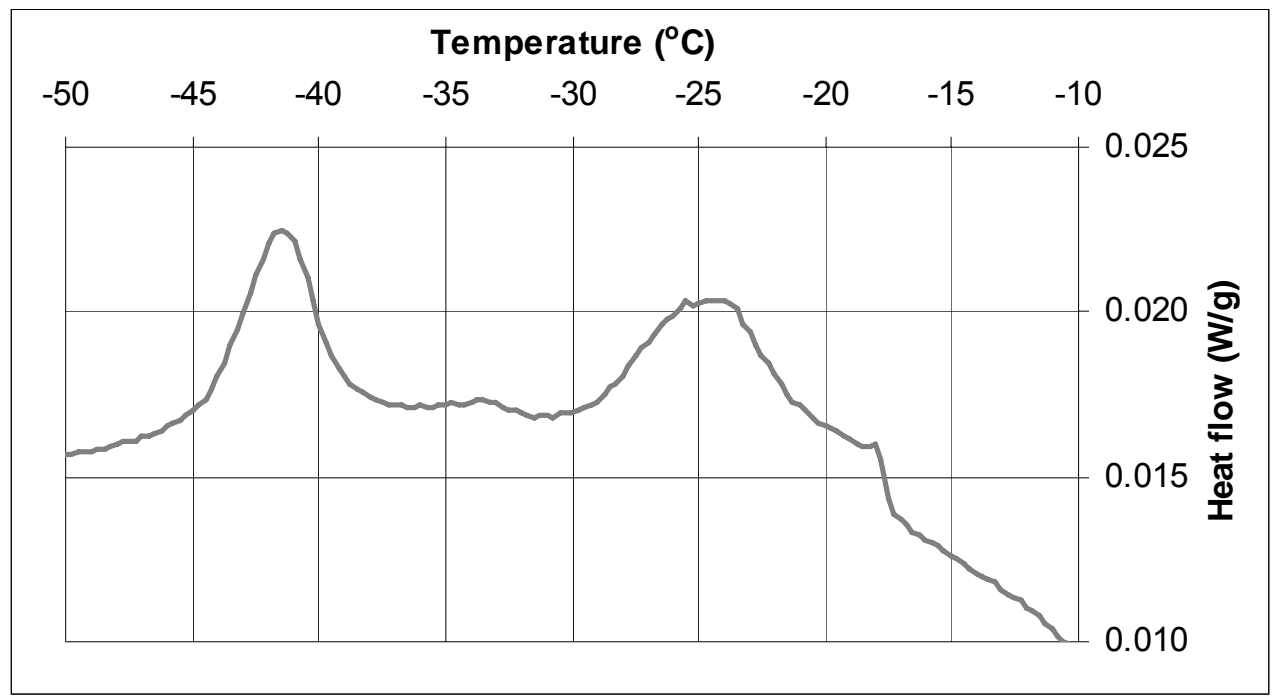

Figure $148 \mathrm{LTC}$ scan for CCRL Cement $152, w / c=0.45$, cured for $3 \mathrm{~d}$ under sealed conditions at $40{ }^{\circ} \mathrm{C}$, then resaturated for $11 \mathrm{~d}$.

Cement: CCRL Cement 152

Solution: Distilled water

w/c: 0.45

Temperature: $40{ }^{\circ} \mathrm{C}$

Degree of hydration: N/A
Curing: Sealed $8 \mathrm{~d} /$ resaturated

Age when tested: $14 \mathrm{~d}$

Sample mass: $68.6 \mathrm{mg}$

Filename: c152w45T40sealres8t14d

Date tested: Feb. 28, 2005

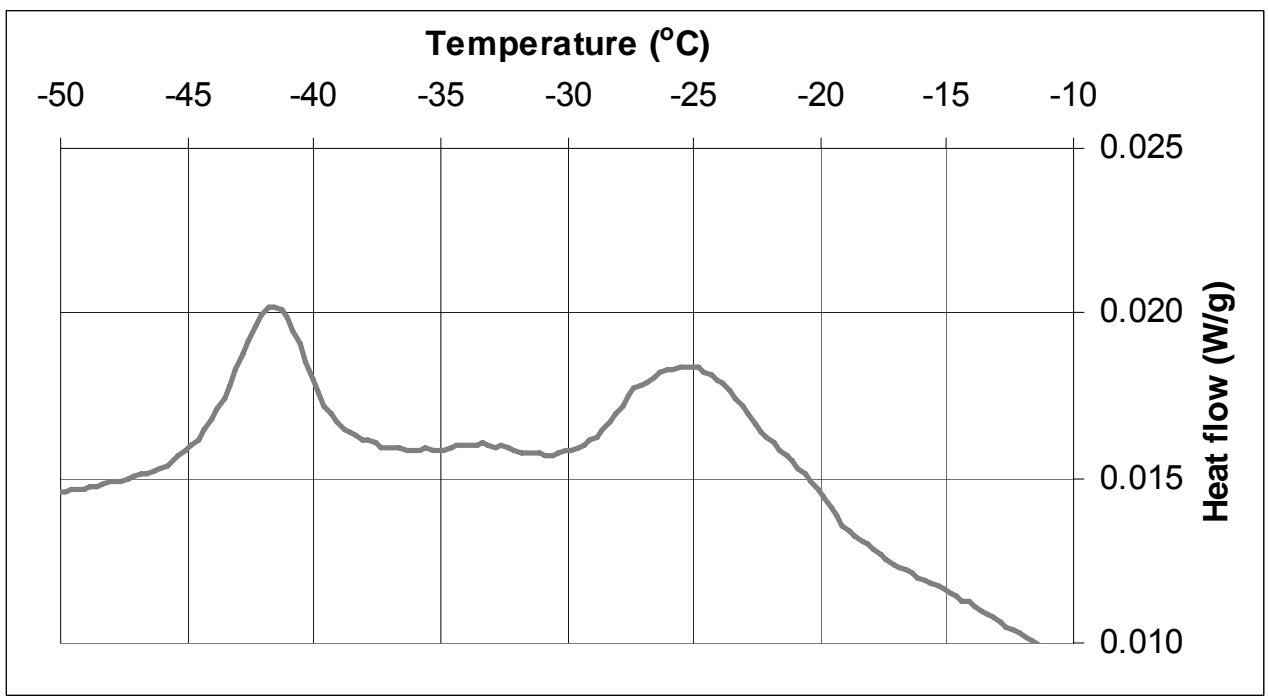

Figure $149 \mathrm{LTC}$ scan for CCRL Cement $152, w / c=0.45$, cured for $8 \mathrm{~d}$ under sealed conditions at $40{ }^{\circ} \mathrm{C}$, then resaturated for $6 \mathrm{~d}$. 
Cement: CCRL Cement 152

Solution: Distilled water

w/c: 0.45

Temperature: $40{ }^{\circ} \mathrm{C}$

Degree of hydration: 0.890
Curing: Saturated

Age when tested: $29 \mathrm{~d}$

Sample mass: $56.8 \mathrm{mg}$

Filename: c152w045T40Csat28d

Date tested: March 15, 2005

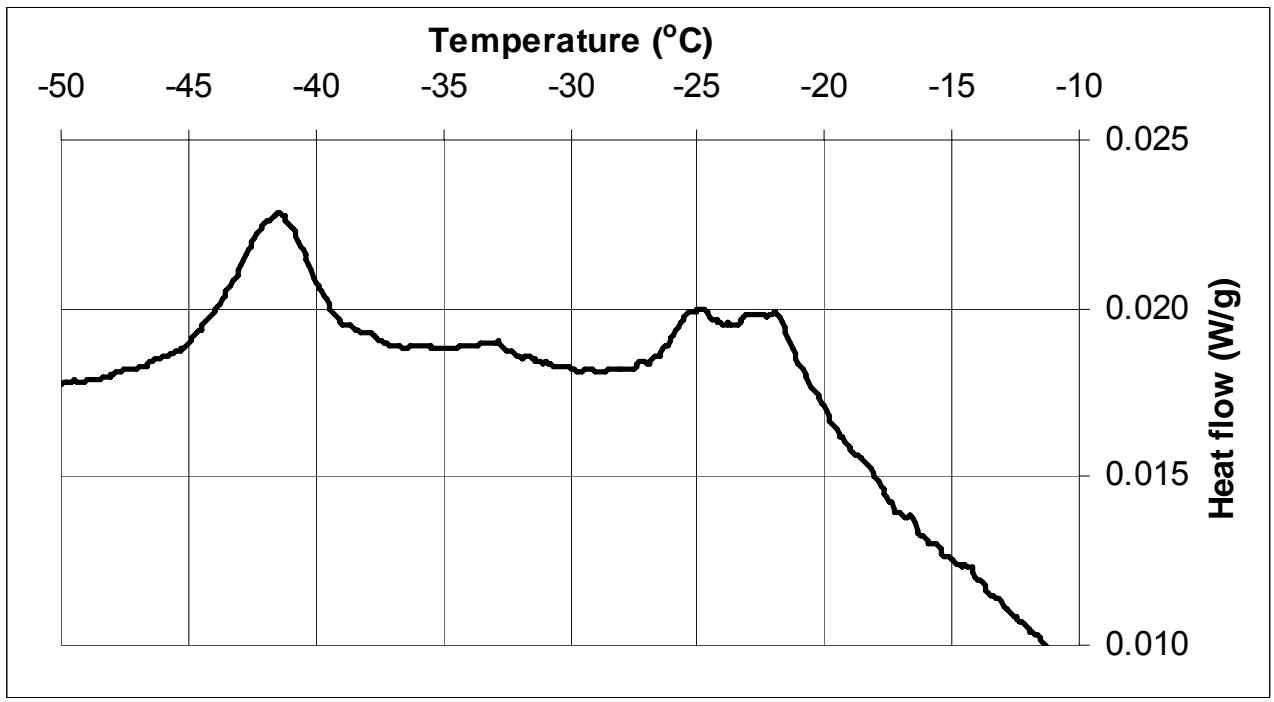

Figure $150 \mathrm{LTC}$ scan for CCRL Cement $152, w / c=0.45$, cured for $29 \mathrm{~d}$ at $40{ }^{\circ} \mathrm{C}$ under saturated conditions.

Cement: CCRL Cement 152

Solution: Distilled water

$w / c: 0.45$

Temperature: $40{ }^{\circ} \mathrm{C}$

Degree of hydration: 0.826
Curing: Sealed

Age when tested: $29 \mathrm{~d}$

Sample mass: $56.7 \mathrm{mg}$

Filename: c152w045T40Cseal28d

Date tested: March 15, 2005

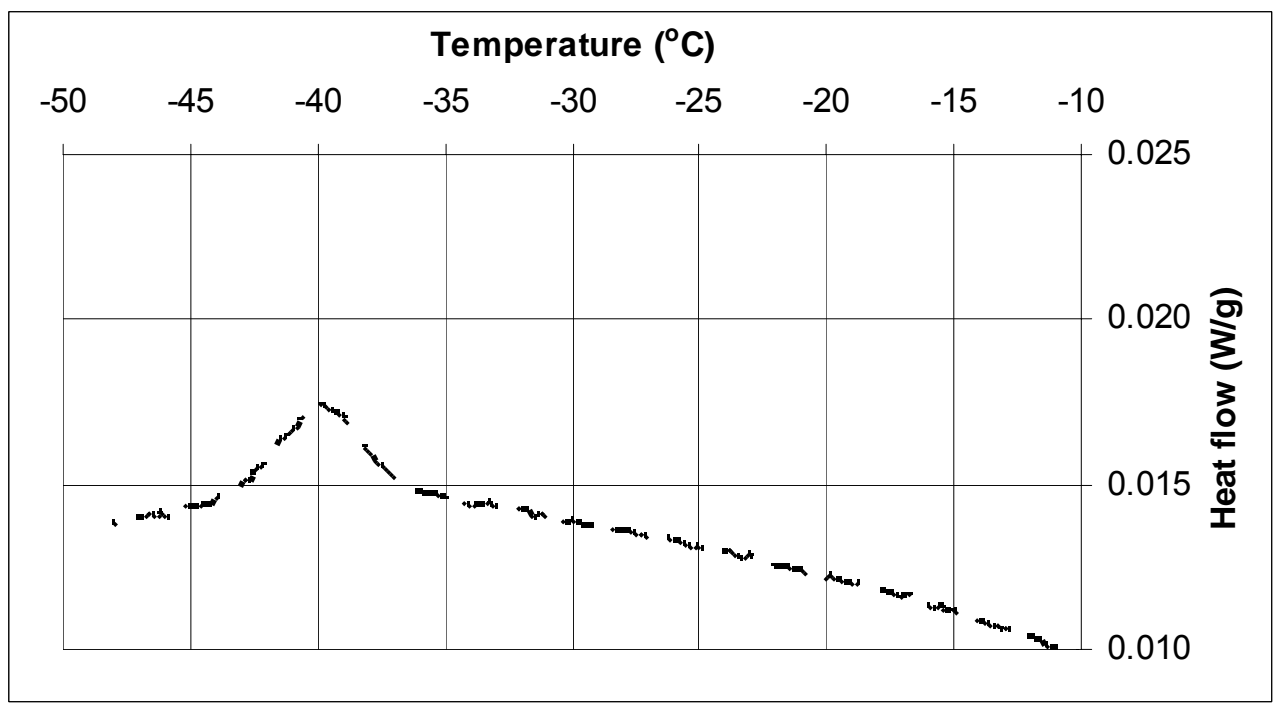

Figure 151 LTC scan for CCRL Cement 152, w/c $=0.45$, cured for $29 \mathrm{~d}$ at $40{ }^{\circ} \mathrm{C}$ under sealed conditions. 
Cement: CCRL Cement 152

Solution: Distilled water

w/c: 0.45

Temperature: $40{ }^{\circ} \mathrm{C}$

Degree of hydration: N/A
Curing: Sealed $28 \mathrm{~d} /$ resaturated

Age when tested: $29 \mathrm{~d}$

Sample mass: $52.2 \mathrm{mg}$

Filename: c152w045T40Cresat28t29d

Date tested: March 15, 2005

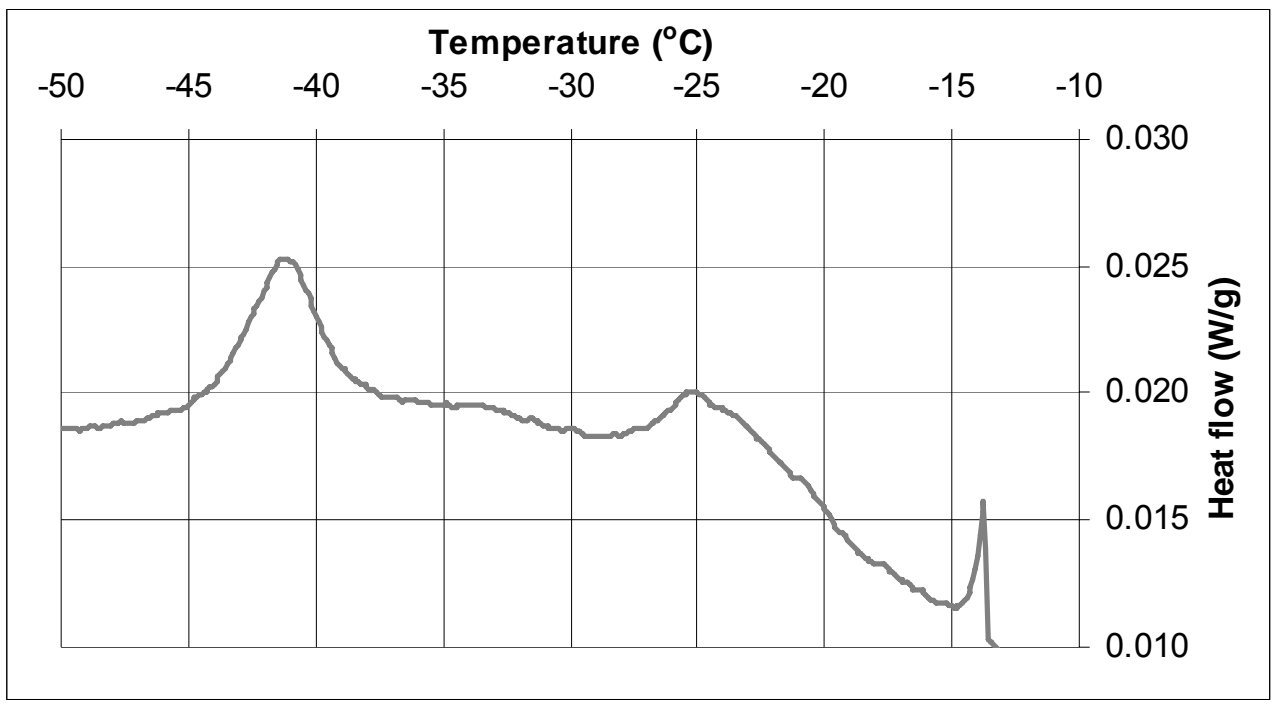

Figure $152 \mathrm{LTC}$ scan for CCRL Cement $152, w / c=0.45$, cured for $28 \mathrm{~d}$ under sealed conditions at $40{ }^{\circ} \mathrm{C}$, then resaturated for $1 \mathrm{~d}$.

\section{CCRL Cement 140}

Cement: CCRL Cement 140

Solution: Distilled water

$w / c: 0.40$

Temperature: $20{ }^{\circ} \mathrm{C}$

Degree of hydration: N/A
Curing: Saturated

Age when tested: $2 \mathrm{~d}$

Sample mass: $64.7 \mathrm{mg}$

Filename: c140w4nalk2d

Date tested: Dec. 30, 2004

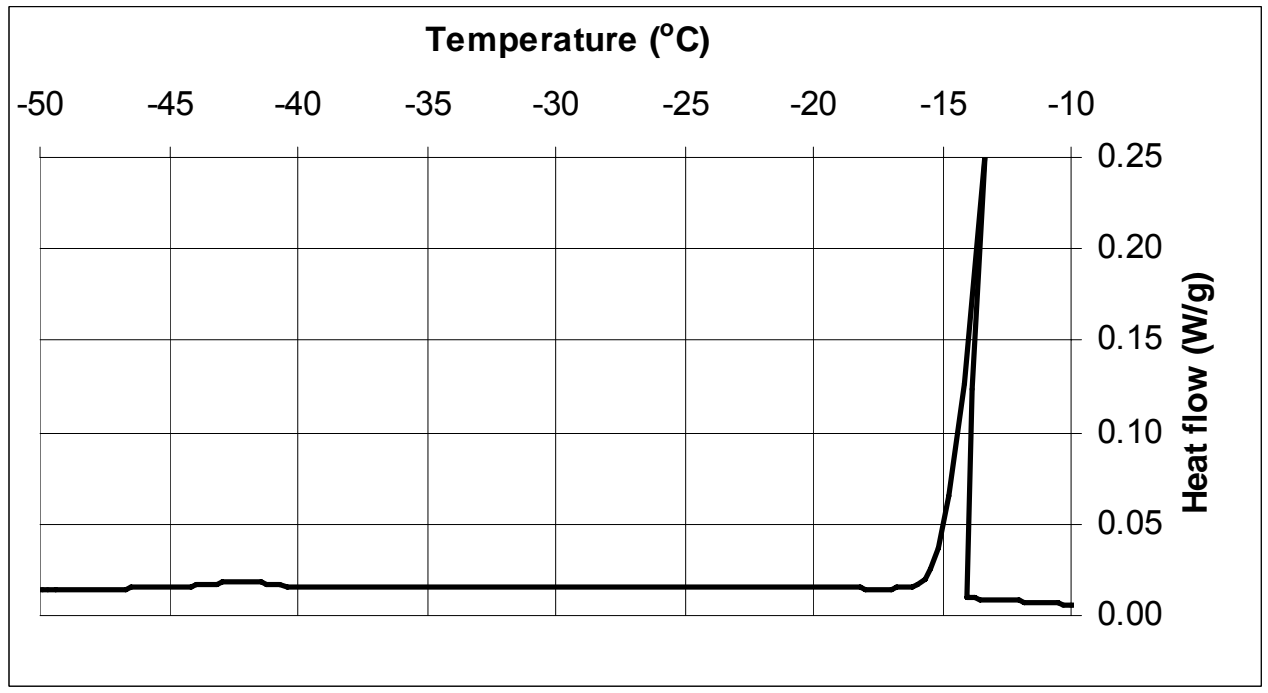

Figure $153 \mathrm{LTC}$ scan for CCRL Cement 140, $w / c=0.40$, prepared with distilled water and cured for $2 \mathrm{~d}$ at $20^{\circ} \mathrm{C}$ under saturated conditions. 
Cement: CCRL Cement 140

Solution: Alkali sulfate solution

$w / c: 0.40$

Temperature: $20{ }^{\circ} \mathrm{C}$

Degree of hydration: N/A
Curing: Saturated

Age when tested: $2 \mathrm{~d}$

Sample mass: $64.1 \mathrm{mg}$

Filename: c140w4walk2d

Date tested: Dec. 30, 2004

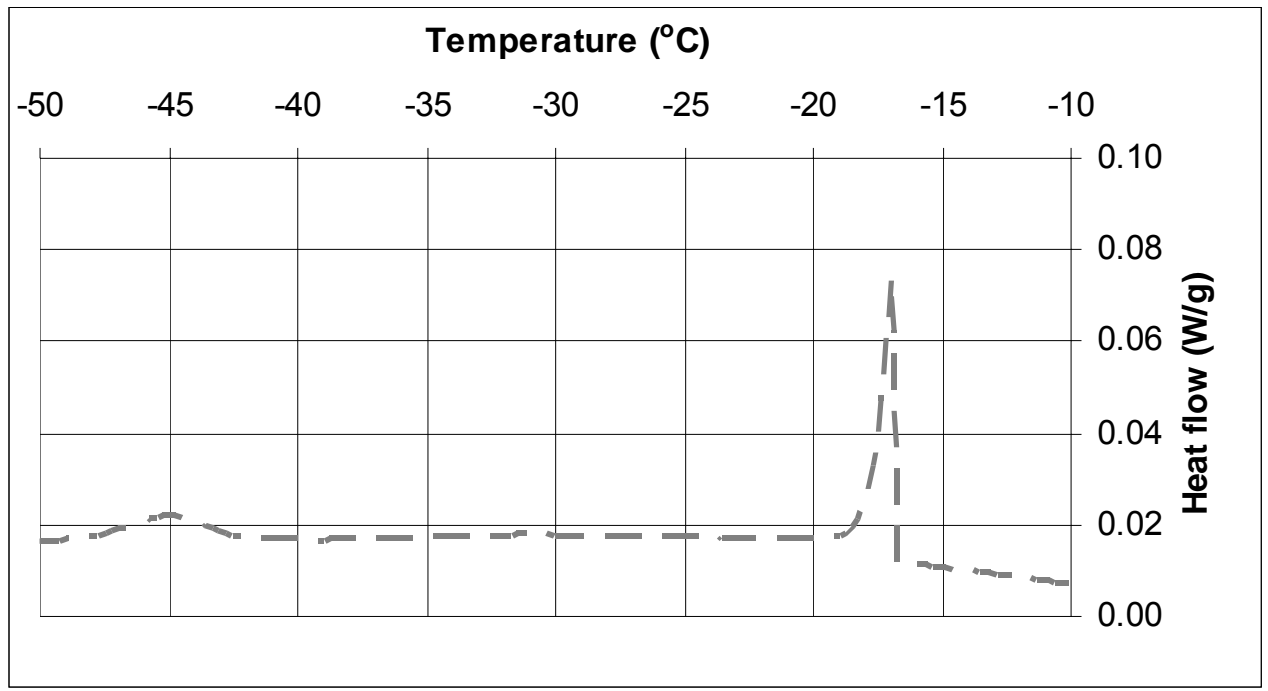

Figure $154 \mathrm{LTC}$ scan for CCRL Cement $140, w / c=0.40$, prepared with a solution of alkali sulfates and cured for $2 \mathrm{~d}$ at $20{ }^{\circ} \mathrm{C}$ under saturated conditions.

Cement: CCRL Cement $140 \quad$ Curing: Saturated

Solution: Alkali hydroxide solution Age when tested: $2 \mathrm{~d}$

$w / c: 0.40$

Temperature: $20{ }^{\circ} \mathrm{C}$

Degree of hydration: N/A
Sample mass: $62.8 \mathrm{mg}$

Filename: c140w4walkoh2d

Date tested: Dec. 30, 2004

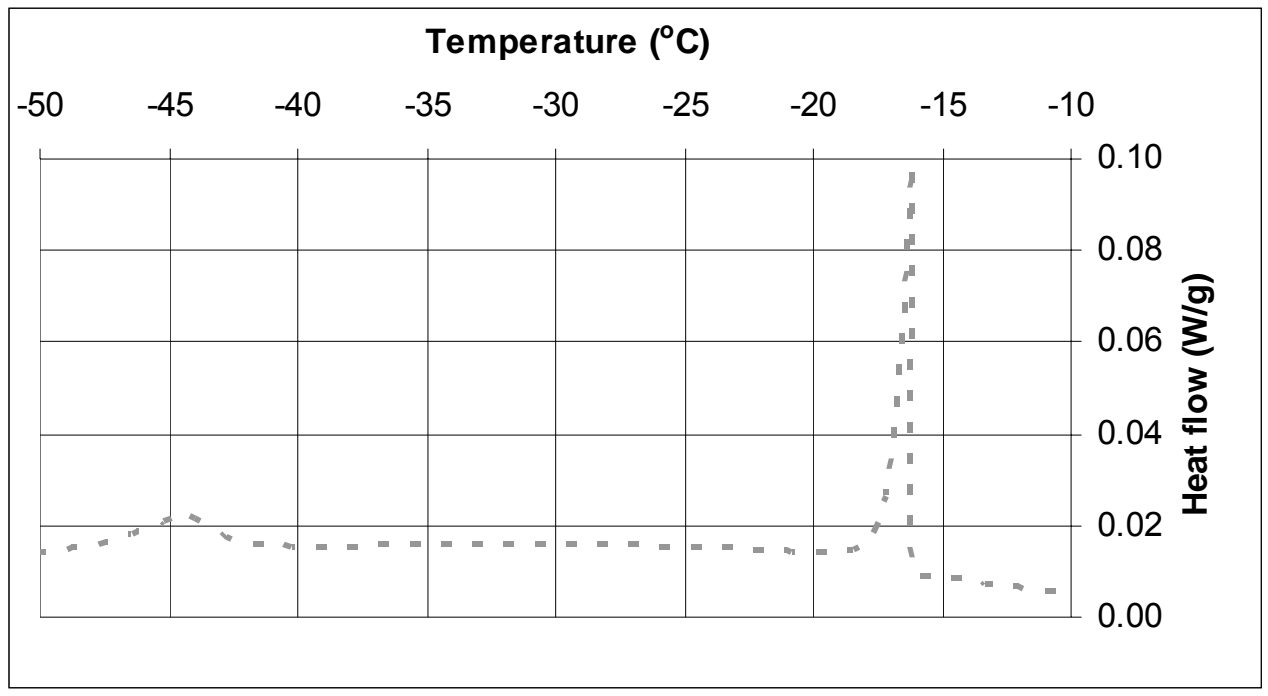

Figure 155 LTC scan for CCRL Cement $140, w / c=0.40$, prepared with a solution of alkali hydroxides and cured for $2 \mathrm{~d}$ at $20^{\circ} \mathrm{C}$ under saturated conditions. 
Cement: CCRL Cement 140

Solution: $\mathrm{LiOH}$ solution

w/c: 0.40

Temperature: $20{ }^{\circ} \mathrm{C}$

Degree of hydration: 0.499
Curing: Saturated

Age when tested: $2 \mathrm{~d}$

Sample mass: $66.6 \mathrm{mg}$

Filename: c140wlioh2d

Date tested: Feb. 3, 2005

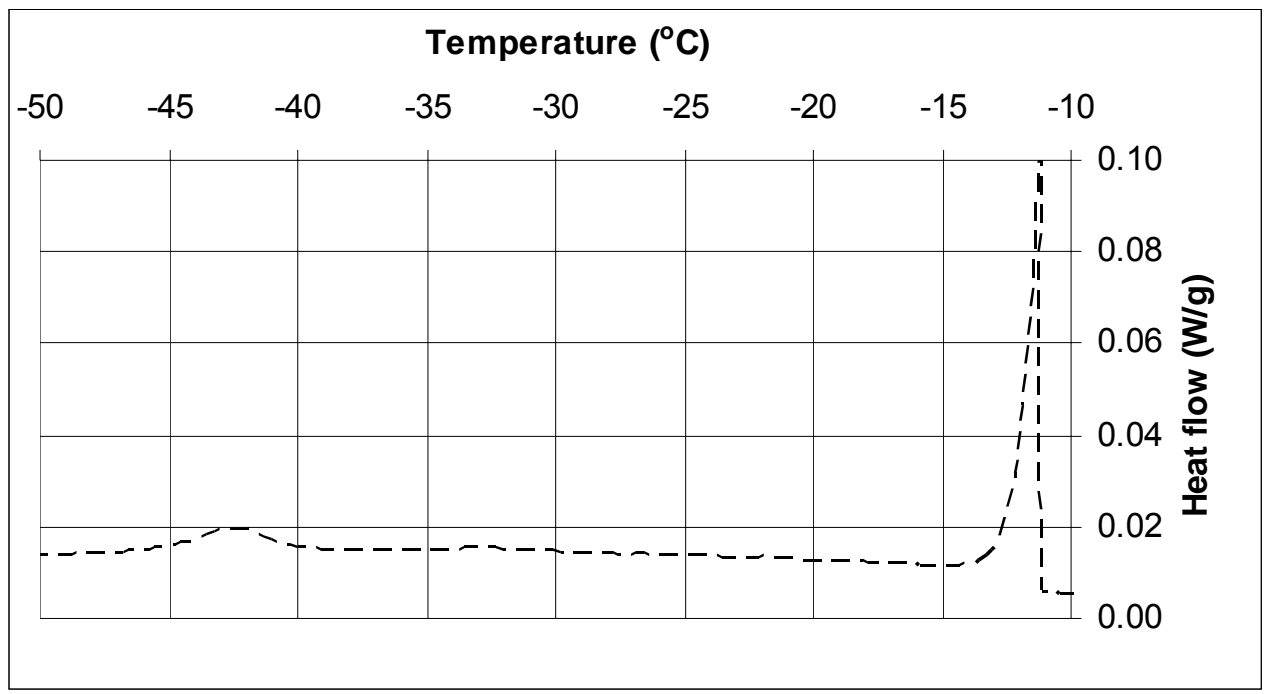

Figure $156 \mathrm{LTC}$ scan for CCRL Cement $140, w / c=0.40$, prepared with a LiOH solution and cured for $2 \mathrm{~d}$ at $20{ }^{\circ} \mathrm{C}$ under saturated conditions.

Cement: CCRL Cement 140

Solution: $\mathrm{LiNO}_{3}$ solution

w/c: 0.40

Temperature: $20^{\circ} \mathrm{C}$

Degree of hydration: 0.472
Curing: Saturated

Age when tested: $2 \mathrm{~d}$

Sample mass: $48.0 \mathrm{mg}$

Filename: c140wlino3a2d

Date tested: Feb. 3, 2005

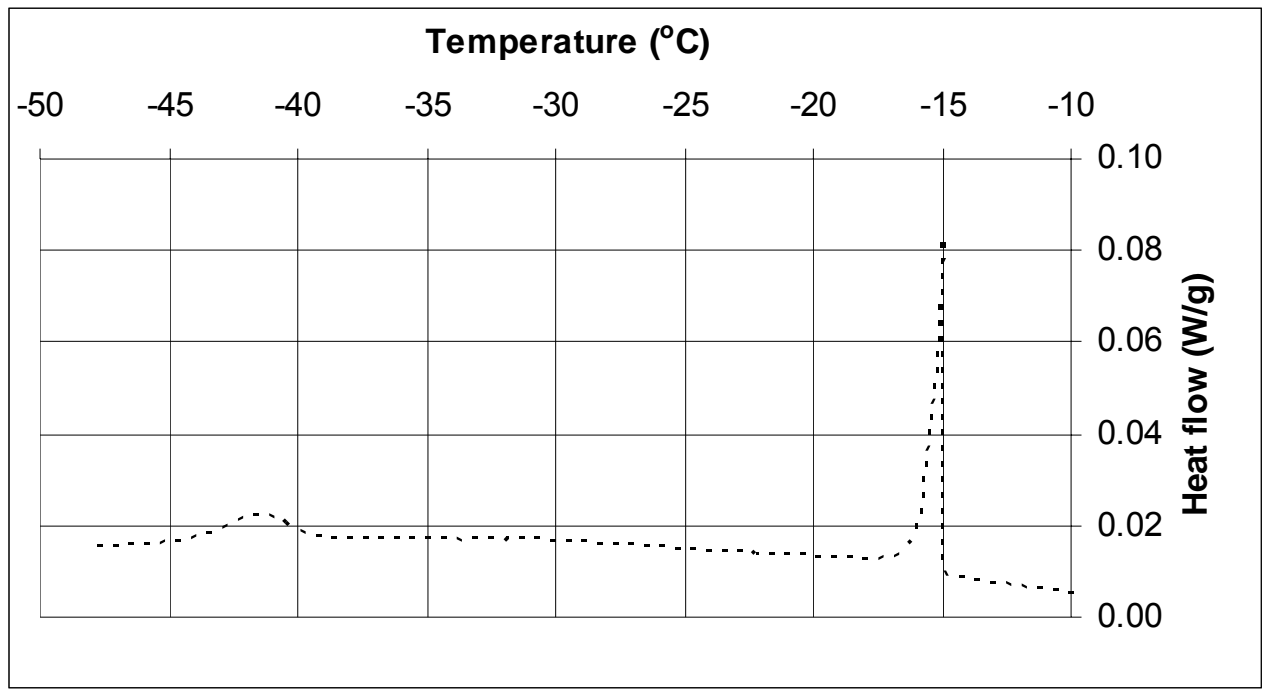

Figure $157 \mathrm{LTC}$ scan for CCRL Cement 140, $w / c=0.40$, prepared with a $\mathrm{LiNO}_{3}$ solution and cured for $2 \mathrm{~d}$ at $20{ }^{\circ} \mathrm{C}$ under saturated conditions. 
Cement: CCRL Cement 140

Solution: $\mathrm{LiOH}$ solution

w/c: 0.40

Temperature: $20{ }^{\circ} \mathrm{C}$

Degree of hydration: N/A
Curing: Saturated

Age when tested: $4 \mathrm{~d}$

Sample mass: $88.0 \mathrm{mg}$

Filename: c140w04lioh4d

Date tested: Feb. 5, 2005

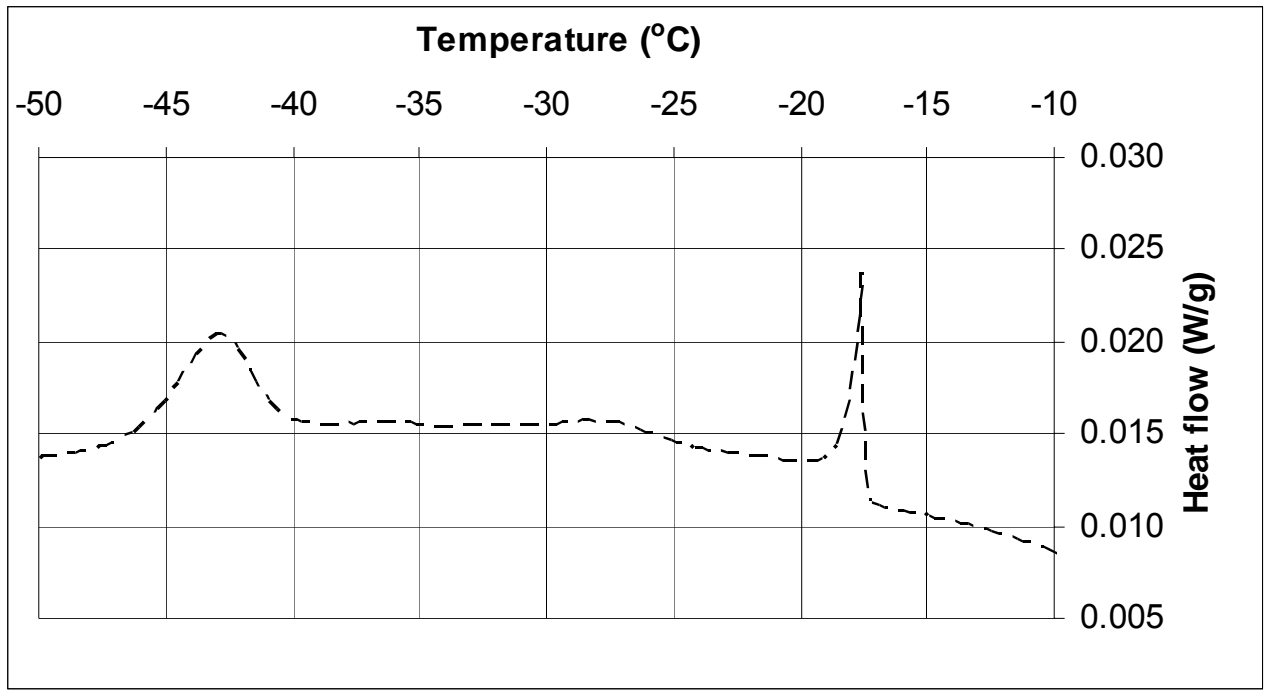

Figure $158 \mathrm{LTC}$ scan for CCRL Cement $140, w / c=0.40$, prepared with a LiOH solution and cured for $4 \mathrm{~d}$ at $20{ }^{\circ} \mathrm{C}$ under saturated conditions.

Cement: CCRL Cement 140

Solution: $\mathrm{LiNO}_{3}$ solution

w/c: 0.40

Temperature: $20^{\circ} \mathrm{C}$

Degree of hydration: N/A
Curing: Saturated

Age when tested: $4 \mathrm{~d}$

Sample mass: $81.0 \mathrm{mg}$

Filename: c140w04lino3a4d

Date tested: Feb. 5, 2005

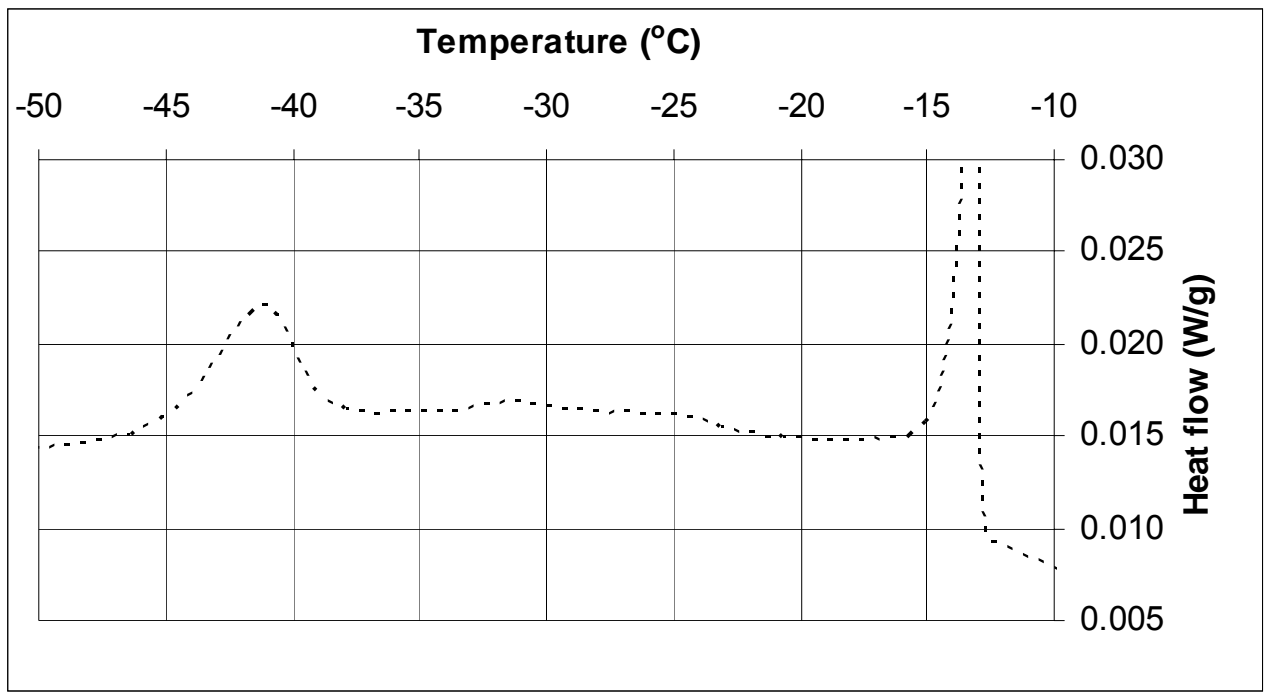

Figure $159 \mathrm{LTC}$ scan for CCRL Cement $140, w / c=0.40$, prepared with a $\mathrm{LiNO}_{3}$ solution and cured for $4 \mathrm{~d}$ at $20{ }^{\circ} \mathrm{C}$ under saturated conditions. 
Cement: CCRL Cement 140

Solution: $\mathrm{LiOH}$ solution

w/c: 0.40

Temperature: $20{ }^{\circ} \mathrm{C}$

Degree of hydration: 0.664
Curing: Saturated

Age when tested: $7 \mathrm{~d}$

Sample mass: $97.8 \mathrm{mg}$

Filename: c140w04lioh7d

Date tested: Feb. 8, 2005

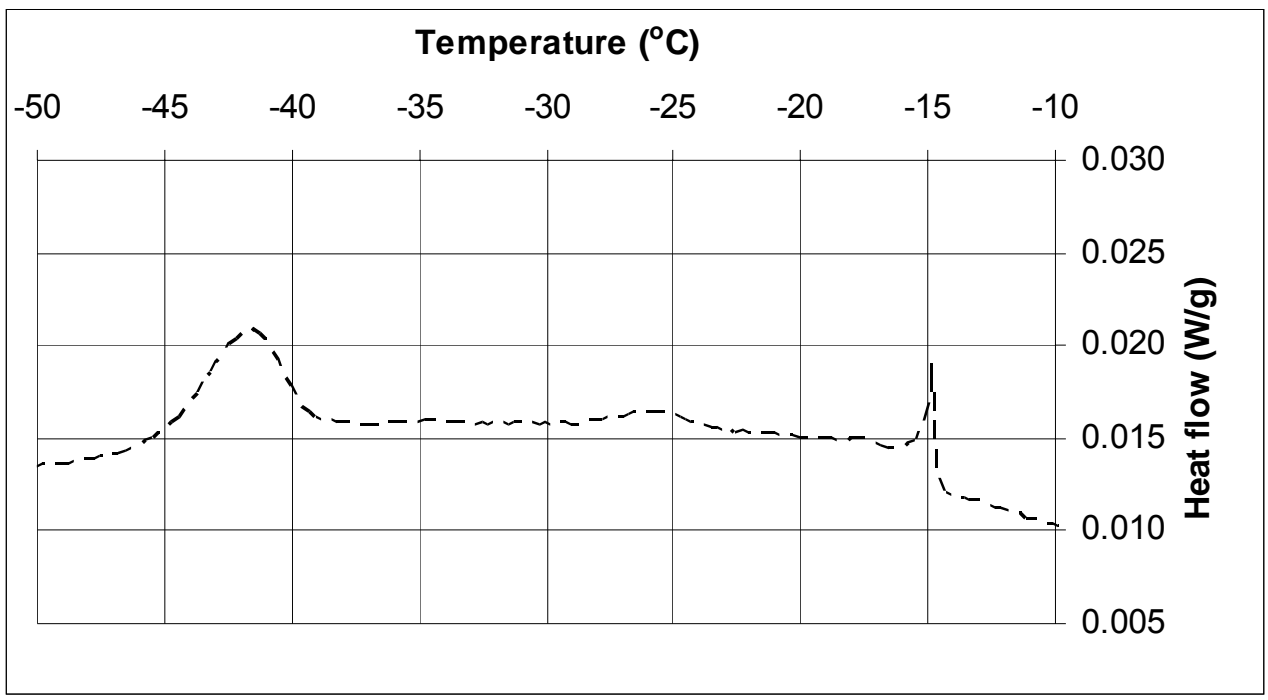

Figure $160 \mathrm{LTC}$ scan for CCRL Cement 140, $w / c=0.40$, prepared with a $\mathrm{LiOH}$ solution and cured for $7 \mathrm{~d}$ at $20{ }^{\circ} \mathrm{C}$ under saturated conditions.

Cement: CCRL Cement 140

Solution: $\mathrm{LiNO}_{3}$ solution

$w / c: 0.40$

Temperature: $2{ }^{\circ} \mathrm{C}$

Degree of hydration: 0.686
Curing: Saturated

Age when tested: $7 \mathrm{~d}$

Sample mass: $67.3 \mathrm{mg}$

Filename: c140w04lino3a7d

Date tested: Feb. 8, 2005

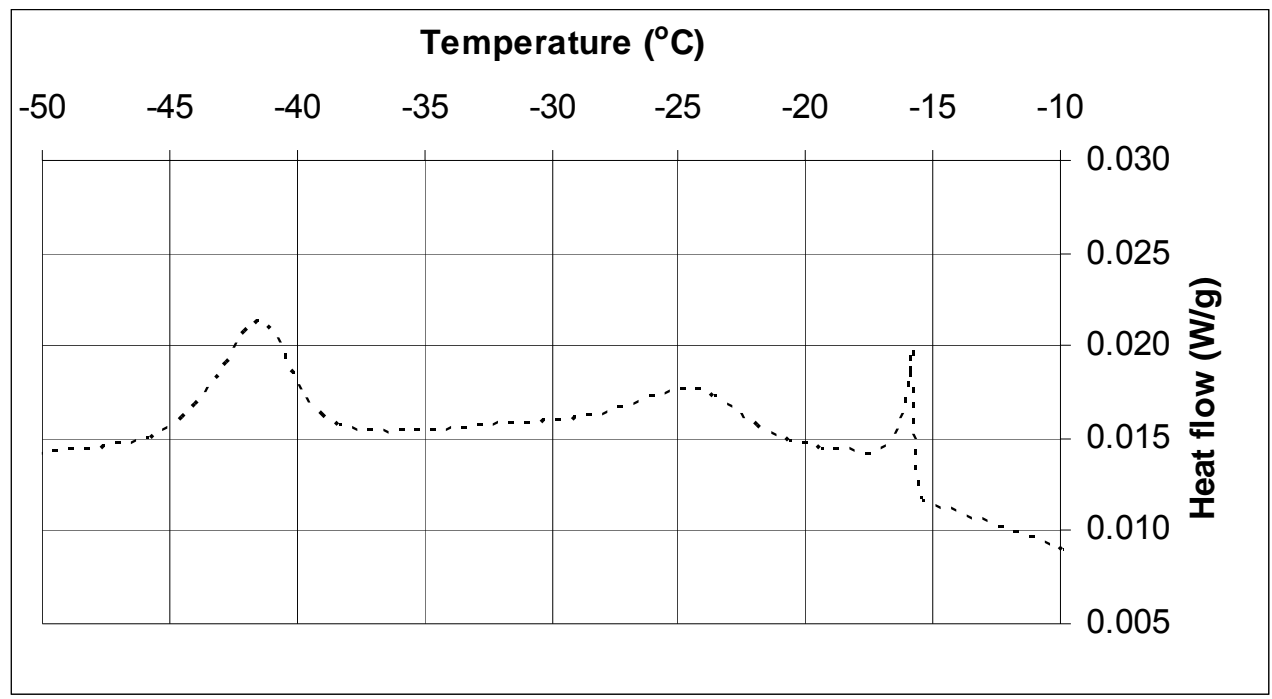

Figure $161 \mathrm{LTC}$ scan for CCRL Cement 140, $w / c=0.40$, prepared with a $\mathrm{LiNO}_{3}$ solution and cured for $7 \mathrm{~d}$ at $20{ }^{\circ} \mathrm{C}$ under saturated conditions. 
Cement: CCRL Cement 140

Solution: Distilled water

w/c: 0.40

Temperature: $2{ }^{\circ} \mathrm{C}$

Degree of hydration: 0.667
Curing: Saturated

Age when tested: $8 \mathrm{~d}$

Sample mass: $62.3 \mathrm{mg}$

Filename: c140w4nalk8d

Date tested: Jan. 5, 2005

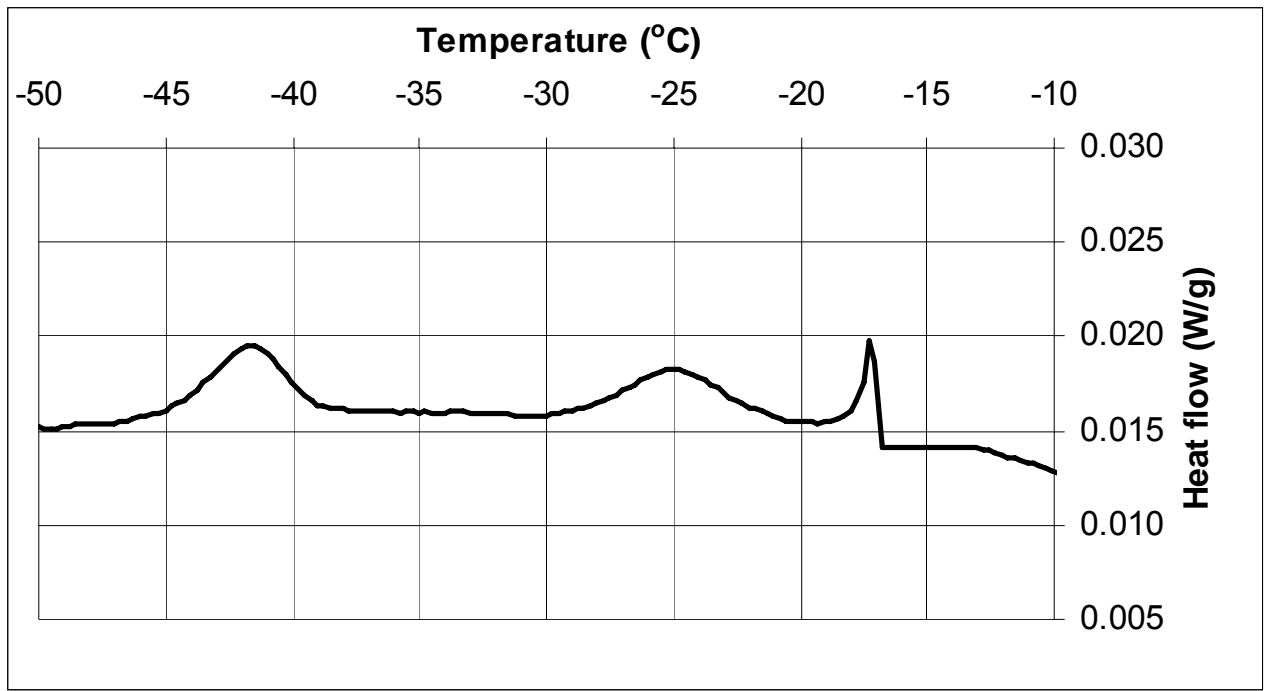

Figure $162 \mathrm{LTC}$ scan for CCRL Cement $140, w / c=0.40$, prepared with distilled water and cured for $8 \mathrm{~d}$ at $20{ }^{\circ} \mathrm{C}$ under saturated conditions.

Cement: CCRL Cement 140

Solution: Alkali sulfate solution

w/c: 0.40

Temperature: $20^{\circ} \mathrm{C}$

Degree of hydration: 0.631
Curing: Saturated

Age when tested: $8 \mathrm{~d}$

Sample mass: $42.5 \mathrm{mg}$

Filename: c140w4walk8d

Date tested: Jan. 5, 2005

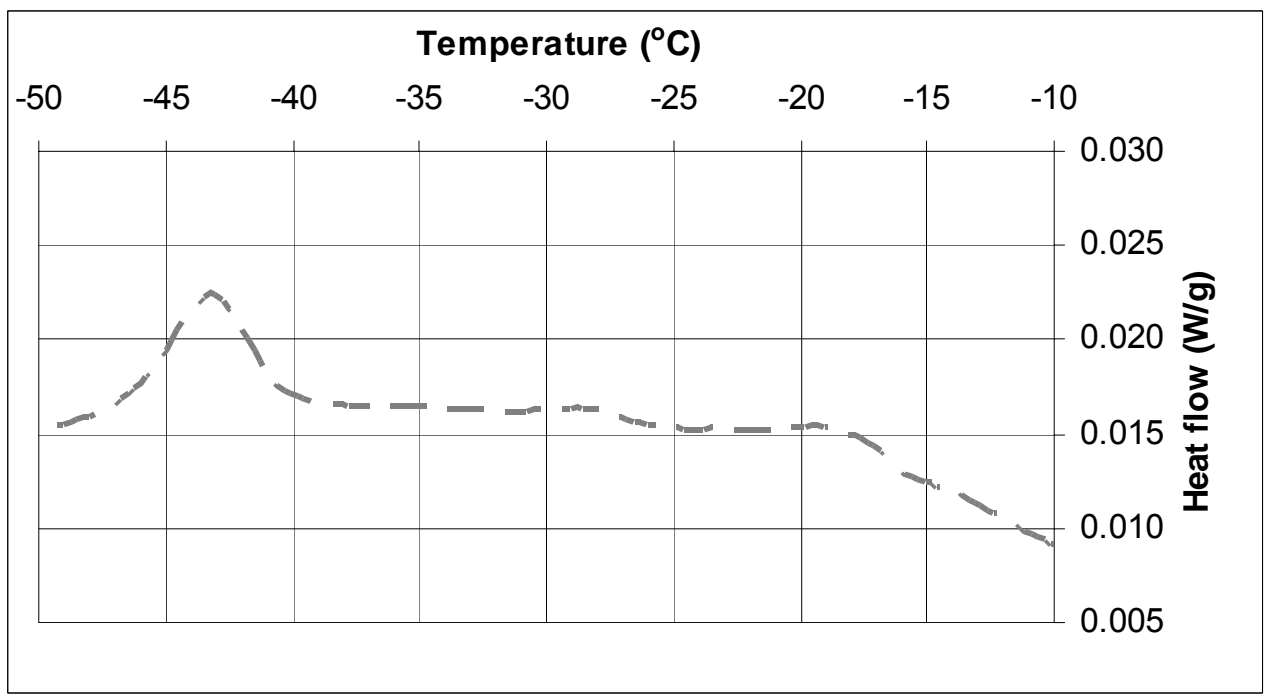

Figure $163 \mathrm{LTC}$ scan for CCRL Cement $140, w / c=0.40$, prepared with a solution of alkali sulfates and cured for $8 \mathrm{~d}$ at $20{ }^{\circ} \mathrm{C}$ under saturated conditions. 
Cement: CCRL Cement $140 \quad$ Curing: Saturated

Solution: Alkali hydroxide solution Age when tested: $8 \mathrm{~d}$

$w / c: 0.40$

Temperature: $20{ }^{\circ} \mathrm{C}$

Sample mass: $61.0 \mathrm{mg}$

Degree of hydration: 0.661

Filename: c140w4walkoh8d

Date tested: Jan. 5, 2005

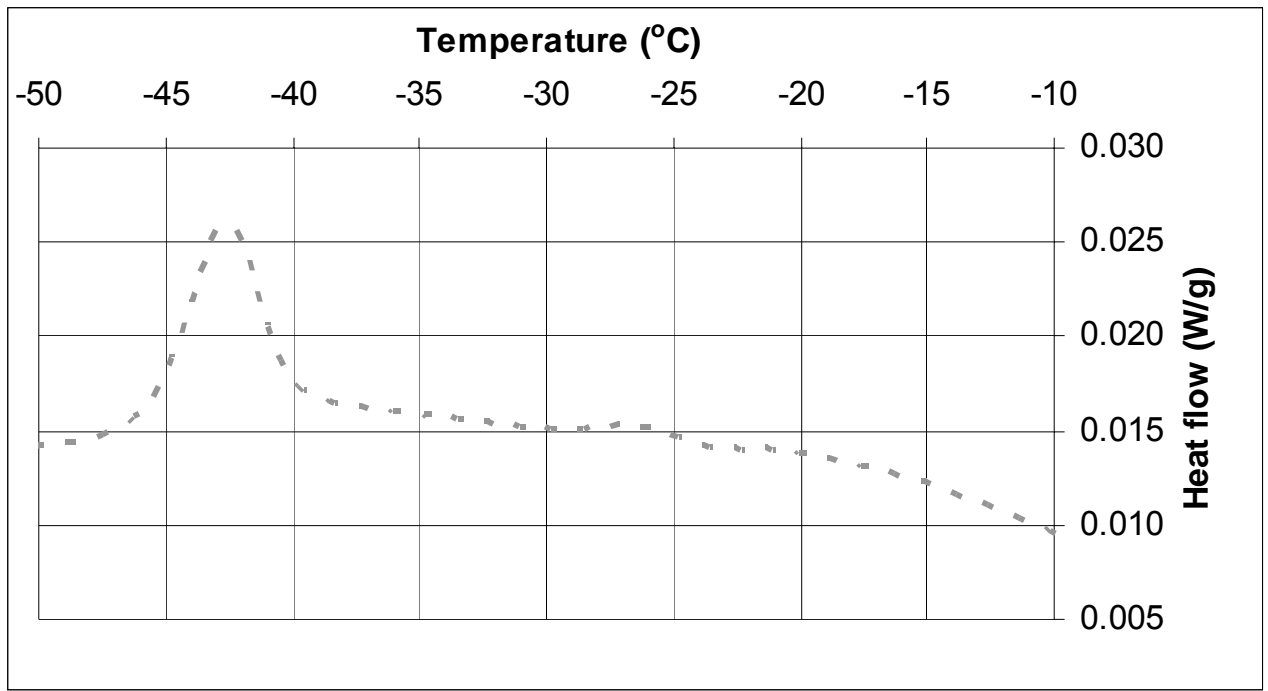

Figure $164 \mathrm{LTC}$ scan for CCRL Cement $140, w / c=0.40$, prepared with a solution of alkali hydroxides and cured for $8 \mathrm{~d}$ at $20^{\circ} \mathrm{C}$ under saturated conditions.

Cement: CCRL Cement 140

Solution: LiOH solution

w/c: 0.40

Temperature: $20{ }^{\circ} \mathrm{C}$

Degree of hydration: 0.692
Curing: Saturated

Age when tested: $8 \mathrm{~d}$

Sample mass: $64.0 \mathrm{mg}$

Filename: c140w04lioh8d

Date tested: Feb. 9, 2005

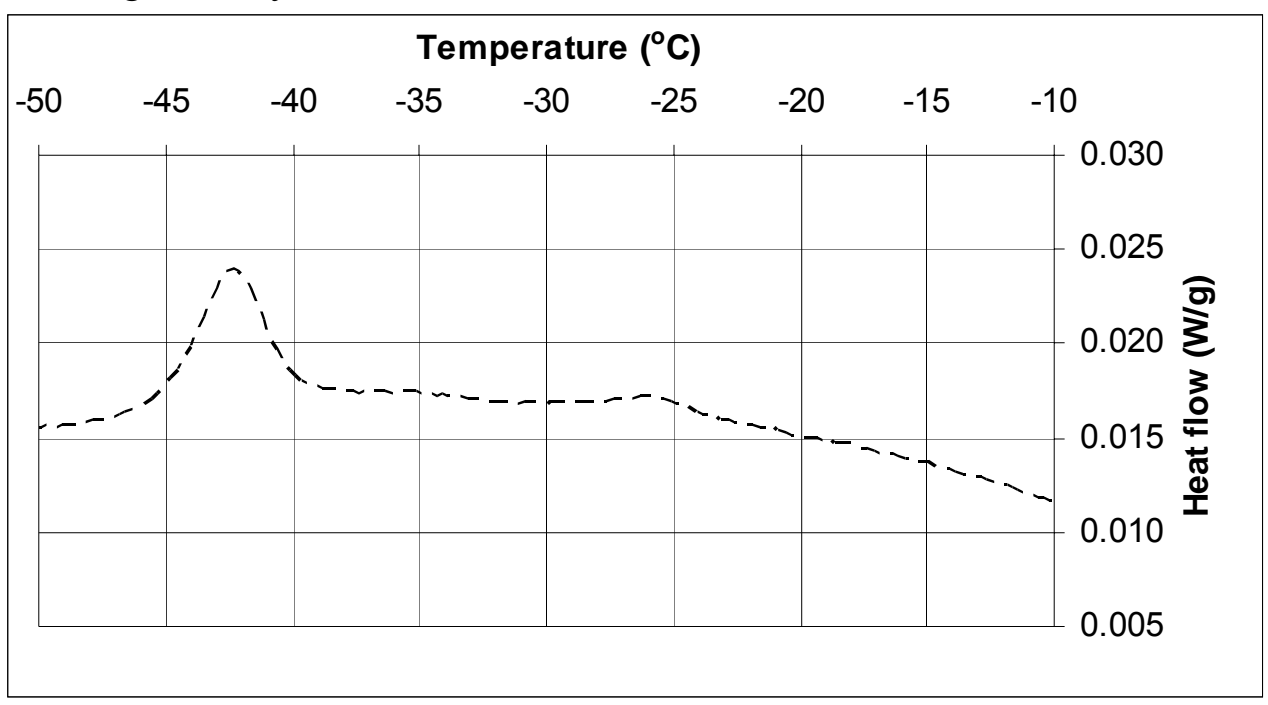

Figure $165 \mathrm{LTC}$ scan for CCRL Cement $140, w / c=0.40$, prepared with a solution of $\mathrm{LiOH}$ and cured for 8 d at $20{ }^{\circ} \mathrm{C}$ under saturated conditions. 
Cement: CCRL Cement 140

Solution: $\mathrm{LiNO}_{3}$ solution

$w / c: 0.40$

Temperature: $20{ }^{\circ} \mathrm{C}$

Degree of hydration: 0.699
Curing: Saturated

Age when tested: $8 \mathrm{~d}$

Sample mass: $59.8 \mathrm{mg}$

Filename: c140w04lino3a8d

Date tested: Feb. 9, 2005

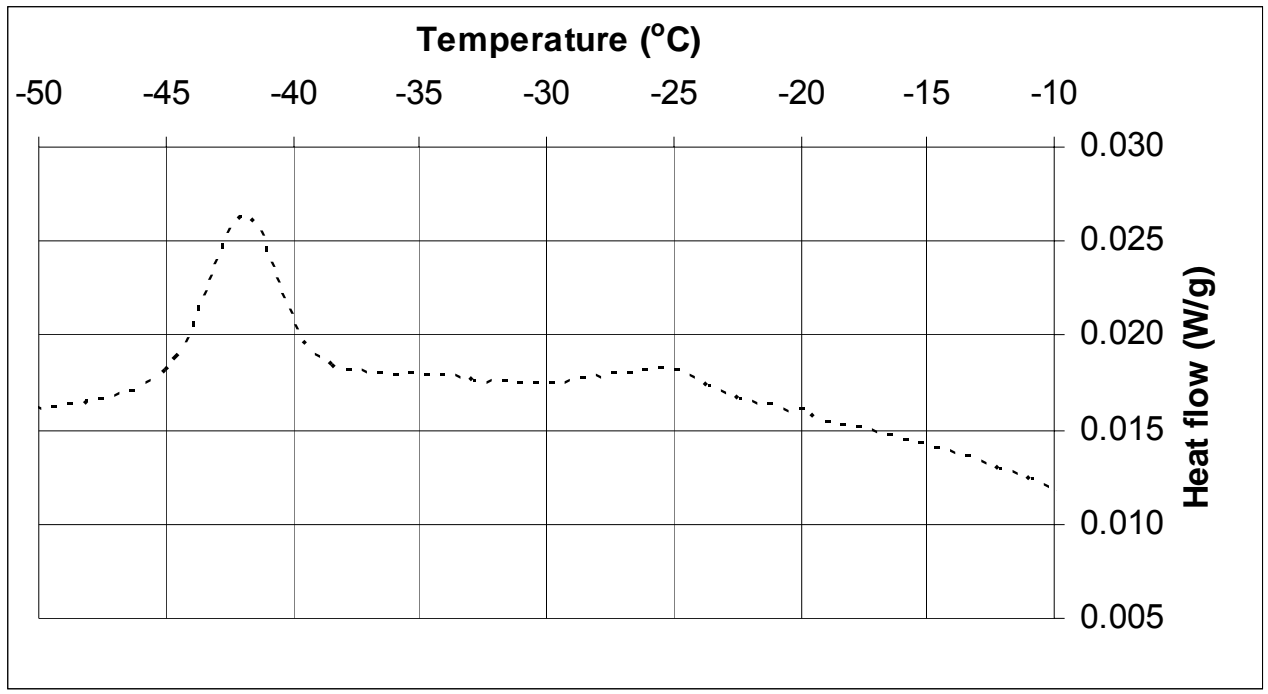

Figure $166 \mathrm{LTC}$ scan for CCRL Cement $140, w / c=0.40$, prepared with a solution of $\mathrm{LiNO}_{3}$ and cured for $8 \mathrm{~d}$ at $20^{\circ} \mathrm{C}$ under saturated conditions.

Cement: CCRL Cement 140

Solution: Distilled water

w/c: 0.40

Temperature: $20^{\circ} \mathrm{C}$

Degree of hydration: 0.732
Curing: Saturated

Age when tested: $14 \mathrm{~d}$

Sample mass: $58.9 \mathrm{mg}$

Filename: c140w04nalk14d

Date tested: Jan. 11, 2005

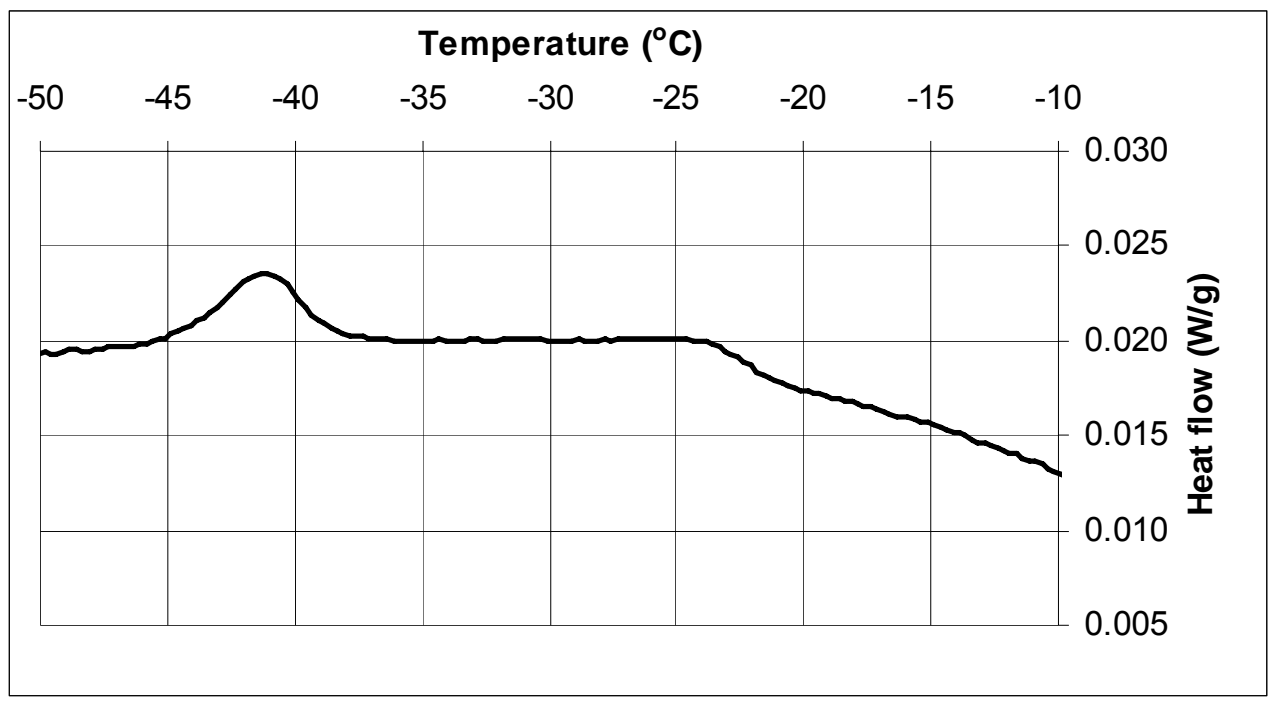

Figure 167 LTC scan for CCRL Cement $140, w / c=0.40$, prepared with distilled water and cured for $14 \mathrm{~d}$ at $20{ }^{\circ} \mathrm{C}$ under saturated conditions. 
Cement: CCRL Cement 140

Solution: Alkali sulfate solution

$w / c: 0.40$

Temperature: $20{ }^{\circ} \mathrm{C}$

Degree of hydration: 0.655
Curing: Saturated

Age when tested: $14 \mathrm{~d}$

Sample mass: $48.7 \mathrm{mg}$

Filename: c140w04walk14d

Date tested: Jan. 11, 2005

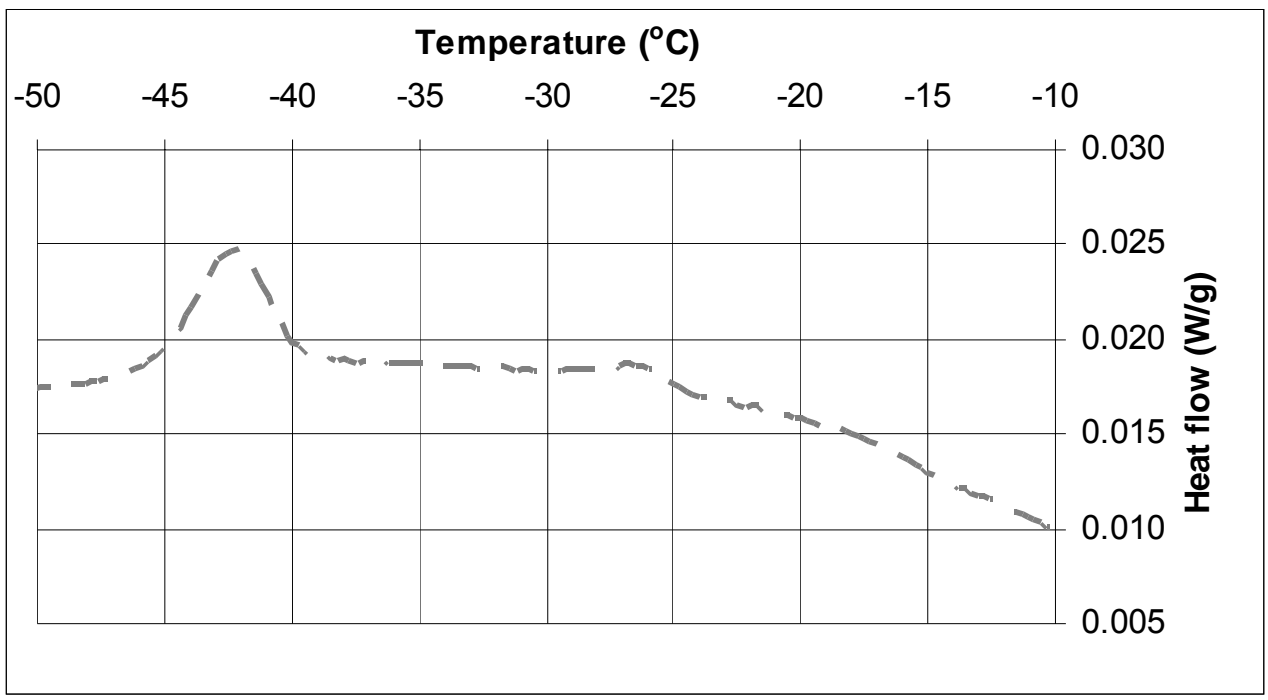

Figure $168 \mathrm{LTC}$ scan for CCRL Cement $140, w / c=0.40$, prepared with a solution of alkali sulfates and cured for $14 \mathrm{~d}$ at $20{ }^{\circ} \mathrm{C}$ under saturated conditions.

Cement: CCRL Cement $140 \quad$ Curing: Saturated

Solution: Alkali hydroxide solution Age when tested: $14 \mathrm{~d}$ $w / c: 0.40$

Temperature: $20{ }^{\circ} \mathrm{C}$

Sample mass: $43.9 \mathrm{mg}$

Degree of hydration: 0.698

Filename: c140w04walkoh14d

Date tested: Jan. 11, 2005

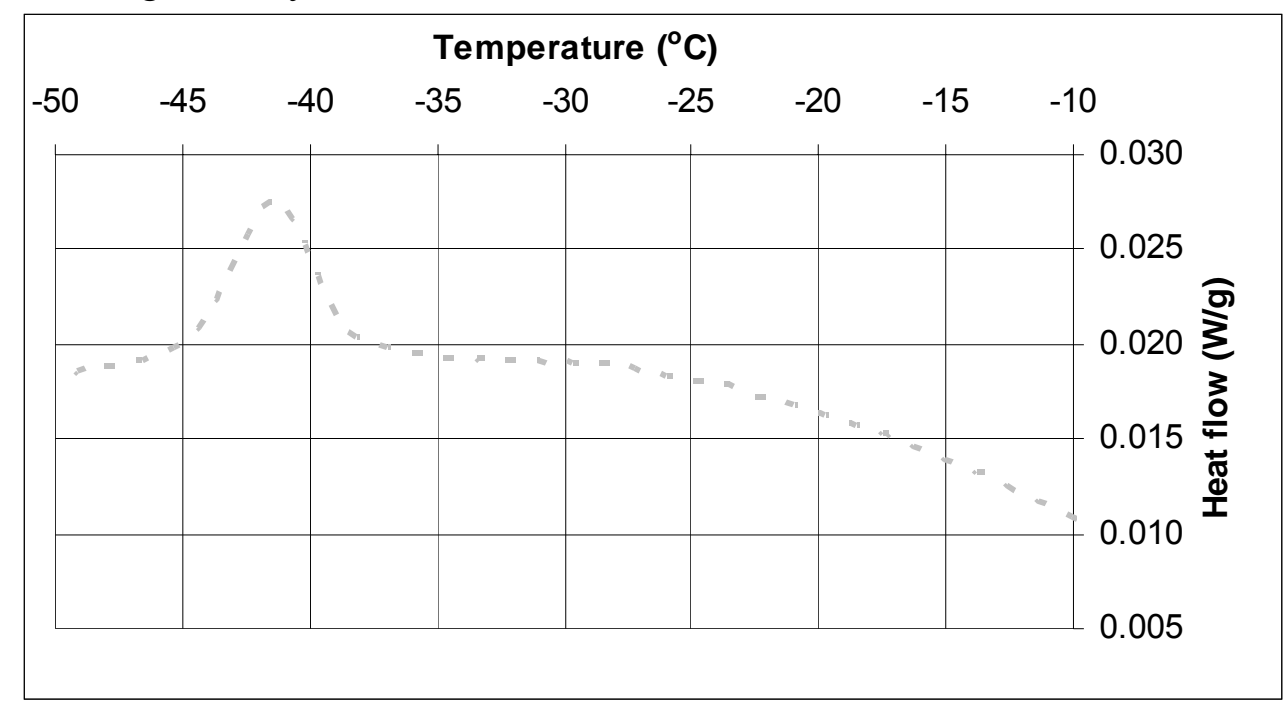

Figure $169 \mathrm{LTC}$ scan for CCRL Cement $140, w / c=0.40$, prepared with a solution of alkali hydroxides and cured for $14 \mathrm{~d}$ at $20{ }^{\circ} \mathrm{C}$ under saturated conditions. 
Cement: CCRL Cement 140

Solution: $\mathrm{LiOH}$ solution

w/c: 0.40

Temperature: $20{ }^{\circ} \mathrm{C}$

Degree of hydration: 0.736
Curing: Saturated

Age when tested: $14 \mathrm{~d}$

Sample mass: $95.7 \mathrm{mg}$

Filename: c140w04lioha14d

Date tested: Feb. 15, 2005

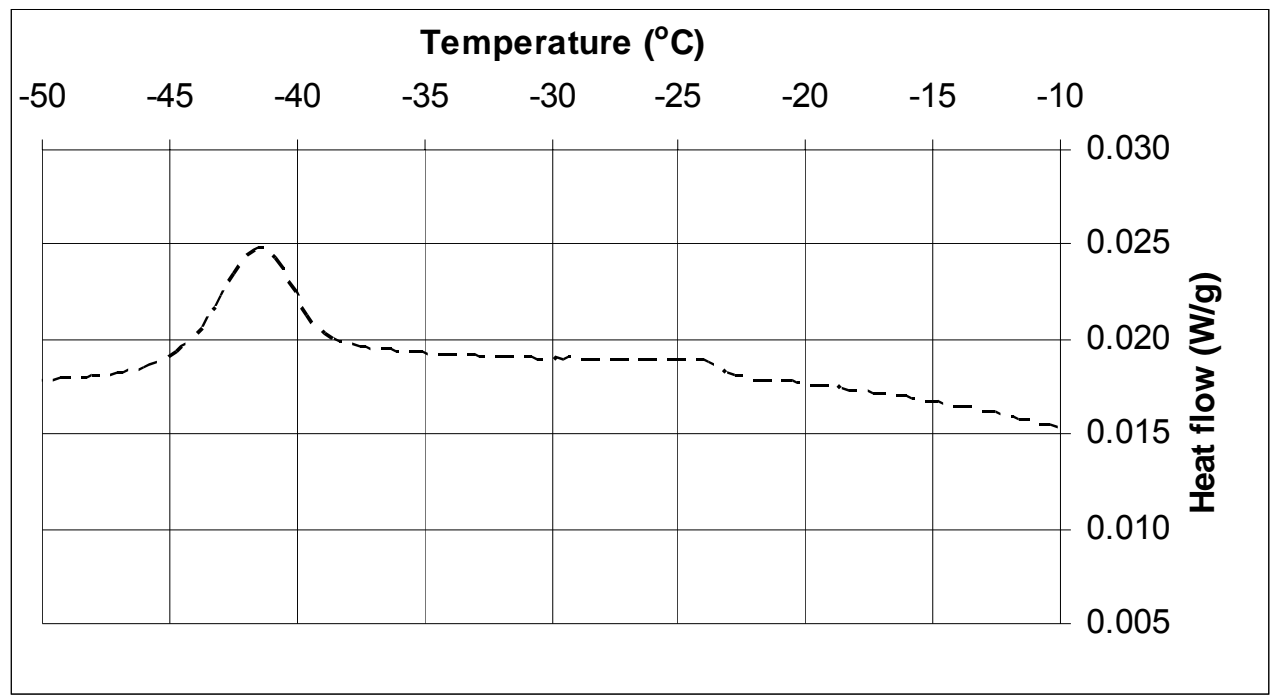

Figure 170 LTC scan for CCRL Cement $140, w / c=0.40$, prepared with a solution of $\mathrm{LiOH}$ and cured for $14 \mathrm{~d}$ at $20{ }^{\circ} \mathrm{C}$ under saturated conditions.

Cement: CCRL Cement 140

Solution: $\mathrm{LiNO}_{3}$ solution

$w / c: 0.40$

Temperature: $20{ }^{\circ} \mathrm{C}$

Degree of hydration: 0.736
Curing: Saturated

Age when tested: $14 \mathrm{~d}$

Sample mass: $53.1 \mathrm{mg}$

Filename: c140w04lino3a14d

Date tested: Feb. 15, 2005

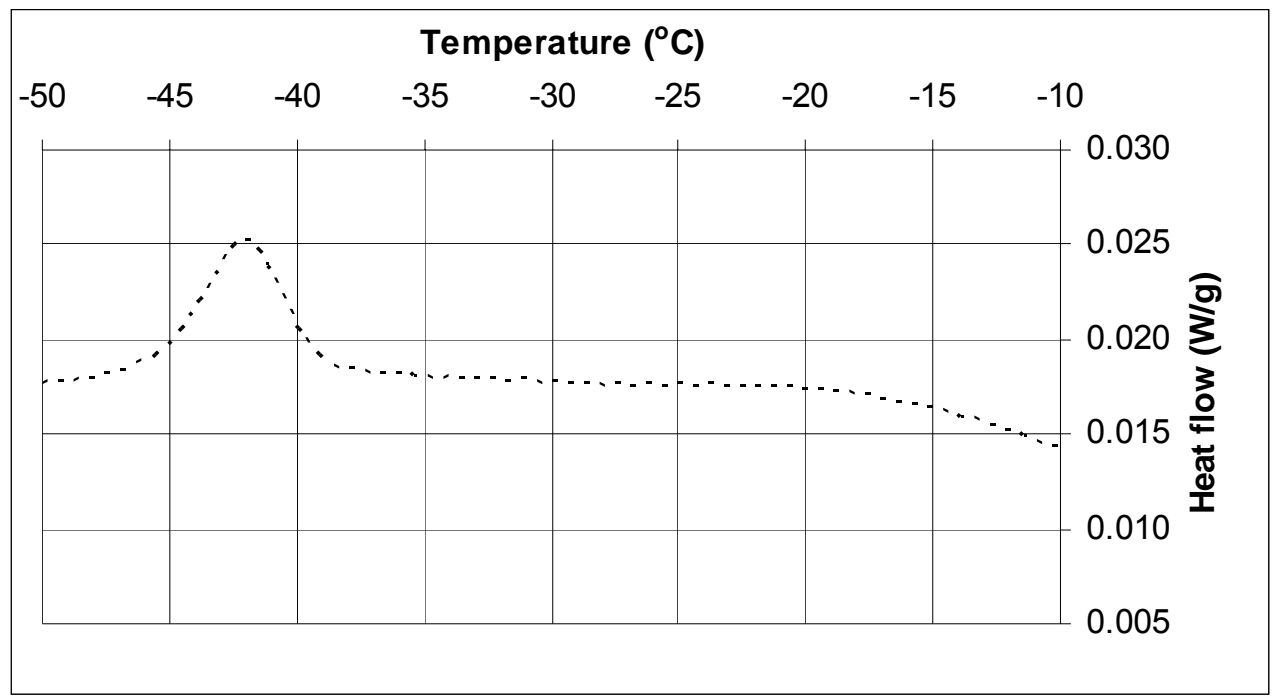

Figure $171 \mathrm{LTC}$ scan for CCRL Cement 140, w/c $=0.40$, prepared with a solution of $\mathrm{LiNO}_{3}$ and cured for $14 \mathrm{~d}$ at $20^{\circ} \mathrm{C}$ under saturated conditions. 
Cement: CCRL Cement 140

Solution: Distilled water

w/c: 0.40

Temperature: $20{ }^{\circ} \mathrm{C}$

Degree of hydration: 0.764
Curing: Saturated

Age when tested: $30 \mathrm{~d}$

Sample mass: $59.1 \mathrm{mg}$

Filename: c140w04nalk30d

Date tested: Jan. 27, 2005

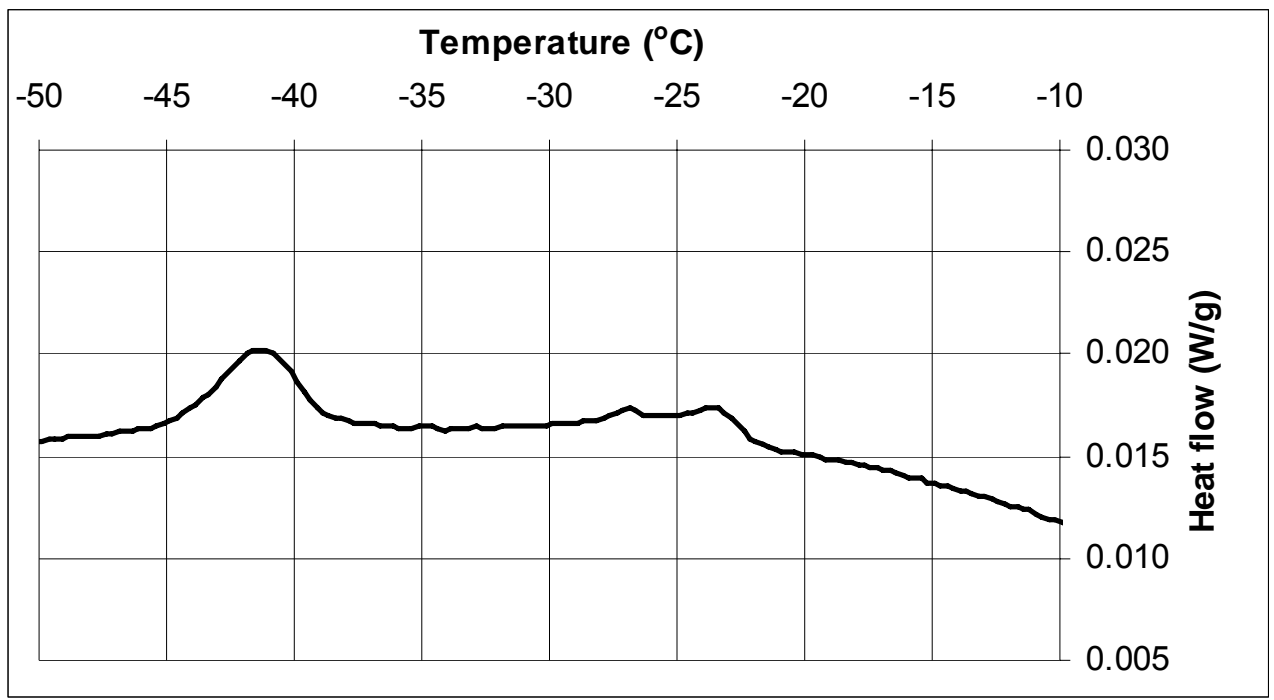

Figure $172 \mathrm{LTC}$ scan for CCRL Cement 140, w/c $=0.40$, prepared with distilled water and cured for $30 \mathrm{~d}$ at $20{ }^{\circ} \mathrm{C}$ under saturated conditions.

Cement: CCRL Cement 140

Solution: Alkali sulfate solution w/c: 0.40

Temperature: $20{ }^{\circ} \mathrm{C}$

Degree of hydration: 0.671
Curing: Saturated

Age when tested: $30 \mathrm{~d}$

Sample mass: $60.4 \mathrm{mg}$

Filename: c140w04walk30d

Date tested: Jan. 27, 2005

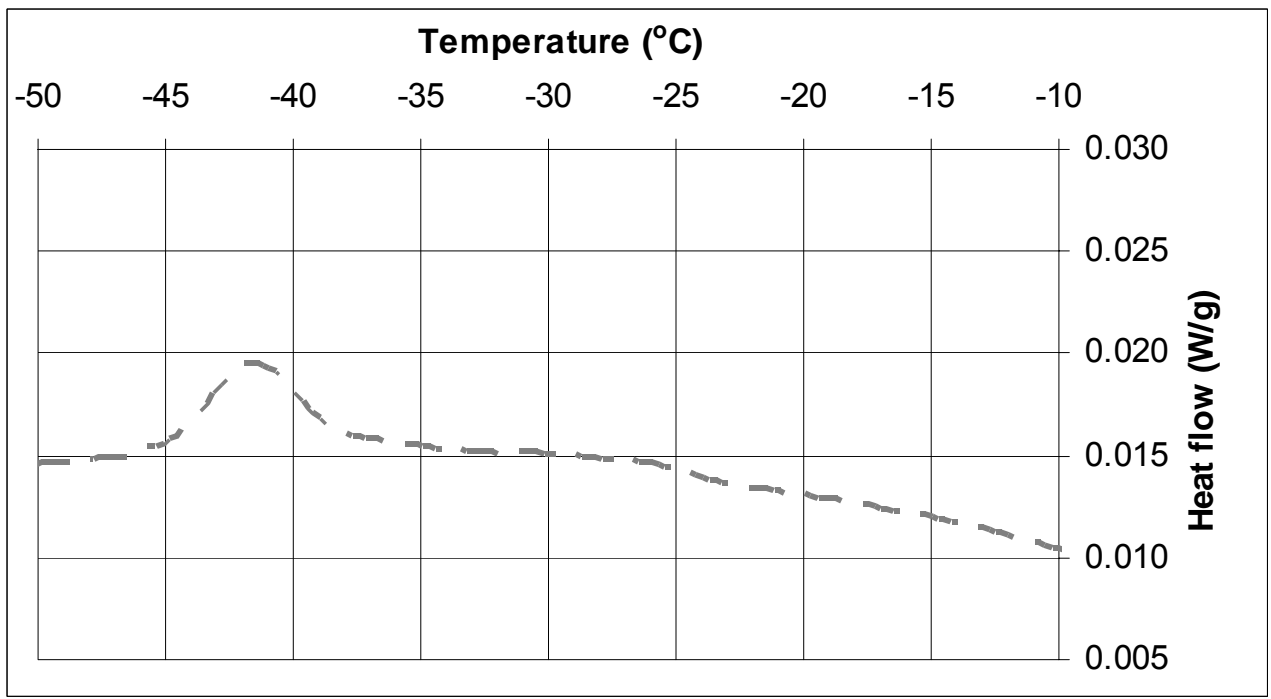

Figure $173 \mathrm{LTC}$ scan for CCRL Cement $140, w / c=0.40$, prepared with a solution of alkali sulfates and cured for $30 \mathrm{~d}$ at $20{ }^{\circ} \mathrm{C}$ under saturated conditions. 
Cement: CCRL Cement $140 \quad$ Curing: Saturated

Solution: Alkali hydroxide solution Age when tested: $30 \mathrm{~d}$

$w / c: 0.40$

Temperature: $20{ }^{\circ} \mathrm{C}$

Sample mass: $75.5 \mathrm{mg}$

Degree of hydration: 0.738

Filename: c140w04walkoh30d

Date tested: Jan. 27, 2005

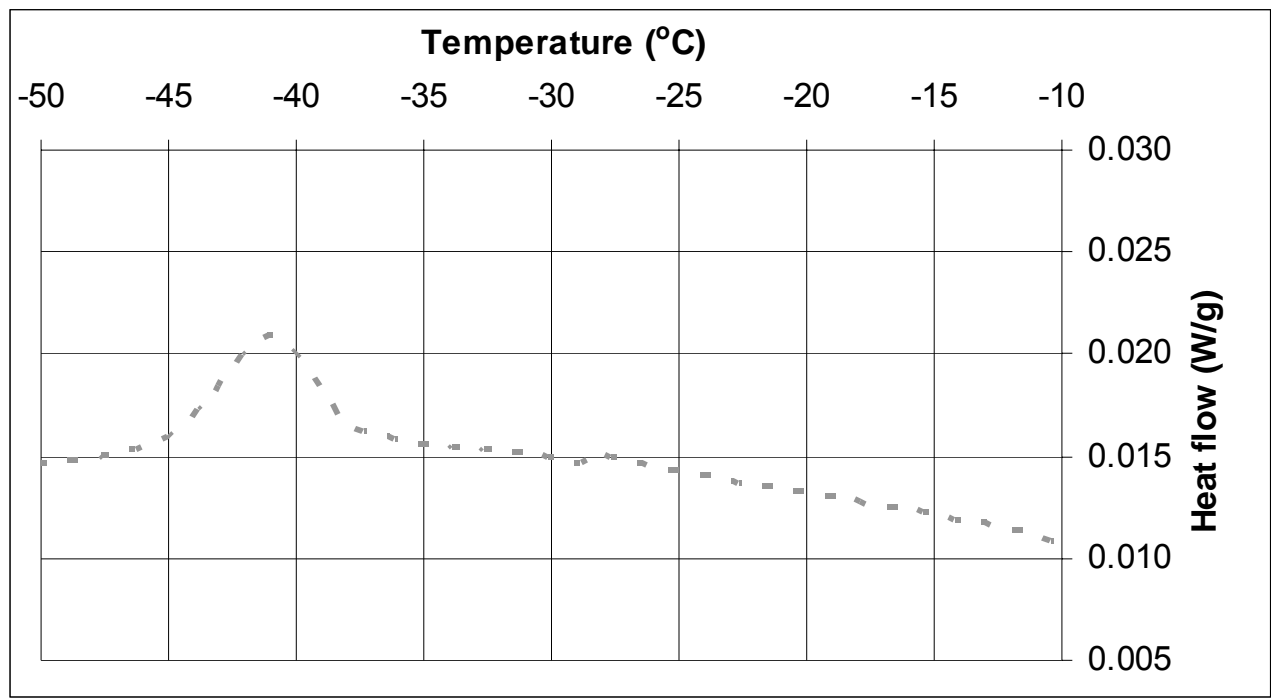

Figure $174 \mathrm{LTC}$ scan for CCRL Cement $140, w / c=0.40$, prepared with a solution of alkali hydroxides and cured for $30 \mathrm{~d}$ at $20{ }^{\circ} \mathrm{C}$ under saturated conditions.

Cement: CCRL Cement 140

Solution: $\mathrm{LiOH}$ solution

$w / c: 0.40$

Temperature: $20{ }^{\circ} \mathrm{C}$

Degree of hydration: 0.761
Curing: Saturated

Age when tested: $30 \mathrm{~d}$

Sample mass: $57.9 \mathrm{mg}$

Filename: c140w04lioh30d

Date tested: March 3, 2005

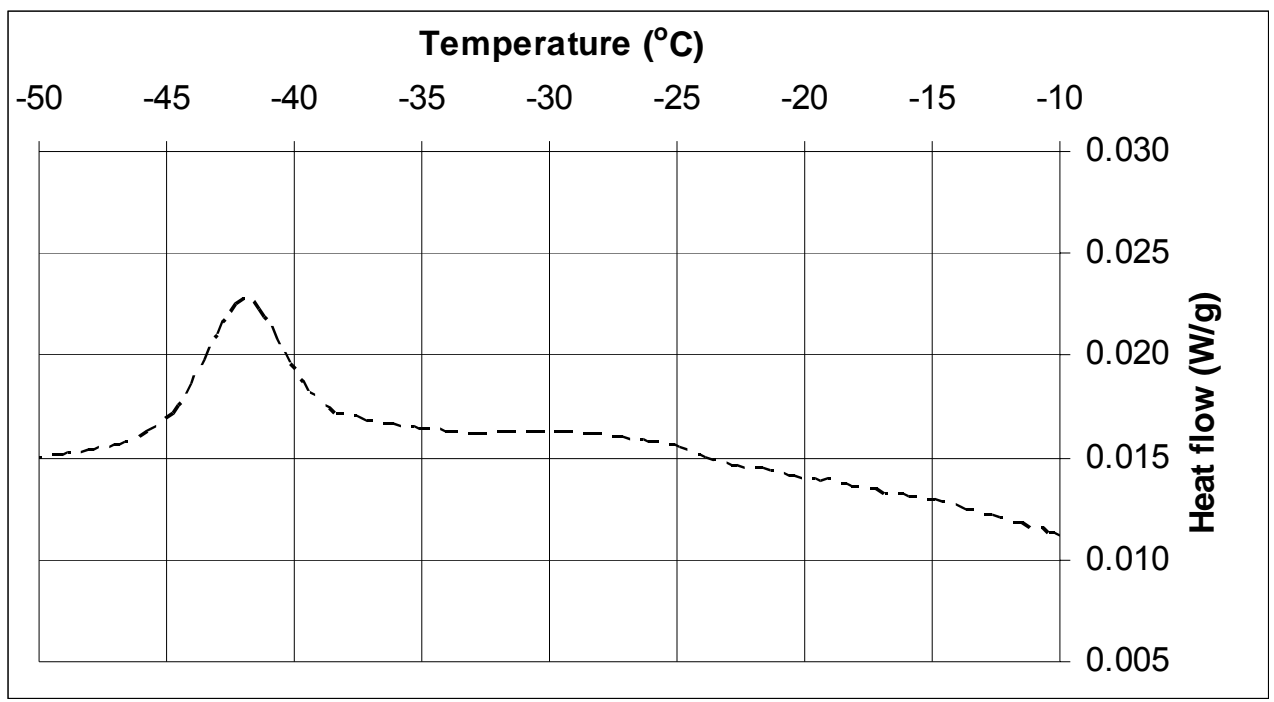

Figure $175 \mathrm{LTC}$ scan for CCRL Cement $140, w / c=0.40$, prepared with a solution of LiOH and cured for $30 \mathrm{~d}$ at $20{ }^{\circ} \mathrm{C}$ under saturated conditions. 
Cement: CCRL Cement 140

Solution: $\mathrm{LiNO}_{3}$ solution

w/c: 0.40

Temperature: $20{ }^{\circ} \mathrm{C}$

Degree of hydration: 0.764
Curing: Saturated

Age when tested: $30 \mathrm{~d}$

Sample mass: $65.8 \mathrm{mg}$

Filename: c140w04lino3a30d

Date tested: March 3, 2005

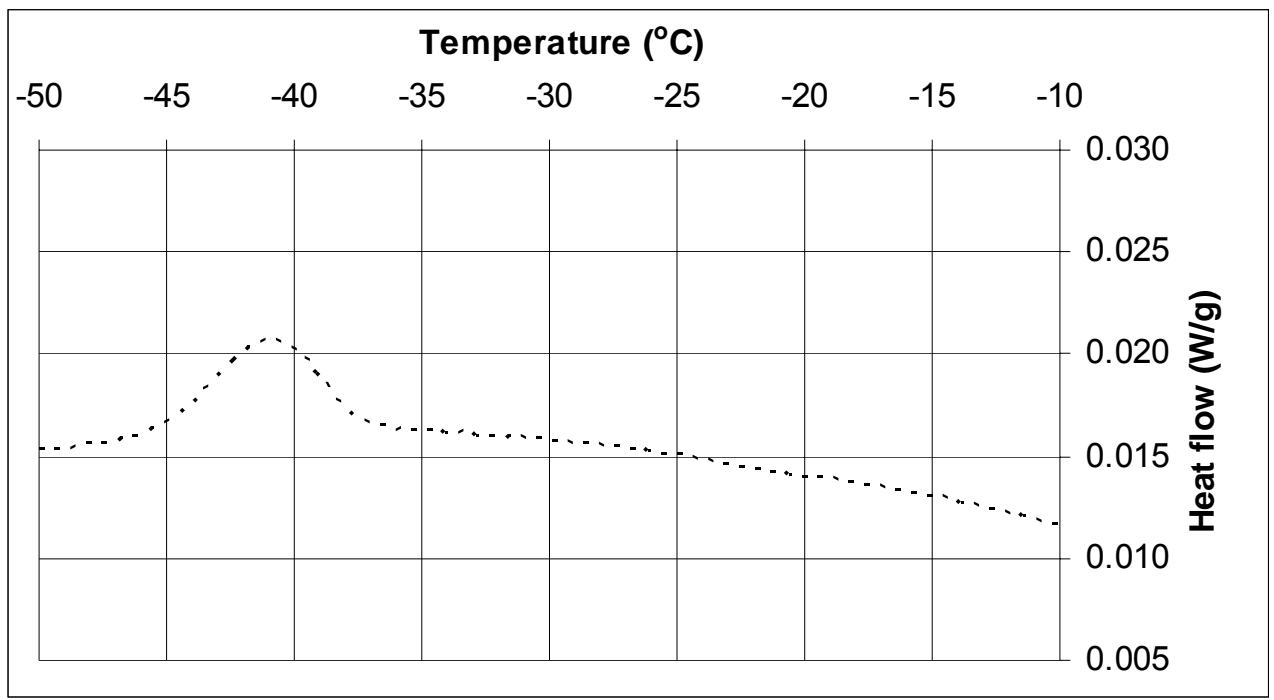

Figure $176 \mathrm{LTC}$ scan for CCRL Cement $140, w / c=0.40$, prepared with a solution of $\mathrm{LiNO}_{3}$ and cured for $30 \mathrm{~d}$ at $20{ }^{\circ} \mathrm{C}$ under saturated conditions.

Cement: CCRL Cement 140

Solution: Distilled water

w/c: 0.40

Temperature: $20^{\circ} \mathrm{C}$

Degree of hydration: 0.82
Curing: Saturated

Age when tested: $63 \mathrm{~d}$

Sample mass: $66.8 \mathrm{mg}$

Filename: C140w4nalksat63d

Date tested: March 1, 2005

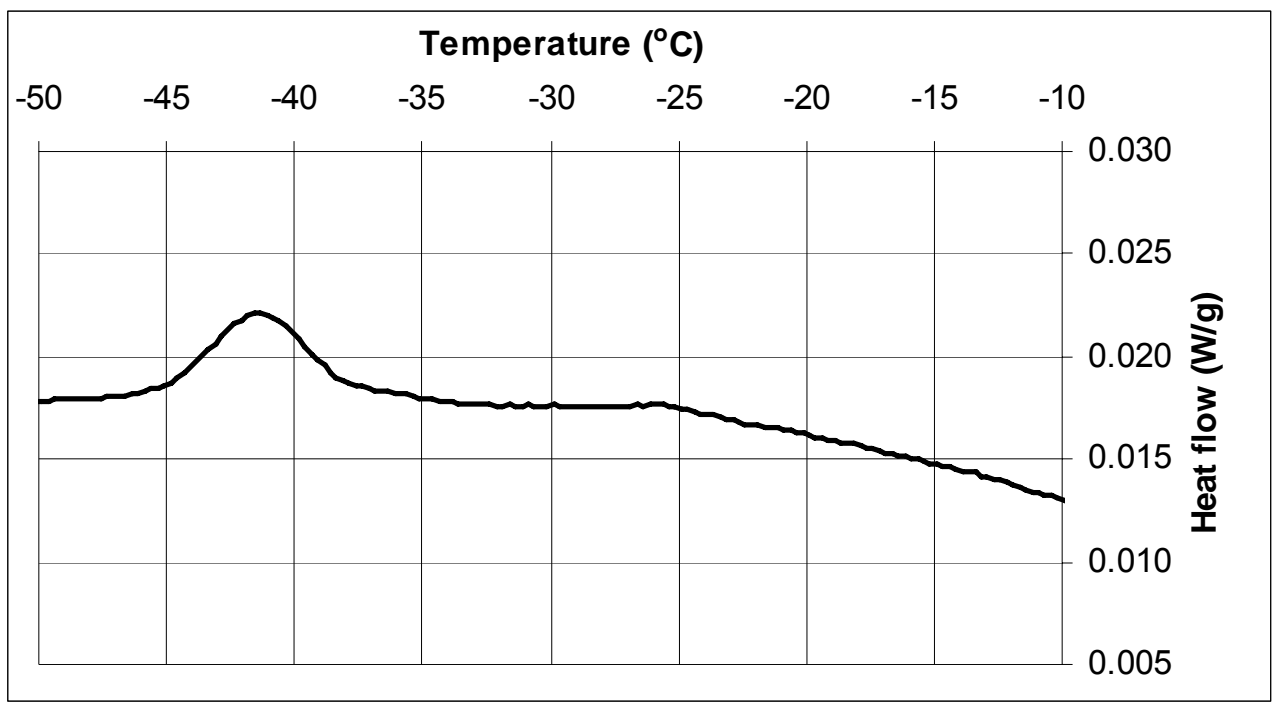

Figure 177 LTC scan for CCRL Cement $140, w / c=0.40$, prepared with distilled water and cured for $63 \mathrm{~d}$ at $20{ }^{\circ} \mathrm{C}$ under saturated conditions. 
Cement: CCRL Cement 140

Solution: Alkali sulfate solution

w/c: 0.40

Temperature: $20{ }^{\circ} \mathrm{C}$

Degree of hydration: 0.737
Curing: Saturated

Age when tested: $63 \mathrm{~d}$

Sample mass: $47.2 \mathrm{mg}$

Filename: C140w4walksat63d

Date tested: March 1, 2005

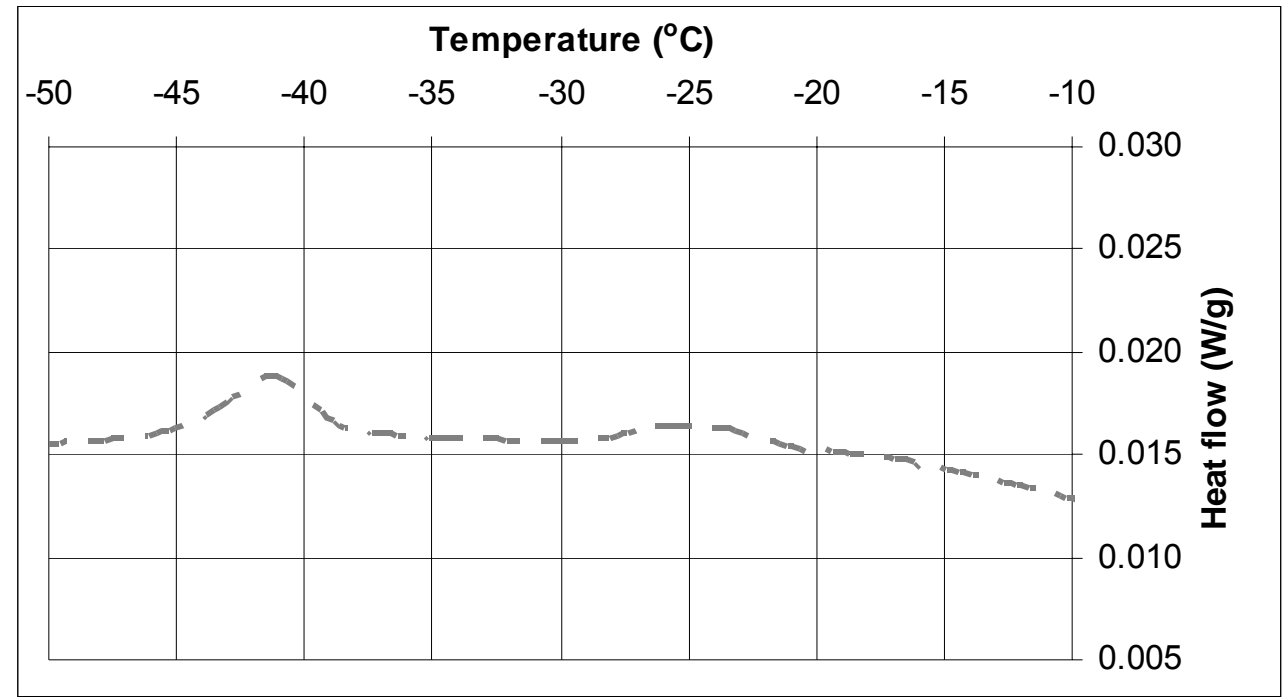

Figure $178 \mathrm{LTC}$ scan for CCRL Cement 140, $w / C=0.40$, prepared with a solution of alkali sulfates and cured for $63 \mathrm{~d}$ at $20{ }^{\circ} \mathrm{C}$ under saturated conditions.

Cement: CCRL Cement $140 \quad$ Curing: Saturated

Solution: Alkali hydroxide solution Age when tested: $63 \mathrm{~d}$ w/c: 0.40

Temperature: $20^{\circ} \mathrm{C}$

Degree of hydration: 0.815

Sample mass: $48.5 \mathrm{mg}$

Filename: C140w4walkohsat63d

Date tested: March 1, 2005

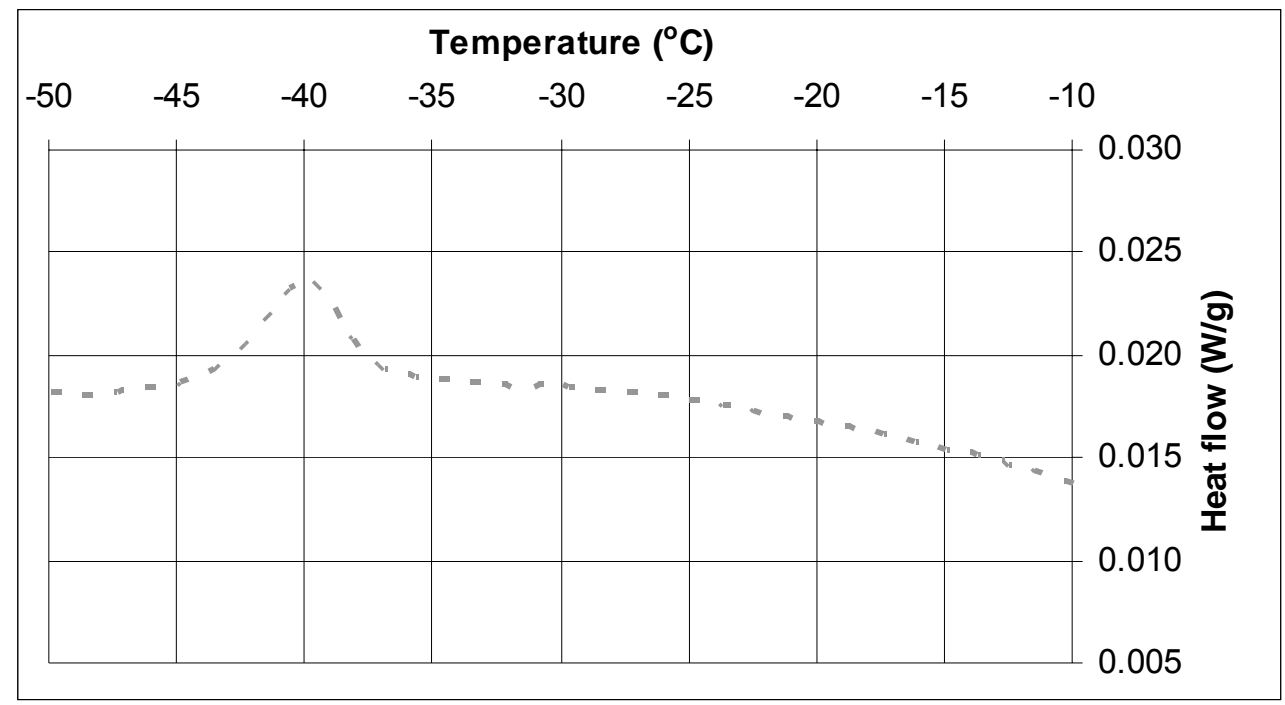

Figure 179 LTC scan for CCRL Cement $140, w / c=0.40$, prepared with a solution of alkali hydroxides and cured for $63 \mathrm{~d}$ at $20{ }^{\circ} \mathrm{C}$ under saturated conditions. 
Cement: CCRL Cement 140

Solution: $\mathrm{LiOH}$ solution

w/c: 0.40

Temperature: $20{ }^{\circ} \mathrm{C}$

Degree of hydration: 0.812
Curing: Saturated

Age when tested: $63 \mathrm{~d}$

Sample mass: $53.7 \mathrm{mg}$

Filename: c140w04lioh63d

Date tested: April 5, 2005

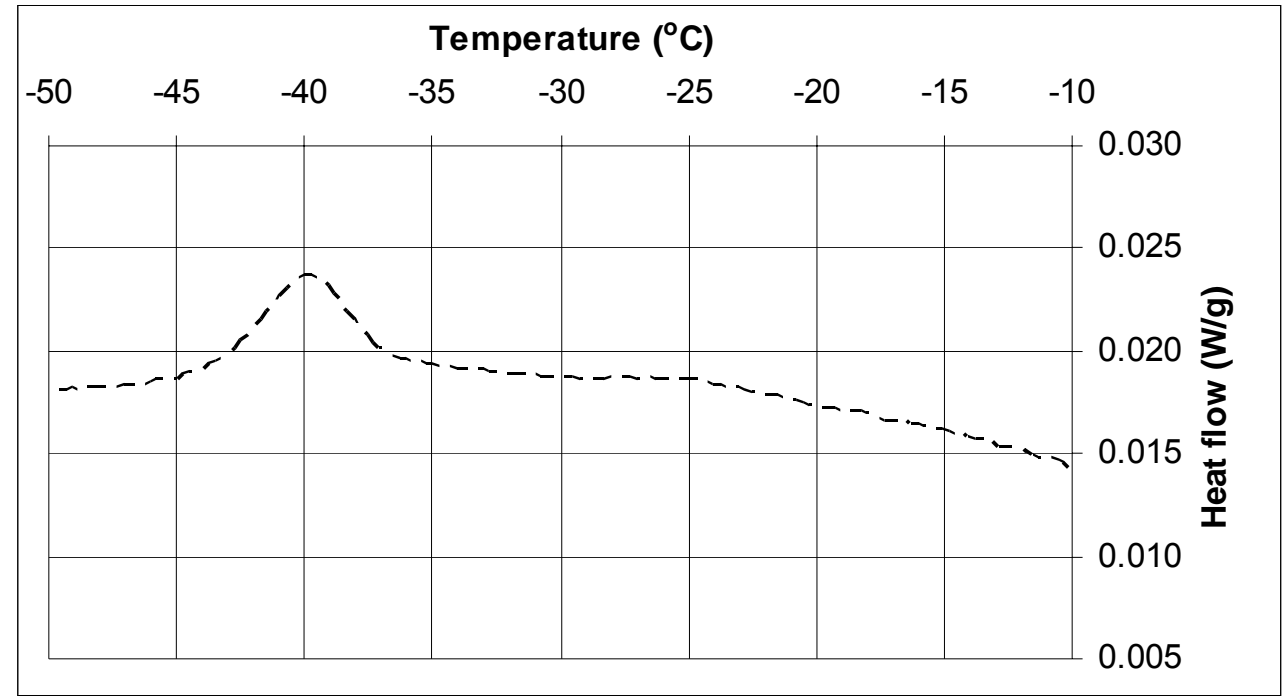

Figure $180 \mathrm{LTC}$ scan for CCRL Cement $140, w / c=0.40$, prepared with a solution of $\mathrm{LiOH}$ and cured for $63 \mathrm{~d}$ at $20^{\circ} \mathrm{C}$ under saturated conditions.

Cement: CCRL Cement 140

Solution: $\mathrm{LiNO}_{3}$ solution

w/c: 0.40

Temperature: $20{ }^{\circ} \mathrm{C}$

Degree of hydration: 0.804
Curing: Saturated

Age when tested: $63 \mathrm{~d}$

Sample mass: $56.2 \mathrm{mg}$

Filename: c140w04lino3a63d

Date tested: April 5, 2005

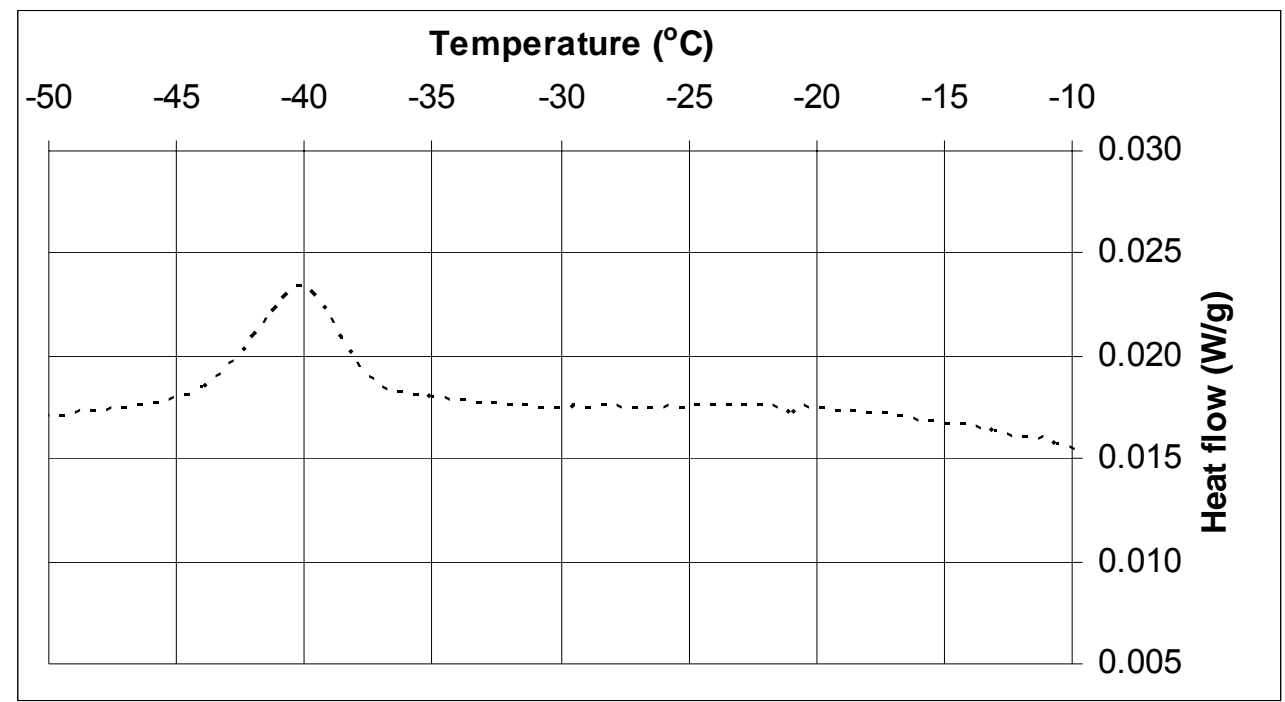

Figure $181 \mathrm{LTC}$ scan for CCRL Cement $140, w / c=0.40$, prepared with a solution of $\mathrm{LiNO}_{3}$ and cured for $63 \mathrm{~d}$ at $20{ }^{\circ} \mathrm{C}$ under saturated conditions. 
Cement: CCRL Cement 140

Solution: Distilled water

w/c: 0.40

Temperature: $20{ }^{\circ} \mathrm{C}$

Degree of hydration: N/A
Curing: Saturated

Age when tested: $90 \mathrm{~d}$

Sample mass: $54.7 \mathrm{mg}$

Filename: c140w04nalk90d

Date tested: March 28, 2005

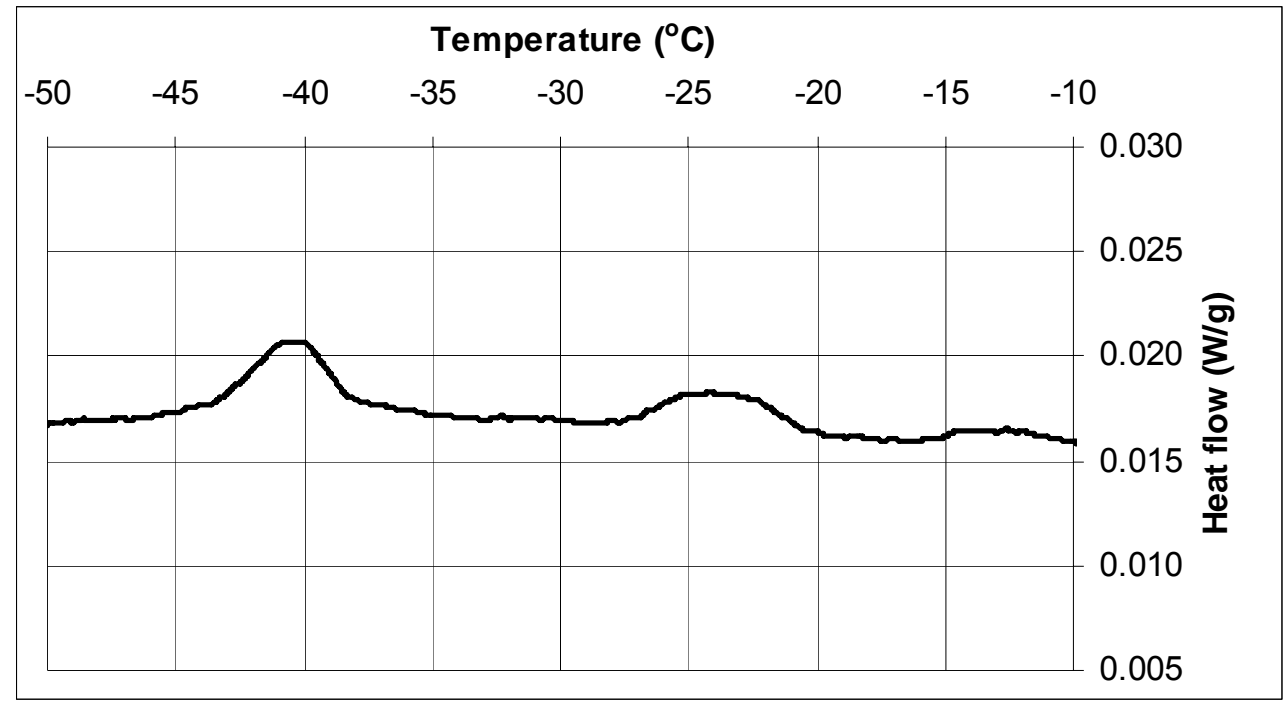

Figure $182 \mathrm{LTC}$ scan for CCRL Cement $140, w / c=0.40$, prepared with distilled water and cured for $90 \mathrm{~d}$ at $20{ }^{\circ} \mathrm{C}$ under saturated conditions.

Cement: CCRL Cement 140

Solution: Distilled water

w/c: 0.40

Temperature: $20^{\circ} \mathrm{C}$

Degree of hydration: N/A
Curing: Saturated

Age when tested: $91 \mathrm{~d}$

Sample mass: $56.4 \mathrm{mg}$

Filename: c140w04nalk91d

Date tested: March 29, 2005

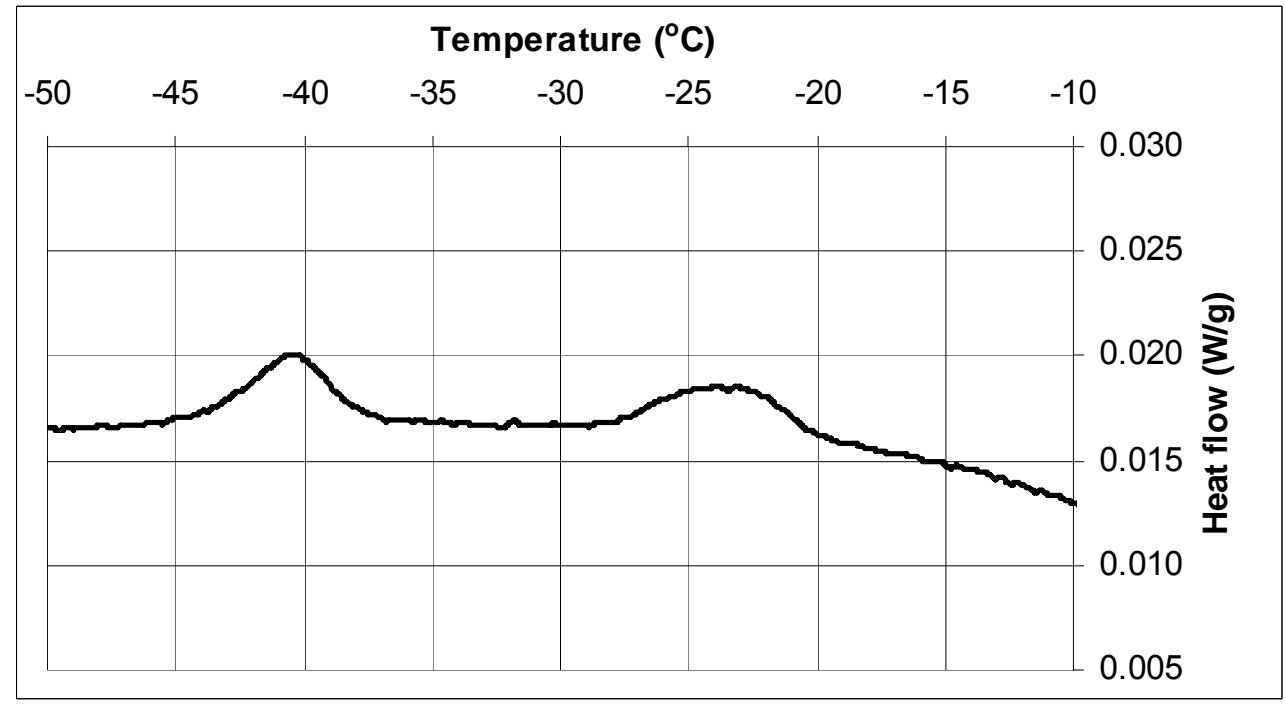

Figure 183 LTC scan for CCRL Cement 140, w/c $=0.40$, prepared with distilled water and cured for $91 \mathrm{~d}$ at $20{ }^{\circ} \mathrm{C}$ under saturated conditions. 
Cement: CCRL Cement 140

Solution: Alkali sulfate solution

$w / c: 0.40$

Temperature: $20{ }^{\circ} \mathrm{C}$

Degree of hydration: N/A
Curing: Saturated

Age when tested: $90 \mathrm{~d}$

Sample mass: $65.2 \mathrm{mg}$

Filename: c140w04walk90d

Date tested: March 28, 2005

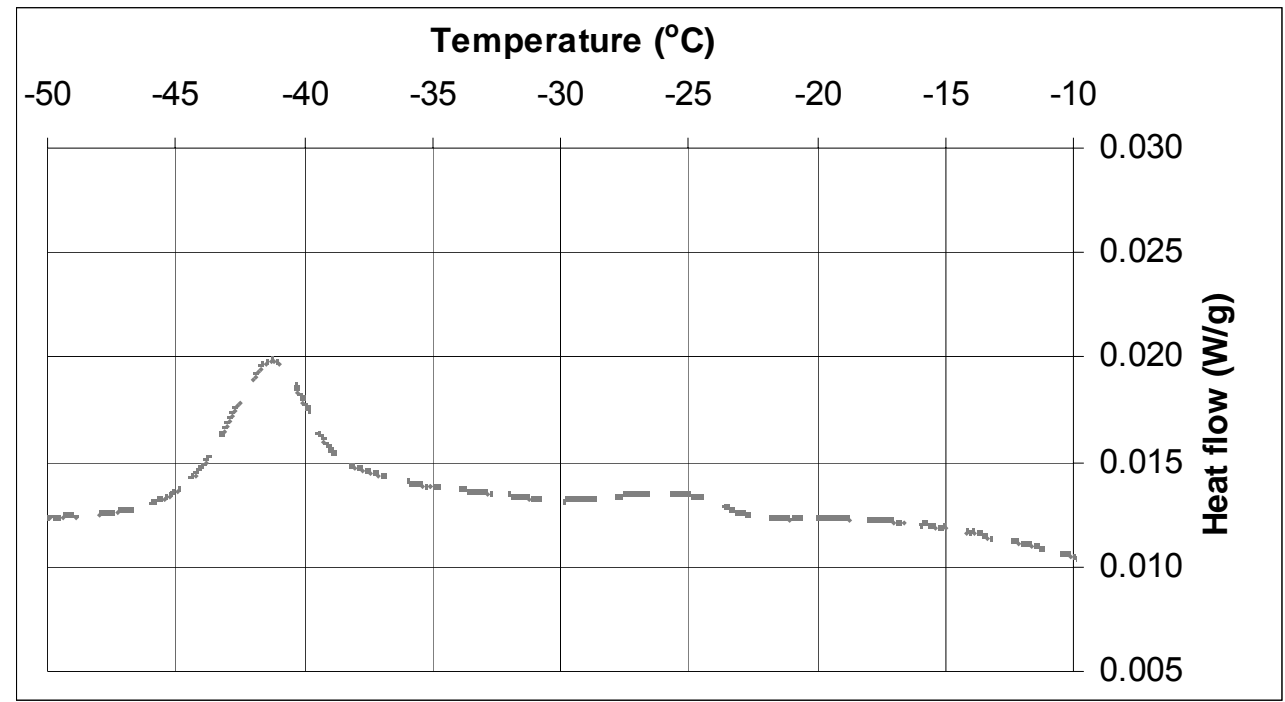

Figure $184 \mathrm{LTC}$ scan for CCRL Cement 140, $w / C=0.40$, prepared with a solution of alkali sulfates and cured for $90 \mathrm{~d}$ at $20^{\circ} \mathrm{C}$ under saturated conditions.

Cement: CCRL Cement 140

Solution: Alkali sulfate solution $w / c: 0.40$

Temperature: $20^{\circ} \mathrm{C}$

Degree of hydration: N/A
Curing: Saturated

Age when tested: $91 \mathrm{~d}$

Sample mass: $74.6 \mathrm{mg}$

Filename: c140w04walk91d

Date tested: March 29, 2005

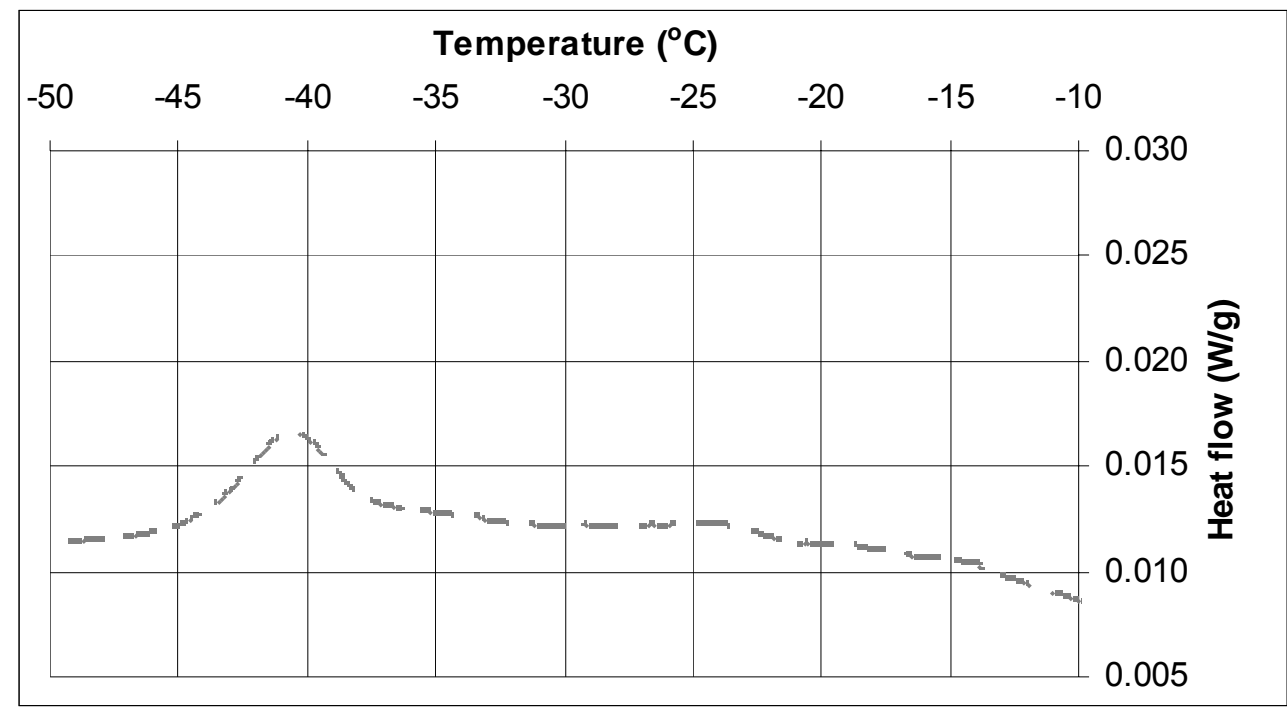

Figure $185 \mathrm{LTC}$ scan for CCRL Cement 140, w/c $=0.40$, prepared with a solution of alkali sulfates and cured for $91 \mathrm{~d}$ at $20^{\circ} \mathrm{C}$ under saturated conditions. 
Cement: CCRL Cement $140 \quad$ Curing: Saturated

Solution: Alkali hydroxide solution Age when tested: $90 \mathrm{~d}$

$w / c: 0.40$

Temperature: $20{ }^{\circ} \mathrm{C}$

Sample mass: $59.8 \mathrm{mg}$

Degree of hydration: N/A

Filename: c140w04walkoh90d

Date tested: March 28, 2005

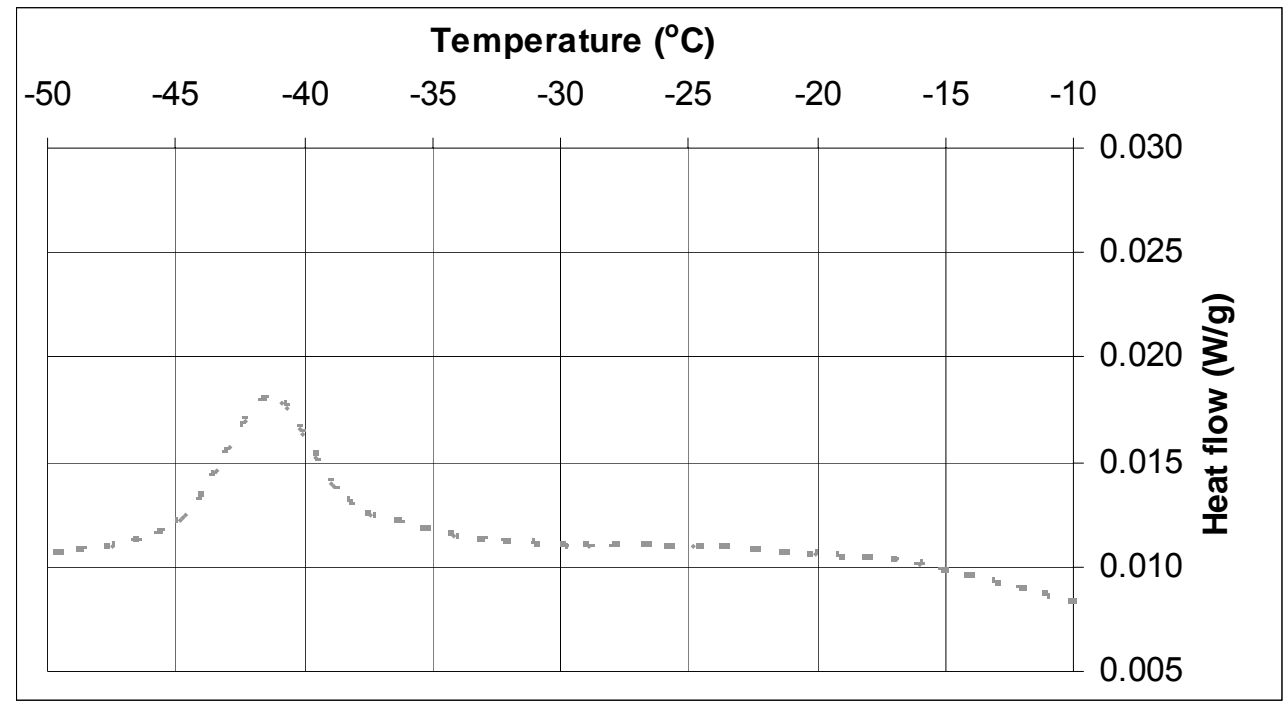

Figure 186 LTC scan for CCRL Cement $140, w / c=0.40$, prepared with a solution of alkali hydroxides and cured for $90 \mathrm{~d}$ at $20{ }^{\circ} \mathrm{C}$ under saturated conditions.

Cement: CCRL Cement 140

Solution: $\mathrm{LiOH}$ solution

$w / c: 0.40$

Temperature: $20{ }^{\circ} \mathrm{C}$

Degree of hydration: 0.831
Curing: Saturated

Age when tested: $90 \mathrm{~d}$

Sample mass: $41.0 \mathrm{mg}$

Filename: c140w04lioh90d

Date tested: May 2, 2005

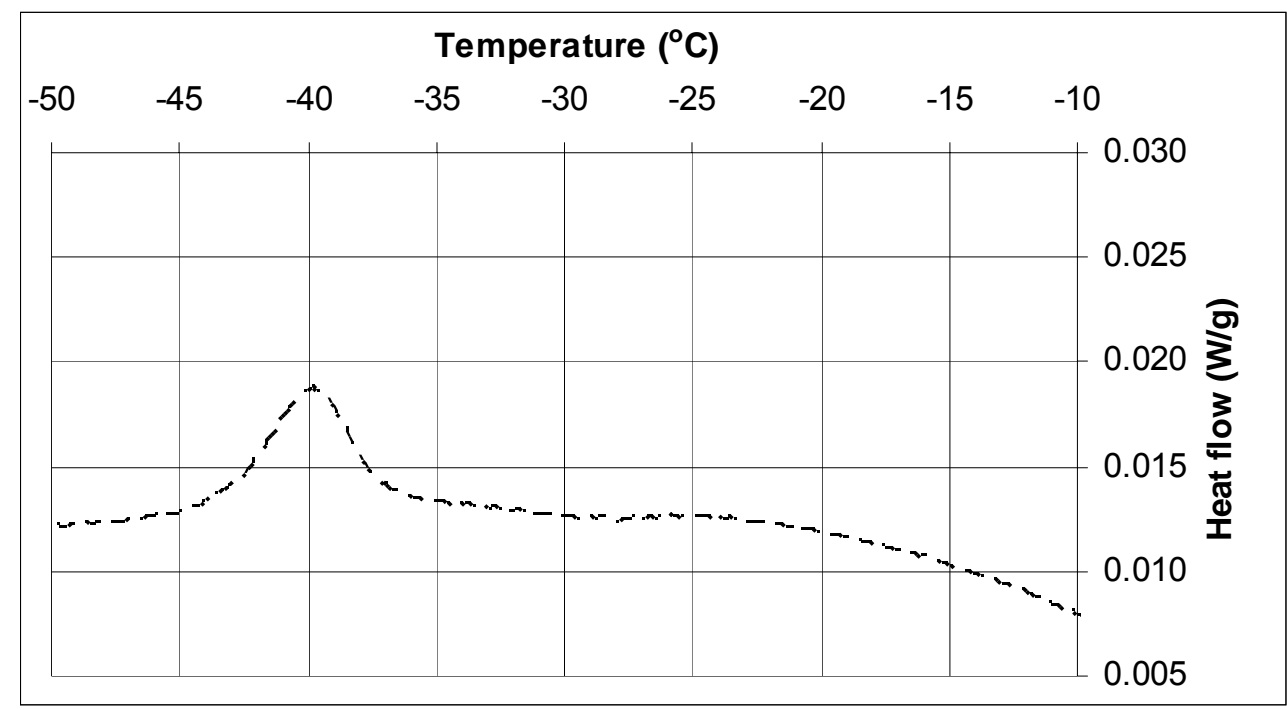

Figure $187 \mathrm{LTC}$ scan for CCRL Cement 140, w/C $=0.40$, prepared with a solution of $\mathrm{LiOH}$ and cured for $90 \mathrm{~d}$ at $20^{\circ} \mathrm{C}$ under saturated conditions. 
Cement: CCRL Cement 140

Solution: $\mathrm{LiNO}_{3}$ solution

w/c: 0.40

Temperature: $20{ }^{\circ} \mathrm{C}$

Degree of hydration: 0.834
Curing: Saturated

Age when tested: $90 \mathrm{~d}$

Sample mass: $54.5 \mathrm{mg}$

Filename: c140w04lino3a90d

Date tested: May 2, 2005

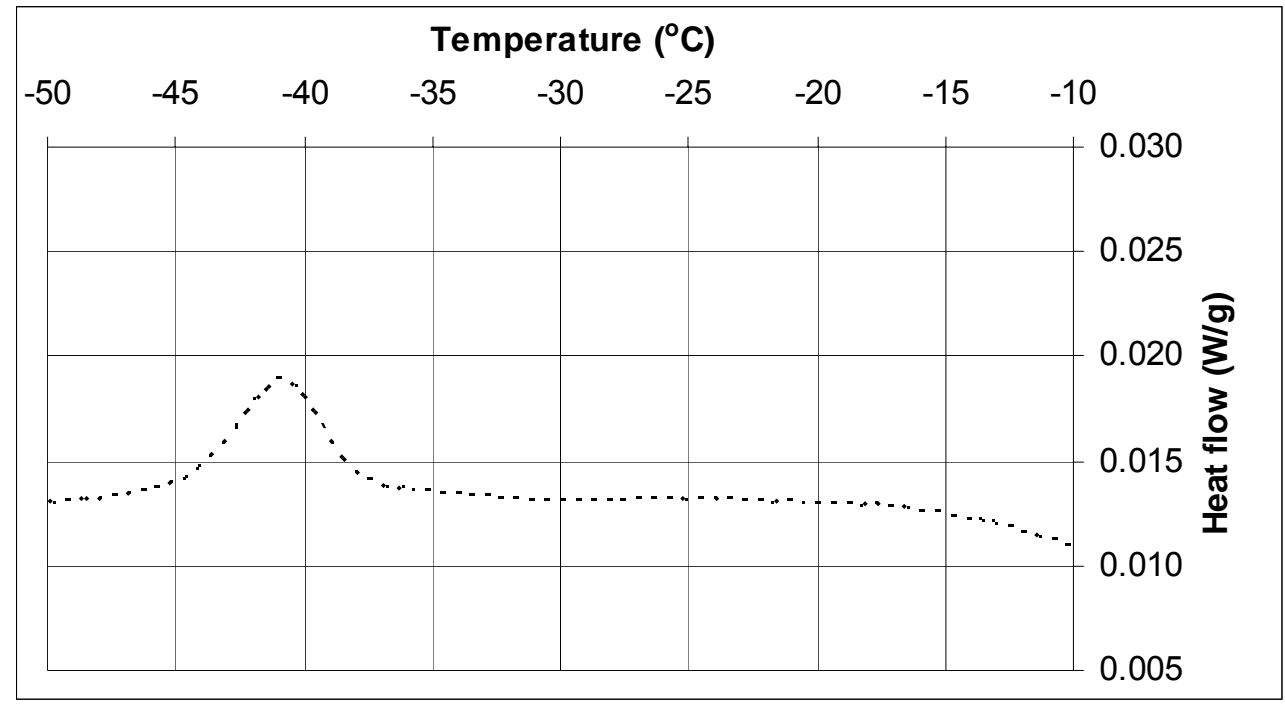

Figure $188 \mathrm{LTC}$ scan for CCRL Cement $140, w / c=0.40$, prepared with a solution of $\mathrm{LiNO}_{3}$ and cured for $90 \mathrm{~d}$ at $20{ }^{\circ} \mathrm{C}$ under saturated conditions.

Cement: CCRL Cement 140

Solution: Distilled water

w/c: 0.40

Temperature: $2{ }^{\circ} \mathrm{C}$

Degree of hydration: N/A
Curing: Saturated

Age when tested: $101 \mathrm{~d}$

Sample mass: $56.4 \mathrm{mg}$

Filename: c140p101d

Date tested: July 18, 2002

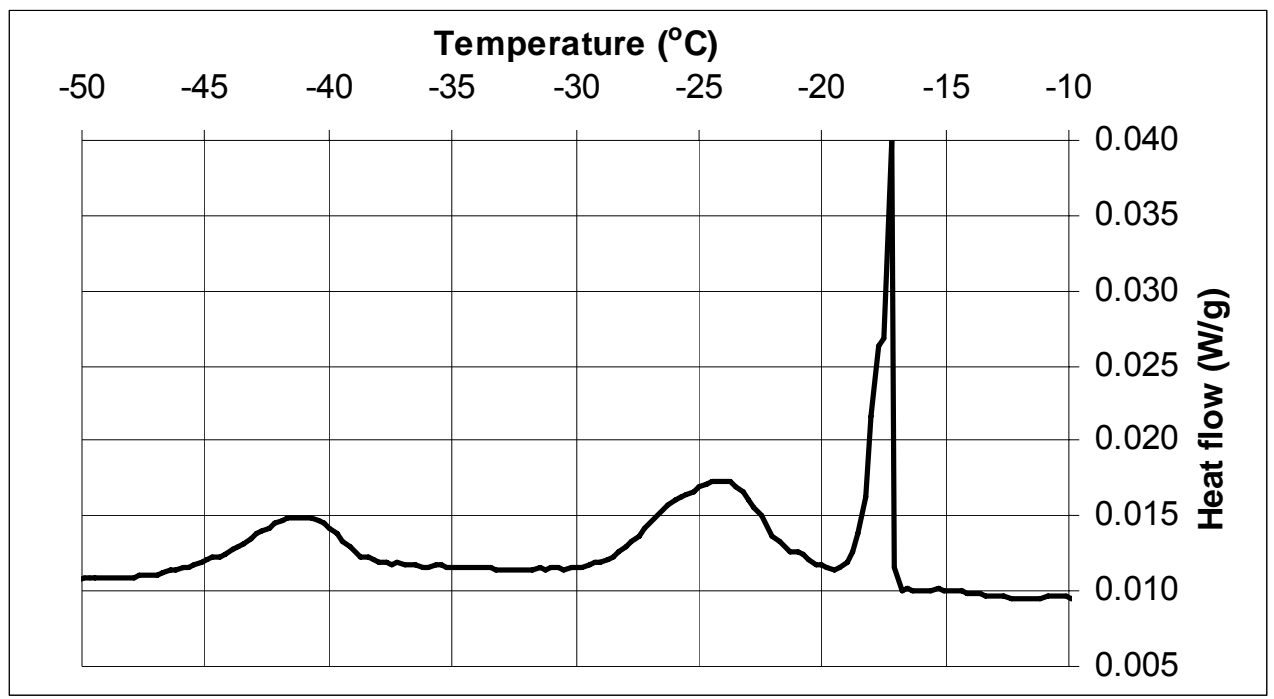

Figure 189 LTC scan for CCRL Cement $140, w / c=0.40$, prepared with distilled water and cured for $101 \mathrm{~d}$ at $20{ }^{\circ} \mathrm{C}$ under saturated conditions. 
Cement: CCRL Cement 140

Solution: Distilled water

$w / c: 0.40$

Temperature: $20{ }^{\circ} \mathrm{C}$

Degree of hydration: N/A
Curing: Saturated

Age when tested: $105 \mathrm{~d}$

Sample mass: $49.8 \mathrm{mg}$

Filename: c140p105d

Date tested: July 22, 2002

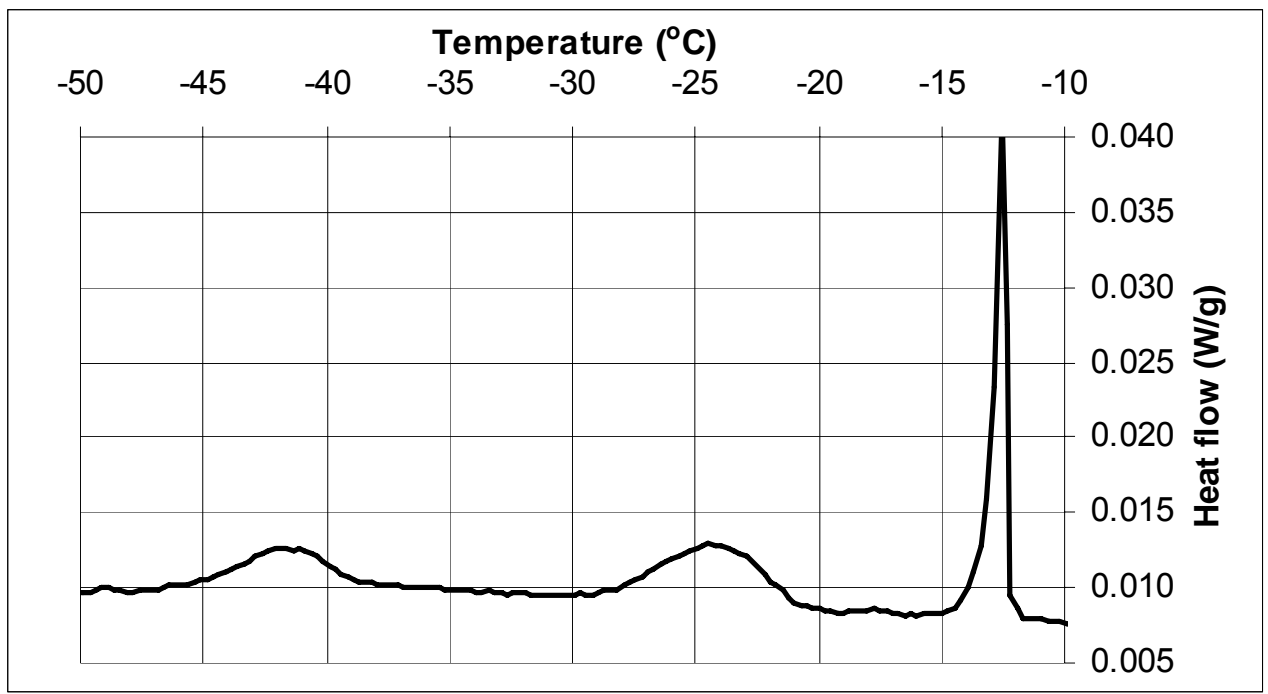

Figure $190 \mathrm{LTC}$ scan for CCRL Cement $140, w / c=0.40$, prepared with distilled water and cured for $105 \mathrm{~d}$ at $20{ }^{\circ} \mathrm{C}$ under saturated conditions.

Cement: CCRL Cement 140

Solution: Alkali sulfate solution

$w / c: 0.40$

Temperature: $20{ }^{\circ} \mathrm{C}$

Degree of hydration: N/A
Curing: Saturated

Age when tested: $101 \mathrm{~d}$

Sample mass: $64.2 \mathrm{mg}$

Filename: c140walk101d

Date tested: July 18, 2002

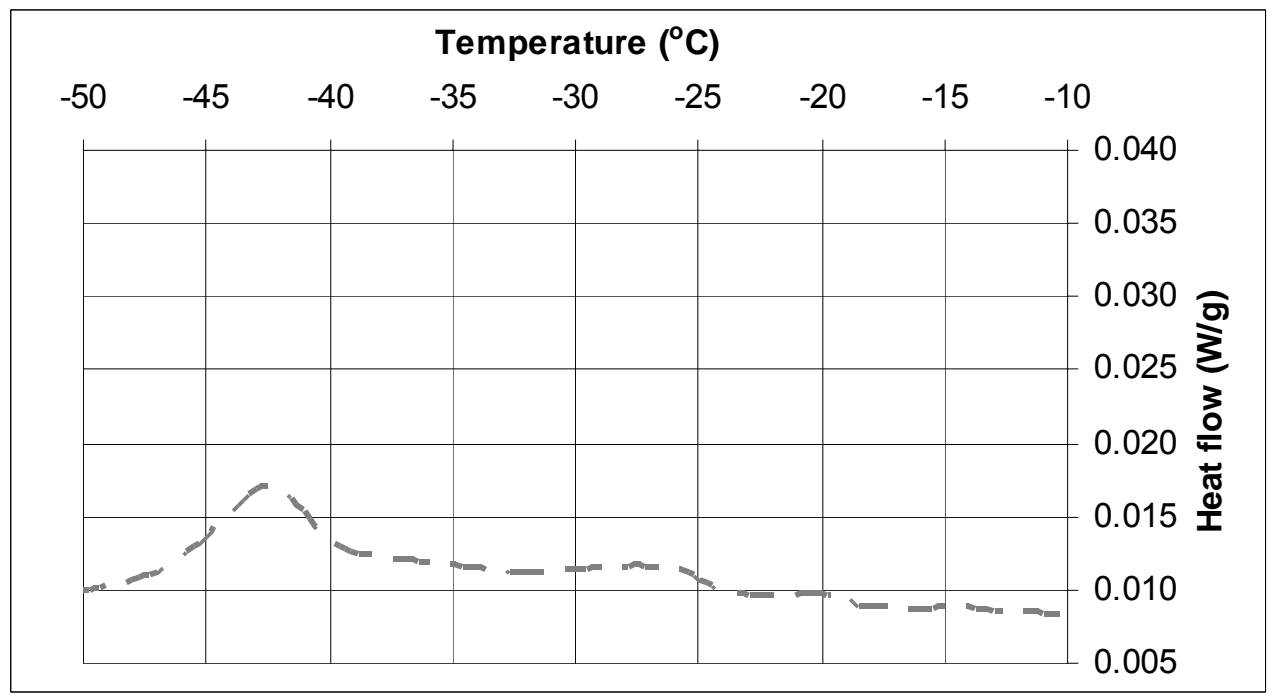

Figure 191 LTC scan for CCRL Cement $140, w / c=0.40$, prepared with a solution of alkali sulfates and cured for $101 \mathrm{~d}$ at $20{ }^{\circ} \mathrm{C}$ under saturated conditions. 
Cement: CCRL Cement 140

Solution: Alkali sulfate solution

$w / c: 0.40$

Temperature: $20{ }^{\circ} \mathrm{C}$

Degree of hydration: N/A
Curing: Saturated

Age when tested: $110 \mathrm{~d}$

Sample mass: $60.6 \mathrm{mg}$

Filename: c140walk110d

Date tested: July 29, 2002

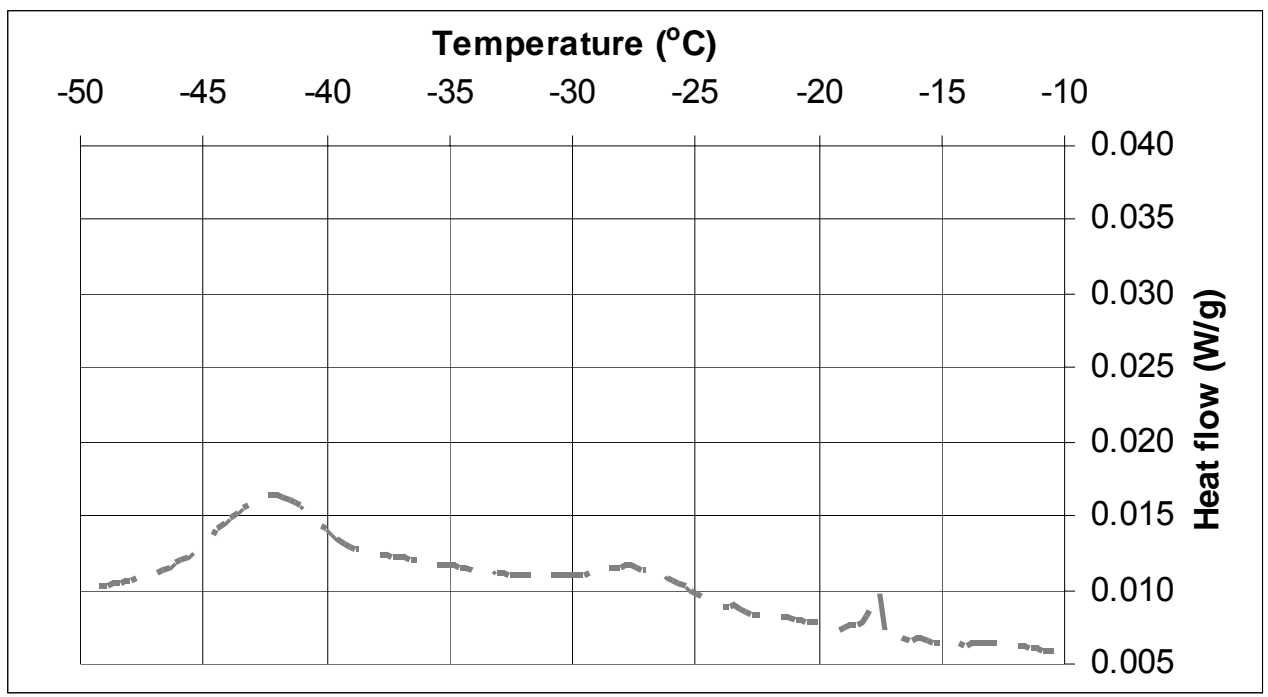

Figure $192 \mathrm{LTC}$ scan for CCRL Cement $140, w / c=0.40$, prepared with a solution of alkali sulfates and cured for $110 \mathrm{~d}$ at $20{ }^{\circ} \mathrm{C}$ under saturated conditions. 


\section{Observations}

1) For low $w / c$, sealed curing first depercolates capillary pores, but then later repercolates them due to self-desiccation stresses, internal shrinkage, and possibly microcrack formation [2]. The sealed/resaturated scans for cement 152, w/c $=0.35$ in Figures 39, 42, $43,48,49,55,59,64,71,73,79$, and 81 illustrate this process for curing at $20^{\circ} \mathrm{C}$. For the small cement paste specimens employed in these studies, continuing resaturation of the specimens cured first under sealed conditions did result in a second depercolation of the repercolated capillary (size) pores; this is illustrated in Figures 67, 72, and 83. In Figures 83 and 84, however, the repercolated open gel (size) pores did not exhibit a second depercolation upon extended resaturation from $204 \mathrm{~d}$ to $224 \mathrm{~d}$ or $238 \mathrm{~d}$. For curing at $40{ }^{\circ} \mathrm{C}$, equivalent depercolation/repercolation behavior is indicated in Figures $124,130,135,136$, and 140 . For cement pastes with a $20 \%$ by mass fraction limestone substitution, equivalent repercolation behavior was observed (Figures 97 and 101), but without any evidence of a subsequent second depercolation of the capillary pores (Figure 98), perhaps due to the higher effective $w / C$ in the specimens with the limestone substitution.

2) For extremely low $w / c=0.25$ at $20{ }^{\circ} \mathrm{C}$, this repercolation was observed both for specimens cured under sealed conditions and then resaturated (Figures $8,11,15,18,21$, 24, 27, and 30) and for specimens cured under nominally "saturated" (water ponded on top) conditions (Figures 4, 6, 9, 13, 16, 19, 22, 25, and 28). Most likely, for this extremely low $w / c$, it was not possible to maintain saturated conditions using the techniques employed in this study. Similar repercolation observations apply for the $40{ }^{\circ} \mathrm{C}$ curing for the $w / c=0.25$ cement pastes, as indicated in Figures 117, 118, and 120 .

3) For saturated curing, more time (and hydration) is required to depercolate the pores in a $w / c=0.35$ cement 152 paste when cured at $40{ }^{\circ} \mathrm{C}$, as opposed to at $20{ }^{\circ} \mathrm{C}$, in spite of the fact that the higher temperature curing significantly accelerates the cement hydration reactions. This suggests the formation of a coarser capillary pore structure when curing at higher temperatures in agreement with conventional wisdom [9]. For $20{ }^{\circ} \mathrm{C}$ curing under saturated conditions, depercolation of the capillary size pores occurred between $3 \mathrm{~d}$ (Figure 37) and $4 \mathrm{~d}$ (Figure 40) of curing. Conversely, for $40{ }^{\circ} \mathrm{C}$ saturated curing, this same depercolation occurred between $7 \mathrm{~d}$ (Figure 127) and $14 \mathrm{~d}$ (Figure 131).

4) For intermediate $w / c$ (e.g., 0.40 to 0.45 ), it appears that some length of sealed curing followed by resaturation may be superior to saturated curing from the time of initial casting, in terms of providing an earlier depercolation of the capillary pores. Evidence for this can be found in Figures 146, 148, and 149 for the cement $152 \mathrm{w} / \mathrm{c}=0.45$ cement pastes cured at $40^{\circ} \mathrm{C}$ for $14 \mathrm{~d}$ and in Figures 87,89 , and 90 for the cement $152 \mathrm{w} / \mathrm{c}=0.435$ cement pastes cured at $20{ }^{\circ} \mathrm{C}$. This effect could be due to the fact that under the initial sealed curing conditions, cement hydration will be localized in the pore entryways and smaller pores and will not be occurring in the larger pores that are emptying due to selfdesiccation (from the chemical shrinkage accompanying the hydration reactions). Figure 193 provides a simple 4-particle model of cement hydration illustrating this hypothesis. 
5) For the low-alkali cement 140 pastes with $w / c=0.40$, repercolation of the capillary and open gel pores was observed to occur at later ages even under saturated curing conditions, as exemplified by the LTC scans in Figures 172, 177, 182, 183, 189, and 190. It is likely that the C-S-H gel formed in this hydrating low-alkali cement paste is very amorphous with a highly random morphology; thus, subsequent rearrangement to a more ordered (nano)structure could be responsible for local shrinkage and the observed repercolation of the open gel and capillary (size) pores [3,4]. Conversely, the addition of alkalis (lithium, sodium, or potassium) results in an earlier depercolation of the capillary pores as indicated by comparing Figures 162 to 166 for specimens cured for $8 \mathrm{~d}$ under saturated conditions. Furthermore, limited evidence of a later age repercolation is observed only for the specimens with potassium and sodium sulfate additions, as shown in Figures 191 and 192. The specimens with alkali hydroxide or lithium nitrate additions cured for $90 \mathrm{~d}$ under saturated conditions exhibited no evidence of either an open gel or capillary pore repercolation (Figures 186, 187, and 188).

a) saturated

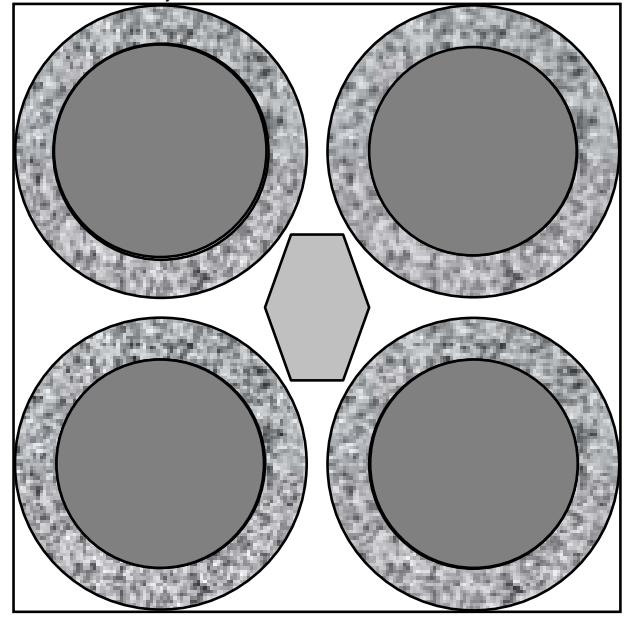

b) sealed

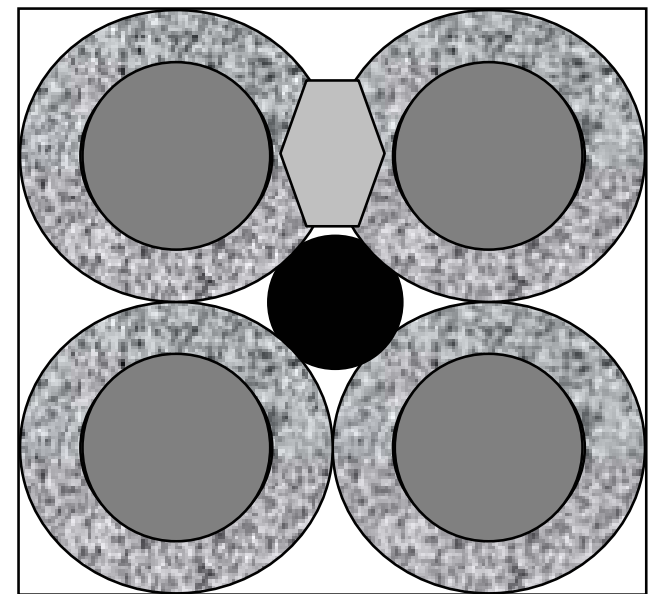

Figure 193 Four particle model for hydrating cement paste microstructure, indicating hydration under saturated and sealed curing conditions. Dark grey is unhydrated cement grains, textured material and light grey are hydration products, white is water-filled porosity, and black is empty porosity, from reference [2].

\section{Conclusions and Future Research}

Low temperature calorimetry has been shown to be a valuable tool for characterizing the porosity of hydrating cement pastes, both in terms of the presence/absence of freezable water as a function of temperature and the percolation state of pore networks with various size entryways (dense gel, open gel, and capillary). Numerous examples of the influences of cement type, w/c, curing temperature, curing time, curing saturation conditions, and the additions of alkali compounds or limestone fillers have been presented in this report. Future efforts will focus on extending these LTC and hydration studies to blended cements to examine the influence of additions of silica fume, slag, fly ash, and the like on the developing porosity. In addition, studies are also underway on the influence of several different shrinkage-reducing admixture (SRA) types and dosages on the freezable water content of hydrating cement pastes. 


\section{References}

[1] Snyder, K.A., and Bentz, D.P., "Suspended Hydration and Loss of Freezable Water in Cement Pastes Exposed to 90\% Relative Humidity," Cement and Concrete Research, Vol. 34 (11), 2045-2056, 2004.

[2] Bentz, D.P., and Stutzman, P.E., "Curing, Hydration, and Microstructure of Cement Paste," submitted to ACI Materials Journal, 2005.

[3] Bentz, D.P., "Influence of Alkalis on Porosity Percolation in Hydrating Cement Pastes," submitted to Cement and Concrete Composites, 2005.

[4] Bentz, D.P., "Lithium, Potassium, and Sodium Additions to Cement Pastes," submitted to Advances in Cement Research, 2005.

[5] Bentz, D.P., "Capillary Porosity Depercolation/Repercolation in Hydrating Cement Pastes via Low Temperature Calorimetry Measurements and CEMHYD3D Modeling," submitted to Journal of the American Ceramic Society, 2005.

[6] Bentz, D.P., "Three-Dimensional Computer Simulation of Cement Hydration and Microstructure Development," Journal of the American Ceramic Society, V. 80 (1), 1997, pp. 3-21.

[7] Molina, L., "On Predicting the Influence of Curing Conditions on the Degree of Hydration," CBI Report 5:92, Swedish Cement and Concrete Research Institute, Stockholm, Sweden, 1992.

[8] CRC Handbook of Chemistry and Physics, $68^{\text {th }}$ edition, CRC Press, Boca Raton, FL, 1987.

[9] Taylor, H.F.W., Cement Chemistry, Thomas Telford, London, 1997. 